RESEARCH

SERIES

NUMBER 126

July 2021

\section{PROJECTIONS OF EXPENDITURE FOR PRIMARY, COMMUNITY AND LONG-TERM CARE IN IRELAND, 2019-2035, BASED ON THE HIPPOCRATES MODEL}

BRENDAN WALSH, CONOR KEEGAN, AOIFE BRICK, SHEELAH CONNOLLY, ADELE BERGIN, MAEV-ANN WREN, SEÁN LYONS, LEONIE HILL AND SAMANTHA SMITH

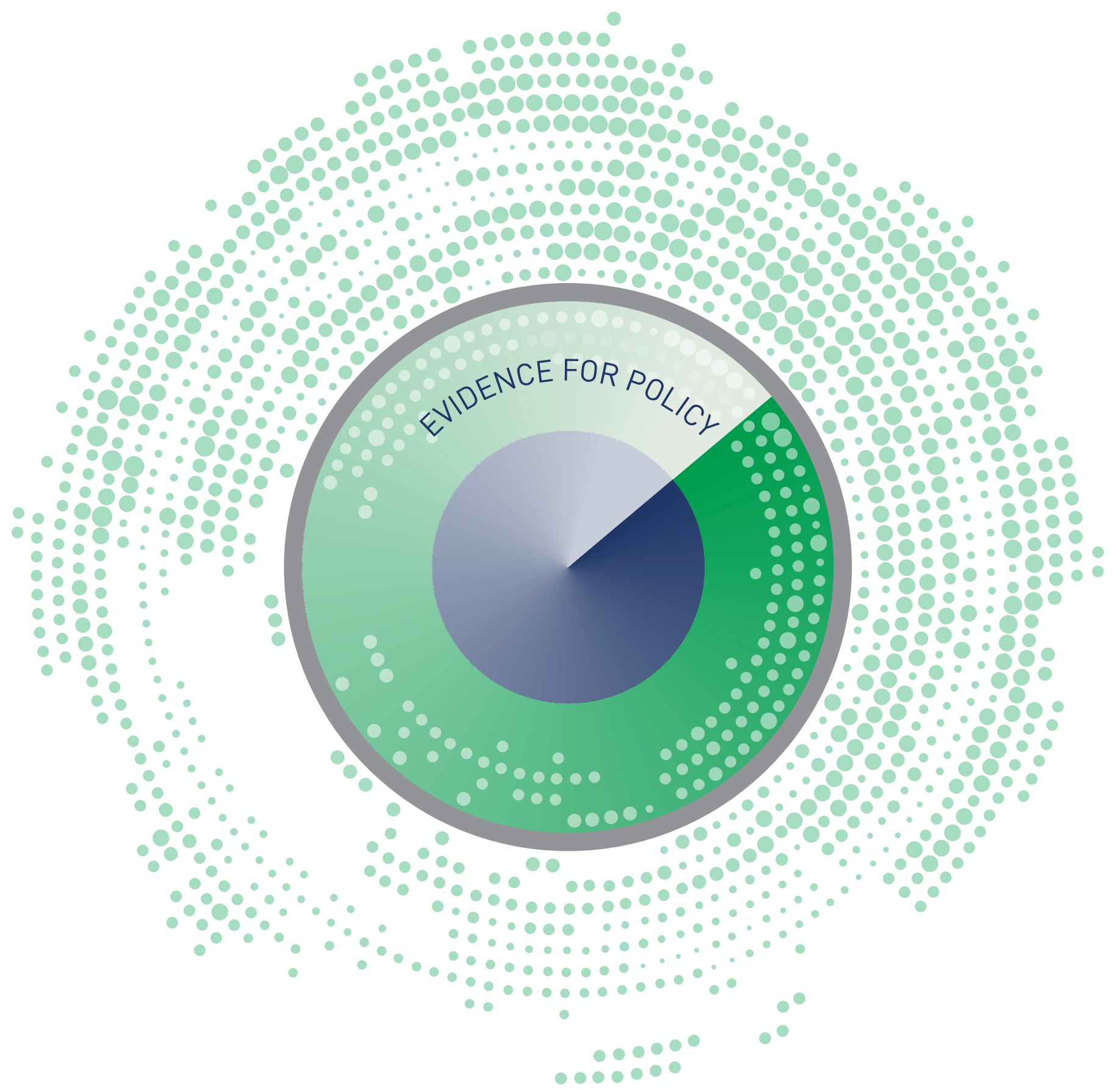




\section{PROJECTIONS OF EXPENDITURE FOR PRIMARY, COMMUNITY AND LONG-TERM CARE IN IRELAND, 2019-2035, BASED ON THE HIPPOCRATES MODEL}

Brendan Walsh

Conor Keegan

Aoife Brick

Sheelah Connolly

Adele Bergin

Maev-Ann Wren

Seán Lyons

Leonie Hill

Samantha Smith

July 2021

RESEARCH SERIES

NUMBER 126

Available to download from www.esri.ie

(C) The Economic and Social Research Institute and the Minister for Health

DOI: https://doi.org/10.26504/rs126

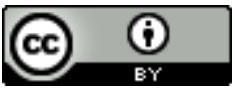

This Open Access work is licensed under a Creative Commons Attribution 4.0 International License (https://creativecommons.org/licenses/by/4.0/), which permits unrestricted use, distribution, and reproduction in any medium, provided the original work is properly credited. 



\section{ABOUT THE ESRI}

The mission of the Economic and Social Research Institute is to advance evidencebased policymaking that supports economic sustainability and social progress in Ireland. ESRI researchers apply the highest standards of academic excellence to challenges facing policymakers, focusing on 12 areas of critical importance to $21^{\text {st }}$ century Ireland.

The Institute was founded in 1960 by a group of senior civil servants led by $\mathrm{Dr}$ T. K. Whitaker, who identified the need for independent and in-depth research analysis to provide a robust evidence base for policymaking in Ireland.

Since then, the Institute has remained committed to independent research and its work is free of any expressed ideology or political position. The Institute publishes all research reaching the appropriate academic standard, irrespective of its findings or who funds the research.

The quality of its research output is guaranteed by a rigorous peer review process. ESRI researchers are experts in their fields and are committed to producing work that meets the highest academic standards and practices.

The work of the Institute is disseminated widely in books, journal articles and reports. ESRI publications are available to download, free of charge, from its website. Additionally, ESRI staff communicate research findings at regular conferences and seminars.

The ESRI is a company limited by guarantee, answerable to its members and governed by a Council, comprising 14 members who represent a cross-section of ESRI members from academia, civil services, state agencies, businesses and civil society. The Institute receives an annual grant-in-aid from the Department of Public Expenditure and Reform to support the scientific and public interest elements of the Institute's activities; the grant accounted for an average of 30 per cent of the Institute's income over the lifetime of the last Research Strategy. The remaining funding comes from research programmes supported by government departments and agencies, public bodies and competitive research programmes.

Further information is available at www.esri.ie. 


\section{ABOUT THE AUTHORS}

Brendan Walsh, Conor Keegan and Aoife Brick are Research Officers at the ESRI and Adjunct Assistant Professors at Trinity College Dublin. Sheelah Connolly is a Senior Research Officer at the ESRI and Adjunct Associate Professor at Trinity College Dublin. Maev-Ann Wren is a Senior Research Officer at the ESRI, an Adjunct Associate Professor at Trinity College Dublin and an Adjunct Associate Professor at the Geary Institute for Public Policy at University College Dublin. Adele Bergin is an Associate Research Professor at the ESRI, an Adjunct Professor at Trinity College Dublin and a Research Fellow at IZA Bonn. Seán Lyons is an Associate Research Professor at the ESRI and an Adjunct Professor at Trinity College Dublin. Leonie Hill is a Research Assistant at the ESRI. Samantha Smith is a Research Fellow in the Centre for Health Policy and Management at Trinity College Dublin and a Research Affiliate at the ESRI.

\section{ACKNOWLEDGEMENTS}

Financial support for this research was provided by the Department of Health. The authors thank the members of the Steering Group of the ESRI Research Programme in Healthcare Reform for their support, input and encouragement. The authors particularly thank Christopher Ryan, Tiago McCarthy and Teresa Maguire of the Department of Health for their assistance with this research project. The authors also thank many officials in the Department of Health, including in the Statistics and Analytics Unit, Community Pharmacy, Dental, Optical and Aural Policy Unit, and Older Persons Policy Reform Unit. The authors would also like to thank staff from the HSE, including but not limited to staff from HSE Primary Care Strategy and Planning, HSE Office of the Nursing and Midwifery Services Director, and HSE Nursing Homes Support Scheme Community Operations who provided substantial assistance in the provision and interpretation of data that formed the basis of the analysis in the report. In addition, the authors are grateful to Nursing Homes Ireland, and Home and Community Care Ireland for data provision and interpretation. Contacts with policymakers, providers and stakeholders have contributed important context and understanding to this research. The authors also acknowledge the contributions of Anne Nolan at the ESRI. Valuable comments on the text and suggestions for revision were provided by three anonymous reviewers. We thank all those who provided contributions while acknowledging that the authors bear sole responsibility for the analyses and interpretations presented. 


\section{TABLE OF CONTENTS}

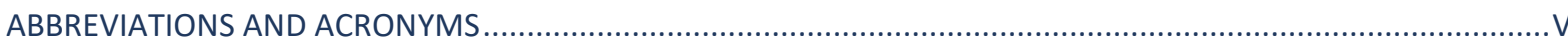

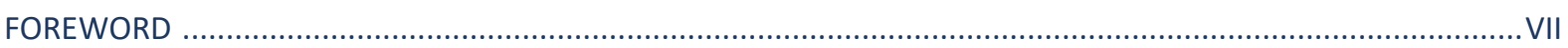

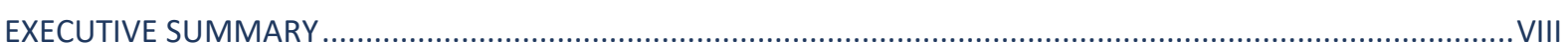

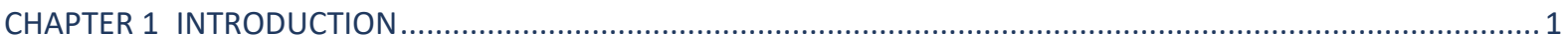

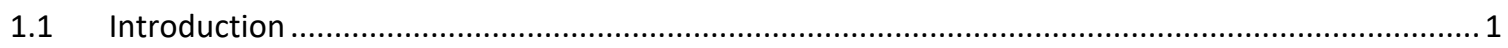

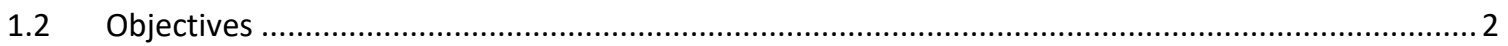

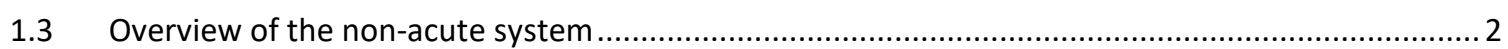

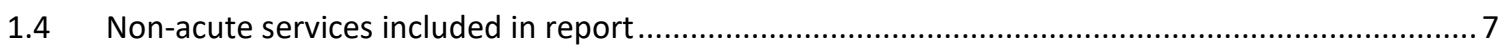

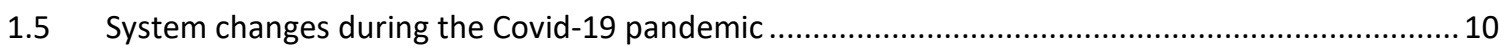

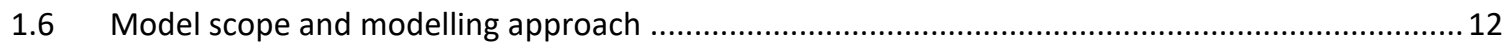

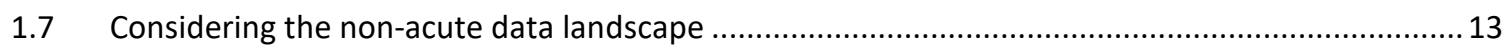

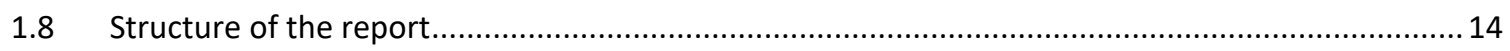

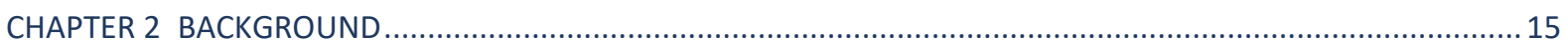

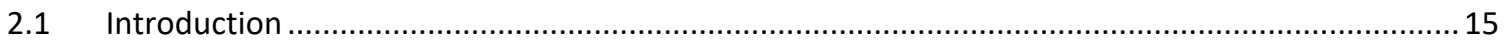

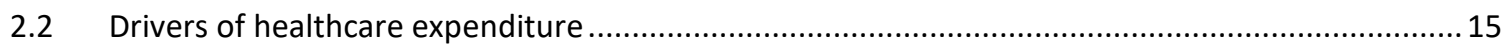

2.3 Previous evidence on health and social care expenditure in Ireland ........................................... 17

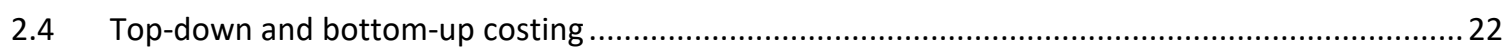

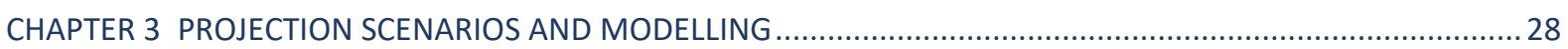

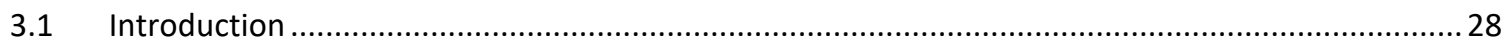

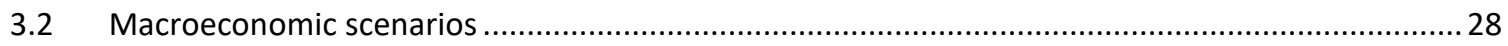

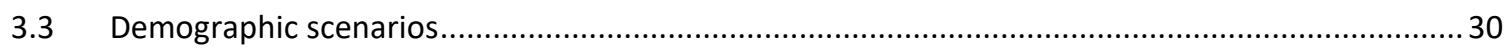

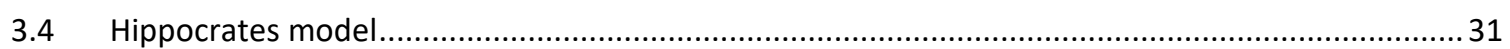

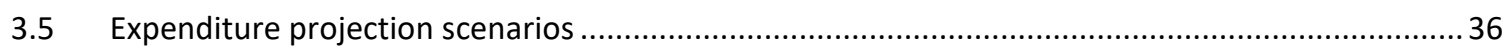

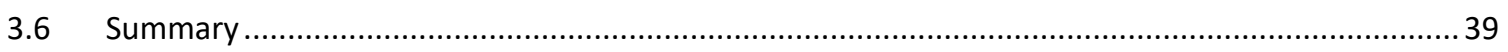

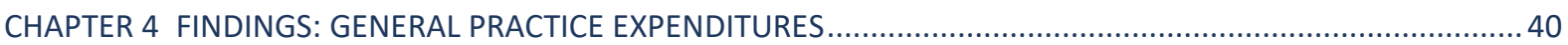

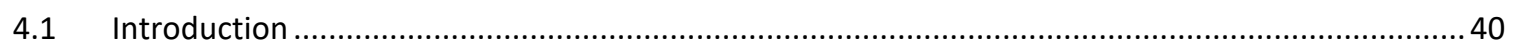

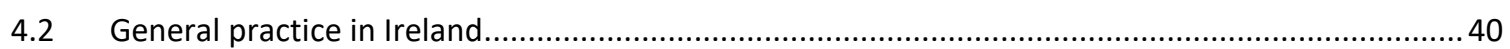

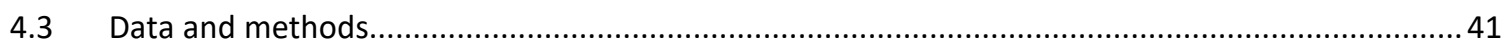

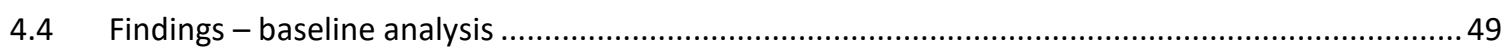

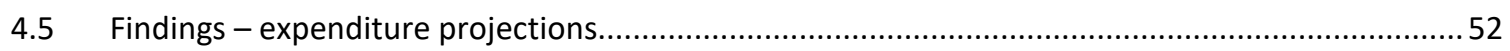

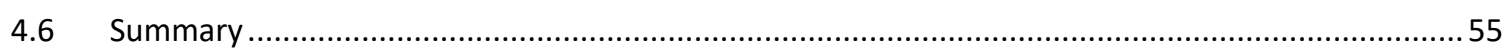

CHAPTER 5 FINDINGS: PUBLIC HEALTH NURSING AND COMMUNITY THERAPY SERVICES EXPENDITURES........58

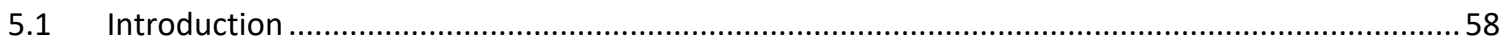

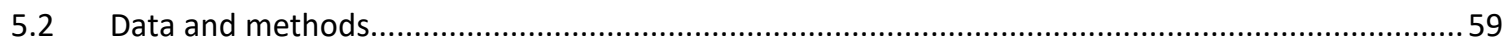

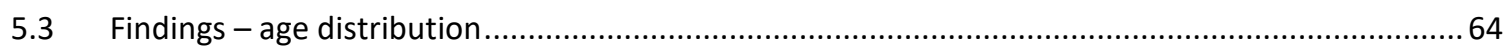

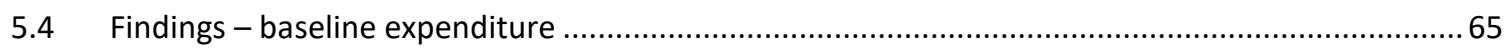

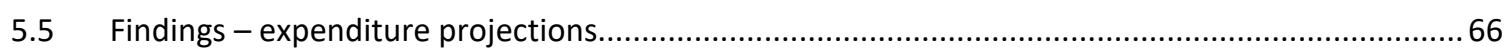

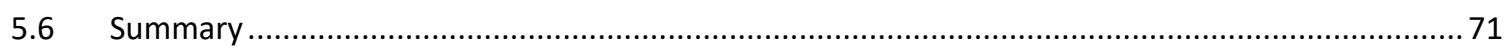

CHAPTER 6 FINDINGS: COMMUNITY PHARMACEUTICAL EXPENDITURES ................................................. 72

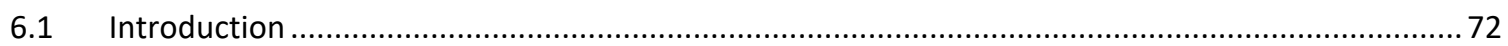

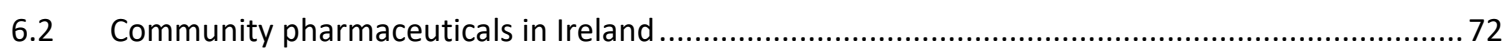

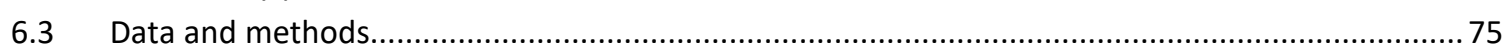

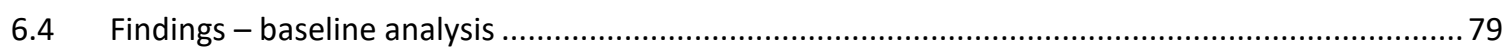

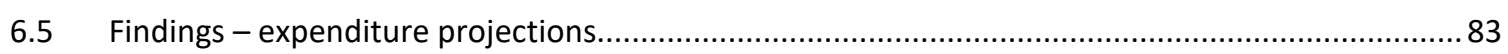

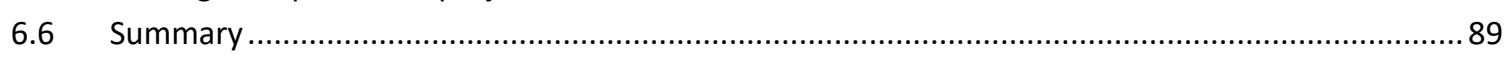

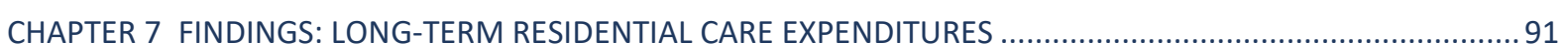

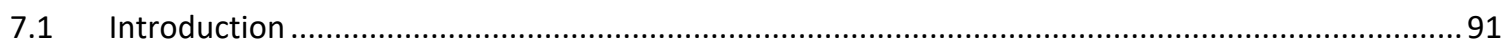

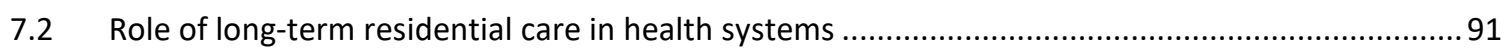




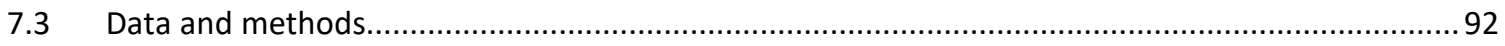

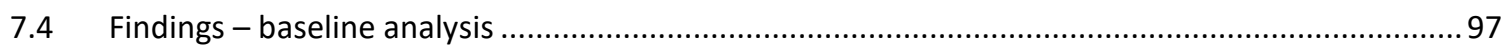

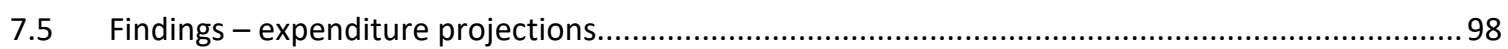

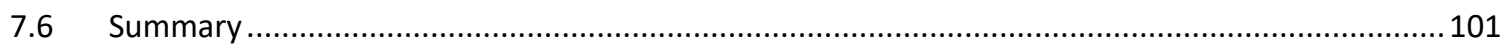

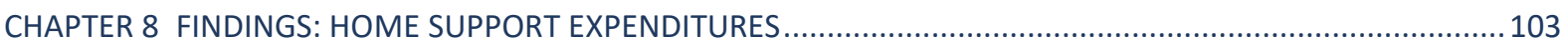

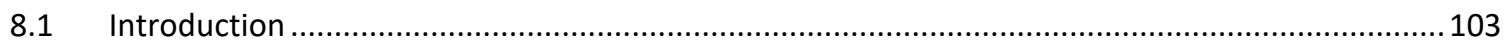

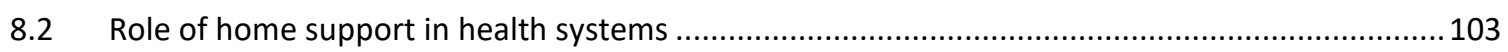

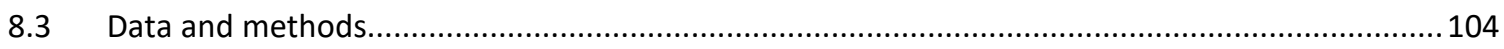

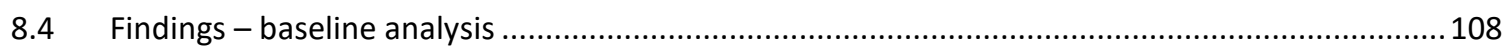

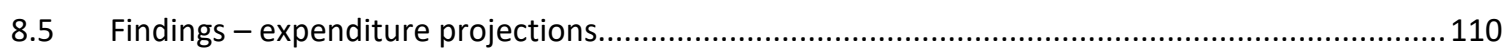

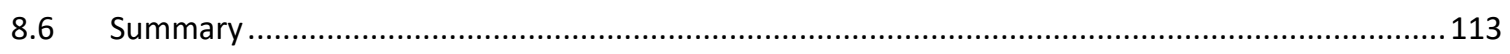

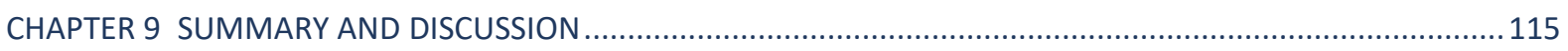

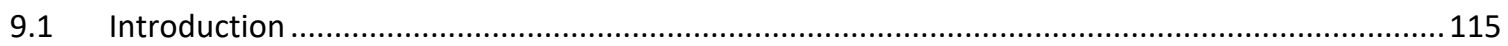

9.2 Summary and discussion of findings on baseline and projected acute expenditure by service..... 116

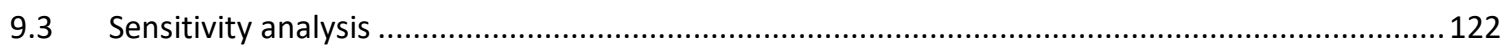

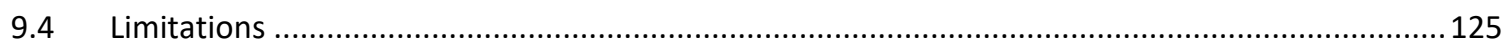

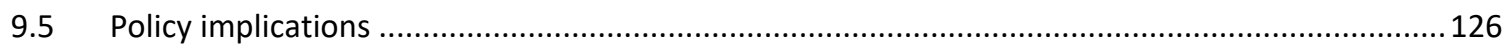

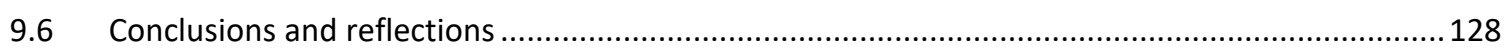

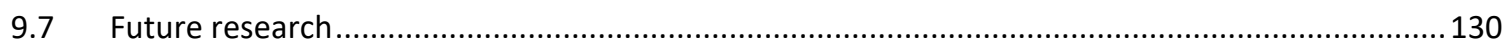

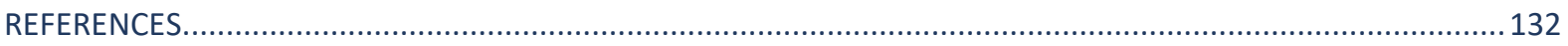

APPENDIX A LOCAL HEALTH OFFICES AND COMMUNITY HEALTH ORGANISATIONS....................................... 140

APPENDIX B MEDICAL CARD AND PRIVATE HEALTH INSURANCE COVERAGE .............................................. 141

APPENDIX C WAITING LIST MANAGEMENT: COMMUNITY THERAPY SERVICES ........................................... 142

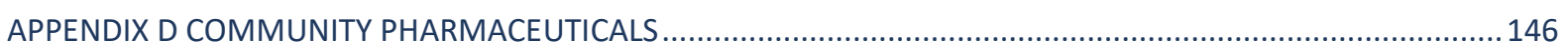




\section{LIST OF TABLES}

TABLE ES.1 Estimated health and social care expenditure, 2019.

TABLE 1.1 Estimated Medical Card, GP Visit Card and private health insurance coverage in Ireland - 2019..5

TABLE 2.1 Drivers of healthcare expenditure - summary ....................................................................17

TABLE 2.2 Irish healthcare expenditure compared to EU15, excluding and including healthcare-related

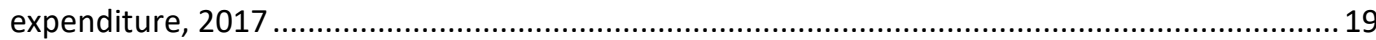

TABLE 2.3 Social care expenditure categories as share of Irish aggregate HCE, 2017 ..............................20

TABLE 2.4 Public acute hospital and acute psychiatric hospital expenditure - 2018 baseline and 2035 lowand high-pressure projections by service ............................................................................. 21

TABLE 2.5 List of healthcare professionals and unit-cost estimation method in Smith et al. (2021) .............24

TABLE 2.6 Estimated unit costs for a publicly employed, community-based healthcare support assistant, 2019

TABLE 3.1

TABLE 3.2

TABLE 3.3

TABLE 3.4

TABLE 3.5

TABLE 3.6

TABLE 4.1

TABLE 4.2

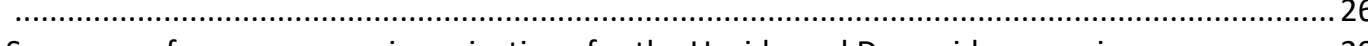

Summary of macroeconomic projections for the Upside and Downside scenarios .....................29

Summary of main assumptions for population scenarios.................................................... 30

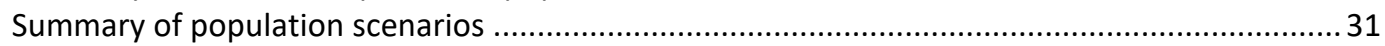

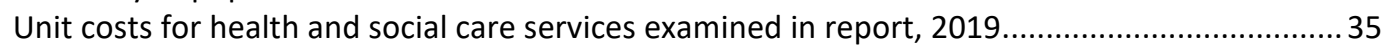

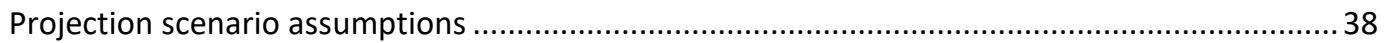

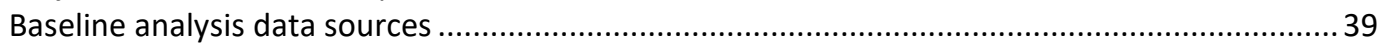

Fees and allowances paid to general practices for cardholders used in the calculation of unit and

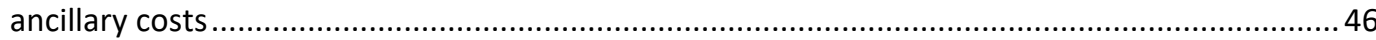

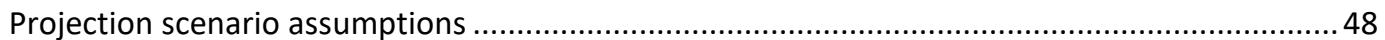

TABLE 4.3 Utilisation, unit costs and pay/non-pay split for general practitioners and practice nurses services,

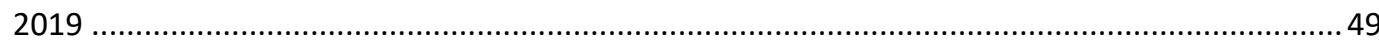

TABLE 4.4 General practice services - projected real and nominal expenditure growth by projection scenario,

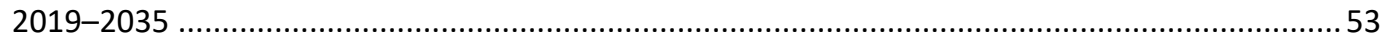

TABLE 4.5 General practice services including ancillary expenditure - projected real and nominal expenditure

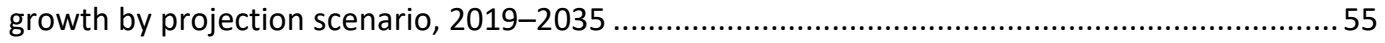

TABLE 5.1

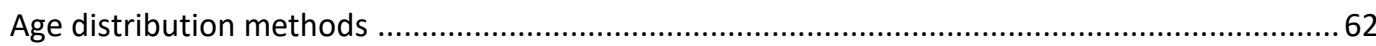

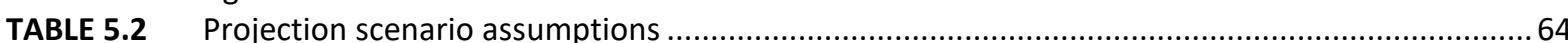

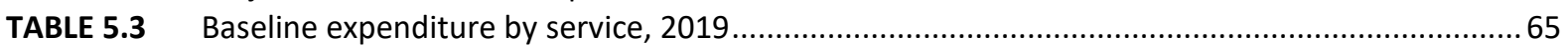

TABLE 5.4 Projected real and nominal expenditure growth and average annual growth by projection

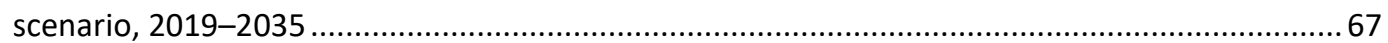

TABLE 6.1 Eligibility criteria, charges and co-payments, by scheme ....................................................74

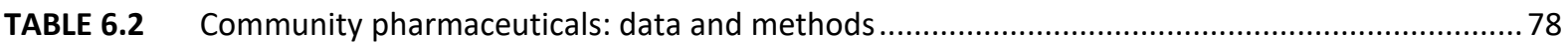

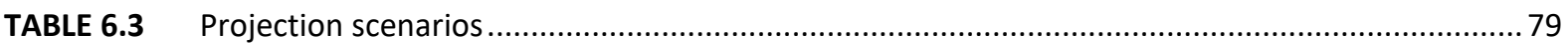

TABLE 6.4 Breakdown of prescription items and gross expenditure by scheme, 2019..............................80

TABLE 6.5 Community pharmaceuticals - projected real and nominal expenditure growth by projection

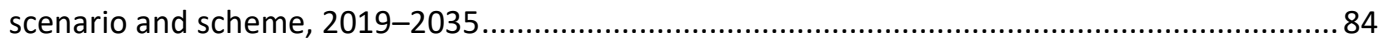

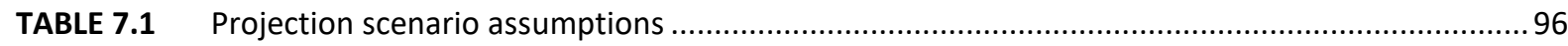

TABLE 7.2 Long-term residential residents and unit costs by category of bed and financing, 2019 .............97

TABLE 7.3 Long-term residential care - projected real and nominal expenditure growth by projection

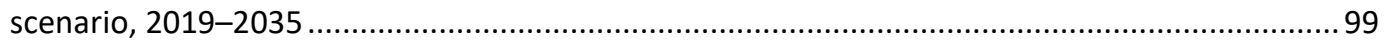

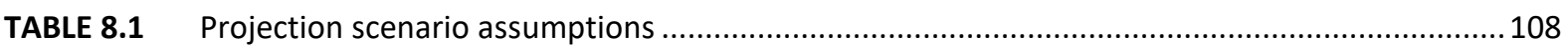

TABLE 8.2 Home support use and unit costs by category of bed and funding, 2019: aged 65+..................109

TABLE 8.3 Home support - projected real and nominal expenditure growth by projection scenario, 2019-

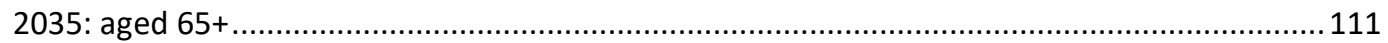

TABLE 9.1 Projected real and nominal expenditure growth - 2019 baseline and 2035 low- and high-pressure

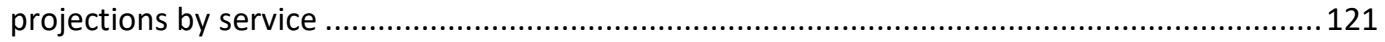

TABLE 9.2 Nominal and real average annual growth rates, 2019-2035.................................................. 122

TABLE 9.3 Sensitivity analysis - effect on projected expenditure for main services of varying common key

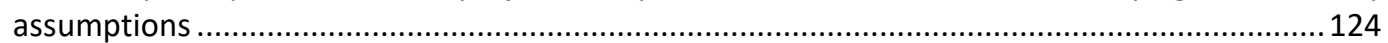

TABLE A.1 Local Health Offices in each Community Health Organisation ................................................. 140

TABLE D.1 Trends in items rate (per 1,000 population), gross drug unit costs, and expenditure, by scheme,

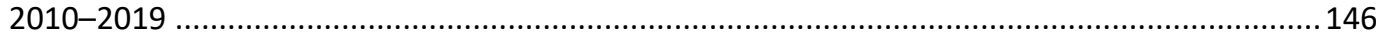




\section{LIST OF FIGURES}

FIGURE ES.1 Projected nominal expenditure growth by health and social care service, 2019-2035 xi

FIGURE 1.1 Estimated Medical Card, GP Visit Card and private health insurance coverage in Ireland by age: aged $18+$

FIGURE 2.1 Public acute hospital gross expenditure - growth decomposition by projection scenario, 2018-

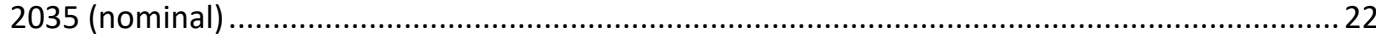

FIGURE 3.1 Hippocrates Model - diagrammatic representation.................................................................32

FIGURE 4.1 General practitioner services - age- and sex-specific expenditure per capita and total expenditure, 2019

FIGURE 4.2 Practice nurse services - age- and sex-specific expenditure and expenditure per capita, $2019 \ldots 51$

FIGURE 4.3 General practice services - decomposition of projected nominal expenditure growth, 2019-2035, by projection scenario.

FIGURE 4.4 General practice services - projected nominal expenditure by age and projection scenario, 2019 and 2035

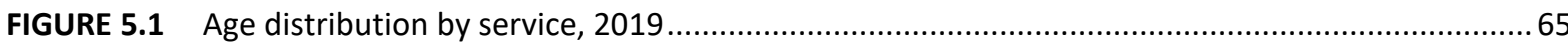

FIGURE 5.2 Decomposition of projected nominal expenditure growth by projection scenario, 2019-2035...69

FIGURE 6.1 Age- and sex-specific activity volumes and activity rates per 1,000 population by scheme, 201982

FIGURE 6.2 Community pharmaceuticals - decomposition of projected nominal expenditure growth, 20192035, by projection scenario ........................................................................................ 86

FIGURE 6.3 Community pharmaceuticals - expenditure by age, projection scenario and scheme, 2019 and projected 2035 (nominal)

FIGURE 7.1 Long-term residential care - age- and sex-specific expenditure and expenditure per capita, 2019

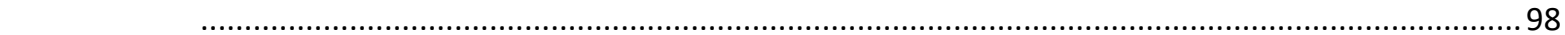

FIGURE 7.2 Long-term residential care - decomposition of projected nominal expenditure growth, 20192035, by projection scenario.

FIGURE 7.3 Long-term residential care - expenditure by age and projection scenario, 2019 and projected 2035 (nominal)

FIGURE 8.1 Home support - age- and sex-specific expenditure and expenditure per capita, 2019: aged 65+

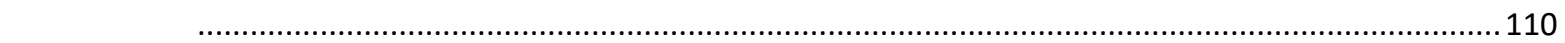

FIGURE 8.2 Home support - decomposition of projected nominal expenditure growth, 2019-2035, by

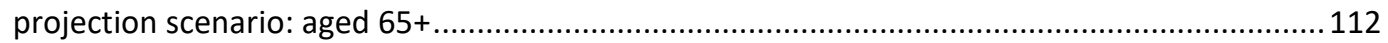

FIGURE 8.3 Home support - expenditure by age and projection scenario, 2019 and projected 2035 (nominal):

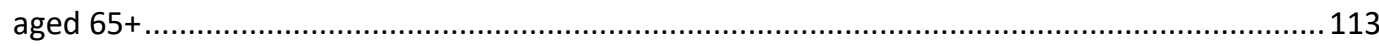

FIGURE B.1 Medical Card and Private Health Insurance coverage in Ireland by age: aged 18+ ................... 141

FIGURE C.1 Community therapy services: waiting lists 2017-2020.................................................... 144 


\section{ABBREVIATIONS AND ACRONYMS}

\begin{tabular}{|c|c|}
\hline ABF & Activity-Based Funding \\
\hline ADL & Activity of Daily Living \\
\hline AMAU/ASAU & Acute Medical/Surgical Assessment Unit \\
\hline BIU & HSE Business Information Unit \\
\hline BVB & Best-value biological \\
\hline $\mathrm{CHO}$ & Community Healthcare Organisation \\
\hline COSMO & COre Structural MOdel of the Irish economy \\
\hline COVID-19 & Coronavirus disease \\
\hline CRGN & Community registered general nurse \\
\hline CSO & Central Statistics Office \\
\hline DMO & District Medical Officer \\
\hline DPER & Department of Public Expenditure and Reform \\
\hline DP & Drugs Payment \\
\hline DSP & Department of Social Protection \\
\hline EHR & Electronic Health Record \\
\hline ESRI & Economic and Social Research Institute \\
\hline GDP & Gross Domestic Product \\
\hline GMS & General Medical Service \\
\hline GNI & Gross National Income \\
\hline GNP & Gross National Product \\
\hline GP & General practitioner \\
\hline GPVC & GP visit card \\
\hline GUI & Growing Up in Ireland dataset \\
\hline $\mathrm{HCCl}$ & Home and Community Care Ireland \\
\hline HCE & Healthcare expenditure \\
\hline HCRE & Healthcare-related expenditure \\
\hline HCSA & Healthcare support assistant \\
\hline HIA & Health Insurance Authority \\
\hline HIPE & Hospital In-Patient Enquiry scheme \\
\hline HIPPOCRATES & $\begin{array}{l}\text { Healthcare in Ireland model of the effects of Population Projections, Patterns Of CaRe and } \\
\text { Ageing Trends on Expenditure and Demand for Services }\end{array}$ \\
\hline HIQA & Health Information and Quality Authority \\
\hline HIS & Healthy Ireland Survey \\
\hline HPO & Healthcare Pricing Office \\
\hline HPSC & Health Protection Surveillance Centre \\
\hline HRB & Health Research Board \\
\hline HSE & Health Service Executive \\
\hline HT & High Tech \\
\hline IED & Income elasticity of demand \\
\hline IHI & Individual Health Identifier \\
\hline IMO & Irish Medical Organisation \\
\hline IPHA & Irish Pharmaceutical Healthcare Association \\
\hline LHO & Local health office \\
\hline LTI & Long-term illness \\
\hline LTRC & Long-term residential care \\
\hline NHS & National Health Service (UK) \\
\hline
\end{tabular}


NHSS

NIESR

NTPF

OECD

OOP

OPD

PCRS

PCTs

PHI

PHN

PN

PPE

PPP

PRSI

PSSRU

RHA

SHA

SLT

SPSS

SYOA

TAPS

TFR

TILDA

VAT

WTE
Nursing Home Support Scheme

National Institute of Economic and Social Research

National Treatment Purchase Fund

Organisation for Economic Co-operation and Development

Out-of-pocket

Outpatient department

Primary Care Reimbursement Service

Primary care teams

Private health insurance

Public health nursing

Practice nurse

Personal protective equipment

Purchasing power parity

Pay-related social insurance

Personal Social Sciences Research Unit

Regional health area

System of Health Accounts

Speech and language therapy

Statistical Package for the Social Sciences

Single year of age

Temporary Assistance Payment Scheme

Total fertility rate

The Irish Longitudinal Study on Ageing

Value added tax

Whole-time equivalent 


\section{FOREWORD}

This report was prepared by researchers at the Economic and Social Research Institute (ESRI) for the ESRI Research Programme in Healthcare Reform, which is funded by the Department of Health. The report analyses expenditure on primary, community and long-term care services and projects expenditure for these services for the years from 2019 to 2035. Published as an ESRI Research Series Report, it is the third report applying the Hippocrates Model of healthcare demand and expenditure developed at the ESRI.

The ESRI Research Programme in Healthcare Reform was agreed between the ESRI and the Department of Health in July 2014. The broad objectives of the programme are to apply economic analysis to explore issues in relation to health services, health expenditure and population health, in order to inform the development of health policy and the Government's healthcare reform agenda. The programme is overseen by a Steering Group comprising nominees of the ESRI and the Department of Health, which agrees its annual work programme. The Steering Group agreed in 2015 that this programme would include the development of a projection model of healthcare demand and expenditure. Work on developing the model, known as the Hippocrates Model, began in that year. The objectives of the development and application of the Hippocrates Model are to inform health and social service planning in Ireland; assist financial planning for the healthcare system; provide information relevant to planning for capacity, services and staffing; identify future demand pressures, and set out a framework in which to analyse the effects of potential system changes and reforms.

The ESRI is responsible for the quality of this research, which has undergone national and international peer review prior to publication. This report was prepared by Dr Brendan Walsh, Dr Conor Keegan, Dr Aoife Brick, Dr Sheelah Connolly, Dr Adele Bergin, Dr Maev-Ann Wren, Dr Seán Lyons, Ms Leonie Hill and Dr Samantha Smith, and reflects their expertise and views. The views expressed in this report are not necessarily those of other ESRI researchers, the Minister for Health, Department of Health or organisations represented on the Steering Group. 


\section{EXECUTIVE SUMMARY}

\section{INTRODUCTION}

This report develops baseline estimates of expenditure in 2019 for ('non-acute') primary, community and long-term care services in Ireland, and projects expenditures for these services to 2035. It provides expenditure projections across different pressure scenarios that incorporate varying assumptions about the drivers of health and social care expenditure.

The broad objectives of this report are to:

- provide comprehensive estimates of current expenditure on primary, community, and long-term care services in Ireland in 2019;

- examine the relative impact of demographic and non-demographic factors on projected expenditure;

\section{METHODS}

The analysis is undertaken using the Hippocrates Model, a macro-simulation model created by the ESRI. The model is developed from a demand and cost base in 2019 to project expenditures for individual services. Demand is projected through developing and applying assumptions in relation to population change, healthy ageing, and other potential demand drivers. Population projections are provided by the ESRI's demographic model (COSMO) based on assumptions in relation to fertility, mortality and net migration. Demographic assumptions have been updated to reflect the effects of the Covid-19 pandemic to date. Projected activity is then multiplied by projected unit costs in each future period to project expenditure. The unit cost of delivering a unit of service in 2019 is estimated and disaggregated into pay and non-pay components. Projections of governmentsector earnings and general inflation inform projected trajectories in pay and nonpay costs. The report does not forecast expenditure but provides projections of expenditure requirements based on clear assumptions on how key drivers of demand and cost will evolve over time.

Projected expenditures for each service out to 2035 are based on scenarios tailored to that service's characteristics. Low-pressure, central and high-pressure scenarios vary assumptions related to population change, healthy ageing, cost drivers, and models of care change for each service.

The report examines most key primary, community and long-term care services in Ireland. Specifically, the services included in the report are:

- general practice - general practitioners (GP) and practice nurses (PN); 
- public health nursing (PHN) and selected primary care community therapy services;

- community pharmaceuticals;

- long-term residential care (LTRC); and

- home support.

\section{SUMMARY OF BASELINE EXPENDITURE}

General practice: we estimate that public and private general practice expenditure was $€ 1,010 \mathrm{~m}$ in 2019. Expenditure on Medical Card and GP visit card (GPVC) holders accounted for $€ 556 \mathrm{~m}$. Most of the general practice expenditure, $€ 876 \mathrm{~m}$ (87\%), was spent on care delivered by a GP.

Public health nursing and primary care community therapy services: we estimate that expenditure on publicly funded PHN was $€ 269 \mathrm{~m}$ in 2019. Estimated expenditure on publicly funded community-based occupational therapy, physiotherapy, and speech and language therapy provided through HSE Primary Care services was $€ 51 \mathrm{~m}, € 54 \mathrm{~m}$ and $€ 50 \mathrm{~m}$ respectively.

Community pharmaceuticals: we estimate that expenditure on all publicly funded community pharmaceutical schemes was $€ 2,265 \mathrm{~m}$ in 2019 . Items dispensed to individuals on the General Medical Service (GMS) scheme accounted for $€ 951 \mathrm{~m}$ (42\%), with items dispensed to individuals via the High Tech (HT) scheme accounting for $€ 850 \mathrm{~m}(39 \%)$.

Long-term residential care: we estimate that expenditure on public and private LTRC was $€ 1,957 \mathrm{~m}$ in 2019. The Nursing Home Support Scheme (NHSS) accounted for $€ 1,422 \mathrm{~m}$. Overall, the State contributed $€ 1,322 \mathrm{~m}(68 \%)$ of total LTRC expenditure.

Home support: we estimate that expenditure on public and private home support was $€ 616 \mathrm{~m}$ in 2019 . The State contributed $€ 456 \mathrm{~m}$ (74\%) of total home support expenditure. 
TABLE ES.1 Estimated health and social care expenditure, 2019

\begin{tabular}{|c|c|c|}
\hline Population coverage & Activity ('000) & Expenditure (€m) \\
\hline General practice ${ }^{a}$ & 23,972 (visits) & $1,009.5$ \\
\hline General Practitioner & 18,890 (visits) & 875.5 \\
\hline Practice Nurse & 5,082 (visits) & 134.1 \\
\hline Public health nursingb & - & 269.1 \\
\hline Occupational therapy ${ }^{b}$ & - & 51.1 \\
\hline Physiotherapy ${ }^{b}$ & - & 53.5 \\
\hline Speech and language therapy ${ }^{b}$ & - & 50.0 \\
\hline Community pharmaceuticals & 78,067 (items) & $2,264.6$ \\
\hline General Medical Service (GMS) & 60,072 & 950.7 \\
\hline Drugs Payment (DP) & 7,777 & 160.3 \\
\hline Long-term illness (LTI) & 9,345 & 258.7 \\
\hline High Tech (HT) & 873 & 894.9 \\
\hline Long-term residential care ${ }^{a}$ & 32 (residents) & $1,956.6$ \\
\hline Home support ${ }^{\mathrm{a}}$ & 24,529 (hours) & 615.8 \\
\hline $\begin{array}{lll}\text { ote: } & \text { a } & \text { Publicly and privately fur } \\
& \text { b } & \text { Provided through HSE Pr } \\
\text { ource: } & & \text { Authors' calculations. }\end{array}$ & $\begin{array}{l}\text { xpenditure includec } \\
5 .\end{array}$ & \\
\hline
\end{tabular}

\section{SUMMARY OF PROJECTED EXPENDITURE}

Expenditure is projected to increase across almost all services examined in this report. Figure ES.1 illustrates projected changes in nominal (growth is driven by changes in demand and cost) expenditures between 2019 and 2035 for each respective service's central scenario. The low- and high-pressure scenario results are presented in parentheses.

General practice: Expenditure on general practice is projected to be $€ 1,735 \mathrm{~m}$ $(€ 1,614 m-€ 2,045 m)$ in 2035 . This implies a 3.4 (2.9-4.5) per cent annual growth rate. Increases in pay contribute 52 per cent and increases in non-pay contribute 26 per cent expenditure growth. Population growth and ageing contribute only a small percentage of the projected expenditure increases.

Public health nursing and primary care community therapy services: Expenditure on PHN is projected to be $€ 574 \mathrm{~m}$ ( $€ 538 \mathrm{~m}-€ 650 \mathrm{~m}$ ) in 2035. Expenditure on the selected community therapy services provided through HSE Primary Care services is projected to be $€ 277 \mathrm{~m}$ ( $€ 260 \mathrm{~m}-€ 312 \mathrm{~m}$ ). Due to substantive data limitations for these services, we are unable to incorporate assumptions on healthy ageing, waiting-list management, or models of care change. This, in addition to the inability to generate comprehensive baseline utilisation profiles, overall may lead to an underestimate of future expenditure requirements for these services.

Community pharmaceuticals: Expenditure on the GMS, Drugs Payment (DP) and Long-Term Illness (LTI) schemes is projected to be $€ 1,787 \mathrm{~m}(€ 1,390 \mathrm{~m}-€ 2,173 \mathrm{~m})$ in 
2035. This implies a 1.7 (0.1-2.9) per cent average annual growth rate. In 2035, nominal expenditure on the HT scheme is projected to be $€ 3,215 \mathrm{~m}$ ( $€ 2,301 \mathrm{~m}-$ $€ 4,434 \mathrm{~m})$. This implies an 8.3 (6.1-10.5) per cent average annual growth rate. The increase in $\mathrm{HT}$ expenditure reflects a continuation of historic growth in demand for expensive, high-tech medicines.

Long-term residential care: Expenditure on LTRC is projected to be $€ 4,391 \mathrm{~m}$ $(€ 3,819 \mathrm{~m}-€ 5,661 \mathrm{~m})$ in 2035 . This implies a $5.2(4.3-6.9)$ per cent annual growth rate. Increases in costs account for 59-66 per cent of expenditure growth. Population ageing also contributes 29-46 per cent of expenditure growth. Substitution to home support may offset expenditure by 15 per cent.

Home support: Expenditure on home support is projected to be $€ 1,941 \mathrm{~m}$ $(€ 1,217 \mathrm{~m}-€ 2,979 \mathrm{~m})$ in 2035 . This implies a 7.4 (4.4-10.4) per cent annual growth rate. Increases in costs are important drivers of home support expenditure increases. However, assumed increased demand as a result of the establishment of the home support scheme is the biggest driver of home support expenditure growth.

FIGURE ES.1 Projected nominal expenditure growth by health and social care service, 2019-2035

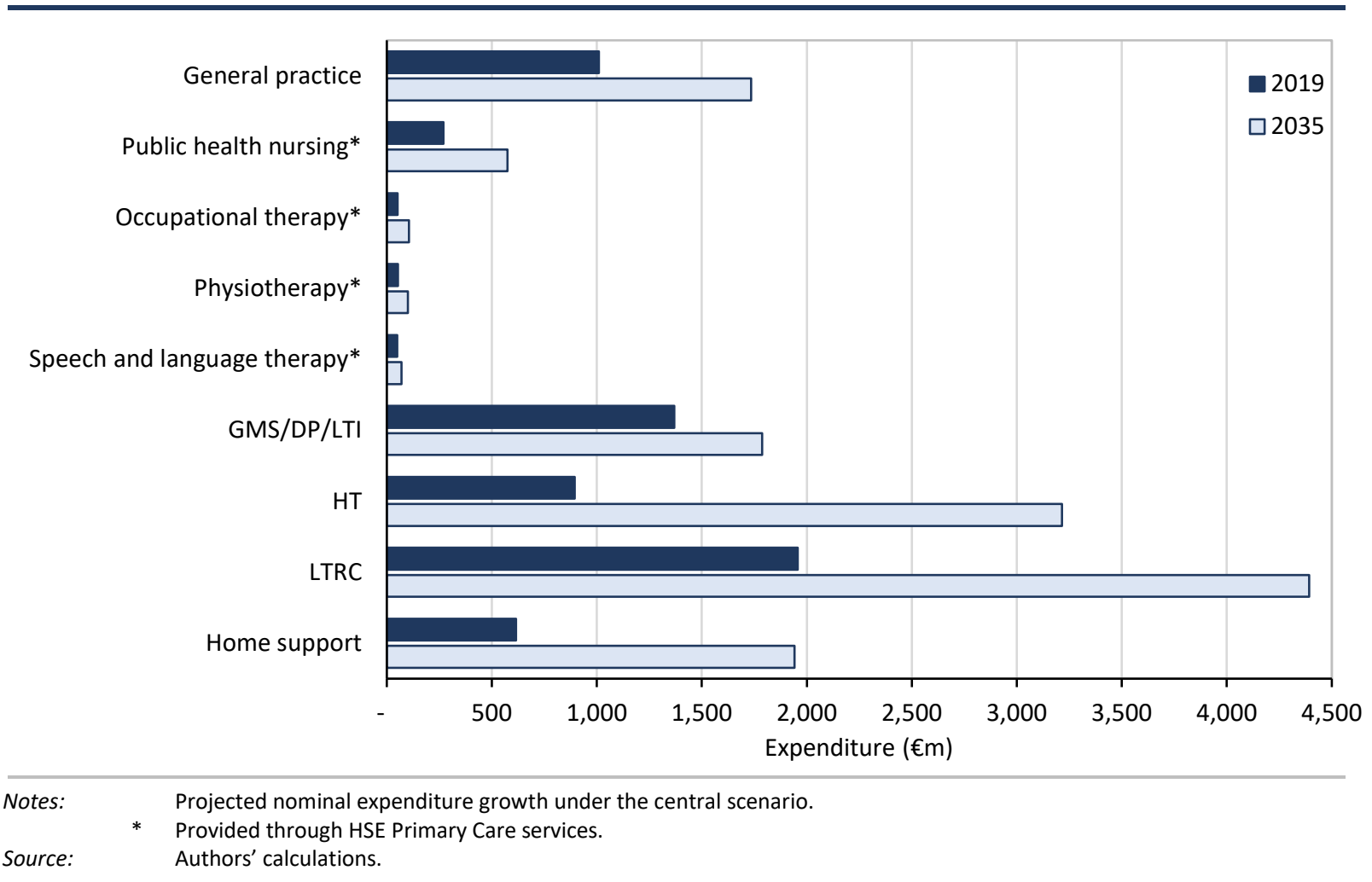




\section{POLICY IMPLICATIONS}

The main finding of this report is that, due to a combination of a growing and ageing population and increasing costs of care delivery, expenditure on primary, community and long-term care will be required to increase substantially by 2035 . The findings provide an evidence base for workforce and capacity planning and for the implementation of some Sláintecare proposals.

The scope of the analysis in this report has been hampered by the poor data available for many services. Policymakers should prioritise designing a health data infrastructure that caters for the requirements of both local and national-level service planners. It should allow for accurate day-to-day patient management and facilitate future demand and expenditure projections and workforce planning. Integrating an individual health identifier (IHI) and electronic health record (EHR) would allow for patients to be followed across services and time, to help understand their overall use of services and provide a picture of the complexity of the patients being treated.

Changes in the cost of delivering care, particularly pay-related costs, is the main driver of expenditure growth. In addition, population ageing, and additional modelled demand for HT medicines and the assumed introduction of the statutory home support scheme, are key drivers of expenditure growth. Identifying approaches to address the projected increases in the unit cost of care delivery should be an important consideration of policymakers.

The analysis in this report does not include model of care changes for many services. Follow-up research will examine the potential impact of introducing proposed Sláintecare reforms, specifically regarding changing models of care of specific patient groups, substitution of care across the acute hospital and nonhospital system, and the potential impact of the Covid-19 pandemic. 


\section{CHAPTER 1}

\section{Introduction}

\section{$1.1 \quad$ INTRODUCTION}

In this report we provide primary, community and long-term care expenditure projections for Ireland over the period 2019-2035. These projections have been generated using the Hippocrates ${ }^{1}$ Model, which was developed at the ESRI in a programme of research funded by the Department of Health.

The Hippocrates Model was first used to provide base-year estimates and projections of health and social care demand for the years 2015-2030 (Wren et al., 2017). It has also been used to provide healthcare expenditure estimates for 2018 and projections to 2035 for public acute hospitals and public acute adult psychiatric hospitals (Keegan et al., 2020). In addition, the model has been used to generate projections of hospital bed capacity (Keegan et al., 2018) and is being extended to develop workforce planning projections and projections for private hospital activity and expenditure.

The Hippocrates Model employs a bottom-up perspective, building, originally, a service-level picture of demand across health and social care services, and projecting that demand over the medium term (Wren et al., 2017; Brick and Keegan, 2020a; Brick et al., 2020b; a; Keegan et al., 2020). In this report, and in Keegan et al. (2020), the modelling framework has been extended to develop health and social care costs. This provides a foundation for developing baseline estimates of expenditure and generating projections of expenditure in the medium term based on assumed trajectories of underlying demographic and nondemographic drivers.

While the base year for the projection analysis is 2019 , within the analysis we are cognisant that the Covid-19 pandemic, beginning in 2020, will alter trajectories of health and social care expenditures over the short to medium term. Where possible, we have adjusted our analysis to reflect effects of the pandemic on services. Key ESRI demographic and macroeconomic projections that inform our demand and unit cost projections have been updated to reflect the most recent information available. 


\subsection{OBJECTIVES}

The objectives of this report are to:

- provide comprehensive estimates of current expenditure on primary, community and long-term care services in Ireland in 2019;

- examine the relative impact of demographic and non-demographic factors on projected expenditure;

Future research is planned to analyse the staffing requirements associated with projected demand, and to develop demand, expenditure and workforce projections at a regional level. As a large proportion of health and social care in Ireland is privately provided and financed, where data availability allows, we examine private general practice, community pharmaceutical and long-term care (long-term residential care [LTRC] and home support) expenditure. Future ESRI research will employ the Hippocrates Model to examine other private healthcare, including private hospital expenditure. It is envisaged that the model will continue to be used to provide a framework to examine the effects of potential changes to the healthcare system and models of care - for example, the introduction of a statutory home support scheme on use of residential care, and the impact on primary and community services of moving some appropriate care out of acute hospitals and into the community.

\subsection{OVERVIEW OF THE NON-ACUTE SYSTEM}

Non-acute health and social care refers to a wide range of services provided by medical, therapeutic and social care practitioners outside of the hospital setting. It includes services provided in the community such as general practice, public health nursing (PHN), community-based therapies, and long-term care (Smith et al., 2019). Services provided in long-term care are often characterised as social care (Wren and Fitzpatrick, 2020).

The Health Service Executive (HSE) funds, and often directly provides, public nonacute care services. For many services, such as community therapy and social care, services are coordinated at the regional level. Currently there are nine Community Health Organisations (CHOs) and 32 Local Health Offices (LHOs). CHOs and LHOs are based on geographic regions. Appendix Table A.1 lists CHOs and LHOs in Ireland. Based on recommendations in the Sláintecare report (Houses of the Oireachtas Committee on the Future of Healthcare, 2017), Regional Health Areas (RHAs) will succeed CHOs. 


\subsubsection{Provision and financing of non-acute care}

Non-acute care services are provided by public, private and often voluntary providers. While this report will concentrate on 'public' non-acute healthcare services, it is important to recognise the role played by private and voluntary providers. While many non-acute services are almost entirely provided by HSE staff (e.g. public health nurses), other services are funded by the HSE but provided by voluntary (via Section 39 service-level agreements) or private providers. All GPs are private operators. However, a substantial amount of GP care is provided to Medical Card and GP Visit Card (GPVC) holders via the General Medical Services (GMS) scheme (Wren et al., 2017). In addition, most home support and LTRC is provided by for-profit home care agencies and privately owned nursing homes (Walsh et al., 2019b).

While many private providers deliver care to public patients, private purchase of privately delivered health and social care is a major component of the Irish system. These services are paid for via out-of-pocket payments (e.g. a GP visit or private home support hour), with the price of services tied to the market rate. Some of these out-of-pocket purchases are fully or partially reimbursed through private health insurance (PHI).

In the community pharmaceutical sector, public financing of pharmaceuticals takes place through the Primary Care Reimbursement Service (PCRS). The PCRS is a part of the HSE that is responsible for making payments from the State to healthcare professionals, including GPs and pharmacists, for health services they provide through schemes such as the GMS scheme and community drug schemes.

\subsubsection{Eligibility and access}

Ireland does not offer universal access to free provision of non-acute healthcare. However, publicly funded programmes such as the GMS scheme provide access to healthcare free or at lower cost for certain populations, such as those with lower incomes or with high levels of health and social care need. Uniquely, access to the current publicly funded home support scheme is not based on having a Medical Card and is free of charge for those who receive support via this scheme.

In Ireland, there are two broad categories of eligibility for public health and social care services. The first category includes individuals with a Medical Card. Individuals who hold a Medical Card can access a range of services free of charge including general practice care, acute public hospital care (e.g. emergency department), and community care services (e.g. PHN, physiotherapy). In addition, Medical Card holders have other non-healthcare benefits, including a reduced Universal Social Charge and reduced children's education expenses (Keane et al., 
2021). Those without a Medical Card may not be entitled (or may not receive quick access) to public community care services such as physiotherapy (Citizens Information, 2015; Houses of the Oireachtas Committee on the Future of Healthcare, 2017).

Medical Card eligibility is largely determined by an income means-test, ${ }^{2}$ and income thresholds vary by age. However, some groups (including children diagnosed with cancer within the past five years) automatically qualify for a Medical Card. Despite the benefits conferred by a Medical Card, over 30 per cent of the population who are eligible for a Medical Card based on their household income do not take up this eligibility (Keane et al., 2021).

Those with incomes approximately 50 per cent above the Medical Card income threshold, along with all children under six and adults aged 70 or over, are eligible for a GPVC, which provides free GP visits only. The majority of the population without a Medical Card have PHI (Health Insurance Authority, 2020). PHI provides some coverage of healthcare costs, and some $\mathrm{PHI}$ policies now provide partial reimbursement for general practice visits (Nolan and Layte, 2017). However, there are considerable differences in coverage across PHI plans. Some less expensive PHI plans offer only limited benefits; people with these plans can often face large outof-pocket payments for private healthcare (Keegan, 2020). The average gross cost of a PHI premium in Ireland in 2019, incorporating child and adult discounts, was $€ 1,200$ (Health Insurance Authority, 2020). ${ }^{3}$ There is recent evidence that, for individuals with household income close to their respective Medical Card income threshold, having a Medical Card greatly reduces the probability of purchasing PHI (Johnston et al., 2019; Keane et al., 2021).

Table 1.1 uses data from the PCRS, the Health Insurance Authority (HIA) and the Healthy Ireland Survey (HIS) waves 3-4 (2017-2018) to illustrate Medical Card/GPVC and PHI coverage in Ireland. For the sake of brevity, Medical Card and GPVC holders are included together. Across the population, 34.1 per cent have a Medical Card/GPVC but no PHI, 38.2 per cent have PHI only, and 7.9 per cent have both a Medical Card/GPVC and PHI. In addition, a sizeable minority, 19.8 per cent, have no Medical Card/GPVC or PHI. 
TABLE 1.1 Estimated Medical Card, GP Visit Card and private health insurance coverage in Ireland - 2019

\begin{tabular}{|l|c|c|c|c|}
\hline Population coverage & $\begin{array}{c}\text { Medical Card/ } \\
\text { GPVC only }\end{array}$ & $\begin{array}{c}\text { Medical Card/GPVC } \\
\text { and PHI }\end{array}$ & $\begin{array}{c}\text { PHI } \\
\text { only }\end{array}$ & $\begin{array}{c}\text { No public or } \\
\text { private coverage }\end{array}$ \\
\hline N (million) & 1.684 & 0.390 & 1.886 & 0.977 \\
\hline$\%$ & 34.1 & 7.9 & 38.2 & 19.8 \\
\hline
\end{tabular}

Source: Medical Card/GPVC: PCRS. December 2019 numbers.

PHI: Health Insurance Authority 2019 annual report. December 2019 numbers (Health Insurance Authority, 2020).

Healthy Ireland Survey waves 3-4 used to help estimate Medical Card/GPVC and PHI, and no public or private coverage.

Figure 1.1 illustrates rates of Medical Card and PHI coverage in the adult population by age (aged 18 years and older). The figure illustrates varying Medical Card/GPVC and $\mathrm{PHI}$ coverage rates across ages. Between the ages of 18 and 60 years, 35 to 40 per cent of the population have a Medical Card/GPVC. A substantial percentage of younger adults have no coverage. For example, over 41 per cent of 30 -year-olds in Ireland have no Medical Card/GPVC or PHI. However, the percentage with no coverage reduces steadily between age 30 and 70 . Only a small percentage of over 70s have no coverage.

PHI rates fall between the ages of 18 and 30 years, before rising at older ages. This uptick in PHI rates in those aged between 30 and 40 years may be in part explained by the introduction of lifetime community rating which penalises individuals if they take out PHI for the first time after age 35 years (Keegan, 2020). At 70 years and older, about 90 per cent of people have a Medical Card/GPVC; income thresholds for Medical Cards are higher at older ages, and everyone aged 70 years and older is now eligible for a GPVC. At older ages, a large percentage of people have 'dual' public and private coverage, but at the oldest ages $\mathrm{PHI}$ rates decline. This is seen more clearly in Appendix A. 
FIGURE 1.1 Estimated Medical Card, GP Visit Card and private health insurance coverage in Ireland by age: aged $18+$

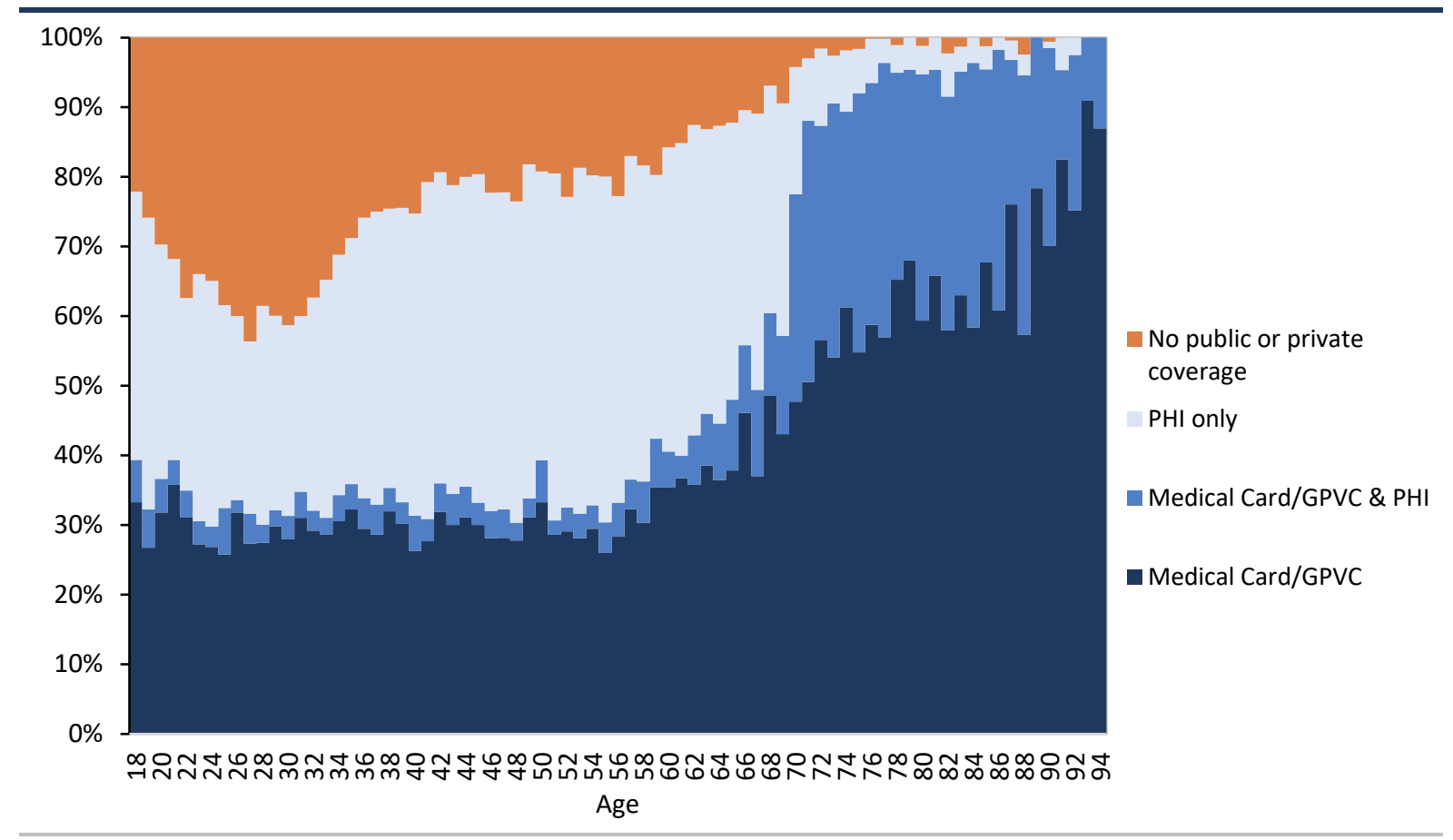

Source: Healthy Ireland Survey waves 3-4.

Figure 1.1 shows that public and private coverage rates differ considerably by age. Such differences might be expected to affect health and social care expenditure. First, previous research has highlighted that having a Medical Card/GPVC or PHI is associated with more intensive use of a range of health and social care services (Walsh et al., 2012; Ma and Nolan, 2016; O'Callaghan et al., 2018; Connolly and Whyte, 2019; Walsh et al., 2019a). These differences in demand should be considered when making health and social care expenditure projections. Second, eligibility and access may influence differences in public and private healthcare expenditure. For example, most of Medical Card holders' healthcare expenditure will be borne by the State. This may not be the case for those without a Medical Card who pay out-of-pocket for care or who pay through PHI. Therefore, in the analysis of general practice care, we estimate demand and expenditure separately for the populations with and without a Medical Card/GPVC. Due to lack of data, we were unable to examine expenditure on privately purchased community therapy services, despite previous evidence pointing to a large role placed on the private community therapy sector (Eighan et al., 2019).

There are several other public schemes that provide access to or subsidise user costs for some non-acute services. Within community pharmaceuticals, four schemes account for virtually all prescription drug items claimed under the PCRS: the GMS scheme, the Drugs Payment (DP) scheme, the Long-Term Illness (LTI) scheme, and the High Tech (HT) drug scheme. Eligibility differs across schemes, as do charges, co-payments and the prescription items covered. 
With long-term care (social care), there is a mixture of publicly and privately financed care. Medical Cards are not currently used when assessing access to, or payments for, long-term care. The Nursing Homes Support Scheme (NHSS - 'Fair Deal') provides a statutory basis for eligibility and financing for people who require publicly funded LTRC. Under the NHSS, previous evidence shows that the State covers approximately 76 per cent of the average cost of an LTRC bed for those availing of the NHSS (Collins, 2019). No such statutory scheme exists for home support. However, the Sláintecare Implementation Strategy and Action Plan 20212023 commits to implementation of a statutory home-support scheme starting in 2022 and to its continued implementation in 2023 (Walsh and Lyons, 2021). Therefore, in this report, we also model demand and expenditure across public and private LTRC and home care support separately.

\subsubsection{Sláintecare}

Sláintecare is a cross-party report on the future direction of health and social care policy in Ireland that was published in 2017 (Houses of the Oireachtas Committee on the Future of Healthcare, 2017; Department of Health, 2019a). The report concluded that the Irish healthcare system should be based on a universal singletier system, with care provided based on clinical need instead of ability to pay. In the report, while some costings were published, it is unclear whether the definition of universality implies free health and social care at the point of use (Connolly and Wren, 2019). For example, while free GP care is explicitly discussed, it is not stated for other services where people will receive care "either free of charge or at a low cost" (Houses of the Oireachtas Committee on the Future of Healthcare, 2017, p60). A subsequent Sláintecare Action Plan also discussed the provision of "universal services at no or low cost to the patient/service user" (Department of Health, 2019, p6). Therefore, in this report, we do not seek to examine the impact of expanding free non-acute care across all services in our projection scenarios. Previous ESRI research has explored the potential cost implications of expanding free GP care to all (Connolly et al., 2018).

A key recommendation of Sláintecare (and the Covid-19 Nursing Homes Expert Panel (Frazer et al., 2021)) is expanding home support for older people. We examine this recommendation in this report. We also examine the impact of establishing a statutory home support scheme on home support expenditure and LTRC expenditure, building on recent analysis by Walsh and Lyons (2021).

\subsection{NON-ACUTE SERVICES INCLUDED IN REPORT}

The analysis in this report encompasses most of the key publicly funded (nonacute) primary, community and long-term care services in Ireland. Projected demand for these services was included in a preceding report (Wren et al., 2017), and has been shown to account for a significant amount of care in Ireland. In 
addition, delivery of these services involves a sizeable proportion of the frontline health and social care workforce in Ireland (Smith et al., 2019), as well as accounting for a high proportion of the total health and social care budget (Wren and Fitzpatrick, 2020).

The analysis mainly focuses on HSE employed and/or publicly funded services. However, where data allow, privately financed expenditure is examined. The next section provides an overview of the services covered in this report.

\subsubsection{General practice}

General practice encompasses care provided by GPs and Practice Nurses (PNs). GPs are self-employed private practitioners. Most hold a GMS scheme contract to provide care that is free at the point of use to holders of a Medical Card or a GPVC. GPs are reimbursed for Medical Card/GPVC holders via capitation. ${ }^{4}$ GPs also provide private care to those without a Medical Card/GPVC, who are charged an out-of-pocket fee per visit. In the past GPs were often sole practitioners, but they are increasingly working in multi-GP practices, with over 75 per cent now doing so (Collins and O'Riordan, 2015; Collins and Homeniuk, 2021).

PNs are nursing professionals employed directly by general practices. While general practices pay the salaries of PNs, practices also receive allowances from the State to reimburse some of the cost of employing a PN (Teljeur et al., 2014). PNs are an increasing component of general practice; in 2021, virtually all (94\%) practices employed a PN at least on a part-time basis, with on average 1.2 PN whole-time equivalents (WTEs) employed in a practice (Collins and Homeniuk, 2021). In this report, public and private general practice demand and expenditure are examined.

\subsubsection{Public health nursing and primary care community therapy services}

A significant amount of care is provided in the community by nurses and community therapists such as physiotherapists, occupational therapists and speech and language therapists (Wren et al., 2017). Care provided by these professionals can be delivered to patients in their own homes and in health centres. While this report focuses on community therapy provided by HSE Primary Care services, a significant proportion of some community-based care is provided by HSE Mental Health and HSE Social Care services which, due to data constraints, are not included in this report. In addition, for some services such as physiotherapy, a significant proportion of care is privately financed and provided (Eighan et al., 2019). This report examines publicly funded therapy services only. 
Many therapy services are also provided in acute hospital settings but are not included in this report.

Public health nurses and community registered general nurses play a key role in primary, community and social care. These are HSE-employed nursing professionals who provide a broad range of services including primary care, home support-based care, child and maternal health, and health protection and promotion (McDonald et al., 2015; Wren et al., 2017). They are also key professionals in the assessment of people for home support or LTRC (McDonald et al., 2015; Wren et al., 2017).

\subsubsection{Community pharmaceuticals}

A substantial proportion of the healthcare budget is now spent on pharmaceuticals dispensed by community pharmacists. Prescription items are provided across four main publicly funded schemes: the GMS, DP, LTI and HT schemes. The GMS scheme covers those with a Medical Card, and there is a prescription charge associated with each prescription item dispensed. ${ }^{5}$ The LTI scheme is aimed at those who suffer from certain illnesses, and it provides necessary prescription items without charge. The DP scheme is primarily focused on those who do not qualify for a Medical Card or the LTI scheme. The scheme reimburses individuals or families for prescription costs above the current monthly threshold of $€ 114$ (this threshold was reduced from $€ 124$ in April 2019). The HT scheme dispenses high-tech medicines, which are generally prescribed or initiated in hospitals. Private pharmaceutical demand and expenditure is not included in this report.

\subsubsection{Long-term care (social care)}

This report examines both residential and home-based (home support or home care) long-term care for older people in Ireland. Lack of data prevented the inclusion of younger people with a disability in the analysis. These long-term care services are increasingly seen as forms of social care, where people are supported in their everyday lives, either in their own homes or in LTRC homes. These services represent a large part of health and social care expenditure in Ireland (Wren and Fitzpatrick, 2020). In the population aged 65 years and older, over 4 per cent use LTRC (Wren et al., 2017) while over 9 per cent are in receipt of home support (Walsh and Lyons, 2021). Long-term care in Ireland is a mixture of both public and private provision and financing. In LTRC, the NHSS is the dominant scheme through which people access residential care. No such scheme exists for home support, but 75 per cent of home support is publicly financed currently; this may increase once

For individuals aged under 70 , there is a charge of $€ 1.50$ per item dispensed up to a maximum of $€ 15$ per month per person or family. For individuals aged 70 and older, the charge is $€ 1$ per item dispensed up to a maximum of $€ 10$ per month per person or family. 
a planned statutory scheme is introduced (Walsh and Lyons, 2021). Both publicly and privately funded long-term care services are examined in this report.

\subsection{SYSTEM CHANGES DURING THE COVID-19 PANDEMIC}

In this report, 2019 is the base year for analysis of demand and unit costs and is used as the basis to project non-acute expenditure to 2035. However, the onset of the Covid-19 pandemic in 2020 affected the delivery of and expenditure on health and social care, which will likely have longer-term implications for drivers of demand and expenditure across all services analysed in this report (Keegan et al., 2020). Recent analysis by (Charlesworth et al., 2021) discusses how the Covid-19 pandemic will affect health and social care spending projection in the short and medium term. A pandemic-induced recession may impede sustainable health and social care spending. Preparedness for further health shocks may also increase overall healthcare spending. In the short term, spending increases will continue to be needed to allow the NHS to respond to the pandemic and also address the growing waiting lists for healthcare that occurred after elective procedures and diagnostic tests were postponed or cancelled (Charlesworth et al., 2021).

In addition to the issues listed by Charlesworth et al. (2021), additional changes that occurred in Ireland during the Covid-19 pandemic to date may affect health and social care expenditure projections. While many aspects of the acute hospital sector have been affected by the pandemic (Keegan et al., 2020; Walsh et al., 2020), within the non-acute services analysed in this report, there have also been considerable changes. In general practice, all Covid-19-related activity among nonGMS scheme patients was reimbursed by the State. GPs and PNs were also funded to provide services for the Covid-19 vaccination programme. Many community therapists were redeployed to Covid-19-related activities such as testing and contract tracing, while therapy visits were greatly reduced. This has exacerbated the already large volume of people on waiting lists for community therapy services and has also increased the length of time people are waiting for assessment or treatment during the pandemic.

LTRC has also been affected by the pandemic. Between March 2020 and April 2021, 2,172 nursing home and community hospital/long-stay unit residents died from confirmed outbreaks of Covid-19 in LTRC homes. ${ }^{6}$ This represents 67 per cent of all Covid-19 deaths as defined and reported by the Health Protection Surveillance Centre (HPSC). During this time, the number of people receiving LTRC as part of the NHSS reduced from 23,307 in December 2019 to 21,710 in March 2021. In addition, there was an increase in state expenditure on LTRC provided by private or

6 https://www.hpsc.ie/a-z/respiratory/coronavirus/novelcoronavirus/surveillance/weeklyreportoncovid19deathsreportedinireland/COVID-19_Weekly_Death_Report_Website_v1.0\%2030042021.pdf - Table 7. This may be an underestimate and only includes deaths linked to confirmed outbreaks. 
voluntary nursing homes such as personal protective equipment (PPE), Covid-19 response teams, greater access to clinical expertise and through the Temporary Assistance Payment Scheme (TAPS). This scheme was initiated during the Covid-19 pandemic to aid LTRC homes in their response to the pandemic.

The demand for home support has also been affected directly and indirectly by the pandemic. Many people had their home support suspended either voluntarily or by their $\mathrm{CHO}$ for periods of time during the pandemic. More recently, the HSE's 2020/21 'Winter Plan' announced large increases in home support hours, with 2021 home support projected to be 25 per cent higher than previously planned (Health Service Executive, 2020b).

Overall health and social care expenditure increased substantially during the pandemic. A public health budget of $€ 22$.1bn was announced for 2021; $€ 1$.8bn of this budget provided for direct Covid-19-related supports (Government of Ireland, 2020). Within the overall funding allocations, and consistent with the Winter Plan objectives, it appears that funding priorities relate to changing the model of care delivery in line with Sláintecare objectives, addressing known capacity deficits and tackling waiting lists (Government of Ireland, 2020).

In this report, we adjust our analysis where appropriate to account for the expenditure adjustments that have occurred since the onset of Covid-19. Following a similar approach to Keegan et al. (2020), we assume that longer-term health and social care expenditure requirements will be shaped by underlying demand and unit-cost drivers. However, we acknowledge that the Covid-19 pandemic may also have implications related to the demand for and cost of delivering non-acute care, which are relevant for modelling trends in expenditures over the medium term. Demographic scenarios have been updated to reflect the effects of the pandemic to date. Specifically, projected net international migration has been adjusted downwards over the short to medium term. In addition, the population estimates for 2020 and 2021 have been adjusted to take account of deaths from Covid-19. Therefore, projection scenarios have been modified, where appropriate, for each service analysed in this report.

Trends in pay and non-pay costs, informed by the ESRI's macro-econometric model COSMO (COre Structural MOdel of the Irish Economy), also take account of the Covid-19 pandemic. As in Keegan et al. (2020), two COSMO scenarios for economic recovery following the Covid-19 pandemic have been included: an Upside scenario and a Downside scenario. In each of the analytical chapters of this report, where appropriate, we provide more details on how demand and expenditure have been affected by the pandemic. 


\subsection{MODEL SCOPE AND MODELLING APPROACH}

The expenditure projections analyses were undertaken in this report using the ESRI's Hippocrates Model. The model has previously been used to project acute and non-acute health and social care demand (Wren et al., 2017), acute hospital bed capacity (Keegan et al., 2018), and acute public hospital expenditure (Keegan et al., 2020). This report focuses on the services provided outside of acute hospitals.

The Hippocrates Model is a macro-simulation, or cell-based, model. This type of model represents a large class of component-based models, which group individuals into cells according to key attributes such as age and sex, and project from that basis. The Hippocrates Model is 'bottom-up' in that demand and cost projections for individual services are built up in detail. In this report, expenditure projections are developed from a demand and cost base in 2019.

The modelling approach used in this report adopts a similar approach to Keegan et al. (2020). We project future demand primarily based on projected demographic change and healthy ageing assumptions. Projected demand for each non-acute service is costed by applying assumed trends in pay, drug and other non-pay costs over the projection horizon. Assumptions relating to healthy ageing and policy changes are based on evidence in the literature (Wren et al., 2017). The alternative expenditure projection scenarios vary assumptions, inter alia, relating to population change, healthy ageing, and pay and non-pay cost drivers. Assumptions are grouped to provide projections of expenditure under low-pressure, central, and high-pressure expenditure scenarios. These 'pressure' assumptions are tailored for each individual service, and are outlined in more detail in the analytical chapters. Where appropriate, the scenarios also incorporate a model of care change dimension, as in Keegan et al. (2020), reflecting important dimensions of the Sláintecare reforms (e.g. establishment of a statutory home support scheme) and reforms introduced during the Covid-19 pandemic.

In this report, a mixture of 'top-down' and 'bottom-up' costing approaches are used to estimate baseline unit costs and expenditure. The report draws on recent work by Smith et al. (2021) which estimated unit costs for non-acute care in Ireland. Where possible, the costs modelled in this report reflect the costs of providing a service. This means that unit costs include all care costs and overhead running costs (e.g. heating and lighting) associated with the delivery of care. In line with Keegan et al. (2020), capital costs or depreciation, which would require separate detailed treatment, are not included in the analysis. Also in line with Keegan et al. (2020), superannuation is excluded from unit-cost estimation. Particularly, since 2011, HSE statutory pension costs have been collated centrally and to assign these to the cost of delivering particular services may be misleading 
(Whyte et al., 2020). A detailed discussion of the methods employed are included in each analytical chapter.

The model is automated using SPSS and R software, with subsidiary analysis undertaken in Microsoft Excel.

\subsection{CONSIDERING THE NON-ACUTE DATA LANDSCAPE}

Where possible, we used administrative data in this analysis. We also supplemented our analysis with sources such as the HIS, the Irish Longitudinal Study on Ageing (TILDA) and Nursing Homes Ireland (NHI) surveys, to derive baseline utilisation and unit-cost information. The dearth of information on community-based specialist mental health and disability services, as well as private healthcare activity and costs, means it was not possible to examine these important services in this report.

Analyses of community-based services in Ireland, such as those presented in this report, are severely hampered by the data environment (Wren et al., 2017; Smith et al., 2019; Walsh et al., 2021). Ireland lacks the data infrastructure to systematically capture and collate utilisation, the cost of delivering care, and the demographic profiles of people availing of many health and social care services. The failure to integrate an individual health identifier $(\mathrm{IHI})$ and electronic health record (EHR) also makes it difficult to follow individuals across health and social care services.

The introduction of Activity Based Funding (ABF) in the acute public hospital system allowed for accurate bottom-up costing of public hospital care using the Hospital In-Patient Enquiry (HIPE) data. This benefitted previous analysis using the Hippocrates Model (Keegan et al., 2020). These data, while limited by the inability to follow patients over time and across hospitals, better reflected the complexity of care provided to individuals in hospitals. No such data reflecting the complexity of care provided to individuals outside hospital are available.

The limitations of data available on health and social care services delivered in the community curtailed the analyses in the report. For many services examined, basic demographic information - such as the age and sex of the individual receiving care and type of care provided - was not available. These constraints are most severe for PHN and community therapy services. However, limitations exist for all services examined. There is no central registry on general practice use. Much of the data on long-term care is collected at an aggregated level. These limitations also curtail the ability for policymakers to quantify and allocate resourcing and financing in an equitable and efficient manner. 
The scope of the services included in this report has been hampered by the poor health data infrastructure in Ireland. Community-based specialist mental health services, community-based specialist disability services, and dental and optical services are important parts of the health and social care system. However, no data that could meaningfully be used to identify utilisation and unit costs for these services were available for this analysis. In addition, it was not possible to examine many important private health and social care services. Due to the large role played by private purchasers and private providers, a lack of knowledge of this care inhibits a true reflection of health and social care use and expenditure.

\subsection{STRUCTURE OF THE REPORT}

The remainder of the report is structured as follows:

- Chapter 2 provides an overview of the drivers of healthcare expenditure, and how non-acute expenditure is measured in previous research and in this report.

- Chapter 3 describes the macroeconomic and demographic scenarios that feed into the projection scenarios for each service, presents and provides an overview of the Hippocrates modelling methodology and expenditure projection scenarios, and details the data sources, unit costs and projection scenarios included.

- Chapter 4 presents findings for our baseline analysis of expenditures and projections for general practice.

- Chapter 5 presents findings for our baseline analysis of expenditures and projections for PHN and public community therapy services.

- Chapter 6 presents findings for our baseline analysis of expenditures and projections for community pharmaceuticals.

- Chapter 7 presents findings for our baseline analysis of expenditures and projections for LTRC.

- Chapter 8 presents findings for our baseline analysis of expenditures and projections for home support.

- Chapter 9 concludes by summarising and discussing the findings presented in the report. 


\section{CHAPTER 2}

\section{Background}

\section{$2.1 \quad$ INTRODUCTION}

This chapter discusses the drivers of health and social care expenditure, previous evidence on health and social care expenditure in Ireland, and the modelling methods used for non-acute health and social care expenditure in this report.

\subsection{DRIVERS OF HEALTHCARE EXPENDITURE}

The path of health and social care expenditure projections is informed by assumptions related to both demographic and non-demographic drivers of expenditure. Previous research has found that, for acute hospital care in particular, the pay component of the projected cost of delivering healthcare in the future will be the main driver of expenditure increases (Irish Fiscal Advisory Council, 2018; Keegan et al., 2020; Parliamentary Budget Office, 2020). Other factors, such as changes in the population size and age structure, will also be key drivers. There is an extensive literature, discussed in detail in Keegan et al. (2020), that examines demographic and non-demographic drivers of healthcare expenditure. The literature points to how these drivers, or the magnitude of their effect, differ across health and social care services.

Keegan et al. (2020) present a conceptual breakdown of healthcare expenditure drivers, apportioned into demographic and non-demographic drivers, informed by previous evidence in this area (de la Maisonneuve and Martins Oliveira, 2015; Marino et al., 2017). Demographic drivers relate broadly to the size and structure of the population, as well as healthy ageing. Non-demographic drivers tend to be the dominant drivers of expenditure, and include income, relative prices, technological advancement and policy effects. Table 2.1 summarises how each component influences health and social care expenditure. In general, demographic drivers such as the size and structure of the population, as well as healthy ageing, influence expenditure through their role in influencing demand for care. In contrast, non-demographic drivers can affect both the demand for and cost of care. For example, income increases result in people demanding more and betterquality healthcare (Charlesworth and Johnson, 2018). However, factors such as the relative prices of healthcare influence expenditure through their role in the price of services. Furthermore, healthcare expenditure is often explained through Baumol's theory of cost disease (Hartwig, 2008). In Baumol's theory, as healthcare is labour-intensive, productivity is often lower than other sectors of the economy. However, as wages in low-productivity sectors must keep up with wages in highproductivity sectors, health and social care prices tend to rise faster than other prices in other sectors (Baltagi and Moscone, 2010). 
One key component that will drive health and social care expenditures, and especially expenditure in the public health system, is policy change. Implementation of Sláintecare proposals, such as moving more care into the community, will require additional funding. Other policy and system-level changes, such as the introduction of a statutory scheme for home support that confers access to home support for those who require it (Walsh and Lyons, 2021), will likely increase demand and expenditure in home support. Reducing the size of waiting lists will also require additional funding over a period of time (Brick and Keegan, 2020b). In Ireland, eligibility for free public health care, conferred from a Medical Card (GPVC), has been shown to increase healthcare utilisation, in particular GP care (Ma and Nolan, 2016; Connolly et al., 2018; O'Callaghan et al., 2018; Walsh et al., 2019a). The universal expansion of free GP care, a proposal of Sláintecare, would result in an additional $€ 500$ million cost for the Exchequer (Connolly et al., 2018).

In the previous chapter, we highlighted the significant age dimension to Medical Card (or GPVC) eligibility; any age-related eligibility effect on utilisation is captured in our baseline expenditure profiles and therefore incorporated in projections. However, in this report we do not explicitly undertake projections based on eligibility. 
TABLE 2.1 Drivers of healthcare expenditure - summary

\begin{tabular}{|c|c|}
\hline Drivers & Explanation \\
\hline \multicolumn{2}{|l|}{ Demographic Drivers } \\
\hline Population size & A population that is increasing will increase total demand and expenditure. \\
\hline Population structure & $\begin{array}{l}\text { In general, demand for healthcare is higher in the first years of life, during maternity years } \\
\text { for women, and in older population ages (European Commission, 2015). }\end{array}$ \\
\hline Healthy ageing & $\begin{array}{l}\text { The relationship between population ageing and health and social care use and expenditure } \\
\text { is complex. The three most common hypotheses to explain whether increases in life } \\
\text { expectancy are linked with better or poorer health (and a hypothesis introduced in Wren et } \\
\text { al. (2017)) are discussed below. }\end{array}$ \\
\hline $\begin{array}{l}\text { Expansion of Morbidity } \\
\text { (Gruenberg, 1977) }\end{array}$ & Gains in longevity accompanied by additional years with chronic disease. \\
\hline $\begin{array}{l}\text { Compression of } \\
\text { Morbidity (Fries, 1980) }\end{array}$ & Disease-free years increasing more than gains in longevity. \\
\hline $\begin{array}{l}\text { Dynamic Equilibrium } \\
\text { (Manton, 1982) }\end{array}$ & $\begin{array}{l}\text { Gains in longevity accompanied by additional years without disability, not necessarily } \\
\text { without chronic disease but disease with less severe progress due to new medical } \\
\text { treatments. }\end{array}$ \\
\hline $\begin{array}{l}\text { Moderate Healthy } \\
\text { Ageing (Wren et al., } \\
\text { 2017) }\end{array}$ & $\begin{array}{l}\text { This healthy ageing assumption was introduced in Wren et al. (2017) as a means of } \\
\text { introducing additional variation to the modelling. The assumption lies between expansion } \\
\text { of morbidity and dynamic equilibrium and assumes that gains in health are set at } 50 \text { per cent } \\
\text { of the gains in life expectancy. }\end{array}$ \\
\hline \multicolumn{2}{|l|}{ Non-Demographic Drivers } \\
\hline Income & $\begin{array}{l}\text { A country's income (e.g. gross domestic product [GDP] per capita) has been shown to explain } \\
\text { differences in healthcare expenditure across countries (Xu et al., 2011). Income growth and } \\
\text { health and social care expenditure are positively correlated. Recent research finds income } \\
\text { elasticity of demand (responsiveness of demand to income increases) to be less than one in } \\
\text { high-income (Martın et al., 2011; Xu et al., 2011; Baltagi et al., 2017) and middle-income } \\
\text { countries (Vargas Bustamante and V Shimoga, 2018) (Martın et al., 2011; Xu et al., 2011; } \\
\text { Baltagi et al., 2017). }\end{array}$ \\
\hline Relative prices & $\begin{array}{l}\text { Health and social care prices tend to increase at a greater rate than prices in other sectors } \\
\text { of the economy (Baumol's theory of cost disease) (Marino et al., 2017). }\end{array}$ \\
\hline Medical technology & $\begin{array}{l}\text { Technology is a key driver of healthcare expenditure (Newhouse, 1992). The use of often } \\
\text { more costly technologies such as MRI scans, laparoscopic or robotic surgery and oncology } \\
\text { drugs increase total healthcare expenditure. Evidence from Denmark estimates that } \\
\text { technological progress and medical practice changes explain approximately } 60 \text { per cent of } \\
\text { increases in healthcare expenditure in recent years (Laudicella et al., 2020). }\end{array}$ \\
\hline $\begin{array}{l}\text { Health and social care } \\
\text { policy }\end{array}$ & $\begin{array}{l}\text { Policy- and system-level changes around models of care, efforts to reduce waiting lists or } \\
\text { expansion of access to services can also increase health and social care expenditure, } \\
\text { especially expenditure in the public health system. For example, the implementation of } \\
\text { Sláintecare is projected to increase public healthcare expenditure substantially (Houses of } \\
\text { the Oireachtas Committee on the Future of Healthcare, 2017). }\end{array}$ \\
\hline $\begin{array}{l}\text { Medical Card } \\
\text { eligibility }\end{array}$ & $\begin{array}{l}\text { Research has shown that having a Medical Card (or a GPVC) increases demand for non-acute } \\
\text { services such as GP care (Ma and Nolan, 2016; Walsh et al., 2019a). Changes to Medical Card } \\
\text { (or GPVC) eligibility will therefore increase demand and expenditure. Increases in the older } \\
\text { population may increase health and social care expenditure through the higher rate of } \\
\text { eligibility in older age groups (Figure 1.1). }\end{array}$ \\
\hline
\end{tabular}

\subsection{PREVIOUS EVIDENCE ON HEALTH AND SOCIAL CARE EXPENDITURE IN IRELAND}

In recent years, several publications based on the Organisation for Economic Cooperation and Development (OECD) Systems of Health Accounts (SHA) approach have estimated the total spend on health and social care in Ireland. While it is difficult to capture all expenditure, the SHA approach to measuring healthcare expenditure is now commonly used in Ireland and across OECD countries. The expenditure included in the Irish SHA is defined as the final consumption expenditure of resident units on healthcare goods and services (OECD et al., 2017). The SHA includes four functional care categories: curative care, rehabilitation 
services, long-term care (health), and other services (e.g. preventive care, pharmaceutical goods). In addition, Wren and Fitzpatrick (2020) have found that Ireland's healthcare expenditure includes healthcare-related expenditure (HCRE) on services such as the social components of long-term care (social care) which some other countries account for outside healthcare expenditure. In this report, as we do not include all services included across the four function care categories of the SHA, we do not compare results from our analysis to Wren and Fitzpatrick (2020).

In 2018 the Central Statistics Office (CSO) estimated that current expenditure on publicly and privately financed healthcare was $€ 22.5 \mathrm{bn}$, the equivalent of $€ 4,623$ per person, or 11.4 per cent of GNI* (Central Statistics Office, 2020b). ${ }^{7}$ Of this spend, 74 per cent was government (public) spending, and $€ 1.2 \mathrm{bn}$ was capital expenditure (Central Statistics Office, 2020b). Hospital care accounted for the largest percentage of current healthcare expenditure (37.2\%) (Central Statistics Office, 2020b). The gross non-capital HSE (public) budget in 2018 was $€ 16.3 \mathrm{bn}$ (Department of Health, 2019b). The acute division accounted for €5.6bn (34.3\%), with primary, community and long-term care accounting for €9bn (55.2\%). The remainder was accounted for by statutory pensions and other spending.

As highlighted by the SHA estimates and the HSE budget allocations, expenditure on primary, community and long-term care services may be as much as twice the spend on the acute hospital sector. Despite this, research has been lacking on nonacute expenditure in Ireland. This report will provide an estimate of the expenditure profiles of such services for the first time. Below we highlight the main analyses of health and social care expenditure in Ireland undertaken to date.

\subsubsection{An analysis of trends in Irish public healthcare expenditure and staffing}

Whyte et al. (2020) examined changes in public current and capital healthcare expenditure in Ireland in recent years. The authors highlighted that comparing expenditure over time differs considerably once factors such as demographics and changes in the prices of goods and services are accounted for. The analysis showed large fluctuations in expenditure across different periods studied, which is unsurprising given the period covered the Great Recession when healthcare expenditure cuts took place.

The authors estimate that, between 2004 and 2017, total healthcare expenditure grew substantially, with nominal public current expenditure growing by 74.2 per cent. However, after adjusting for prices and the ageing of the population, public current expenditure grew 2.1 per cent (Whyte et al., 2020). The authors also 
highlight a decrease in public capital healthcare expenditure over this period. The share of public healthcare expenditure accounted for by capital expenditure reduced from 5.1 per cent in 2004 to 3.2 per cent in 2017. When explicitly examining HSE pay (2007-2017), the authors show that pay is the largest component of healthcare expenditure in Ireland; and, between 2007 and 2017, pay for HSE staff increased by 4.4 per cent. However, this masks effects of the Great Recession, where reductions of 5.6 per cent occurred between 2010 and 2013. As a consequence of these cuts as well as incentivised early retirement, voluntary redundancies and a moratorium on recruitment, HSE staff pay reduced from 64.3 per cent of public healthcare expenditure in 2007 to 58.4 per cent in 2017. Some of these reductions were offset by increases in HSE staff superannuation.

\subsubsection{How does Irish healthcare expenditure compare internationally?}

In the most comprehensive comparative analysis of Irish health and social care expenditure undertaken to date, Wren and Fitzpatrick (2020) examined the SHA approach to measuring healthcare expenditure (HCE). and analysed HCRE which comprises long-term care (social care) expenditure and health promotion.

It is not straightforward to compare healthcare expenditure in an international context (Turner, 2018). In their comparative analysis, as shown in Table 2.2, Wren and Fitzpatrick (2020) highlighted the difficulties when measuring and comparing expenditure across countries. They found that the expenditure measure used affects Ireland's healthcare expenditure ranking in the EU15. Depending upon the measure, and adjustments used, the Irish ranking differs between $1^{\text {st }}$ and $9^{\text {th }}$ in the EU15 in 2017 (Wren and Fitzpatrick, 2020).

TABLE 2.2 Irish healthcare expenditure compared to EU15, excluding and including healthcare-related expenditure, 2017

\begin{tabular}{|l|c|c|c|c|c|c|}
\hline \multirow{2}{*}{ HCE measure } & \multicolumn{3}{|c|}{ Irish HCE ranking in EU15 } & \multicolumn{3}{c|}{$\begin{array}{c}\text { Irish HCE as percentage } \\
\text { of EU15 mean }\end{array}$} \\
\cline { 2 - 7 } & Public & Private & Total & Public & Private & Total \\
\hline HCE as \% GDP (Ire \%GNI*) & 5 & 2 & 1 & 113 & 138 & 119 \\
\hline HCE + HCRE as \% GDP (Ire \%GNI*) & 6 & 3 & 3 & 109 & 134 & 115 \\
\hline HCE pc US\$ PPP & 9 & 2 & 9 & 100 & 130 & 106 \\
\hline HCE + HCRE pc US\$ PPP & 10 & 2 & 9 & 96 & 126 & 102 \\
\hline
\end{tabular}

Note: $\quad$ This table refers to current HCE; capital expenditure is not examined. pc: per capita. PPP: purchasing power parity.

Source: Wren and Fitzpatrick (2020).

In their analysis of Irish SHA expenditure for Ireland in 2017 (the latest year possible at the time of the analysis), Wren and Fitzpatrick (2020) found that Ireland includes a significant proportion of 'social care' expenditure. In 2017, of the $€ 15.5 \mathrm{bn}$ recorded as current public healthcare expenditure, 30 per cent was expenditure in these areas: HSE Services for Older People, HSE Disability Services, and Department 
of Employment Affairs and Social Protection (DSP) payments to carers of adults and children with disabilities (Table 2.3). Combined, social care expenditure was $€ 4.6 \mathrm{bn}$, comprising 22 per cent of Irish total HCE.

TABLE 2.3 Social care expenditure categories as share of Irish aggregate HCE, 2017

\begin{tabular}{|c|c|c|c|}
\hline & $\begin{array}{l}\text { Ireland } \\
€ m\end{array}$ & $\begin{array}{l}\text { Share of Irish Total } \\
\text { Current HCE \% }\end{array}$ & \\
\hline Total Current Healthcare Expenditure & 21,130 & 100 & \\
\hline Private Current Healthcare Expenditure & 5,643 & 27 & \\
\hline Public Current Healthcare Expenditure & 15,487 & 73 & \\
\hline Within Public Current HCE: & $€ \mathrm{~m}$ & $\%$ & $\begin{array}{l}\text { Share of Irish Public } \\
\text { Current HCE \% }\end{array}$ \\
\hline HSE Services for Older People & 1,824 & 9 & 12 \\
\hline HSE Disability Services & 1,659 & 8 & 11 \\
\hline $\begin{array}{l}\text { HSE corporate costs allocated to Older } \\
\text { People and Disability Services }\end{array}$ & 221 & 1 & 1 \\
\hline DSP transfer payments & 918 & 4 & 6 \\
\hline $\begin{array}{l}\text { HCE in HSE and DSP Social Care } \\
\text { categories combined }\end{array}$ & 4,621 & 22 & 30 \\
\hline
\end{tabular}

Source: Wren and Fitzpatrick (2020).

The authors concluded that, while the SHA is an important attempt to examine health and social care expenditure, the Irish approach to SHA accounting warrants review and should be supported by improved data on health and social care expenditure. It is hoped that the analysis in this report will assist in that review. Future research will endeavour to reconcile the approaches taken in this analysis to the SHA approach.

\subsubsection{Projections of expenditure for public hospitals in Ireland, 2018-2035}

Keegan et al. (2020) extended the Hippocrates Model to provide baseline estimates of expenditure in 2018 for public acute hospitals and acute adult psychiatric in-patient, and expenditure projections for these services to 2035. Comprehensive age and sex-specific profiles of public acute hospital expenditure in 2018 were developed, which for the first time, allowed Irish age-cost profiles to be used to inform the European Commission's Ageing Reports.

Table 2.4 illustrates that HSE gross expenditure on public acute hospitals was $€ 5,907 \mathrm{~m}$ in $2018 .{ }^{8}$ It also highlights that large increases in public acute hospital expenditures are projected across all services. Real expenditure (which removes the effects of cost increases) on public acute hospitals is projected to require increases of between 1.2 and 1.7 per cent on average annually to 2035. This equates to expenditure requirements of between $€ 7,183 \mathrm{~m}$ and $€ 7,834 \mathrm{~m}$ in 2035 . The equivalent nominal expenditure increases to 2035 are between 3.6 and 5.4 per

8 This figure relates to HSE Consolidated Financial Intelligence data on end-year 2018 gross expenditure on Acute Hospitals. The data were provided through personal communication with HSE Acute Finance. 
cent annually, and expenditure in 2035 of between $€ 10,761 \mathrm{~m}$ and $€ 14,363 \mathrm{~m}$. The largest increases in expenditures are observed for day-patient and in-patient discharges.

TABLE 2.4 Public acute hospital and acute psychiatric hospital expenditure - 2018 baseline and 2035 low- and high-pressure projections by service

\begin{tabular}{|c|c|c|c|c|c|c|}
\hline & & \multirow{2}{*}{$\begin{array}{c}\begin{array}{c}\text { Baseline } \\
\text { expenditure }\end{array} \\
2018\end{array}$} & \multicolumn{2}{|c|}{ Projected expenditure 2035} & \multicolumn{2}{|c|}{$\begin{array}{c}\text { Percentage change } \\
2018-2035\end{array}$} \\
\hline & & & Real $^{a}$ & Nominal & Real $^{\mathrm{a}}$ & Nominal \\
\hline & & $€ m$ & $€ \mathrm{~m}$ & $€ m$ & $\%$ & $\%$ \\
\hline \multicolumn{7}{|c|}{ Attendances } \\
\hline ED & & 418.6 & $467.5-496.0$ & $679.0-876.0$ & $11.7-18.5$ & $62.2-109.2$ \\
\hline OPD & & 676.4 & $758.5-798.6$ & $1,105.2-1,404.3$ & $12.1-18.1$ & 63.4-107.6 \\
\hline \multicolumn{7}{|c|}{ Discharges } \\
\hline \multicolumn{2}{|c|}{ Day patient $\mathrm{t}^{\mathrm{b}}$} & 919.5 & $1,109.8-1,201.5$ & $1,765.8-2,396.9$ & $20.7-30.7$ & $92.0-160.7$ \\
\hline \multicolumn{2}{|c|}{ In-patient ${ }^{b}$} & $3,220.5$ & $4,029.4-4,445.6$ & $5,985.3-8,050.0$ & $25.1-38.0$ & $85.9-150.0$ \\
\hline \multicolumn{2}{|c|}{ Elective $^{c}$} & 790.9 & $967.7-1,061.3$ & $1,437.4-1,921.7$ & $22.4-34.2$ & $81.7-143.0$ \\
\hline \multicolumn{2}{|c|}{ Emergency $^{d}$} & $2,143.5$ & $2,764.7-3,093.4$ & $4,106.8-5,601.4$ & $29.0-44.3$ & $91.6-161.3$ \\
\hline \multicolumn{2}{|c|}{ Acute gross expenditure } & $5,907.1$ & $7,183.2-7,834.1$ & $10,760.6-14,363.3$ & $21.6-32.6$ & $82.2-143.2$ \\
\hline \multicolumn{2}{|c|}{ Acute psychiatric in-patient } & 179.3 & $208.8-223.3$ & $302.7-395.2$ & $16.4-24.5$ & $68.8-120.4$ \\
\hline \multirow{5}{*}{\multicolumn{7}{|c|}{ only activity in pub }} \\
\hline & & & & & & \\
\hline & & & & & & \\
\hline & & & & & & \\
\hline & & & & & & \\
\hline Source: & Keegan et al. (2020) & & & & & \\
\hline
\end{tabular}

Keegan et al. (2020) projected that the cost of delivering future healthcare, rather than the demographic impacts on demand, will be the main driver of public acute hospital expenditure increases to 2035 (Figure 2.1). Pay costs, followed by non-pay (non-drug) costs, are the largest driver of projected public acute hospital expenditure increases in Ireland. 
FIGURE 2.1 Public acute hospital gross expenditure - growth decomposition by projection scenario, 2018-2035 (nominal)

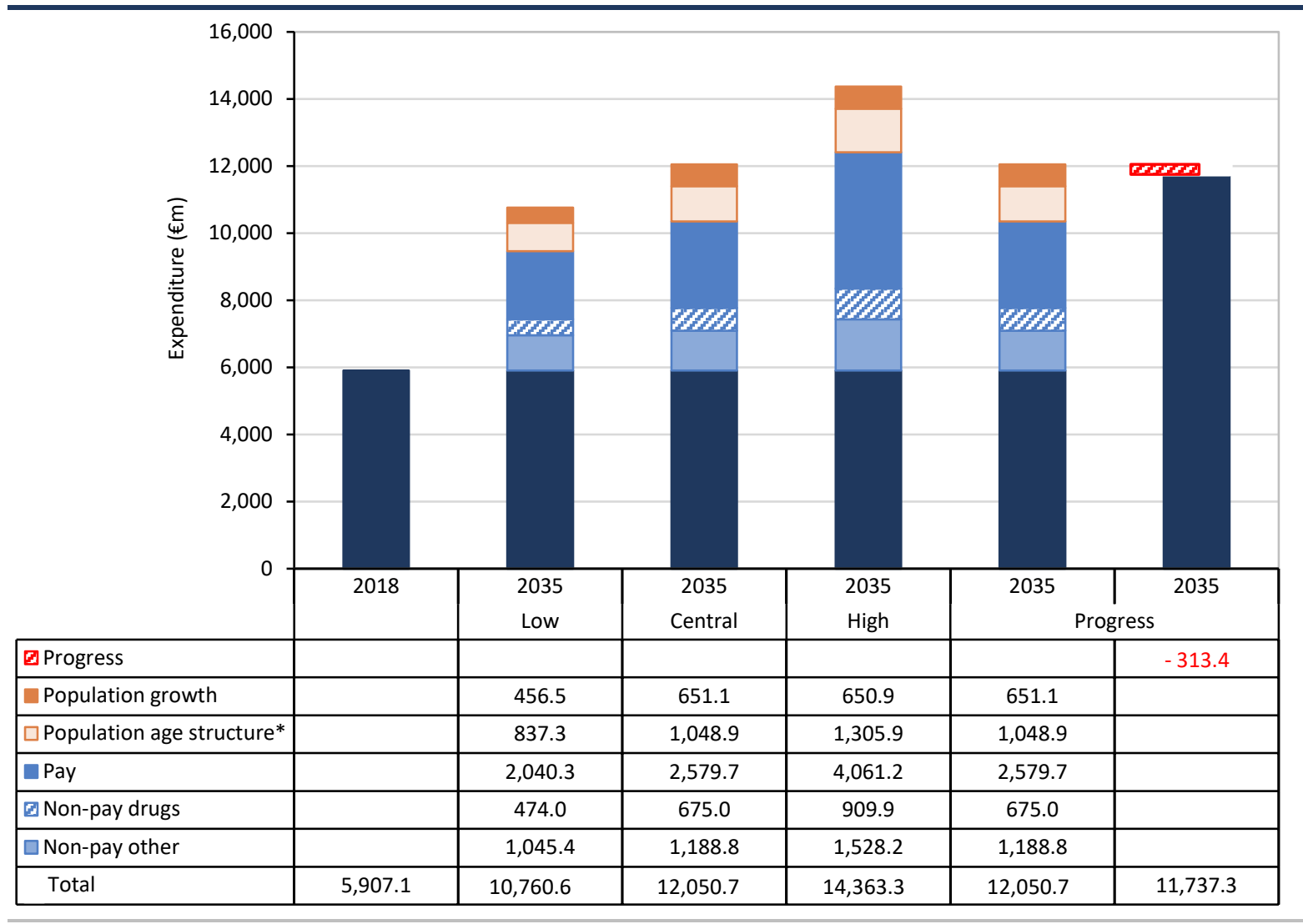

Notes: $\quad * \quad$ Adjusted for healthy ageing in the low and high scenarios.

Source: $\quad$ Keegan et al. (2020).

Much of the background literature on healthcare expenditure, as well as the modelling methods and projection parameters adopted in this report, have been covered in detail in Keegan et al. (2020). Therefore, where appropriate, we reference sections from that report rather than reiterating those sections once more in this report. However, in order to capture the most recent impact of Covid19 , there are slight differences in demographic and macroeconomic projections included in this report compared to Keegan et al. (2020). These are discussed in Chapter 3.

\subsection{TOP-DOWN AND BOTTOM-UP COSTING}

There are two broad methodological approaches for estimating unit costs in health and social care: the top-down approach (also known as the step-down, gross costing or average costing approach) and the bottom-up approach (encompassing micro-costing, activity-based costing, and patient-level costing) (Olsson, 2011; Batura et al., 2014; Whyte et al., 2018). There are advantages to each approach, and it is generally accepted that different costing methods are appropriate depending on the specific service under investigation (Mayer et al., 2020). 
Internationally, some countries have established unit-cost databases, though different valuation methods are used (Mayer et al., 2020). One of the longestestablished unit-cost databases was developed by the Personal Social Sciences Research Unit (PSSRU) in England. The PSSRU has compiled annual unit-cost estimates since 1992 for the most prominent acute and non-acute services in England. ${ }^{9}$ In Ireland, while detailed cost analysis of acute public hospital care is undertaken by the HPO, until recently there was no central database of unit costs for non-acute health and social care services. Progress has been made in this area with the recent publication of unit costs for selected primary, community and longterm care services for 2016 to 2019 (Smith et al., 2021).

\subsubsection{Top-down costing}

This approach assumes that costs are equally distributed across patients. It is seen as suitable for relatively homogenous services with similar material and personnel costs, and utilisation patterns across patients (Beecham, 1995; Edbrooke and Hibbert, 1999; Oostenbrink et al., 2002; Waters and Hussey, 2004; Mogyorosy and Smith, 2005). The top-down approach is appropriate for services examined in this report where expenditure is matched to underlying activity rather than the intensity of care received by the different patients in a single visit (e.g. private GPs, home support hour, LTRC bed) (Whyte et al., 2018). However, the top-down approach, even when variation in cost across groups/subgroups is captured, may be unsuitable for services where considerable variation in the resources used by different patients exists as part of a single episode of care (Whyte et al., 2018). In this context, it was not seen as the suitable approach in Keegan et al. (2020) for estimating acute public hospital care expenditure.

\subsubsection{Bottom-up costing}

In the bottom-up costing approach, each component of resource used to produce a given health or social care service is identified, measured, valued, summed, then divided by a specific unit (e.g. per contact, per hour) of activity. This means that resources - including staff salaries, equipment costs, office space and utility costs - are captured and included accordingly (Mayer et al., 2020). For example, a visit to a community-based occupational therapist in a local health centre requires several resource components including direct salary costs (i.e. the occupational therapist's salary), indirect salary costs (e.g. local health centre office staff), indirect administrative costs (e.g. utilities, office supplies, printing), capital overhead costs (e.g. building costs) and others (Smith et al., 2021). In addition to the direct salary costs, for publicly employed health and social care staff, pensions and superannuation costs can be included. The bottom-up approach was applied by Keegan et al. (2020) using the micro-costing ABF data available to the researchers. Smith et al. (2021) used a bottom-up approach to estimate health and 
social care unit costs for Ireland. (Charlesworth et al., 2021) also highlight that bottom-up costing methods provide more robust forecasts on health and social care expenditure.

\subsubsection{Unit costs for non-acute care in Ireland 2016-2019}

In the acute public hospital sector, the Healthcare Pricing Office (HPO) collects detailed costing data through HIPE. As mentioned above, no Irish database of unit costs for non-acute health and social care services existed until recently. Smith et al. (2021) developed unit costs for 16 healthcare professionals and services such as GPs, public health nurses and LTRC beds. For most services, micro-costing bottomup methods based on PSSRU methods were used. However, where data did not allow such micro-costing methods, or where they would be less appropriate (i.e. private GP care), a top-down method or survey data were used. Table 2.5 provides a list of services included in Smith et al. (2021) and the unit-cost estimation method used for each service.

TABLE 2.5 List of healthcare professionals and unit-cost estimation method in Smith et al. (2021)

\begin{tabular}{|c|c|c|c|}
\hline Healthcare professional & Staff Category & Staff Group & Unit cost estimation method \\
\hline Dietitian & Health \& Social Care & Therapies & Micro-costing (based on PSSRU methods) \\
\hline Occupational therapist & Health \& Social Care & Therapies & Micro-costing (based on PSSRU methods) \\
\hline Physiotherapist & Health \& Social Care & Therapies & Micro-costing (based on PSSRU methods) \\
\hline Podiatrist and chiropodist & Health \& Social Care & Therapies & Micro-costing (based on PSSRU methods) \\
\hline Psychologist & Health \& Social Care & Therapies & Micro-costing (based on PSSRU methods) \\
\hline Social care worker & Health \& Social Care & Therapies & Micro-costing (based on PSSRU methods) \\
\hline Public health nurse & Nursing \& Midwifery & Public Health Nurse & Micro-costing (based on PSSRU methods) \\
\hline Attendant (multi-task) & Patient \& Client Care & $\begin{array}{l}\text { Health Care } \\
\text { Assistants }\end{array}$ & Micro-costing (based on PSSRU methods) \\
\hline $\begin{array}{l}\text { Care assistant } \\
\text { (Disability Services) }\end{array}$ & Patient \& Client Care & $\begin{array}{l}\text { Health Care } \\
\text { Assistants }\end{array}$ & Micro-costing (based on PSSRU methods) \\
\hline Health care assistant & Patient \& Client Care & $\begin{array}{l}\text { Health Care } \\
\text { Assistants }\end{array}$ & Micro-costing (based on PSSRU methods) \\
\hline $\begin{array}{l}\text { Health care support assistant } \\
\text { (formerly home help) }\end{array}$ & Patient \& Client Care & Home Help & Micro-costing (based on PSSRU methods) \\
\hline GP public & $\mathrm{n} / \mathrm{a}$ & $\mathrm{n} / \mathrm{a}$ & Top-down method \\
\hline GP private & $\mathrm{n} / \mathrm{a}$ & $\mathrm{n} / \mathrm{a}$ & Survey of private fees \\
\hline Dentist public & $\mathrm{n} / \mathrm{a}$ & $\mathrm{n} / \mathrm{a}$ & Survey of private fees \\
\hline \multicolumn{4}{|l|}{ Dentist private } \\
\hline Long-term residential care & $\mathrm{n} / \mathrm{a}$ & $\mathrm{n} / \mathrm{a}$ & $\begin{array}{l}\text { Bottom-up (public) and negotiated fees } \\
\text { (private) }\end{array}$ \\
\hline
\end{tabular}

The bottom-up cost estimation approach developed by the PSSRU and used in Smith et al. (2021) aims to be transparent and flexible, and to incorporate all resource components used to deliver a unit of health or social care. The unit cost is broken down into its different components, including wages, salary oncosts (these encompassing employers' [the HSE] national insurance and superannuation contributions), overheads (e.g. secretarial staff salaries, utilities) and capital 
overheads. ${ }^{10}$ Where appropriate, and available, ancillary costs such as travel costs can be included. The total cost will represent the sum of the components. The unit cost per hour is finally estimated by summing each component and dividing by the number of hours worked per year. In many instances the unit cost per hour may equate to the unit cost of providing a service, though not in general.

Using the example of a healthcare support assistant (HCSA - formerly home help), Table 2.6 provides an example of the bottom-up micro-costing unit cost developed by Smith et al. (2021). The average basic salary (i.e. excluding overtime, allowances, etc) for a HCSA in 2019 was $€ 30,554$ per annum. Salary oncosts, including the employer's Pay-Related Social Insurance (PRSI) contribution and superannuation, totalled $€ 8,581$ per annum. In this example, an overhead of 40 per cent of basic salary (€12,222 per annum) and capital overheads of €4,111 were included. These cost components summed to a total cost of $€ 55,468$ per annum, or $€ 33$ per hour. Similar approaches were undertaken for most of the services outlined in Table 2.5. For services where data did not allow this approach to be taken, alternative approaches were undertaken based on service activity. For example, the unit cost of privately funded GP visits used evidence from the HIS.

10 As described in Section 1.6, for the purposes of this report unit costs are estimated excluding superannuation and capital overheads. 
TABLE 2.6 Estimated unit costs for a publicly employed, community-based healthcare support assistant, 2019

\begin{tabular}{|c|c|c|}
\hline Baseline (overheads 40\%) & & Description \\
\hline Cost component & $€$ & \\
\hline Wages/salary & 30,554 & Annual mean WTE basic salary. \\
\hline Salary oncosts & 8,581 & $\begin{array}{l}\text { PRSI contribution, calculated at } 10.75-10.95 \text { per cent of annual } \\
\text { mean WTE basic salary for a HCSA. } \\
\text { Superannuation: weighted average of the public-sector pension } \\
\text { contribution rates for pre- } 2013 \text { and post- } 2013 \text { pension cohorts } \\
\text { estimated by the Department of Public Expenditure and } \\
\text { Reform (with adjustment for the Pension Related } \\
\text { Deduction/Annual Superannuation Charge). Average pension } \\
\text { contribution of } 15-19 \text { per cent for publicly employed HCSAs. }\end{array}$ \\
\hline Qualifications & - & Not included in this analysis \\
\hline Overheads & 12,222 & $\begin{array}{l}\text { Estimated overhead costs for utilities, accommodation costs, } \\
\text { office facilities and general supplies as well as administrative } \\
\text { and management staff costs, using available guidelines. } \\
\text { Baseline estimate of } 40 \text { per cent of basic salary. }\end{array}$ \\
\hline Capital overheads & 4,111 & $\begin{array}{l}\text { Estimated capital overhead costs based on average capital } \\
\text { costs estimated by the PSSRU. } \\
\text { Estimate of } 11-13 \text { per cent of total salary (basic plus oncosts) } \\
\text { for the period 2016-2019. }\end{array}$ \\
\hline Travel & - & Not included in this analysis \\
\hline Total costs $\left(\sum A-F\right)$ & 55,468 & \\
\hline Working time & Hours & \\
\hline Number of hours worked per annum & 1,684 & $\begin{array}{l}\text { Total number of days worked per annum (number of working } \\
\text { days in a given year minus annual leave entitlement and } \\
\text { estimated sickness absence days) multiplied by number of } \\
\text { hours worked per day. }\end{array}$ \\
\hline I Ratio of direct to indirect time & - & Not included in this analysis \\
\hline Unit costs & $€$ & \\
\hline J Unit cost per hour $(\mathrm{G} / \mathrm{H})$ & 33 & \\
\hline
\end{tabular}

\subsubsection{Advantages and disadvantages of the costing approaches}

A key benefit of the bottom-up approach is the precision gained by adding together the costs of each component of care. This makes this approach useful in capturing variations in costs when changes are being made to existing services (Constenla et al., 2009). These benefits of the bottom-up approach do not, however, come without some disadvantages, as acquiring such extensive data requires time and money. The method is also more complex; with so many data points to collect, the possibility of overlooking a cost input can increase.

A key benefit of the top-down approach is that it is often a more straightforward way of determining unit costs than the bottom-up approach. It has fewer data requirements, and much of the data is routinely collected for accounts and management. These data-collection methods may also have been audited to ensure their accuracy. Research using top-down approaches is, therefore, less demanding in terms of data required and time (Raftery, 2000), while it also captures total recorded expenditure in a base year. On the other hand, the topdown approach often fails to capture cost differences across heterogeneous patient groups/subgroups. The more nuanced top-down approach, where an average cost can be calculated for subgroups, can increase precision. However, the 
creation of each subgroup also increases the number of data points required, increasing the resources needed to attain unit costs.

In practice, many studies use a mix of top-down and bottom-up approaches depending on data availability and the significance of each cost item to the overall analysis (Hendriks et al., 2014); this is in line with available international costing guidelines for health economic analysis (Drummond et al., 2015). As we will discuss throughout this report, we also use a mix of approaches to inform our analysis. 


\section{CHAPTER 3}

\section{Projection scenarios and modelling}

\subsection{INTRODUCTION}

This chapter presents the macroeconomic and demographic projection scenarios included in the analysis, and the methods used to estimate baseline health and social care expenditure profiles. It also provides an overview of the Hippocrates Model projection methodology; outlines the units of activity (e.g. GP visits, dispensed pharmaceutical items), baseline unit costs, and assumptions included on the drivers of expenditure for each service examined in this report.

\subsection{MACROECONOMIC SCENARIOS}

Following Wren et al. (2017) and Keegan et al. (2020), the macroeconomic projections are generated using the ESRI's macroeconometric model COSMO. COSMO is a structural macroeconometric model of the Irish economy designed for medium-term economic projections and policy analysis. It models the behaviour of the economy in a small open-economy framework, and accounts for economic conditions both in Ireland and internationally, using the global multi-country model NiGEM (Bergin et al., 2016; Bergin et al., 2017). COSMO initially focuses on the supply side (output side) of the economy, and then examines the expenditure (demand side) and income consequences. This report incorporates up-to-date macroeconomic projections that account for the potential impact of Covid-19, including the 'third wave' of the pandemic that occurred in Ireland in winter 2020/21 and spring 2021.

As a result of the uncertainty of the economic outlook due to Covid-19, we examine two alternative macroeconomic scenarios: Upside and Downside. Our approach is to replicate the economic shock(s) associated with Covid-19 and to model potential recovery paths for the economy. A similar approach was taken in Keegan et al. (2020), where more details on the approach can be found. The two scenarios update the assumptions made in Keegan et al. (2020). In both scenarios, economic growth is severely curtailed in the short run, but by less than assumed in Keegan et al. (2020). The two scenarios can be broadly characterised as follows:

- The Upside scenario assumes that public health restrictions are gradually relaxed in 2021 Q2, that the rollout of effective vaccines is successful and there is a relatively rapid return to pre-lockdown levels of activity from the second half of 2021.

- The Downside scenario assumes that the recovery in the domestic economy is slower because of factors that could include new variants of Covid-19, the continuation of some public health restrictions and continued uncertainty 
surrounding Covid-19. This scenario also includes scarring effects, where some of the losses in domestic sectors are assumed to be permanent.

Across both scenarios, the economy reverts to pre-Covid-19 trend growth over the medium term. Therefore, the real GDP growth in both scenarios averages around 3.7 per cent per annum between 2019 and 2035. Table 3.1 summarises the macroeconomic projections for both scenarios, averaged over the 2019-2035 period. Projections of the pay component of unit costs in this analysis are based on (average) projected government-sector, nominal average wage growth from these scenarios. Projections of the non-pay (overhead) component of unit costs are based on the projected inflation rate from these scenarios. The projections are in line with the scenarios included in Keegan et al. (2020).

TABLE 3.1 Summary of macroeconomic projections for the Upside and Downside scenarios

\begin{tabular}{|c|c|c|c|c|}
\hline \multicolumn{3}{|c|}{ Averaged over: } & \multicolumn{2}{|c|}{ 2019-2035 } \\
\hline & & & Upside scenario & Downside scenario \\
\hline \multicolumn{3}{|c|}{ GDP, constant prices, \% growth } & 3.8 & 3.7 \\
\hline \multicolumn{3}{|c|}{ GNP, constant prices, \% growth } & 5.1 & 4.6 \\
\hline \multicolumn{3}{|c|}{ GDP, current prices, \% growth } & 5.2 & 5.6 \\
\hline \multicolumn{3}{|c|}{ GNP, current prices, \% growth } & 6.4 & 6.9 \\
\hline \multicolumn{3}{|c|}{ Government sector, nominal average wage \% growth } & 2.5 & 2.2 \\
\hline \multicolumn{3}{|c|}{ Inflation rate, $\%^{a}$} & 1.4 & 1.5 \\
\hline Note: & a & \multicolumn{3}{|c|}{$\begin{array}{l}\text { The inflation rate in COSMO is the deflator on personal consumption and so it is a broader measure of price pressures } \\
\text { than the traditional consumer price index, which considers price changes in a specific basket of goods. Over time the two } \\
\text { measures tend to track each other quite closely. The GDP deflator is often used as well in these types of analyses. In } \\
\text { Ireland, as a small open economy, the GDP deflator is influenced by other prices including those for exports, which are } \\
\text { not directly relevant for the analysis in this report. }\end{array}$} \\
\hline Source: & & Projections from COSMO model. & & \\
\hline
\end{tabular}

Wages are a key driver of healthcare expenditure in Ireland (Keegan et al., 2020; Whyte et al., 2020). In line with Keegan et al. (2020), we assume that nominal wages in the government sector experience average annual growth of 2.5 per cent per annum over the period in the Upside scenario and 2.2 per cent per annum in the Downside scenario. ${ }^{11}$ These are policy modelling assumptions that reflect the long-run model projection for wages in the sector, which are ultimately linked to wage developments in other sectors of the economy. Over the longer term, using constant per annum growth in wages smooths out fluctuations that might occur in some periods. However, a deterioration in the public finances may lead to downward pressure on wages in the government sector.

11 In COSMO, government-sector wages are modelled at an aggregate level. Although the model does not explicitly differentiate between different components of the wage bill, including increments, the projections are consistent with long-run historical wage developments in the health sector. For example, Eurostat data show that nominal average annual wage growth in the health sector was 2.6 per cent between 1995 and 2019. 


\subsection{DEMOGRAPHIC SCENARIOS}

The demographic assumptions in this report follow closely those developed for the preceding reports using the Hippocrates Model (Wren et al., 2017; Keegan et al., 2020). For this report, some new data have been incorporated; in particular, population estimates for 2020 and 2021 have been adjusted to take account of deaths from Covid-19. ${ }^{12}$ Nevertheless, the demographic projection scenarios in this report are very closely aligned to those included in Keegan et al. (2020). Therefore, the section below provides an overview of the main assumptions and updated population scenarios.

\subsubsection{Demographic assumptions}

Table 3.2 outlines the main assumptions on mortality, fertility and net international migration for each demographic scenario. The assumptions differ slightly from Wren et al. (2017) but are very closely aligned to Keegan et al. (2020), where they are described in detail.

TABLE 3.2 Summary of main assumptions for population scenarios

\begin{tabular}{|c|c|c|c|}
\hline 2020 Projections & $\begin{array}{c}\text { Central } \\
\text { scenario }\end{array}$ & $\begin{array}{l}\text { High Population } \\
\text { scenario }\end{array}$ & $\begin{array}{c}\text { Low Population } \\
\text { scenario }\end{array}$ \\
\hline \multicolumn{4}{|l|}{ Mortality } \\
\hline $\begin{array}{l}\text { Mortality rates assumed to } \\
\text { decrease with gains in life } \\
\text { expectancy at birth from } \\
80.5 \text { ( } 84.5 \text { ) years for males } \\
\text { (females) in } 2019 \text { to: }\end{array}$ & $\begin{array}{l}83.5 \text { (86.5) years for males } \\
\text { (females) in } 2035\end{array}$ & $\begin{array}{l}83.8 \text { (86.7) years for males } \\
\text { (females) in } 2035\end{array}$ & $\begin{array}{l}83.2 \text { (86.2) years for males } \\
\text { (females) in } 2035\end{array}$ \\
\hline \multicolumn{4}{|l|}{ Migration } \\
\hline $\begin{array}{l}\text { Net immigration over the } \\
\text { projection horizon: }\end{array}$ & $\begin{array}{l}\text { Declining from } 2019 \text { level } \\
\text { of }+33,700 \text { to }+5,000 \text { until } \\
2022 \text { and then constant at } \\
+10,000 \text { p.a. over long term }\end{array}$ & $\begin{array}{l}\text { Declining from } 2019 \text { level } \\
\text { of }+33,700 \text { to between } \\
+15,000 \text { and }+20,000 \text { until } \\
2022 \text { and then constant at } \\
+25,000 \text { p.a. thereafter }\end{array}$ & $\begin{array}{l}\text { Declining from } 2019 \text { level } \\
\text { of }+33,700 \text { to between } \\
-5,000 \text { and zero net } \\
\text { migration until } 2022 \text { and } \\
\text { then constant at } 5,000 \text { p.a. } \\
\text { thereafter }\end{array}$ \\
\hline \multicolumn{4}{|l|}{ Fertility } \\
\hline Total fertility rate: & $\begin{array}{l}\text { Unchanged from } 2019 \text { rate } \\
\text { of } 1.72\end{array}$ & $\begin{array}{l}\text { Rises from } 2019 \text { rate } 1.96 \\
\text { by } 2026 \text { and remains } \\
\text { constant thereafter }\end{array}$ & $\begin{array}{c}\text { Declines from } 2019 \text { to } 1.6 \\
\text { by } 2035\end{array}$ \\
\hline
\end{tabular}

\subsubsection{Population scenarios}

Based on the assumptions around population change on mortality, migration and fertility, Table 3.3 shows the population projections across the central, low and high population scenarios. Projections are broken out by key age cohorts that are relevant for different services examined in this report.

12 For 2020 and 2021, mortality rates have been adjusted to take account of deaths from Covid-19 (from CSO data). The projections assume that, although the virus may be present for some time, the number of deaths associated with Covid-19 will not be as large in the coming years. 
In terms of overall growth, the population is expected to increase from $4.9 \mathrm{~m}$ in 2019 to $5.4 \mathrm{~m}$ in 2035 in the central scenario, corresponding to average annual growth of around 0.6 per cent per annum. In the high (low) population growth scenario, the population is expected to grow by 1 per cent $(0.4 \%)$ on average per annum, resulting in a total population of $5.8 \mathrm{~m}(5.2 \mathrm{~m})$ in the high (low) population growth scenarios in 2035. The different assumptions on migration are the key driver of differences in the overall population across scenarios.

Despite strong population growth, the ageing of the population is apparent, with the share of the population over the age of 65 rising steadily over time in each scenario. The largest growth rates will be in older age groups. For example, in the central scenario, the overall population is expected to increase by 9 per cent over the 2019 to 2035 period, while the corresponding increases in the population aged over 65 (over 85) is 56 (116) per cent. The table also shows the young-age and oldage dependency ratios. ${ }^{13}$ The old-age dependency rate rises from 0.22 in 2019 to 0.32 in 2035 in both the central and low population growth scenarios, while it also increases strongly in the high population growth scenario, to 0.31 by 2035 .

TABLE 3.3 Summary of population scenarios

\begin{tabular}{|c|c|c|c|c|c|c|c|c|}
\hline & \multirow{2}{*}{\multicolumn{2}{|c|}{2019}} & \multicolumn{6}{|c|}{2035} \\
\hline & & & \multicolumn{2}{|c|}{ Low } & \multicolumn{2}{|c|}{ Central } & \multicolumn{2}{|c|}{ High } \\
\hline & $N(' 000)$ & $\%$ & $N\left({ }^{\prime} 000\right)$ & $\%$ & $N(' 000)$ & $\%$ & $N\left({ }^{\prime} 000\right)$ & $\%$ \\
\hline $0-14$ & 1,006 & 20 & 794 & 15 & 857 & 16 & 1,027 & 18 \\
\hline $15-64$ & 3,229 & 65 & 3,368 & 64 & 3,448 & 64 & 3,652 & 63 \\
\hline $65+$ & 701 & 14 & 1,083 & 21 & 1,096 & 20 & 1,116 & 19 \\
\hline $85+$ & 74 & 2 & 156 & 3 & 161 & 3 & 167 & 3 \\
\hline Total population & 4,937 & 100 & 5,245 & 100 & 5,402 & 100 & 5,794 & 100 \\
\hline Young-age dependency ratio & \multicolumn{2}{|c|}{0.31} & \multicolumn{2}{|c|}{0.24} & \multicolumn{2}{|c|}{0.25} & \multicolumn{2}{|c|}{0.28} \\
\hline Old-age dependency ratio & \multicolumn{2}{|c|}{0.22} & \multicolumn{2}{|c|}{0.32} & \multicolumn{2}{|c|}{0.32} & \multicolumn{2}{|c|}{0.31} \\
\hline
\end{tabular}

\subsection{HIPPOCRATES MODEL}

The Hippocrates Model is a component-based healthcare projection model that projects from a bottom-up service or sectoral perspective. For most services examined, expenditure is projected by separately modelling the evolution of service demand and cost. A detailed discussion of the model and underlying methods is described in Keegan et al. (2020), Chapter 4. Below, Figure 3.1 provides an overview of the model and describes the steps in the modelling process for this report. This approach applies to all analytical chapters with the exception of

13 The young-age dependency ratio is the ratio of the number of young people at an age when they are normally economically inactive (under 15 years old) compared to the working-age population (those aged 15 to 64), while the old age dependency ratio refers to the number of older people at an age when they are generally economically inactive (over 65 years old) compared to the working-age population. 
Chapter 5 where data limitations necessitated a top-down, expenditure-based approach for PHN and community therapy services.

\subsubsection{Activity}

The first step is to develop base-year ( $\mathrm{t}$ ) age- and sex-specific activity rate profiles for each service under consideration (e.g. GP visit rate, home support hour rate). The base year for this analysis is 2019. Base-year activity rates are calculated by dividing age- and sex-specific activity volumes by corresponding age- and sexspecific population volumes in 2019. Where the data allow, age cohorts are disaggregated by single-year-of-age (SYOA). Where SYOA data are not available, we use the most detailed level of age disaggregation available (e.g. 5-year age groups).

FIGURE 3.1 Hippocrates Model - diagrammatic representation

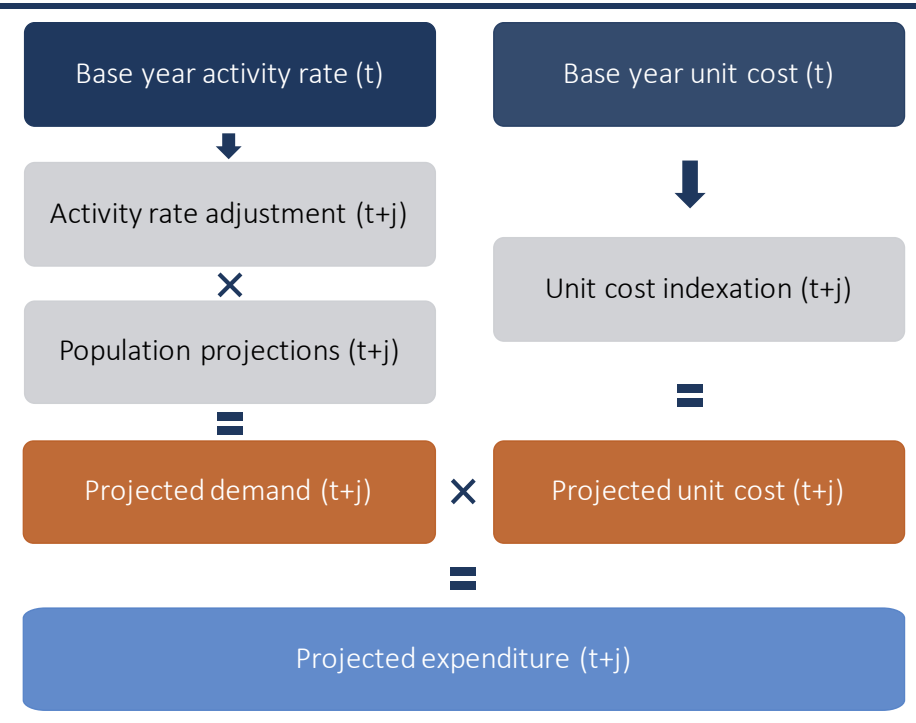

Source: Keegan et al. (2020).

The second step involves adjusting age- and sex-specific activity rate profiles for each year (j) of the projection horizon (2020-2035). In this report we adjust activity rate profiles in a number of ways.

\section{Healthy ageing}

For all services, age- and sex-specific activity rates are adjusted through the projection horizon to account for healthy ageing. Healthy ageing adjustments are made to account for the fact that, as life expectancy increases, not all additional life years may be spent in bad health. The healthy ageing assumptions employed are discussed in Chapter 2, and in detail in Wren et al. (2017). To simulate these effects, we shift age- and sex-specific activity curves to the right in proportion to projected life-expectancy change. This is based on an approach adopted from the 
European Commission (European Commission, 2011; 2014; 2017) and applied previously (Wren et al., 2017; Keegan et al., 2020).

Activity rate shifts are only applied where activity rates, proxying morbidity, are increasing through the age distribution. Additionally, activity rates shifts are not applied to the entire age distribution as variation in activity rates at younger ages may be less reflective of variation in morbidity (Blanco-Moreno et al., 2013). Activity rate shifts are therefore limited to those aged 35 and over. The exception to this is for analysis of LTRC and home support where the nature of the services being examined make it more appropriate to apply activity shifts at 65 and over.

\section{Unmet demand}

The model has also been developed to adjust activity rates to account for unmet demand such as people on a waiting list for care in 2019. Using information on people awaiting care in 2019, volumes of waiters are converted to rates to adjust activity in the Hippocrates Model. As unmet demand and waiting-list targets differ across services, slightly different methods are applied across services. Therefore, we discuss unmet demand, if applicable, in each service chapter.

\section{Additional activity rate shifts}

In some chapters, a third step is added to the activity rate adjustments to capture other impacts on activity rates not driven by healthy ageing effects or unmet demand. For instance, while 2019 is the base year in this report, as a consequence of Covid-19 and the soon-to-be-introduced statutory home support scheme, there have been changes in utilisation of long-term care services in 2020 and 2021. Therefore, to account for these changes since 2019, we apply additional shifts. Furthermore, when modelling the projected expenditure on the HT scheme, we model additional activity-rate growth that has been evident historically, related to uptake of new drugs. These adjustments are discussed in detail in the respective chapters.

\subsubsection{Projecting demand to 2035}

Following adjustments to activity rates outlined in the previous section, demand for care is then projected by multiplying annual age- and sex-specific activity rate profiles by corresponding annual age- and sex-specific projected population volumes.

\subsubsection{Developing unit costs for $\mathbf{2 0 1 9}$}

To generate base-year and projected health and social care expenditure, we estimate the unit cost of the (projected) activity of delivering one unit of a 
particular service (e.g. a GP visit). As discussed in Chapter 2, a range of resources are required to deliver a unit of health or social care activity. From the perspective of projection modelling, it is important to also know the relative component shares of the unit cost in the base year to allow for differential modelling of the growth rates of these components through the projection horizon. Following Keegan et al. (2020), we focus on two main components of unit costs: pay costs and non-pay costs. Pay costs relate to medical, nursing, and non-clinical staff costs required to deliver care (e.g. the salary of a PN). Non-pay costs are varied and differ across the services examined in this report but capture elements of cost such as laboratory equipment and overheads.

In this report, where possible, we use the bottom-up unit-cost method. For many services examined, the costs included are informed by Smith et al. (2021). The approach to unit-cost estimation varies across chapters and is influenced by the underlying data availability. In some instances, top-down costing is required. In Chapter 5, given the available data, it was not possible to estimate age- and sexspecific activity profiles for PHN and community therapy services. Rather, an alternative top-down approach is applied, taking, as the starting point, total cost of employment of the selected HSE staff categories allocated as HSE Primary Care WTEs in 2019. To this, an estimated pay and non-pay overhead rate is applied, followed by the best available age distribution for each service. Dividing by population arrives at baseline per capita expenditure (proxying unit costs as per European Commission (2018).

Table 3.4 outlines the unit of activity, the unit-cost method, and the average cost of a unit of activity for each service examined in this report. The unit of activity included differs significantly across services, and follows the unit of activity included in previous demand projection estimates (Wren et al., 2017). 
TABLE 3.4 Unit costs for health and social care services examined in report, 2019

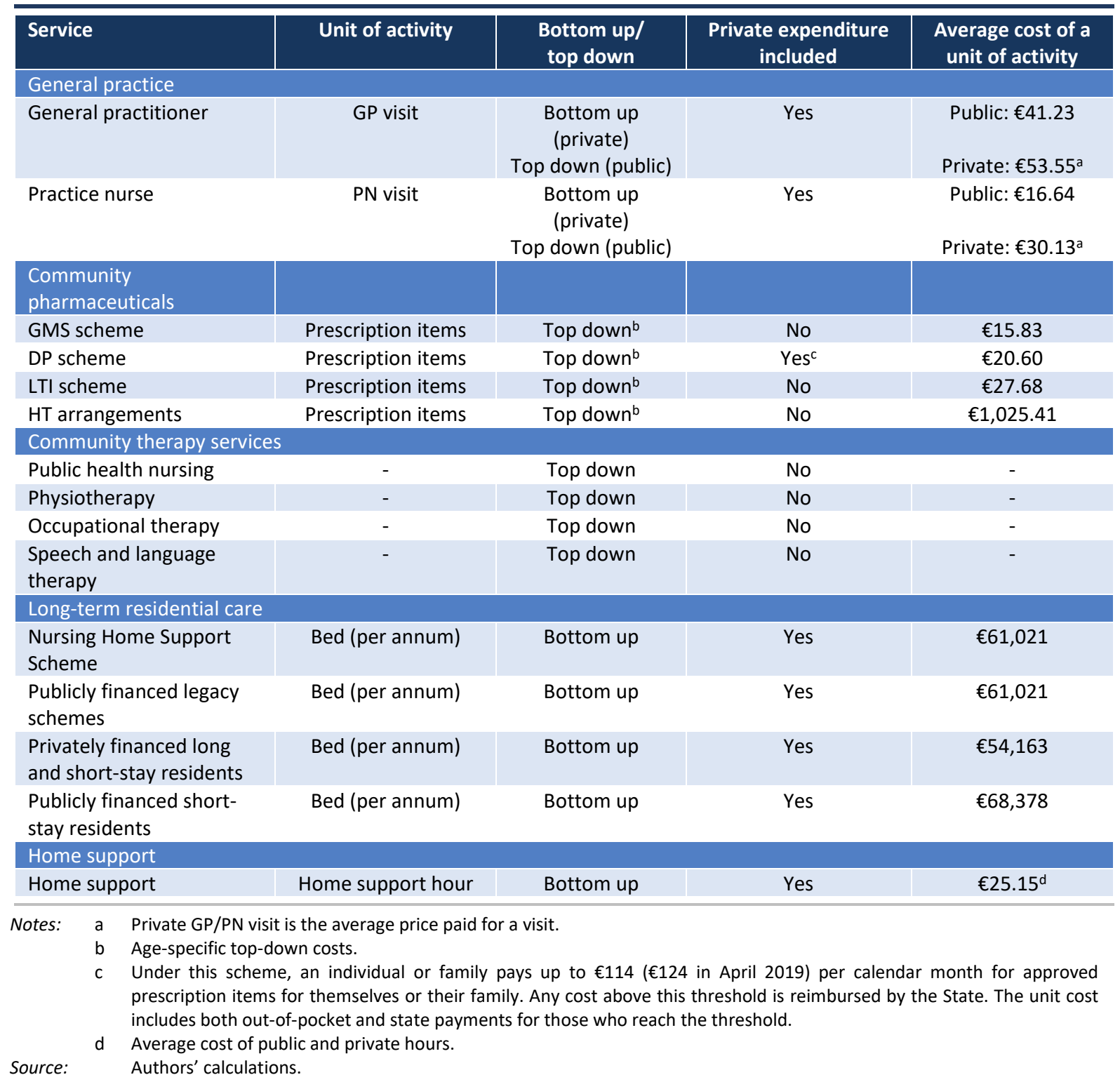

\subsubsection{Project unit costs to 2035}

The next step discusses the assumptions adopted in projecting unit costs of care through the projection horizon. In Keegan et al. (2020) it was possible to split unit costs into their pay and non-pay components and project these along separate indices. The approach in this report differs and varies across chapters.

\section{Pay and non-pay costs}

Owing to the labour-intensiveness of health and social care, increases in healthcare expenditure are often explained by supply-side effects. Health and social care salaries, for instance, need to increase to keep pace with remuneration in the broader economy to encourage recruitment and retention of workers. As described in Section 3.2, over the 2019 to 2035 period, nominal average annual government-sector wage growth is projected to be 2.5 per cent under the Upside scenario and 2.2 per cent under the Downside scenario, and tied to projected wage 
growth in the wider economy. In all chapters (with the exception of Chapter 6) it is possible to identify a pay component of unit cost. In Chapters 6 (general practice), 7 (LTRC) and 8 (home support), this approximates a direct care pay cost of delivering a unit of service. The remaining component of the unit cost is an overhead term capturing a mix of non-care pay costs and non-pay costs. The inability to split out the non-care pay component of the overhead means that for these chapters we assume that the pay-to-overhead ratio applied at baseline remains stable through time.

In Chapter 5, a top-down method for estimating total expenditure is used, with total cost of employment as the starting point. To this an estimated overhead, split into pay and non-pay components, is applied (Smith et al., 2021). Non-pay components are modelled separately. Non-pay costs are indexed to projected inflation from COSMO's macroeconomic scenarios plus 0.5 percentage point per annum to reflect assumed higher growth of community therapy non-pay service delivery costs above inflation. In Chapter 6 we project the unit costs of prescription community pharmaceuticals based on historical trends as these unit costs are not subject to pay and overhead splits.

\subsubsection{Developing expenditure profiles and projecting to 2035}

For the 2019 base year we combine activity profiles with unit costs to develop base-year age- and sex-specific expenditure profiles. Annual projected expenditure is estimated through multiplying annual demand projections by annual unit cost projections. For major service categories, we also decompose expenditure growth into its underlying drivers.

\subsection{EXPENDITURE PROJECTION SCENARIOS}

Following Wren et al. (2017) and Keegan et al. (2020), we develop a range of projection scenarios that group drivers together in a consistent manner. Given the uncertainty inherent in all projections, this provides a basis for developing a projection range charting the likely course of future expenditures.

Table 3.5 outlines the projection scenarios included in the report. For all health and social care services included, we apply a set of low, central and high-pressure scenarios. To account for the uncertainty in relation to the expected course of expenditure drivers, we vary projected demand and expenditure across drivers, though some - such as unmet need - are not included for all services:

- population size and structure;

- healthy ageing;

- unmet demand; 
- model of care changes (additional modelled demand);

- macroeconomics projections.

These assumptions are grouped within different pressure scenarios, and we examine trajectories where demand and cost drivers place relatively lesser or greater pressures on projected expenditures.

As outlined in Section 3.3, we include three population projection scenarios (low, central and high) to examine how alternative assumptions on demographic change may affect projected demand. Healthy ageing assumptions also vary across pressure scenarios and conform to the assumptions included in Wren et al. (2017). More pessimistic (optimistic) assumptions around healthy ageing are incorporated in the high (low)-pressure scenario. Where applicable, unmet demand is included in the central and high-pressure scenarios.

Additional adjustments to activity are included for some services. For example, the introduction of the statutory home support scheme is scheduled to be established in 2022, and we assume it will be fully operational in 2023. Therefore, in this analysis we make specific assumptions that consider the impact the introduction of such a scheme will have on home support demand, but also demand for LTRC. When modelling HT scheme expenditure, we also introduce additional assumptions related to demand growth over and above demographic effects, reflective of historical trends.

Macroeconomic projections, as outlined in Section 3.2, provide a basis for modelling costs. These macroeconomic projections are based on the Upside and Downside scenarios that vary around optimism on medium-term economic growth as a result of the Covid-19 pandemic. Pay growth is linked to government-sector average wage growth (linked to wages in other sectors of the economy). Pay:nonpay ratios estimated in the base year are assumed to remain the same over the projection horizon.

Table 3.5 outlines the assumptions made for each health and social care service examined across the pressure scenarios. 
TABLE 3.5 Projection scenario assumptions

\begin{tabular}{|c|c|c|c|}
\hline & Low pressure & Central & High pressure \\
\hline \multicolumn{4}{|l|}{ General practice } \\
\hline \multicolumn{4}{|l|}{ Demand assumptions } \\
\hline Population growth and age structure & Low & Central & Central \\
\hline Healthy ageing & $\begin{array}{c}\text { Moderate healthy } \\
\text { ageing }\end{array}$ & Moderate healthy ageing & Expansion of morbidity \\
\hline Unmet demand & No & No & No \\
\hline \multicolumn{4}{|l|}{ Cost assumptions } \\
\hline Pay & $\begin{array}{c}\text { COSMO Downside - } \\
\text { wage growth } 2.2 \% \text { p.a. }\end{array}$ & $\begin{array}{c}\text { COSMO Upside - } \\
\text { wage growth } 2.5 \% \text { p.a. }\end{array}$ & $\begin{array}{l}\text { COSMO Upside - wage } \\
\text { growth } 3.5 \% \text { p.a. }\end{array}$ \\
\hline Non-pay & $2.2 \%$ p.a. & $2.5 \%$ p.a. & 3.5\% p.a. \\
\hline \multicolumn{4}{|c|}{ Public health nursing and community therapy services } \\
\hline \multicolumn{4}{|c|}{ Demand assumptions } \\
\hline Population growth and age structure & Low & Central & Central \\
\hline Healthy ageing & - & - & - \\
\hline Waiting-list management & No & No & No \\
\hline \multicolumn{4}{|l|}{ Cost assumptions } \\
\hline Pay & $\begin{array}{c}\text { COSMO Downside - } \\
\text { wage growth } 2.2 \% \text { p.a. }\end{array}$ & $\begin{array}{c}\text { COSMO Upside - } \\
\text { wage growth } 2.5 \% \text { p.a. }\end{array}$ & $\begin{array}{l}\text { COSMO Upside - wage } \\
\text { growth 3.5\% p.a. }\end{array}$ \\
\hline Non-pay & $\begin{array}{c}\text { COSMO Downside - } \\
\text { indexed to projected } \\
\text { inflation rates }+0.5 \mathrm{pct} \\
\text { point p.a. }\end{array}$ & $\begin{array}{c}\text { COSMO Upside - } \\
\text { indexed to projected } \\
\text { inflation rates+ } 0.5 \text { pct } \\
\text { point p.a. }\end{array}$ & $\begin{array}{c}\text { COSMO Upside - } \\
\text { indexed to projected } \\
\text { inflation rates }+0.5 \text { pct } \\
\text { point p.a. }\end{array}$ \\
\hline \multicolumn{4}{|l|}{ Community pharmaceuticals } \\
\hline \multicolumn{4}{|l|}{ Demand assumptions } \\
\hline Population growth and age structure & Low & Central & Central \\
\hline Healthy ageing & Dynamic equilibrium & Dynamic Equilibrium & $\begin{array}{l}\text { Moderate healthy } \\
\text { ageing }\end{array}$ \\
\hline Unmet demand & No & No & No \\
\hline Additional modelled activity growth & $2 \%$ p.a. & 3.5\% p.a. & $5 \%$ p.a. \\
\hline \multicolumn{4}{|l|}{ Cost assumptions } \\
\hline Unit cost (GMS, DP, LTI schemes) & $-1.5 \%$ p.a. & No change & $1.0 \%$ p.a. \\
\hline Unit cost (HT scheme) & $3.0 \%$ p.a. & $3.5 \%$ p.a. & $4.0 \%$ p.a. \\
\hline \multicolumn{4}{|l|}{ Long-term residential care } \\
\hline \multicolumn{4}{|l|}{ Demand assumptions } \\
\hline Population growth and age structure & Low & Central & Central \\
\hline Healthy ageing & $\begin{array}{l}\text { Compression of } \\
\text { morbidity }\end{array}$ & Compression of morbidity & Dynamic equilibrium \\
\hline Unmet demand & No & No & Yes \\
\hline Substitution & Yes & No & No \\
\hline \multicolumn{4}{|l|}{ Cost assumptions } \\
\hline Pay & $\begin{array}{c}\text { COSMO Downside - } \\
\text { wage growth } 2.2 \% \text { p.a. }\end{array}$ & $\begin{array}{c}\text { COSMO Upside - } \\
\text { wage growth } 2.5 \% \text { p.a. }\end{array}$ & $\begin{array}{l}\text { COSMO Upside - wage } \\
\text { growth 3.5\% p.a. }\end{array}$ \\
\hline Non-pay & $2.2 \%$ p.a. & $2.5 \%$ p.a. & 3.5\% p.a. \\
\hline \multicolumn{4}{|l|}{ Home support } \\
\hline \multicolumn{4}{|l|}{ Demand assumptions } \\
\hline Population growth and age structure & Low & Central & Central \\
\hline Healthy ageing & $\begin{array}{l}\text { Compression of } \\
\text { morbidity }\end{array}$ & Compression of morbidity & Dynamic equilibrium \\
\hline Unmet demand & No & Yes & Yes \\
\hline Substitution & No & Yes & Yes \\
\hline \multicolumn{4}{|l|}{ Cost assumptions } \\
\hline Pay & $\begin{array}{c}\text { COSMO Downside - } \\
\text { wage growth } 2.2 \% \text { p.a. }\end{array}$ & $\begin{array}{c}\text { COSMO Upside - } \\
\text { wage growth } 2.5 \% \text { p.a. }\end{array}$ & $\begin{array}{l}\text { COSMO Upside - wage } \\
\text { growth 3.5\% p.a. }\end{array}$ \\
\hline Non-pay & $2.2 \%$ p.a. & $2.5 \%$ p.a. & 3.5\% p.a. \\
\hline
\end{tabular}

Note: $\quad$ No healthy ageing assumptions are included for PHN and community therapy services due to the lack of activity data.

Source: Authors' representation. 
Table 3.6 outlines the data sources used in each individual chapter. A combination of administrative and survey-based data was used in the analysis.

TABLE 3.6 Baseline analysis data sources

\begin{tabular}{|c|c|}
\hline Activity / Unmet Demand & Costs \\
\hline \multicolumn{2}{|l|}{ General Practice } \\
\hline $\begin{array}{l}\text { Healthy Ireland Survey - Waves } 4 \text { and } 5 \\
\text { Growing Up in Ireland }\end{array}$ & $\begin{array}{l}\text { Healthy Ireland Survey - Waves } 4 \text { and } 5 \\
\text { PCRS GP Reimbursement Data }\end{array}$ \\
\hline \multicolumn{2}{|l|}{ Public health nursing and community therapy services } \\
\hline $\begin{array}{l}\text { HSE Business Intelligence Unit - primary care, metrics } \\
\text { TILDA - Wave } 3 \text { and } 4 \\
\text { Healthy Ireland Survey - Wave } 5 \\
\text { HSE Health Protection Surveillance Centre }\end{array}$ & $\begin{array}{l}\text { HSE Finance - Payroll } \\
\text { Smith et al., } 2021\end{array}$ \\
\hline \multicolumn{2}{|l|}{ Community pharmaceuticals } \\
\hline PCRS Drug Reimbursement Data & PCRS Drug Reimbursement Data \\
\hline \multicolumn{2}{|l|}{ Long-term residential care } \\
\hline $\begin{array}{l}\text { HSE Social Care Division Data } \\
\text { NHI - 2019/2020 Private \& Voluntary Nursing Home } \\
\text { Survey }\end{array}$ & $\begin{array}{l}\text { HSE Social Care Division Data } \\
\text { NHI - 2019/2020 Private \& Voluntary Nursing Home } \\
\text { Survey }\end{array}$ \\
\hline \multicolumn{2}{|l|}{ Home Support } \\
\hline $\begin{array}{l}\text { HSE Social Care Division Data } \\
\text { TILDA - Waves 2-5 } \\
\mathrm{HCCl}\end{array}$ & $\begin{array}{l}\text { HSE Social Care Division Data } \\
\text { TILDA - Waves 2-5 } \\
\mathrm{HCCl}\end{array}$ \\
\hline
\end{tabular}

Expenditure projections are presented in both real and nominal terms between 2019 and 2035. Real projections hold costs constant at 2019 values, thus enabling analysis of projected volumes of care as if the cost of care had not changed. Projected real expenditure growth is driven by assumptions in relation to demographic change and healthy ageing. Nominal projections capture both demand and cost effects. Projected nominal expenditure growth is driven by assumptions in relation to the evolution of both demand and cost drivers.

\subsection{SUMMARY}

This chapter provided a detailed description of the projection methods, applied in the analysis in this report. The development of projection methods was informed by a detailed review of the evidence on the drivers of healthcare expenditure and their application to component-based modelling, reviewed in Chapter 2. The chapter also outlined the final expenditure projection scenarios to be applied in Chapters 4 to 8 and provided an overview of the data sources employed for the analysis. 


\section{CHAPTER 4}

\section{Findings: General practice expenditures}

\subsection{INTRODUCTION}

This chapter presents findings for baseline expenditure in 2019 and projected expenditure to 2035 for general practice services, including GPs and PNs. The analysis distinguishes between cardholders (Medical Card or GPVC holders) and non-cardholders. Further, the relative contributions of different demand and cost drivers for projected expenditures for 2035 are identified. By way of context, the next section will provide a brief overview of general practice in Ireland.

\subsection{GENERAL PRACTICE IN IRELAND}

General practices are generally individuals' first point of contact with the healthcare system in Ireland. They provide a variety of diagnostic services and medical treatments and act as gatekeepers for a range of secondary care services (Nolan, 2007). GPs and PNs play a central role in general practice and are the focus of this chapter.

An estimated 3,351 GPs were practising in Ireland in 2018 (Connolly et al., 2021). GPs are self-employed private practitioners, with most providing services to those with a Medical Card/GPVC as well as those with no card. PNs are an increasing component of general practice; in 2020 approximately 94 per cent of general practices employed a practice nurse (Collins and Homeniuk, 2021). PNs carry out a variety of tasks and services, including immunisations, screening, health promotion, phlebotomy and the management of chronic conditions (Irish Practice Nurses Association, 2014). PNs are employed by the practice and practices are given subsidies to contribute to the cost of employing a PN (Teljeur et al., 2014). According to the Irish General Practice Nurses Educational Association, there are approximately 2,000 practice nurses in Ireland. ${ }^{14}$

Chapter 1 provides an overview of the different eligibility categories for public healthcare services in Ireland. In relation to general practice, those with a Medical Card/GPVC are entitled to free general practice care, with the practice reimbursed through the GMS scheme. Under the GMS scheme, GP practices are paid an annual capitation payment (which includes a weighting for age and sex) for each eligible patient on their list, as well as a range of other fees and allowances. For those without a card, GP practices are largely reimbursed on a fee-for-service basis from individual patients, with the fee determined by individual practices. 
A number of reform proposals for the Irish healthcare system have emphasised the need to strengthen primary care and general practice in Ireland (Department of Health and Children, 2001; Houses of the Oireachtas Committee on the Future of Healthcare, 2017). Sláintecare recommended a phased extension of entitlement to free GP care to the entire population and an increase in capacity. However, progress to date in this regard has been slow (Connolly and Wren, 2019; Thomas et al., 2021). In 2019, there was a new GP agreement between the Department of Health, the HSE and the Irish Medical Organisation (IMO) regarding the development of GP services (Department of Health, 2019c). It included plans for additional payments to GPs over a phased basis to support three main strands: i) fee increases under the GMS contract in return for delivery of a package of 'Service Modernisation and Reform Measures'; ii) the introduction of a new 'Integrated Model of Chronic Disease Prevention and Management' and additional special items of service, supported by additional funding; iii) the extension of GPVCs to all children aged under 13 years.

The Covid-19 pandemic had substantial impacts on general practice. Research found a significant decrease in face-to-face consultations and a significant increase in telemedicine consultations during Covid-19 (Collins and Homeniuk, 2021). The research also noted that a majority of practices reported a reduced practice profit during 2020. It is possible that changes that occurred during the pandemic, such as the use of telemedicine, will be an increasing feature of general practice in the future.

\subsection{DATA AND METHODS}

\subsubsection{Data}

Activity and expenditure data for this analysis were derived from a variety of sources including the HIS, the Growing Up in Ireland (GUI) study and the PCRS. Activity data capture utilization of GP and PN services. Expenditure data capture the related cost of such services.

\section{Healthy Ireland Survey}

The HIS is an annual face-to-face survey, with interviews conducted with a representative sample of the population aged 15 and older living in Ireland (Ipsos $\mathrm{MRBI}, 2018)$. To date, five waves of the survey have been completed, in the years $2015,2016,2017,2018$ and 2019. The sample size is in the region of 7,500 people per wave.

Waves 4 and 5 of the survey include the following question (and possible responses) in relation to GP utilisation: 
'When was the last time you consulted a GP or family doctor on your own behalf? This includes home visits and phone consultations but excludes nurse-only consultations.'

- Less than 12 months ago;

- More than 12 months ago;

- Never consulted;

- Don't know;

- Refused.

Those who reported that they had consulted less than 12 months ago were asked the following question:

'How often in the last 4 weeks did you consult a GP on your own behalf, excluding nurse only consultations?'.

Waves 4 and 5 of the survey also included the following question (and possible responses) in relation to $\mathrm{PN}$ utilisation:

'When was the last time you consulted a nurse within a GP practice on your own behalf, excluding visits where you also consulted the GP?'.

- Less than 12 months ago;

- More than 12 months ago;

- Never consulted;

- Don't know;

- Refused.

Those who reported that they had consulted less than 12 months ago were asked the following question.

'How often in the last 4 weeks did you consult such a nurse working within a GP practice on your own behalf, excluding visits where you also consulted the GP?'

Wave 5 of the HIS included questions relating to children of the survey respondent. While previous analysis using the Hippocrates model (Wren et al., 2017) used the GUI survey to estimate GP utilisation for children, in this analysis the HIS was used as some of the GUI data is relatively old and may not reflect current GP utilisation rates, especially for those aged $<6$ who subsequently became entitled to free GP visits. In the HIS, each respondent was asked whether they had children, the age of each child, whether each child had attended a GP in the past 12 month, and the number of visits in the previous four weeks. 
Wave 5 also included questions relating to payment for GP and PN visits. Each respondent was asked the following question in relation to the price of a GP visit:

'Thinking of your most recent GP consultation, how much did you pay for this consultation? By this I mean how much you paid for the consultation alone not including any additional tests or medicines.'

The following question was asked in relation to the price for a PN visit:

'Thinking of your most recent occasion of consulting a nurse in a GP practice, how much did you pay for this consultation? By this I mean how much you paid for the consultation alone not including any additional tests or medicines.'

\section{Growing Up in Ireland study}

The GUI study is a longitudinal study of children and young people in Ireland that started in 2006. It follows two groups of children: 8,000 nine-year-olds (child cohort) and 10,000 nine-month-olds (infant cohort). Various waves of the GUI study included a question relating to PN utilisation. For example, the infant cohort waves 2, 3 and 5 asked the following question: In the past 12 months, how many times have you seen or talked on the telephone with any of the following about $<$ child's> physical or emotional health?

- A practice nurse (i.e. a nurse in a GP's surgery/clinic)

\section{PCRS annual report}

The PCRS annual reports ${ }^{15}$ provide detailed analysis of claims and payments to a variety of healthcare professionals (including GPs) who provide free or reducedcost services to the public across a range of primary care schemes, including to those with a Medical Card/GPVC.

\subsubsection{Methods}

\section{Activity rates}

To obtain activity rates for 2019, GP and PN utilisation rates for adults were estimated from HIS waves 4 and 5 . These data include out-of-hours visits. As the survey only includes people living in the community, utilisation for nursing home residents and other individuals living in communal settings is not included.

The weighted mean number of GP and PN visits per annum by sex and 10-year age bands for those aged 16 and over, for both cardholders and non-cardholders, was estimated by multiplying the number of visits in the previous four weeks by 13 (thereby equating to the 52 weeks in a year). A similar approach was adopted to 
estimate GP visiting rates for children (from HIS wave 5 ) for the following age bands: $<5,5-11$ and 12-15. No data was collected on the sex or cardholder status of the child. For children aged 6 and over, it was assumed that they had the same eligibility status as the respondent parent or guardian. As all children aged less than 6 are entitled to a GPVC (though not all avail of the card), the analysis assumed that cardholders and non-cardholders had the same visiting rate.

Visiting rates relating to PNs for children were estimated using the GUI study. Different waves/cohorts of GUI were used to estimate PN utilisation for different age groups:

- GUI infant cohort wave 2 relating to 3-year-olds was used to estimate utilisation for those aged 1-4.

- GUI infant cohort wave 5 relating to 9-year-olds was used to estimate utilisation for those aged 5-11.

- GUI child cohort wave 2 relating to 13 -year-olds was used to estimate utilisation for those aged 12-15.

Under the current childhood immunisation schedule, it is recommended that children visit their GP on five separate occasions to receive scheduled vaccines in the first 13 months of life. It is assumed that PNs play a key role in the administration of these vaccines; however, these visits would not be captured by the GUI data, which relate specifically to three-year-olds. While no data are available on the number of these vaccinations that are administered by the PN rather than the GP, in this analysis it is assumed that 50 per cent of children receive these vaccinations from the PN. We assumed that children aged one had on average $2.5 \mathrm{PN}$ visits annually.

\section{Unit costs}

It was not possible to estimate the cost of a GP/PN visit using the bottom-up approach that has been used for some other services in this report, and while cardholders and non-cardholders are treated by the same GPs and PNs, the price paid differs depending on whether the individual is a cardholder or noncardholder. In this analysis, for non-cardholders, the unit cost reflects the price paid by the individual at the point-of-use, while for cardholders, the unit cost was estimated based on payments to general practice from the PCRS.

The average price paid by a non-cardholder (for those who didn't report a zero price) for their most recent GP/PN consultation was estimated from HIS wave 5 . For cardholders, a unit cost for each visit was estimated by dividing total payments to GPs in 2019 by the estimated number of GP visits for cardholders. Data on 
payments to GPs were obtained from the 2019 PCRS annual report (Health Service Executive, 2020a). Data on the number of GP visits were estimated by multiplying the age- and sex-specific number of GP visits for cardholders by the age- and sexspecific number of cardholders.

Payments to GPs via the GMS scheme include a range of fees and allowances. When estimating the unit cost of a GP visit for a cardholder, some fees and allowances were excluded and analysed separately (Table 4.1), including allowances relating to PNs and allowances which likely do not relate directly to the provision of care to cardholders. Allowances relating to PNs were extracted and examined separately. In the PCRS data, these allowances are grouped with allowances for administrative staff. Data from the PCRS indicated that, in 2019, 44 per cent of the allowances related to administrative staff and 56 per cent to nursing staff. ${ }^{16}$ Consequently, for this analysis 56 per cent of these allowances were used to estimate the unit cost of a PN visit for a cardholder, with the other 44 per cent contributing to the unit cost for a GP visit. For cardholders, PN-related allowances were divided by the number of PN visits for cardholders to estimate a unit cost for a PN visit.

A range of allowances and payments which do not necessarily relate to the provision of services for current cardholders were excluded when estimating the unit cost of a GP and PN visit (Table 4.1). They were subsequently grouped together as ancillary costs and projected separately. Payments relating to superannuation were excluded from the analysis.

A constant unit cost across all age groups is assumed as there is little data to inform how unit costs might differ across age groups. However, it is possible that the cost of a GP visit could differ by age group if, for example, older people were more likely to have multi-morbidities and therefore require a longer visit.

16 Personal communication with the PCRS, 8 June 2021. 
TABLE 4.1 Fees and allowances paid to general practices for cardholders used in the calculation of unit and ancillary costs

\begin{tabular}{|c|c|c|c|}
\hline & $\begin{array}{c}\text { GP unit } \\
\text { cost }\end{array}$ & $\begin{array}{c}\text { PN unit } \\
\text { cost }\end{array}$ & $\begin{array}{c}\text { Ancillary } \\
\text { costs }\end{array}$ \\
\hline \multicolumn{4}{|l|}{ Fees } \\
\hline Capitation & $\checkmark$ & & \\
\hline Special claims/services & $\checkmark$ & & \\
\hline Out-of-hours & $\checkmark$ & & \\
\hline Dispensing & & & $\checkmark$ \\
\hline Items of service contract & & & $\checkmark$ \\
\hline Asylum-seekers & & & $\checkmark$ \\
\hline Vaccinations & $\checkmark$ & & \\
\hline Asthma registration & $\checkmark$ & & \\
\hline Asthma capitation & $\checkmark$ & & \\
\hline Contribution for GP Height Measure and Self Zeroing Scale & $\checkmark$ & & \\
\hline Diabetes capitation & $\checkmark$ & & \\
\hline Diabetes registration & $\checkmark$ & & \\
\hline \multicolumn{4}{|l|}{ Allowances } \\
\hline Secretarial/nursing & $\checkmark 44 \%$ & $\checkmark 56 \%$ & \\
\hline Annual leave & $\checkmark$ & & \\
\hline Rostering/out-of-hours & $\checkmark$ & & \\
\hline Medical indemnity insurance & $\checkmark$ & & \\
\hline Rural practice & $\checkmark$ & & \\
\hline Study leave & $\checkmark$ & & \\
\hline Maternity leave/paternity leave & $\checkmark$ & & \\
\hline Locum and practice expenses & $\checkmark$ & & \\
\hline \multicolumn{4}{|l|}{ Other } \\
\hline Benefits to retired District Medical Officers (DMOs) & & & $\checkmark$ \\
\hline Former DMOs & & & $\checkmark$ \\
\hline Superannuation fund & $\mathrm{X}$ & $\mathrm{X}$ & $\mathrm{X}$ \\
\hline National Cancer Screening services & & & $\checkmark$ \\
\hline Opioid substitution treatment scheme & & & $\checkmark$ \\
\hline Primary childhood immunisation scheme & & & $\checkmark$ \\
\hline Heartwatch & & & $\checkmark$ \\
\hline Maternity \& Infant care scheme & & & $\checkmark$ \\
\hline Health (Amendment) Act 1996 & & & $\checkmark$ \\
\hline
\end{tabular}

\section{Expenditure projections}

Base-year and projected age- and sex-specific expenditure volumes are generated by combining age- and sex-specific utilisation profiles with unit-cost profiles. As with other services included in this report, the expenditure projections are decomposed into their constituent drivers.

\section{Projection scenarios}

We develop a number of projection scenarios that group drivers together in a consistent manner. The projection scenarios used in this chapter are presented in Table 4.2. Under the central scenario, demand for GP and PN services evolves in line with the central population growth scenario, combined with moderate healthy ageing. 
Unmet demand for general practice services is not included in this analysis due to a lack of data. The EU-SILC survey includes a general question on unmet healthcare needs; however, it is not clear how many of these unmet needs relate specifically to general practice services. While the HIS included a specific question about unmet need for a GP (with a number of potential options relating to the reason for the unmet need), preliminary analysis found that the most common reason for not visiting the GP when needed was that the respondent waited to see if the problem got better by itself or that they didn't have enough time; it is not apparent that such reasons for not visiting the GP would be considered to be unmet needs which should be addressed by policymakers. In addition, it is not clear what happens to these unmet needs for GP services over time; previous research has highlighted the need to take a dynamic perspective when considering unmet needs to identify what happens to the unmet needs over time (Smith and Connolly, 2020). A small body of research has considered the relationship between unmet need and subsequent health service use. For example, a US study (Long et al., 2005) found that individuals reporting unmet need in 1999 were more likely to use ED and hospital care in 2000 than those not reporting unmet need. Conversely, a Canadian study found that overall unmet healthcare needs were not associated with an increased risk of admission to hospital among those with chronic conditions; however, the authors noted that certain types of unmet needs may be associated with higher or lower risk (Ronksley et al., 2013). Given the lack of an evidence base on which to estimate how a self-reported unmet need for GP services at a particular point in time would affect future utilisation of general practice services, unmet need for GP services was not included in this analysis.

Under the central scenario, both pay and non-pay costs are projected to increase by 2.5 per cent per annum. Unlike some other services included in this report, given the method used to estimate the unit cost for a GP/PN visit (see subsection 4.3.2), it is not possible to identify what proportion of the unit cost relates to pay and what relates to non-pay. Consequently, a simplifying assumption was adopted: in relation to the unit cost for a GP visit for cardholders, the proportion of the unit cost associated with capitation payments was assumed to equate to pay, while the proportion of the unit cost associated with fees and allowances was assumed to relate to non-pay. The same pay:non-pay ratio was also applied to the unit cost for a GP visit for non-cardholders.

For PNs, an alternative approach was adopted; here, it was assumed that 90 per cent of the unit cost for a PN visit (for both cardholders and non-cardholders) related to pay and 10 per cent to non-pay. This assumption was adopted because the maximum allowance for a PN per annum (€37,822.72 in 2019) (Health Service Executive, 2020a) is similar to the average salary of a staff nurse (Irish Nurses and Midwives Organisation), so the majority of the unit cost for a PN is likely to relate to pay. Given the difficulty in separating pay and non-pay components for general 
practice services, we assume that the pay and non-pay components of the unit cost are kept constant through the projection horizon.

Under the low-pressure scenario, demand evolves in line with lower projected population growth and moderate healthy ageing. Under this scenario, pay and nonpay components are projected to increase by 2.2 per cent per annum. Under the high-pressure scenario, demand evolves in line with central population growth along with an expansion of morbidity. Pay and non-pay components are projected to increase by 3.5 per cent per annum.

The 2019 agreement between the Department of Health, HSE and the IMO will have implications for payments to GPs and demand for general practice services. While not explicitly modelled here, it is assumed that the additional payments will, to a large extent, be captured in the annual increase in unit costs included in the analysis. The impact of the new agreement on the demand for general practice is currently unknown and so has not been incorporated into the model; however, it is likely that the expansion of morbidity assumption included in the high-pressure scenario would capture some of the additional demand that could occur under the new agreement (Smith et al., 2021).

Separately, ancillary expenditures were projected based on projected population growth and inflation. In keeping with the rest of the analysis, the central scenario included central population growth and cost inflation based on the Upside scenario. The low-pressure scenario was based on low population growth and inflation based on the Downside scenario, while the high-pressure scenario was based on central population growth and inflation based on the Upside scenario.

TABLE 4.2 Projection scenario assumptions

\begin{tabular}{|c|c|c|c|}
\hline & Low pressure & Central & High pressure \\
\hline \multicolumn{4}{|l|}{ Demand assumptions } \\
\hline Population growth and ageing & Low & Central & Central \\
\hline Healthy ageing & Moderate healthy ageing & Moderate healthy ageing & Expansion of morbidity \\
\hline Unmet demand & No & No & No \\
\hline \multicolumn{4}{|l|}{ Cost assumptions } \\
\hline Pay (capitation) & $\begin{array}{c}\text { COSMO Downside - } \\
\text { projected government- } \\
\text { sector wage growth ( } 2.2 \% \\
\text { p.a.) }\end{array}$ & $\begin{array}{c}\text { COSMO Upside - } \\
\text { projected government- } \\
\text { sector wage growth }(2.5 \% \\
\text { p.a.) }\end{array}$ & $\begin{array}{c}\text { COSMO Upside - } \\
\text { projected government- } \\
\text { sector wage growth }+1 \text { pct } \\
\text { point p.a. (3.5\% p.a.) }\end{array}$ \\
\hline Non-pay (fees and allowances) & $2.2 \%$ per annum & $2.5 \%$ per annum & $3.5 \%$ per annum \\
\hline
\end{tabular}

Source: Authors' representation. 


\subsection{FINDINGS - BASELINE ANALYSIS}

Table 4.3 shows that, in 2019 , there were an estimated $18.8 \mathrm{~m}$ GP visits and $5.1 \mathrm{~m}$ PN visits by both cardholders and non-cardholders. ${ }^{17}$ There were an estimated $11.5 \mathrm{~m}$ GP visits (61\% of all GP visits) and $3.1 \mathrm{~m}$ PN visits (69\% of all PN visits) by cardholders. The unit cost of a GP visit was $€ 41.23$ for a cardholder and $€ 53.55$ for a non-cardholder, while the unit cost of a PN visit was $€ 16.64$ for a cardholder and $€ 30.13$ for a non-cardholder. Ancillary costs in general practice in 2019 amounted to approximately $€ 32 \mathrm{~m}$.

TABLE 4.3 Utilisation, unit costs and pay/non-pay split for general practitioners and practice nurses services, 2019

\begin{tabular}{|c|c|c|c|c|}
\hline & \multicolumn{2}{|c|}{ General practitioner } & \multicolumn{2}{|c|}{ Practice nurse } \\
\hline & $\begin{array}{c}\text { Cardholder } \\
\text { ( } 41 \% \text { of population) }\end{array}$ & $\begin{array}{l}\text { Non-cardholder } \\
\text { (59\% of population) }\end{array}$ & $\begin{array}{c}\text { Cardholder } \\
\text { ( } 41 \% \text { of population) }\end{array}$ & $\begin{array}{c}\text { Non-cardholder } \\
\text { (59\% of population) }\end{array}$ \\
\hline Total number of visits (million) & 11.5 & 7.3 & 3.1 & 2.0 \\
\hline Unit cost $(€)$ & 41.23 & 53.55 & 16.64 & 30.13 \\
\hline Pay: non-pay ratio (\%) & $63 / 37$ & $63 / 37$ & $90 / 10$ & $90 / 10$ \\
\hline Ancillary costs $(€ m)$ & & & & \\
\hline
\end{tabular}

Figure 4.1 shows the age- and sex-specific per capita and total expenditure on care delivered by GPs for cardholders and non-cardholders separately. At the younger ages, no sex breakdown was available, so the male and female per capita expenditures are assumed to be identical for those aged $0-15$ years. The unit cost is constant across age groups, so variation in per capita expenditure is driven by variations in utilisation.

For cardholders, per capita expenditures are higher in the youngest age group $(<5$ years) relative to the 5-11 and 12-15 age-groups. From the age of 16 onwards, per capita expenditure generally increases with age, although there is a slight dip in expenditure for the 65-74 age group. In general, total expenditure increases with age from 16 years onwards. For non-cardholders, ${ }^{18}$ per capita expenditure also tends to increase with age from 16 onwards. In the middle age groups, female per capita expenditure is higher than that of males (reflecting higher use of GP services among females for the management of gynaecological and reproductive issues). From the age of 65 onwards, total expenditure falls, reflecting the relatively small number of people in this age group without a Medical Card/GPVC.

17 This is likely to be an underestimate of GP visits as it does not include GP visits made to those in communal establishments, including long-stay residential care settings.

18 While all children aged less than six are entitled to a GPVC, not all children avail of a card and some continue to pay out-of-pocket for general practice services. While the exact reasons for the non-take-up of these cards is not known, it is likely to be, in part, explained by a lack of awareness about entitlement to a GPVC. In addition, not all GPs accept the GPVC and it is possible that some individuals continue to pay out-of-pocket rather than seek an alternative GP for their child. 
FIGURE 4.1 General practitioner services - age- and sex-specific expenditure per capita and total expenditure, 2019
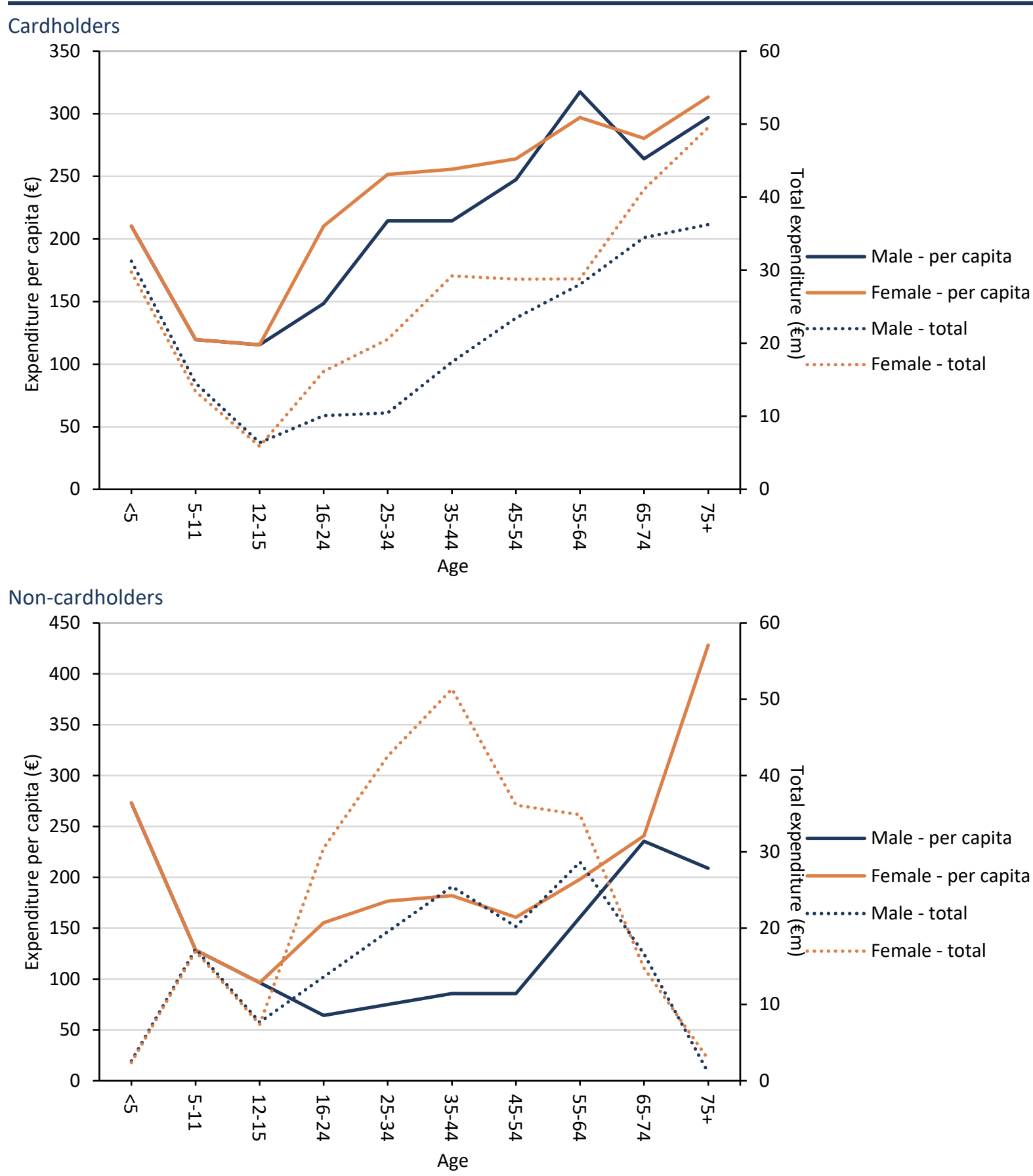

Source: $\quad$ Authors' calculations - based on HIS waves 4 and 5.

Figure 4.2 shows the age- and sex-specific per capita and total expenditure on care delivered by PNs for cardholders and non-cardholders separately. Per capita expenditure for cardholders is somewhat erratic across the age groups, reflecting different utilisation of the PN in different age groups. For example, in the middle age groups utilisation of the PN is higher for male cardholders relative to female cardholders, while the opposite is the case for non-cardholders. Total expenditure for cardholders, however, tends to increase with age, reflecting, in part, the greater number of people with cards in the older age groups. 
For non-cardholders, again per capita expenditure is somewhat erratic reflecting different utilisation of PNs in different age groups. Total expenditure is highest for females aged 35-44 and for males aged 55-64. Low total expenditure in the oldest age category reflects the relatively few people in this category without a card.

FIGURE 4.2 Practice nurse services - age- and sex-specific expenditure and expenditure per capita, 2019

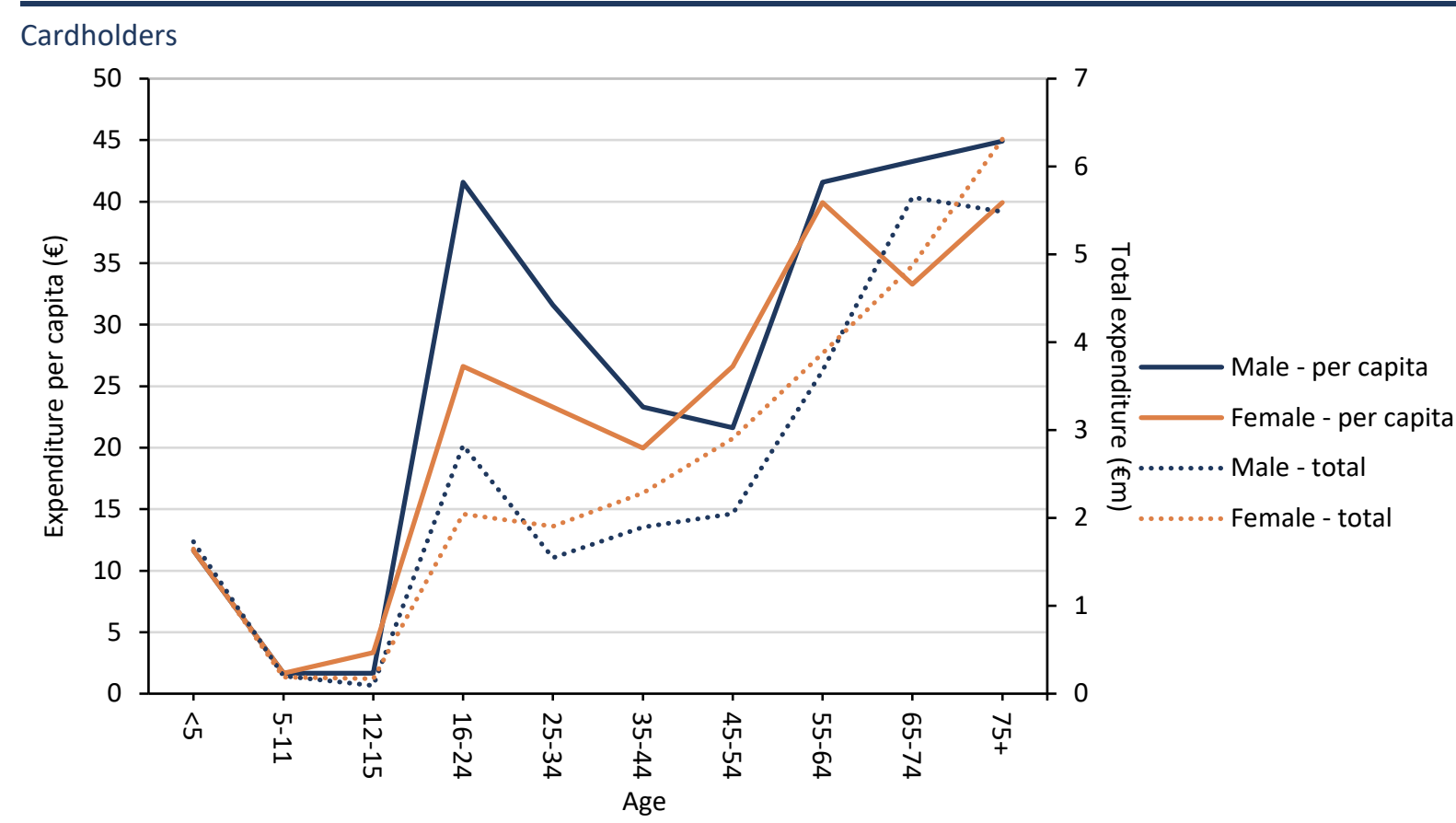

Non-cardholders

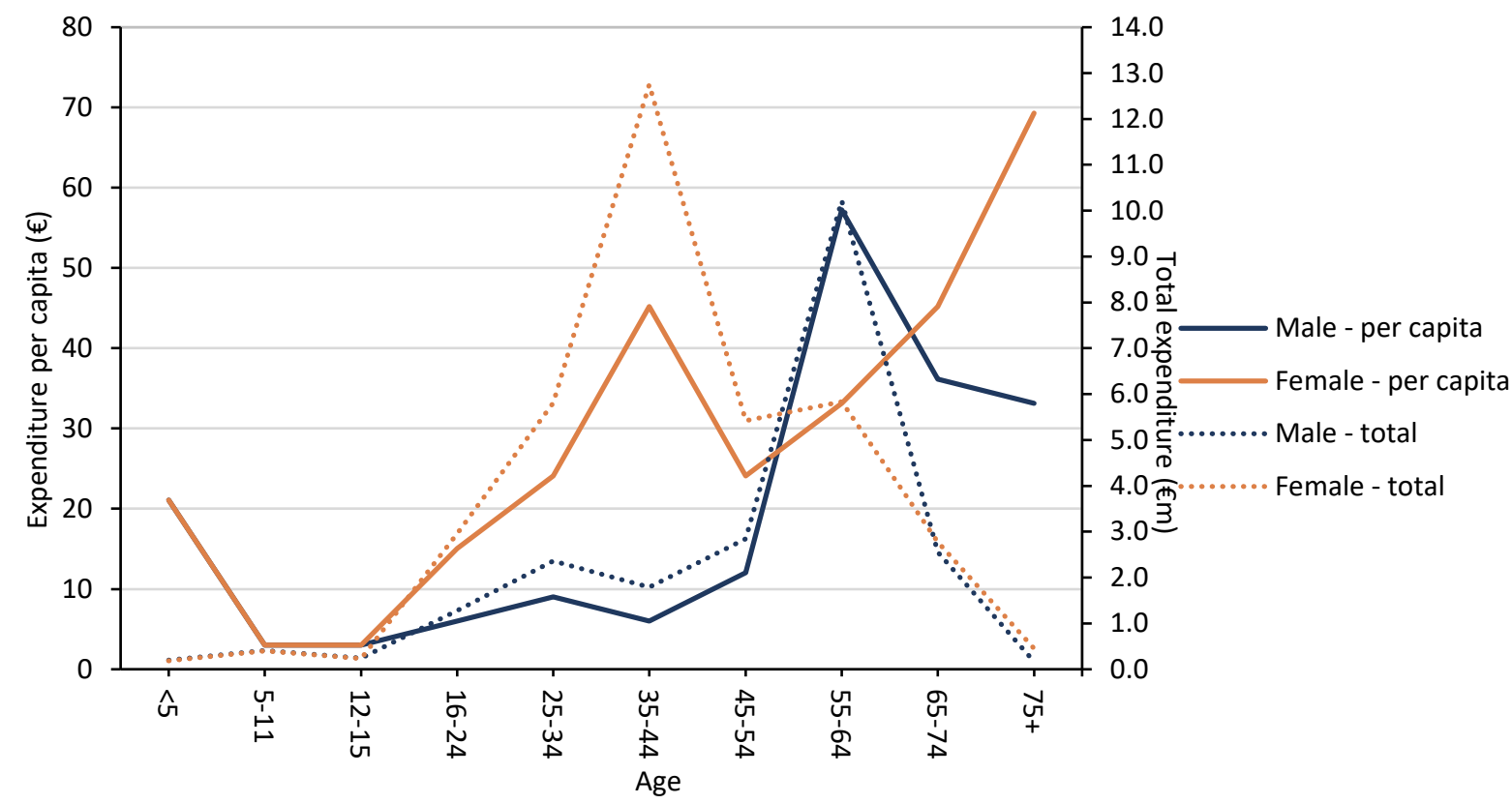

Source: Authors' calculations - based on HIS waves 4 and 5 and GUI infant cohort waves 2 and 5 and child cohort wave 2 . 


\subsection{FINDINGS - EXPENDITURE PROJECTIONS}

Table 4.4 presents the projected increase in general practice expenditure between 2019 and 2035 in real and nominal terms for the low-pressure, central and highpressure scenarios.

Real projections hold costs at 2019 values, and are driven by assumptions in relation to demographic change and healthy ageing. Larger projected increases are observed for cardholders relative to non-cardholders, reflecting the increase in the number of people aged 65 and over in 2035, the majority of whom will be eligible for a Medical Card/GPVC if current eligibility categories remain constant. Between 2019 and 2035, real expenditure requirements are projected to grow by between 14.3 and 18.3 per cent across all services. This represents average annual increases of between 0.8 and 1.1 per cent. In 2035, expenditure required in real terms on general practice is projected to be between $€ 1,154 \mathrm{~m}$ and $€ 1,194 \mathrm{~m}$.

Nominal projected expenditure growth is driven by assumptions in relation to the evolution of both demand and cost drivers. Again, larger increases are projected for cardholders relative to non-cardholders, reflecting the increase in the number of people aged 65 and over in 2035. Nominal expenditure on all services is projected to grow by between 59.8 and 102.5 per cent between 2019 and 2035 . This represents average annual increase of between 2.9 and 4.5 per cent. In 2035, expenditure required in nominal terms on general practice is projected to be between $€ 1,614 \mathrm{~m}$ and $€ 2,045 \mathrm{~m}$. 
TABLE 4.4 General practice services - projected real and nominal expenditure growth by projection scenario, 2019-2035

\begin{tabular}{|c|c|c|c|c|c|c|c|c|c|}
\hline & & \multicolumn{2}{|c|}{2019} & \multicolumn{6}{|c|}{ Projected HCE growth 2019-2035 (\%) } \\
\hline & & \multirow{2}{*}{$\begin{array}{c}\text { Activity } \\
\mathrm{N} \text { (million) }\end{array}$} & \multirow{2}{*}{$\begin{array}{c}\text { Expenditure } \\
€ m\end{array}$} & \multicolumn{3}{|c|}{ Reala $^{\mathrm{a}}$} & \multicolumn{3}{|c|}{ Nominal } \\
\hline & & & & Low & Central & High & Low & Central & High \\
\hline \multicolumn{10}{|l|}{ GP } \\
\hline \multirow{3}{*}{ Cardholder } & Male & 5.1 & 214.7 & 18.8 & 22.4 & 23.2 & 68.3 & 81.7 & 113.6 \\
\hline & Female & 6.4 & 266.8 & 19.2 & 22.3 & 22.6 & 68.8 & 81.6 & 112.7 \\
\hline & Total & 11.5 & 481.5 & 19.0 & 22.3 & 22.9 & 68.6 & 81.6 & 113.1 \\
\hline \multirow{3}{*}{ Non-cardholder } & Male & 2.8 & 152.5 & 3.3 & 5.8 & 8.0 & 46.3 & 57.1 & 87.3 \\
\hline & Female & 4.5 & 241.5 & 3.7 & 6.3 & 6.9 & 46.9 & 57.8 & 85.4 \\
\hline & Total & 7.4 & 394.0 & 3.5 & 6.1 & 7.3 & 46.6 & $\mathbf{5 7 . 5}$ & 86.1 \\
\hline \multicolumn{10}{|l|}{ Practice nurse } \\
\hline \multirow{3}{*}{ Cardholder } & Male & 1.5 & 36.7 & 28.8 & 31.4 & 32.7 & 82.4 & 95.1 & 130.2 \\
\hline & Female & 1.6 & 38.1 & 27.3 & 29.7 & 30.9 & 80.3 & 92.5 & 127.0 \\
\hline & Total & 3.1 & 74.8 & 28.0 & 30.5 & 31.8 & 81.3 & 93.8 & 128.5 \\
\hline \multirow{3}{*}{ Non-cardholder } & Male & 0.7 & 22.1 & 12.1 & 13.3 & 20.1 & 58.8 & 63.8 & 108.3 \\
\hline & Female & 1.2 & 37.1 & 1.7 & 4.0 & 6.3 & 44.1 & 54.4 & 84.4 \\
\hline & Total & 2.0 & 59.2 & 5.6 & 7.5 & 10.6 & 49.6 & 59.6 & 93.3 \\
\hline \multirow[t]{4}{*}{ All services } & Total & 23.9 & 1009.6 & 14.3 & 17.2 & 18.3 & 59.8 & 71.8 & 102.5 \\
\hline & & & & \multicolumn{6}{|c|}{ Projected HCE average annual growth 2019-2035 (\%) } \\
\hline & & & & \multicolumn{3}{|c|}{ Real } & \multicolumn{3}{|c|}{ Nominal } \\
\hline & & & & Low & Central & High & Low & Central & High \\
\hline All services & & & & 0.8 & 1.0 & 1.1 & 2.9 & 3.4 & 4.5 \\
\hline $\begin{array}{ll}\text { a } & \text { Rea } \\
& \text { Aut }\end{array}$ & alculatio & hased on $\mathrm{H}$ & $\begin{array}{l}\text { nt at their } 20 \\
\text { ives } 4 \text { and } 5 \text {, }\end{array}$ & $\begin{array}{l}\text { lues. } \\
\text { fant }\end{array}$ & ? & 5 and & coho & ave? and & SS data. \\
\hline
\end{tabular}

Figure 4.3 shows the relative contribution of demand and cost drivers for the nominal expenditure projections. Under all scenarios, changes in pay and non-payrelated costs are the greatest drivers of projected general practice expenditure growth. For example, in the central scenario, increases in pay contribute 52 per cent to projected expenditure growth, increases in non-pay contribute 26 per cent, population ageing contributes 7 per cent and population growth contributes 15 per cent. 
FIGURE 4.3 General practice services - decomposition of projected nominal expenditure growth, 2019-2035, by projection scenario

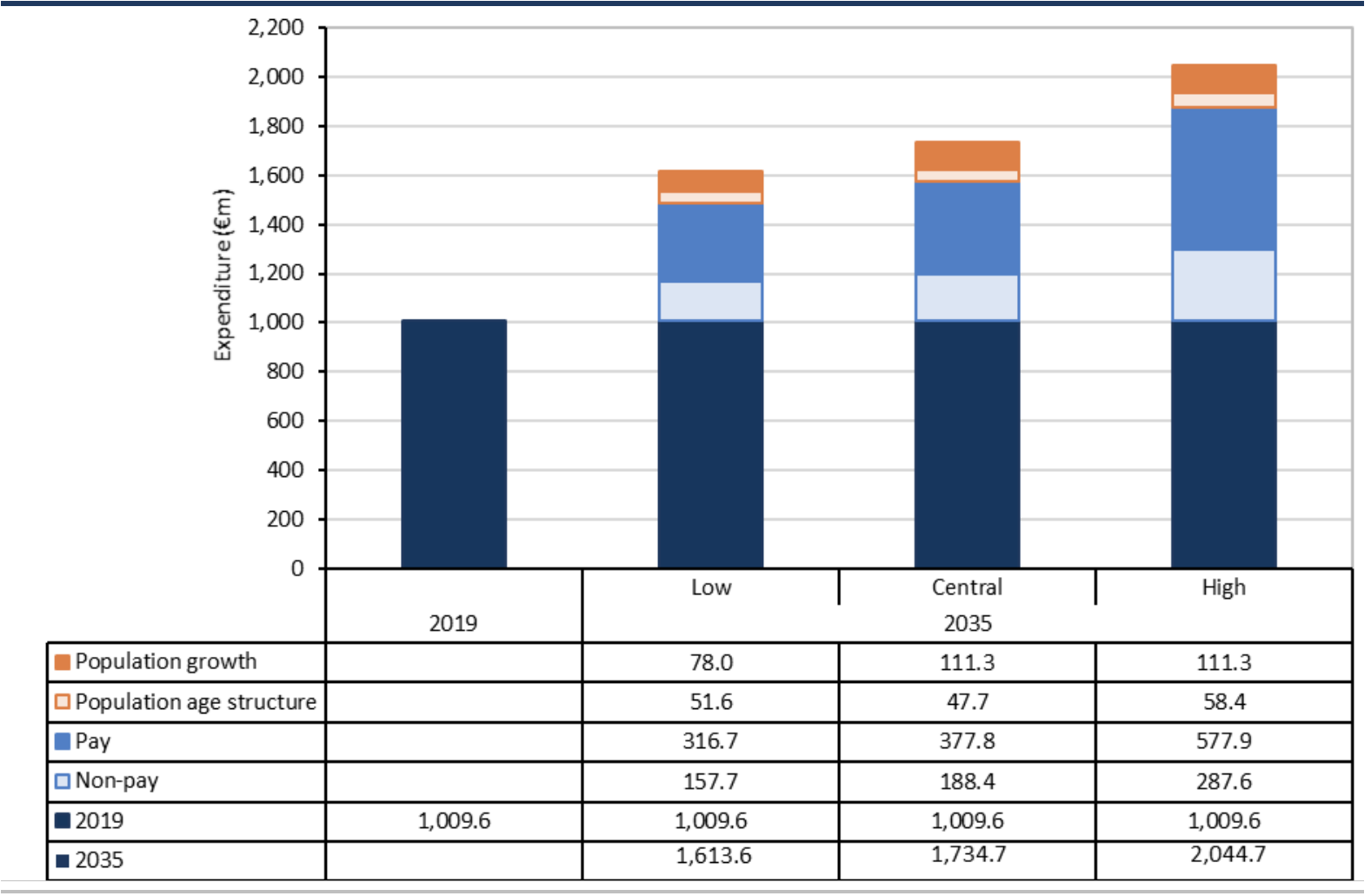

Source: Authors' calculations - based on HIS waves 4 and 5, GUI infant cohort waves 2 and 5 and child cohort wave 2 and PCRS data.

Figure 4.4 shows general practice expenditure in 2019 by age group and projected expenditures for the low-pressure, central and high-pressure scenarios. Growth in expenditure between 2019 and 2035 is largest for the oldest age group, reflecting changes in the age structure of the population. 
FIGURE 4.4 General practice services - projected nominal expenditure by age and projection scenario, 2019 and 2035

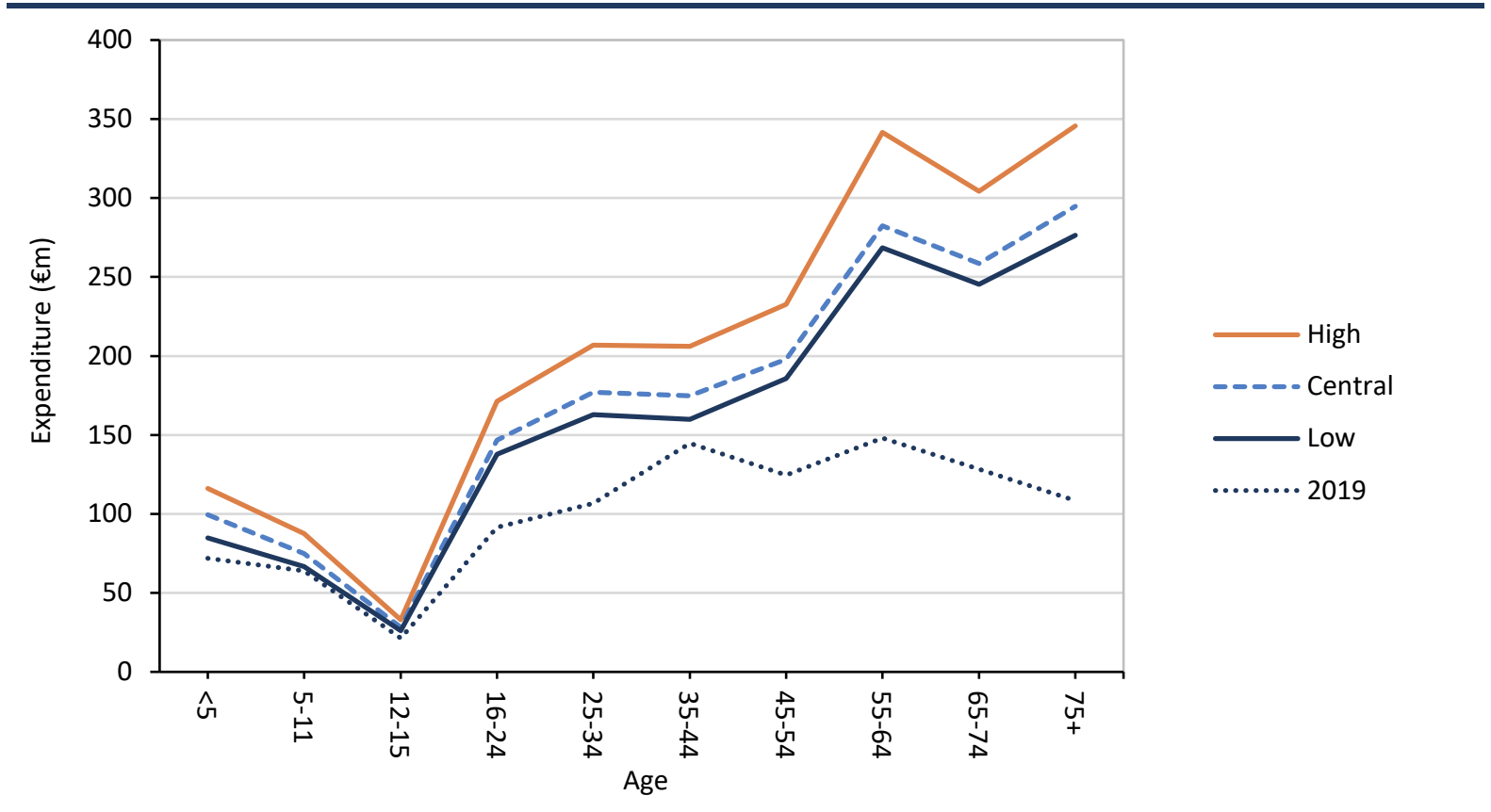

Source: Authors' calculations - based on HIS waves 4 and 5, GUI infant cohort waves 2 and 5 and child cohort wave2 and PCRS data.

Table 4.5 combines the GP and PN specific expenditure and ancillary expenditure to provide an overall estimate of projected general practice expenditure growth between 2019 and 2035. Between 2019 and 2035, nominal ancillary expenditure requirements are projected to grow by between 34.4 and 35.2 per cent. In 2035, ancillary expenditure in nominal terms is projected to be between $€ 43.6 \mathrm{~m}$ and $€ 43.8 \mathrm{~m}$. In nominal terms, total general practice expenditure (including ancillary costs) is projected to increase by between 59.0 and 100.4 per cent between 2019 and 2035, equating to expenditures of between $€ 1,657.2 \mathrm{~m}$ and $€ 2,088.5 \mathrm{~m}$.

TABLE 4.5 General practice services including ancillary expenditure - projected real and nominal expenditure growth by projection scenario, 2019-2035

\begin{tabular}{|c|c|c|c|c|c|c|c|}
\hline & \multirow{3}{*}{$\begin{array}{c}2019 \\
\text { expenditure } \\
€ m\end{array}$} & \multicolumn{6}{|c|}{ Projected HCE growth, 2019-2035 (\%) } \\
\hline & & \multicolumn{3}{|c|}{ Reala $^{\mathrm{a}}$} & \multicolumn{3}{|c|}{ Nominal } \\
\hline & & Low & Central & High & Low & Central & High \\
\hline GP + PN (Table 4.4) & $1,009.6$ & 14.3 & 17.2 & 18.3 & 59.8 & 71.8 & 102.5 \\
\hline Ancillary & 32.4 & 6.2 & 9.4 & 9.4 & 34.4 & 35.2 & 35.2 \\
\hline Total & $1,042.0$ & 14.1 & 17.0 & 18.1 & 59.0 & 70.7 & 100.4 \\
\hline
\end{tabular}

\subsection{SUMMARY}

The analysis presented in this chapter estimated general practice expenditure to 2035 for three different scenarios. Expenditure relating to GPs and PNs was projected to increase by between 14.3 and 18.3 per cent in real terms and 59.8 and 102.5 per cent in nominal terms. Under all scenarios, changes in pay and non-pay- 
related costs are the greatest driver of projected expenditure growth. For example, in the central scenario, increases in pay contribute 52 per cent to projected expenditure growth, increases in non-pay related costs contribute 26 per cent, population ageing contributes 7 per cent and population growth contributes 15 per cent. Ancillary expenditures were projected to increase by between 34.4 and 35.2 per cent in nominal terms between 2019 and 2035. Total general practice expenditure (including ancillary expenditure) was projected to increase by between 59.0 and 100.4 per cent in nominal terms between 2019 and 2035, equating to expenditure in the region of $€ 1,657.2 \mathrm{~m}$ and $€ 2,088.5 \mathrm{~m}$.

The utilisation projections are based on utilisation of general practice services in 2019 , with adjustments made for population change and healthy ageing. However, a number of other factors may affect the utilisation of general practice services in the coming years over and above the assumptions made in this analysis. For example, the new GP agreement will likely lead to an increase in utilisation associated with greater management of chronic disease in general practice and the potential extension of GPVCs to all those aged under 13 years (Department of Health, 2019c). In addition, the Covid-19 pandemic has had a major impact on the delivery of general practice services in 2020 and 2021, with a significant shift towards telemedicine consultations (Collins and Homeniuk, 2021). While one of the commonly reported benefits of telemedicine is to reduce time demands on general practice staff, a number of studies have noted that this does not always happen in practice (McKinstry et al., 2002; Newbould et al., 2017). McKinstry et al. (2002), for example, found that, while telephone consultations took less time than face-to-face consultations, patients consulting by telephone reconsulted the GP more frequently in the two weeks that followed. Banks et al. (2018) undertook qualitative interviews with six general practices in the West of England that piloted an e-consultation system for 15 months during 2015 and 2016; they found that most e-consultations resulted in GPs needing to follow up with a telephone or faceto-face appointment because the e-consultation did not contain sufficient information to inform clinical decision-making. From the patient perspective, it is likely that telemedicine is more suitable for some patient groups (Carter et al., 2018) and for particular services (Car and Sheikh, 2003). Consequently, it is too early to say how telemedicine will be used in general practice in the future.

The analysis in this chapter was hampered by the lack of a central register for GPs and the nature of practice in Ireland, with GPs operating independently. Given this, information about both GP numbers and the volume of general practice consultations is difficult to identify (Collins and Homeniuk, 2021). While the HIS includes questions on GP and PN utilisation for adults, and more recently on GP utilisation for children, the survey does not capture utilisation for those residing in communal settings. In addition, the survey does not capture the Medical Card/GPVC status of children, or their sex, making analysis such as included in this 
chapter somewhat difficult. Some studies have examined general practice utilisation by surveying GPs themselves (Collins and Homeniuk, 2021). Such studies are useful as they should capture all utilisation within a particular practice, including that relating to those residing in communal establishments. However, such an approach may exclude out-of-hours consultations. In addition, responding practices may differ to non-responding practices, thus overestimating utilisation compared to population-based surveys since those who do not register for or use general practice services are excluded. 


\section{CHAPTER 5}

\section{Findings: Public health nursing and community therapy services expenditures}

\section{$5.1 \quad$ INTRODUCTION}

This chapter presents findings for baseline public expenditure in 2019 and projected expenditure to 2035 for services provided in the community through HSE Primary Care services. The services examined are public health nursing (PHN) and selected community therapy services: physiotherapy, occupational therapy and speech and language therapy. While acknowledging the substantial role played by therapists in the private sector, due to a lack of comparable data we have been unable to include privately financed services in the analysis. It should be noted that the analysis is substantively limited by the lack of suitable activity data. We provide some suggestions on additions to the data currently collected which would allow for more meaningful projections in future iterations of the Hippocrates Model. The following subsections describe the roles of the relevant professionals.

\subsubsection{Public health nursing}

Public health nurses and community registered nurses deliver nursing services in the community. Public health nurses are registered nurses with a specialist nursing qualification. They provide a generalist nursing service to a broad range of patient groups, including older people who live at home, individuals who are chronically or acutely ill or dying at home, expectant mothers and mothers who have recently given birth, people with disabilities, and children (Health Service Executive, 2021c). These nurses liaise with individuals, families and carers, family doctors (GPs), practice nurses, hospitals, hospices and other health service providers as part of multidisciplinary primary care teams (PCTs) to ensure that the needs of the patient are met by the overall health service.

Community registered general nurses focus on the care of individual patients and care of the older person (Health Service Executive, 2021c). They work with the public health nurses collaboratively to assess, plan and implement nursing care and work in the home and clinic environment. Both public health nurses and community registered nurses are based in health centres and primary care centres.

In addition to the pivotal role played in the care of older people in the community, a central role of the PHN service is the provision of care in the community to preschool and school children. This includes five developmental assessments for preschool children beginning from within 72 hours of post-maternity service discharge, school hearing and vision screening, and school immunisation programmes. 


\subsubsection{Occupational therapy}

According to the representative body of occupational therapists in Ireland, an occupational therapist's primary goal is to enable individuals who, through illness or disability, are in need of support or changes to their lifestyle to participate in the activities of their everyday life (occupations) (Association of Occupational Therapists of Ireland, 2017). Occupational therapists can advise on any changes that may be needed in the home to support a person with special needs, and on activities that will help a person to regain their independence (Health Service Executive, 2021d). Occupational therapists' roles have gradually changed to include working in multidisciplinary PCTs.

\subsubsection{Physiotherapy}

According to the national representative body for physiotherapists, physiotherapy is concerned with helping to restore individuals' health and wellness following an injury, pain, disability or illness, thereby allowing the individual to develop, maintain and restore movement and functional ability (Irish Society of Chartered Physiotherapists, 2017). Physiotherapists may also work in multidisciplinary PCTs and have gradually integrated into working within teams rather than working apart from other professionals as a standalone form of care. There is evidence that physiotherapists are also moving from generalised physiotherapy to more specialised care provision (French and Galvin, 2017).

\subsubsection{Speech and language therapy}

A speech and language therapist is a qualified professional who provides care to individuals who present with speech, language and communication difficulties (Irish Association of Speech and Language Therapists, 2017). Their work encompasses the assessment, diagnosis, management and prevention of disorders of communication within the community. Speech and language therapists may specialise in the care of a particular group of individuals, such as children who have speech difficulties or older people with an acquired brain injury. Often care is provided for other functions such as eating, drinking or swallowing, with the aim to reduce the need for surgical intervention and poor nutrition in the case of people with swallowing difficulties (Health Service Executive, 2021b). As with the other services, speech and language therapists may also work in multidisciplinary PCTs.

\subsection{DATA AND METHODS}

\subsubsection{Overview}

The approach to establishing baseline expenditure in this chapter differs from the approach adopted for other services examined in this report due to limitations in the available activity data. Ideally, an age- and sex-specific activity rate profile 
would be adjusted for patient complexity which would reflect resource input. A unit cost would then be applied to establish a baseline expenditure profile. Unfortunately, the activity metrics currently available are not at the level of granularity required to apply this bottom-up costing approach. Alternatively, a topdown approach is applied, taking total cost of employment of the selected HSE Primary Care services staff in 2019 as the starting point.

\subsubsection{Data}

\section{Data sources}

The data employed for this analysis include HSE Primary Care activity metrics provided by the HSE Business Intelligence Unit (BIU). These data are supplemented with vaccine uptake data from the HSE Health Protection Surveillance Centre (HSE Health Protection Surveillance Centre, 2020; 2021), ${ }^{19}$ and utilisation data from HIS Wave 5 and the Irish Longitudinal Study on Ageing (TILDA - Waves 3 and 4). Aggregate data on the total cost of employment for each service were provided by HSE Health Business Services.

\section{Limitations}

As mentioned above, activity data on publicly funded PHN and community therapy services are problematic. There are several issues with the scope of the data collected and ultimately reported, and the level of detail provided, due to the manual data-collection systems employed. This substantively limits the analysis that can be undertaken.

First, there is an absence of standardisation in the methodology used to assign staff to care groups within the HSE - that is, Primary Care, Disabilities, Older Persons and associated cost centres. This makes it challenging to align activity reported in the BIU primary care metrics data sets with reported salary costs as activity may be reported through Primary Care while staff are aligned to other care groups.

Second, some publicly funded non-acute services may be provided by voluntary/non-statutory service providers. In general, such activity metrics on the services provided by these organisations are not reported, making it difficult to draw meaningful conclusions on the level of community therapy service provision. ${ }^{20}$ 
Third, the activity metrics collected across the various services are inconsistent and do not lend themselves to accurate costing. For most services there is no caseload metric - that is, the number of patients or clients currently receiving a service. Ideally this would be adjusted to ensure that patients receiving a more intensive service both in terms of the case complexity and frequency of interaction could be accounted for. In many cases, even when contact frequency data is gathered, there is no age or sex profile available.

Finally, where age is reported it is generally in four highly aggregated categories $(0-4,5-17,18-64$, and 65 years and older). As discussed in Appendix 5 of Wren et al. (2017), this is not ideal as the greater the level of age aggregation the less sensitive projections will be to future changes in the population age structure. To ameliorate against this, where possible we use survey data from TILDA and the HIS to provide additional age breakdowns for some services.

\subsubsection{Methods}

\section{Age distribution}

The data for the analysis provided by the BIU contain a selection of metrics reflecting the care provided by HSE-employed Primary Care nursing and community therapy staff. ${ }^{21}$ The aim is to establish the most appropriate proxy for the age distribution of service use for each of the services under consideration. While a range of metrics (e.g. referrals) are reported for each service, an age distribution for these metrics is not always available. For example, for PHN the age distribution of patients seen for individual face-to-face visits is available; for other services, the best available age distributions available are the number of 'new referrals' in the case of physiotherapy and occupational therapy, and the number of 'clients seen' in the case of speech and language therapy. These latter metrics are not sensitive to the volume of service use across the age distribution. While a similar number of patients may be referred or seen across particular age cohorts, the frequency of attendance may be quite different. This is not possible to overcome with currently available data.

In the case of PHN, where the number of face-to-face visits is available, it is possible to make an additional adjustment to the age distribution to account for the difference in resource use required for a first visit versus a subsequent visit. Following consultation with the $\mathrm{HSE},{ }^{22}$ the following weights have been applied to the available activity to reflect the level of resource use required: for subsequent visits for those aged $0-79$ years a weight of 0.50 is applied; for subsequent visits

21 We note that, for the speech and language therapy service, the BIU activity metrics include activity provided by staff in voluntary/non-statutory service providers and this cannot be separated out. It is possible that including this activity alters the age distribution but, with currently available data, it is not possible to ascertain how great an issue this is. 
for those aged 80 years and older a weight of 0.67 is applied. In addition, all child development visits are given the same weight as a first visit, while for immunisation contacts and school vision and hearing screening activity a weight of 0.20 is applied.

As discussed in subsection 5.2.2, data from the HSE Health Protection Surveillance Centre and survey data (TILDA and HIS) are used to provide additional detail on service utilisation where possible. We acknowledge that the lack of detail on visiting rates is problematic, and the nuanced differences in the level of service use for these age groups will not be fully reflected. Table 5.1 summarises the methods used to establish an age distribution for each service.

TABLE 5.1 Age distribution methods

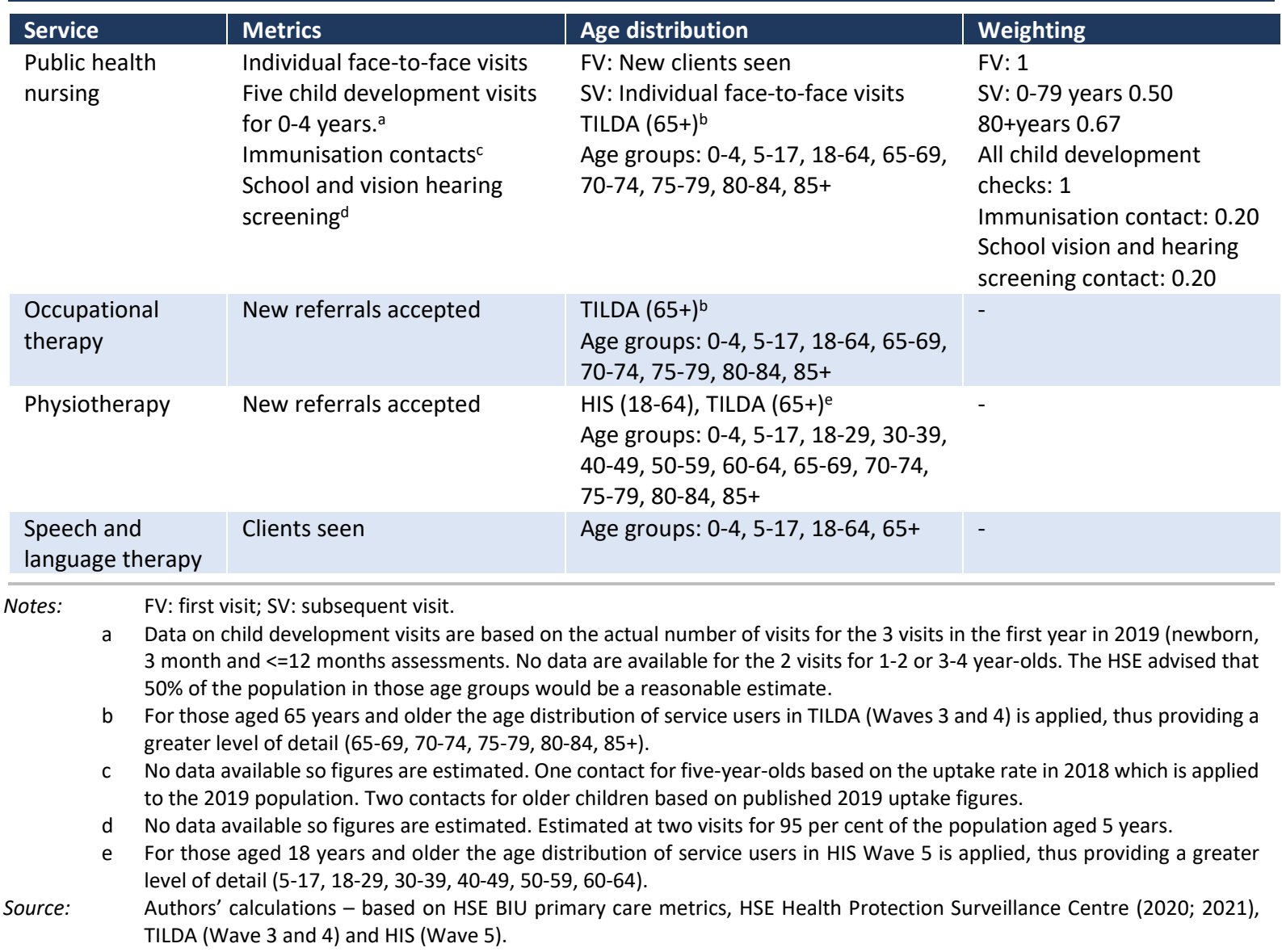

It is important to note that, while for some services the proportion of activity in a particular age cohort may appear low, this may be for several reasons. It may reflect that in some areas a proportion of the service is provided by WTEs allocated to HSE services other than Primary Care or that services are provided by other agencies that do not report the activity data. It may also reflect a more fundamental lack of service provision to particular age cohorts in the community either nationally or in particular locations; for example, speech and language therapy services are primarily provided in the younger age cohorts. Without 
comparable metrics across all services and care groups, it is not possible to comment further.

\section{Baseline expenditure}

The calculation of baseline expenditure for 2019 takes as its starting point the total cost of employment of the selected HSE staff categories allocated as Primary Care WTEs in 2019. ${ }^{23}$ Total cost of employment includes basic salary, overtime, on call, allowances, weekends, arrears/other and employer PRSI. ${ }^{24}$ To this an overhead is applied to account for management and other non-care staff costs and non-staff costs. The overhead proportions follow the approach taken in recent research in England and Ireland (Curtis and Burns, 2019; Smith et al., 2021). Management and other non-care staff costs are calculated at 24.5 per cent, and non-staff costs at 38.2 per cent, of basic pay plus PRSI. ${ }^{25}$

To this the age distribution, which is based on the best available activity metric for each service, is applied to arrive at an age-weighted baseline expenditure profile and baseline per capita ${ }^{26}$ expenditure profile using ESRI population estimates for 2019.

\section{Expenditure projections}

The projection scenarios used in this chapter, presented in Table 5.2, apply to each of the four services under consideration. Due to data limitations, there are no assumptions on healthy ageing, and waiting-list management ${ }^{27}$ is not considered as part of the expenditure projections.

Under the central scenario, demand for services evolves in line with the central population growth scenario. Pay costs evolve in line with government-sector average wage growth from COSMO's Upside scenario. Non-pay costs are indexed to a projected inflation rate from COSMO's Upside scenario plus 0.5 percentage points per annum to reflect assumed higher growth of community therapy nonpay service delivery costs above inflation (see Chapter 3 for further detail).

Under the low-pressure scenario, demand evolves in line with lower projected population growth. Under this scenario, pay costs evolve in line with governmentsector average wage growth from COSMO's Downside scenario. Non-pay costs are indexed to a projected inflation rate from COSMO's Downside scenario plus 0.5 
percentage points per annum to reflect assumed higher growth of community therapy non-pay service delivery costs above inflation.

Under the high-pressure scenario, we adopt the same population and non-pay assumptions as the central scenario. Under this scenario, pay costs evolve in line with government-sector average wage growth from COSMO's Upside scenario, with an additional 1 percentage point per annum.

Expenditure projections are presented in both real and nominal terms for 2019 to 2035. Real projections hold per capita expenditure constant at 2019 values, thus enabling analysis of projected volumes of care as if the cost of care had not changed. Nominal projections allow per capita expenditure (proxying unit costs as per European Commission (2018)) to vary.

TABLE 5.2 Projection scenario assumptions

\begin{tabular}{|c|c|c|c|}
\hline & Low pressure & Central & High pressure \\
\hline \multicolumn{4}{|l|}{ Demand assumptions } \\
\hline Population growth and ageing & Low & Central & Central \\
\hline Healthy ageing & No & No & No \\
\hline $\begin{array}{l}\text { Unmet demand (waiting-list } \\
\text { management) }\end{array}$ & No & No & No \\
\hline \multicolumn{4}{|l|}{ Cost assumptions } \\
\hline Pay & $\begin{array}{l}\text { COSMO Downside - } \\
\text { projected government-sector } \\
\text { wage growth ( } 2.2 \% \text { p.a. })\end{array}$ & $\begin{array}{l}\text { COSMO Upside - } \\
\text { projected government-sector } \\
\text { wage growth ( } 2.5 \% \text { p.a.) }\end{array}$ & $\begin{array}{c}\text { COSMO Upside - } \\
\text { projected government-sector } \\
\text { wage growth }+1 \text { pct point p.a. } \\
(3.5 \% \text { p.a. })\end{array}$ \\
\hline Non-pay overhead & $\begin{array}{l}\text { COSMO Downside - } \\
\text { indexed to projected inflation } \\
\text { rates }+0.5 \text { pct point p.a. }\end{array}$ & $\begin{array}{l}\text { COSMO Upside - } \\
\text { indexed to projected inflation } \\
\text { rates+ } 0.5 \text { pct point p.a. }\end{array}$ & $\begin{array}{l}\text { COSMO Upside - } \\
\text { indexed to projected inflation } \\
\text { rates }+0.5 \text { pct point p.a. }\end{array}$ \\
\hline
\end{tabular}

\subsection{FINDINGS - AGE DISTRIBUTION}

The age distributions calculated for each service are best estimates of current service use applying what we consider the most appropriate metric available. ${ }^{28}$ Figure 5.1 shows the age distributions for the four services under consideration. The speech and language service as delivered through Primary Care is concentrated in the youngest age categories, with low levels of provision in other age cohorts; for physiotherapy, most services are provided to the adult and 65and-older cohorts. PHN and occupational therapy services are mainly delivered to those aged 65 years and older. Notably, for PHNs the early-years child development checks ( $0-4$ years), vaccination activity and school vision and hearing screening (5-17 years) are estimated to account for one-quarter of the PHN service activity.

28 Note that the underlying data reflect services provided through HSE Primary Care and not the entirety of services provided in the community. The exception to this is for speech and language therapy for which Primary Care activity data for services provided by non-HSE providers are included in the BIU metrics. 
FIGURE 5.1 Age distribution by service, 2019

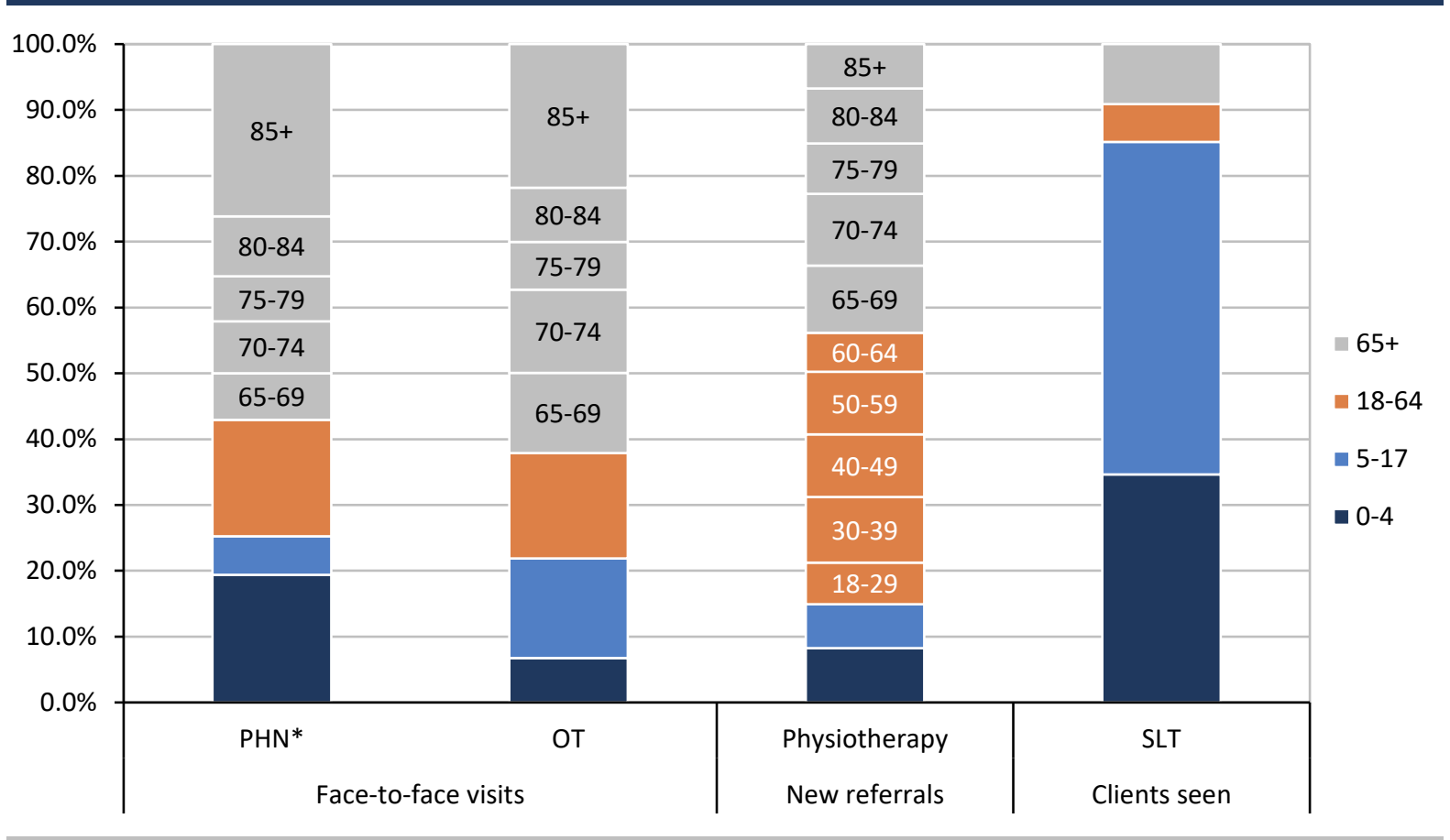

Notes: $\quad$ Services provided through HSE Primary Care only.

For physiotherapy, occupational therapy and PHN, additional details on the age distribution are calculated using data from the HIS and TILDA.

* Weighting applied for selected visits and activity types - see Table 5.1.

Source: $\quad$ Authors' calculations - based on HSE BIU, HIS and TILDA data.

\subsection{FINDINGS - BASELINE EXPENDITURE}

Table 5.3 presents our estimates for baseline expenditure by service. We estimate that expenditure on PHN and selected community therapy services delivered by HSE Primary Care staff in 2019 ranged from approximately $€ 50 \mathrm{~m}$ for each of the three therapy services to almost $€ 270 \mathrm{~m}$ for PHN. The split between pay (cost of employment and overhead pay) and non-pay is, due to the methods adopted (see section 5.2.3), the same across all services - at 77 per cent pay and 23 per cent non-pay.

TABLE 5.3 Baseline expenditure by service, 2019

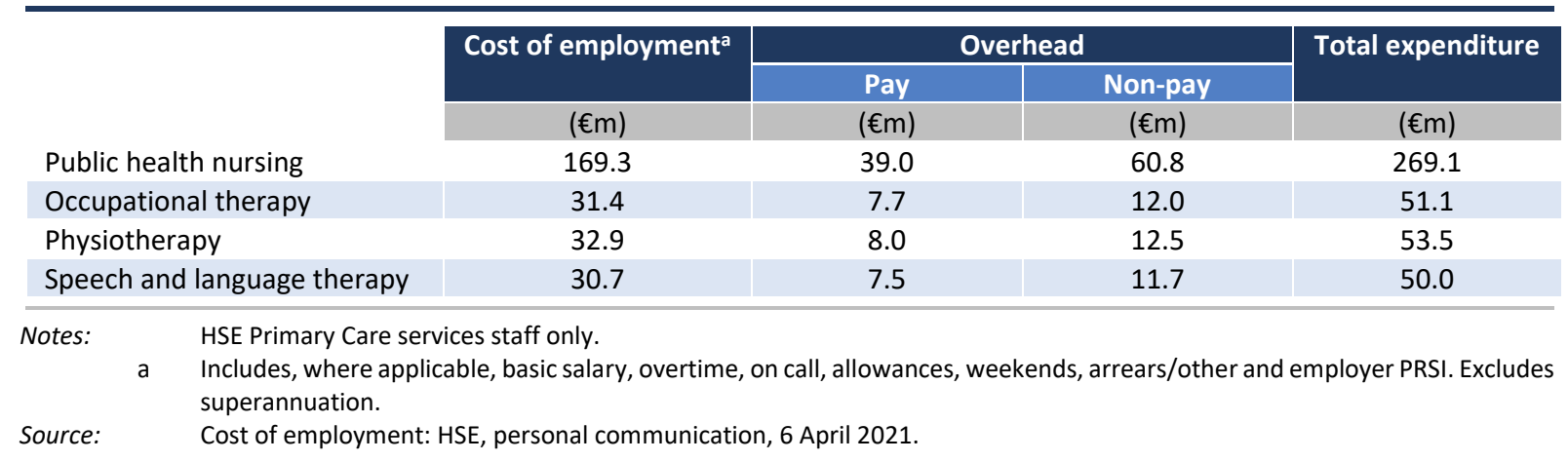




\subsection{FINDINGS - EXPENDITURE PROJECTIONS}

Table 5.4 presents real and nominal projected expenditure growth and average annual growth in projected expenditure to 2035 across our low-pressure, central and high-pressure projection scenarios.

Public health nursing: In real terms, expenditure is projected to increase by 42 per cent in the low-pressure scenario and 47 per cent in our central and high-pressure scenarios between 2019 and 2035. This equates to projected real expenditure in 2035 of between $€ 382.8 \mathrm{~m}$ and $€ 395.8 \mathrm{~m}$. In nominal terms, expenditure is projected to increase by between 100 per cent in the low-pressure scenario and 113 per cent in our central scenario and 142 per cent in our high-pressure scenario between 2019 and 2035. This equates to projected nominal expenditure in 2035 of between $€ 538.0 \mathrm{~m}$ and $€ 650.1 \mathrm{~m}$. Average annual growth in real terms ranges from 2.2 to 2.4 per cent and in nominal terms from 4.4 to 5.7 per cent per annum.

Occupational therapy: In real terms, expenditure is projected to increase by 41 per cent in the low-pressure scenario and 45 per cent in our central and high-pressure scenarios between 2019 and 2035. This equates to projected real expenditure in 2035 of between $€ 72.0 \mathrm{~m}$ and $€ 73.9 \mathrm{~m}$. In nominal terms, expenditure is projected to increase by between 98 per cent in the low-pressure scenario and 110 per cent in our central scenario and 138 per cent in our high-pressure scenario between 2019 and 2035. This equates to projected nominal expenditure in 2035 of between $€ 101.2 \mathrm{~m}$ and $€ 121.3 \mathrm{~m}$. Average annual growth in real terms ranges from 2.2 to 2.3 per cent and in nominal terms from 4.4 to 5.6 per cent per annum.

Physiotherapy: Projected real growth rates are between 27 per cent in the lowpressure scenario and 30 per cent in the central and high-pressure scenarios. This equates to projected real expenditure of between $€ 67.8 \mathrm{~m}$ and $€ 69.5 \mathrm{~m}$ in 2035. In nominal terms, expenditure is projected to increase by 78 per cent, 88 per cent and 113 per cent in the low-pressure, central and high-pressure scenarios, respectively. This equates to projected nominal expenditure of between $€ 95.3 \mathrm{~m}$ and $€ 114.1 \mathrm{~m}$ in 2035 . Average annual growth in real terms ranges from 1.5 to 1.6 per cent and in nominal terms from 3.7 to 3.8 per cent per annum.

Speech and language therapy: Projected real growth rates for speech and language therapy are between -4.5 per cent in the central and high-pressure scenarios and -10.3 in the low-pressure scenario. This equates to projected real expenditure of between $€ 44.9 \mathrm{~m}$ and $€ 47.7 \mathrm{~m}$ for speech and language therapy in 2035 . In nominal terms, it is projected to increase by 26.1 per cent, 38.5 per cent and 56.9 per cent in the low-pressure, central and high-pressure scenarios, respectively. This equates to projected nominal expenditure of between $€ 63.1 \mathrm{~m}$ and $€ 78.4 \mathrm{~m}$. Average annual 
growth in real terms ranges from -0.7 to -0.3 per cent and in nominal terms from 1.5 to 2.9 per cent per annum.

The underlying age distributions established are the drivers for service growth for services. As a comparatively higher proportion of the age distribution is in younger age cohorts, the growth rates for physiotherapy and speech and language therapy are lower than for PHN and occupational therapy. In fact, for speech and language therapy real growth rates are negative as children account for most of the age distribution under current service provision and the population size in these age groups is projected to fall over the projection period considered.

TABLE 5.4 Projected real and nominal expenditure growth and average annual growth by projection scenario, 2019-2035

\begin{tabular}{|c|c|c|c|c|c|c|c|}
\hline & \multirow{3}{*}{$\begin{array}{l}2019 \\
(€ m)\end{array}$} & \multicolumn{6}{|c|}{ Projected expenditure growth 2019-2035 (\%) } \\
\hline & & \multicolumn{3}{|c|}{ Real } & \multicolumn{3}{|c|}{ Nominal } \\
\hline & & Low & Central & High & Low & Central & High \\
\hline Public health nursing & 269.1 & 42.3 & 47.1 & 47.1 & 100.0 & 113.4 & 141.6 \\
\hline Occupational therapy & 51.1 & 40.9 & 44.6 & 44.6 & 98.0 & 109.7 & 137.5 \\
\hline Physiotherapy & 53.5 & 26.7 & 29.8 & 29.8 & 78.1 & 88.2 & 113.2 \\
\hline \multirow[t]{4}{*}{ Speech and language therapy } & 50.0 & -10.3 & -4.5 & -4.5 & 26.1 & 38.5 & 56.9 \\
\hline & & \multicolumn{6}{|c|}{ Projected expenditure average annual growth 2019-2035 (\%) } \\
\hline & & \multicolumn{3}{|c|}{ Reala } & \multicolumn{3}{|c|}{ Nominal } \\
\hline & & Low & Central & High & Low & Central & High \\
\hline Public health nursing & & 2.2 & 2.4 & 2.4 & 4.4 & 4.9 & 5.7 \\
\hline Occupational therapy & & 2.2 & 2.3 & 2.3 & 4.4 & 4.7 & 5.6 \\
\hline Physiotherapy & & 1.5 & 1.6 & 1.6 & 3.7 & 4.0 & 4.8 \\
\hline Speech and language therapy & & -0.7 & -0.3 & -0.3 & 1.5 & 2.1 & 2.9 \\
\hline
\end{tabular}

Figure 5.3 takes a closer look at the relative contribution of demand and unit-cost drivers, through decomposing nominal expenditure projections by scenario for each service.

Public health nursing: Under all scenarios, changes in pay and population ageing are the greatest drivers of projected expenditure growth. For example, in the central scenario, increases in pay contribute 48.4 per cent to projected expenditure growth and population ageing contributes 33.2 per cent, while non-pay costs contribute 10.0 per cent and population growth 8.3 per cent.

Occupational therapy: With a similar age distribution, the drivers of expenditure growth for occupational therapy to 2035 are similar to PHN. Under all scenarios, changes in pay and population ageing are the greatest drivers of projected expenditure growth. For example, in the central scenario, increases in pay contribute 49.2 per cent to projected expenditure growth and population ageing 
contributes 32.0 per cent, while non-pay costs contribute 10.2 per cent and population growth 8.6 per cent.

Physiotherapy: With service provision concentrated in the adult and older age cohorts, physiotherapy expenditure growth drivers are similar to those for PHN and occupational therapy services. Under all scenarios, changes in pay and population ageing are the greatest drivers of projected expenditure growth. For example, in the central scenario, increases in pay contribute 54.9 per cent to projected expenditure growth. Population ageing contributes 23.1 per cent, slightly less than for PHN and occupational therapy, which reflects a comparatively larger proportion of service users in the 18-64 years age category. Non-pay costs contribute 11.4 per cent and population growth 10.7 per cent.

Speech and language therapy: The current concentration of speech and language therapy services in the youngest age cohorts means that the expenditure drivers differ from other services. Under all scenarios, population ageing has a strong negative impact on expenditure, which reflects a decrease in the projected population in the youngest age cohorts by 2035 . 
FIGURE 5.2 Decomposition of projected nominal expenditure growth by projection scenario, 2019-2035

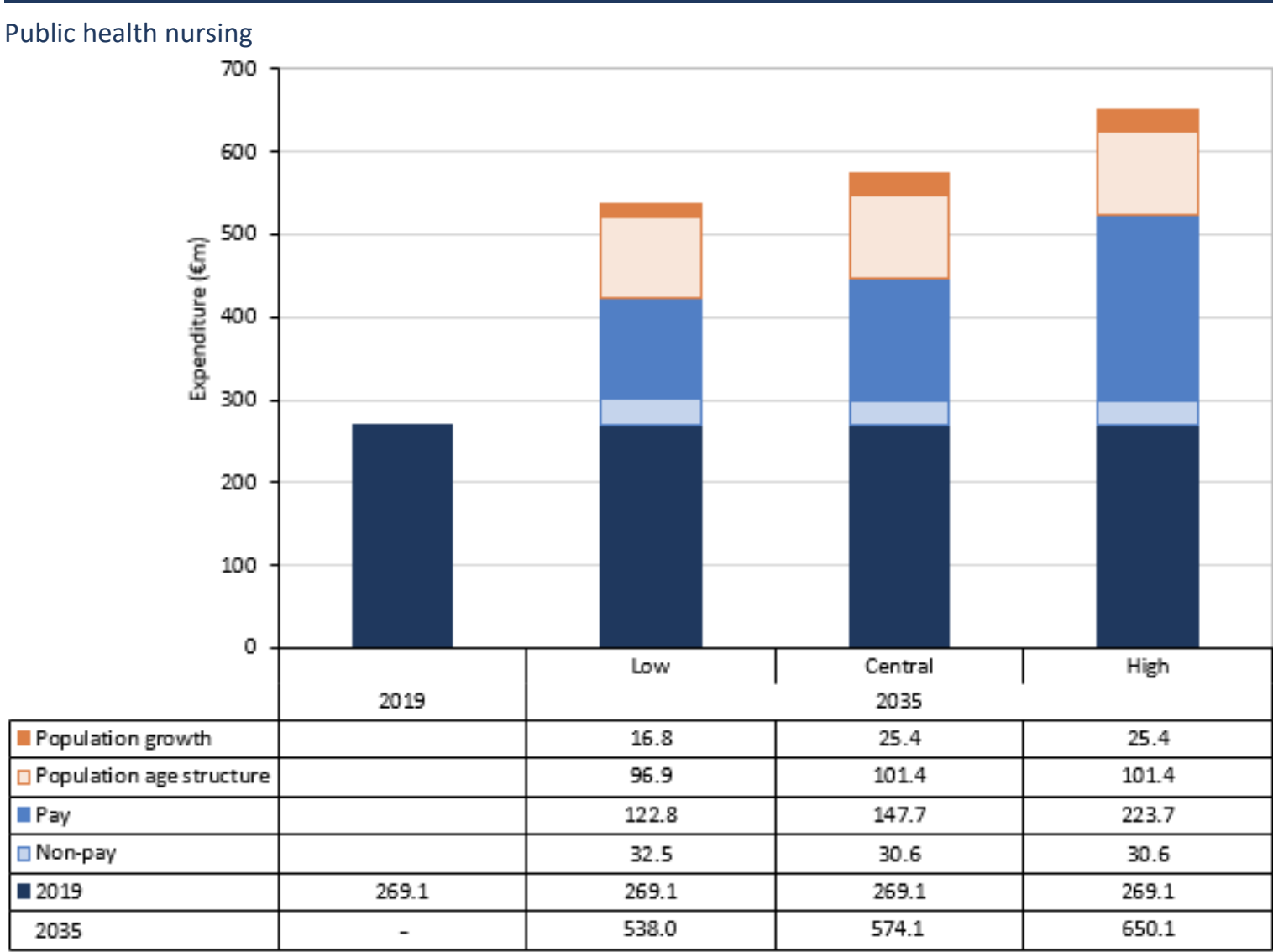

Occupational therapy

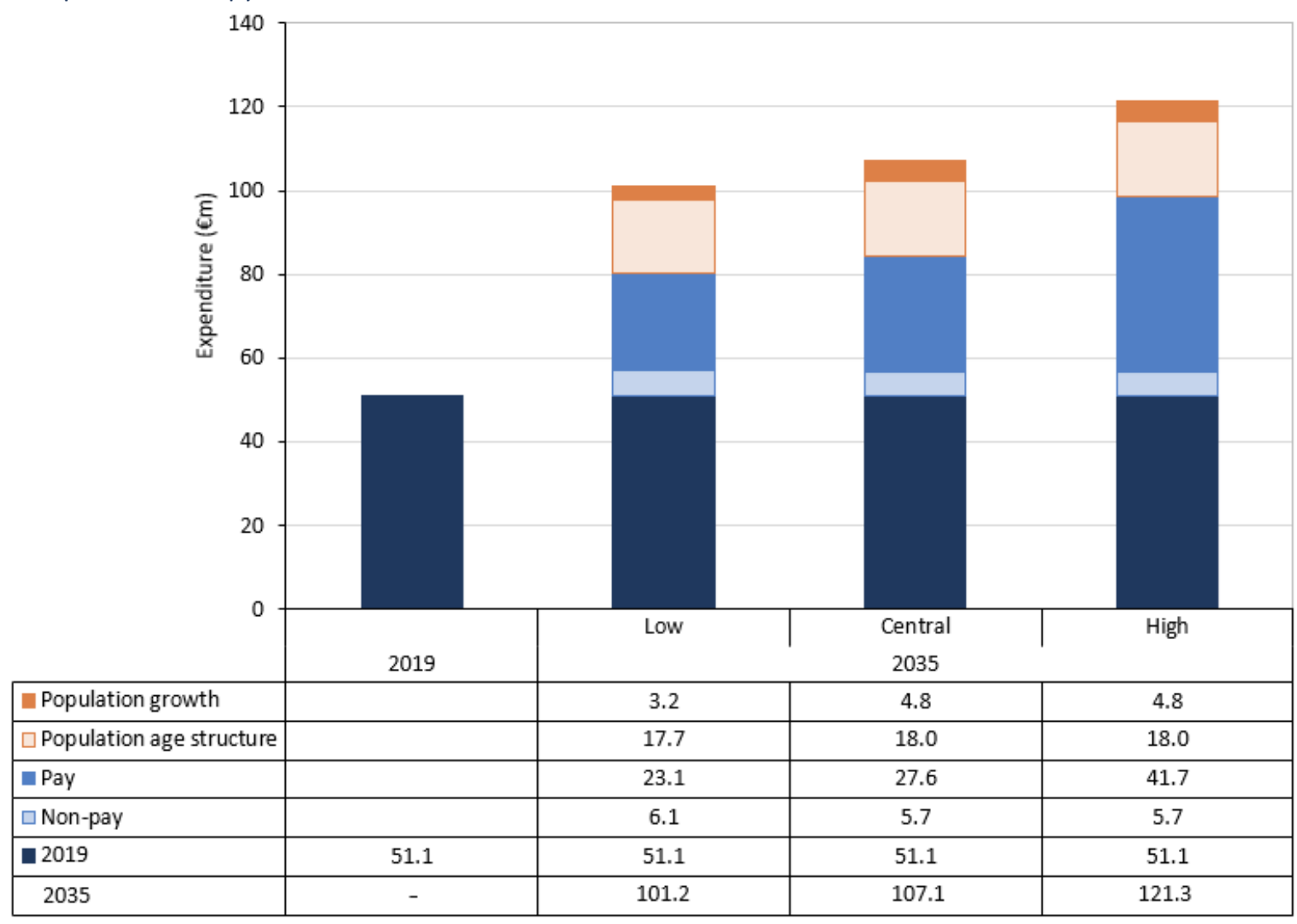


Physiotherapy

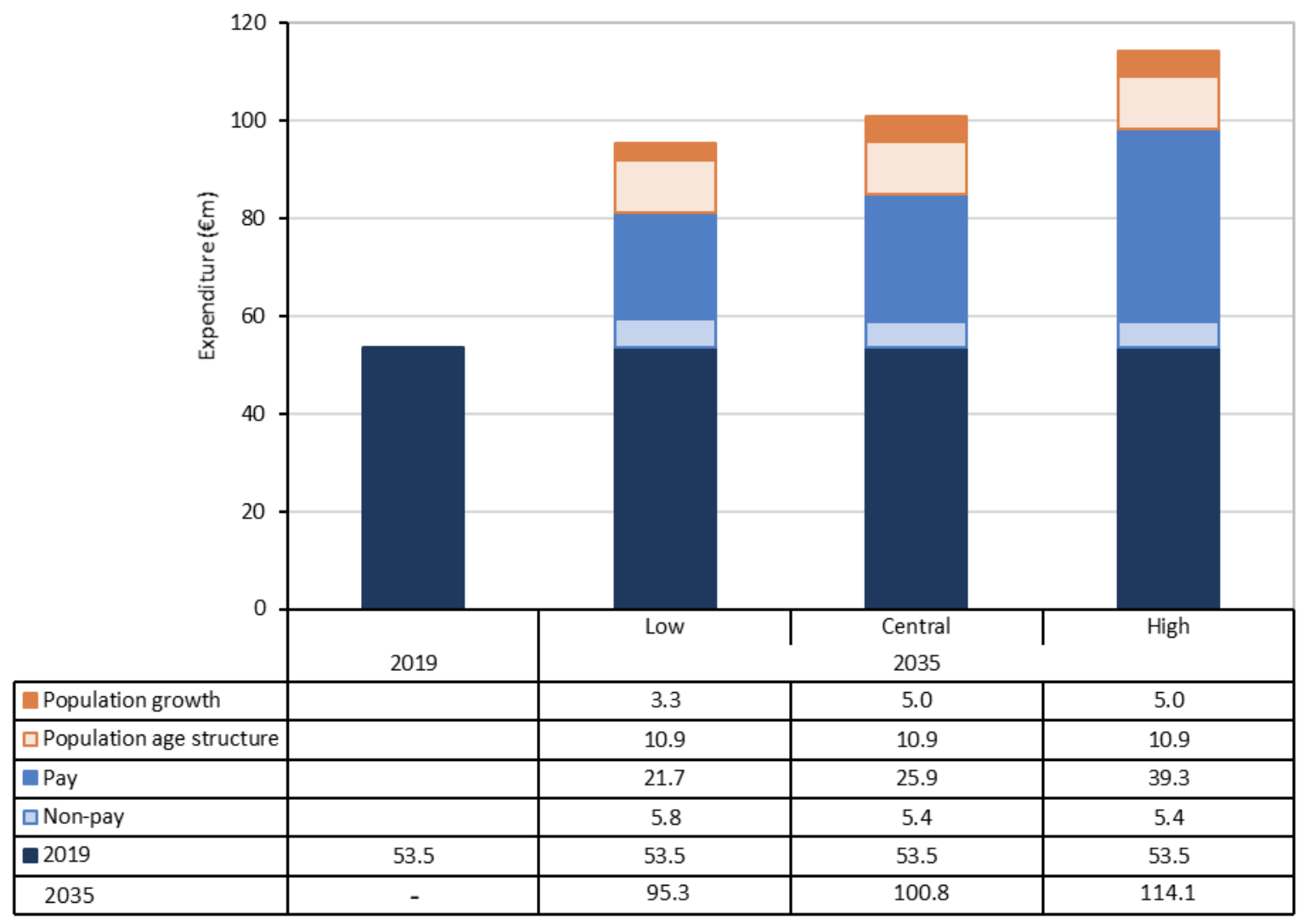

Speech and language therapy

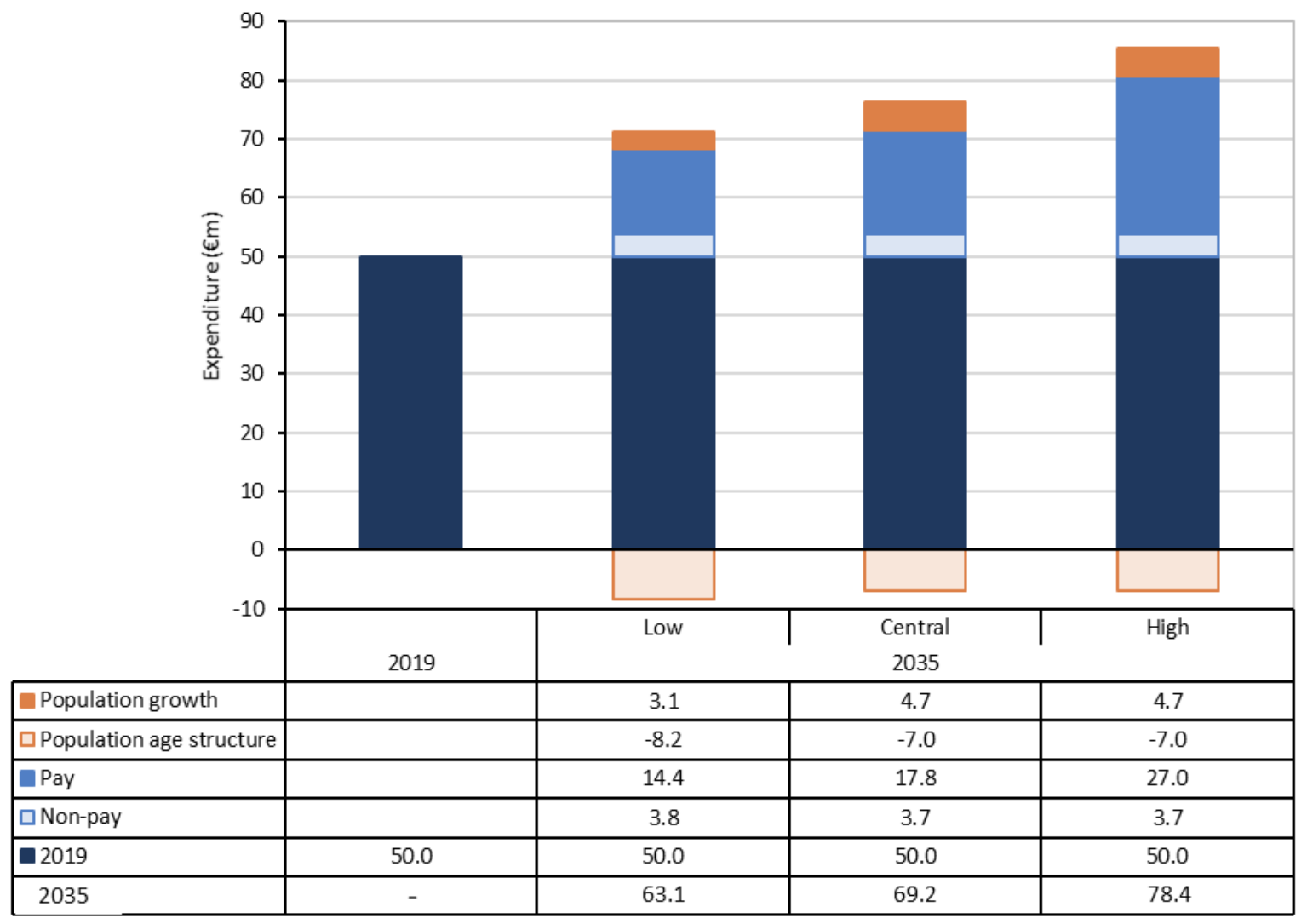

Source: Authors' calculations - based on HSE BIU, HIS and TILDA data. 


\subsection{SUMMARY}

The analysis presented in this chapter estimated expenditure on PHN and selected community therapy services provided by HSE Primary Care services to 2035 for three scenarios - low-pressure, central and high-pressure. Increases in expenditure are projected to be highest for PHN and occupational therapy, at between 41 and 47 per cent in real terms and 98 and 142 per cent in nominal terms by 2035 . More modest increases are projected for physiotherapy, at between 27 and 30 per cent in real terms and 78 and 113 per cent in nominal terms by 2035 . For speech and language therapy, due in particular to the concentration of current service provision in the youngest age cohorts, projected real growth of between -10 per cent and -5 per cent and 26 per cent and 57 per cent in nominal terms by 2035 are projected.

Data limitations mean that the projection methodology employed in this chapter differs substantively from that in other chapters, by employing a top-down approach. Without a complexity-adjusted caseload metric with detail on patient/client age and sex, it is not possible to accurately estimate baseline expenditure profiles. This makes it difficult to comprehensively capture the impact of population change on projected expenditures. Due to substantive data limitations for these services, we are unable to incorporate assumptions on healthy ageing, waiting-list management ${ }^{29}$ (unmet demand), or models of care change. This, in addition to the inability to generate comprehensive baseline utilisation profiles, overall may lead to an underestimate of future expenditure requirements for these services.

As part of Sláintecare's plan to reorientate acute care to community-based settings, an additional $€ 150 m$ (total $€ 186 m$ investment in $2020-21$ ) has been designated to enhance community services (Government of Ireland, 2021). This includes the expansion of the Community Health Networks, Community Intervention Teams, and integrated care teams. Moreover, these measures will in the short term see over 3,000 staff recruited, with a particular focus on nursing and community therapists such as physiotherapists, occupational therapists and speech and language therapists (Government of Ireland, 2021), together with changes to the ways of working and the models of care employed. 


\section{CHAPTER 6}

\section{Findings: Community pharmaceutical expenditures}

\section{$6.1 \quad$ INTRODUCTION}

This chapter presents findings on expenditure in 2019 and projects expenditure to 2035 for publicly funded community pharmaceuticals dispensed under the four main community schemes; the GMS, DP, LTI, and HT schemes. ${ }^{30}$

\subsection{COMMUNITY PHARMACEUTICALS IN IRELAND}

The PCRS is responsible for making payments to healthcare professionals such as GPs, dentists and pharmacists for the free or reduced-cost health services they provide to the public, under a variety of community schemes. The four schemes examined in this report account for just under 99 per cent of all pharmaceutical payments under the service in 2019 (Health Service Executive, 2020a).

\subsubsection{General Medical Services scheme}

The GMS scheme is the largest of the community schemes operating in Ireland. In 2019 , the PCRS reported that there were $1.544 \mathrm{~m}$ people with a Medical Card under the GMS scheme. ${ }^{31}$ As discussed in Chapter 1 , eligibility for the GMS scheme is income means-tested, with thresholds varying by age. Prescription items supplied via the GMS scheme are provided through retail pharmacies. In most cases prescriptions are provided by a doctor (GP or hospital doctor), and prescription items are dispensed through any pharmacy that has an agreement with the HSE to dispense GMS prescriptions. ${ }^{32}$ Under the GMS scheme, the pharmacist receives a dispensing fee but no mark-up.

Prior to October 2010 all individuals within the GMS scheme were entitled to prescription medications free of charge. However, at that time, in the context of reductions in the public healthcare budget in response to the economic and fiscal crisis, a prescription fee of $€ 0.50$ was introduced for each item dispensed. This charge has since been subject to several iterations, and currently stands at a rate of $€ 1.50$ (subject to a maximum of $€ 15$ per month per person or family) with a reduced rate of $€ 1$ for those aged over 70 (up to a maximum of $€ 10$ per month per person or family) (Citizens Information, 2020).

30 For the purposes of presentation in this chapter, we use slightly altered names and acronyms to those reported by the PCRS.

31 The PCRS annual reports are publicly available at https://www.sspcrs.ie/portal/annual-reporting/report/annual.

32 In rural areas, a small number of GPs hold contracts to dispense drugs and medications to GMS cardholders directly (Health Service Executive, 2020a). 


\subsubsection{Drugs Payment scheme}

The DP scheme is primarily aimed at those who do not qualify for a Medical Card or the LTI scheme, and thus would be required to pay the full cost of their medication out-of-pocket. As of November 2020, under this scheme, an individual or family pays no more than the threshold of $€ 114$ in a calendar month for approved prescription items for themselves or their family. Any cost above this threshold is reimbursed by the State. This threshold was reduced from €124 per month in April 2019. To benefit under this scheme a person must register themselves and their dependants with their LHO. Under the DP scheme, a pharmacist receives both a dispensing fee and a mark-up.

\subsubsection{Long-Term Illness scheme}

On approval by the HSE, individuals who suffer from one or more of a schedule of illnesses are entitled to obtain, without charge and irrespective of income or Medical Card status, necessary prescription items under the LTI scheme. The LTI book lists the drugs and medicines for treating a condition which will be provided free of charge through a pharmacist. Drugs and medicines administered under the LTI scheme are not subject to the prescription charge. Other drugs and medicines not related to the specified condition must be paid for outside the scheme. The central component of spend on the LTI scheme is for items relating to diabetes mellitus, which accounted for 76 per cent of the total spend in 2016 (Connors, 2017a)..$^{33}$ Under the LTI scheme, a pharmacist receives both a dispensing fee and a mark-up.

\subsubsection{High Tech scheme}

Arrangements are also in place for the supply and dispensing of high-tech medicines through community pharmacies. Such medicines are generally only prescribed or initiated in hospital and would include items such as anti-rejection drugs for transplant patients or medicines used in conjunction with chemotherapy or growth hormones. The medicines are purchased by the HSE and supplied through community pharmacies; pharmacists are paid a patient care fee through the PCRS.

This scheme is designed to provide a quality community-based service to patients, by ensuring the active involvement of community pharmacists in the dispensing of high-tech medicines that were previously only supplied through hospitals. The scheme is coordinated centrally through the PCRS High-Tech Co-ordination Unit (Irish Pharmaceutical Healthcare Association, 2020a). Individuals with a Medical

33 The conditions covered by the scheme are acute leukaemia; mental handicap; cerebral palsy; mental illness (in a person under 16); cystic fibrosis; multiple sclerosis; diabetes insipidus; muscular dystrophies; diabetes mellitus; parkinsonism; epilepsy; phenylketonuria; haemophilia; spina bifida; hydrocephalus; and conditions arising from the use of Thalidomide (Health Service Executive, 2021a). 
Card, or who are prescribed a medicine for a specific condition covered by the LTI scheme, do not pay for prescription items. However, where individuals are not eligible under the GMS or LTI scheme, they are covered by the DP scheme, whereby any cost above $€ 114$ ( $€ 124$ in April 2019) per month is reimbursed by the PCRS.

Table 6.1 lists the eligibility criteria and charges/co-payments required for each scheme.

TABLE 6.1 Eligibility criteria, charges and co-payments, by scheme

\begin{tabular}{l|l|l}
\hline Scheme & Eligibility criteria & Charges or co-payments \\
GMS & $\begin{array}{l}\text { Income means-tested with thresholds varying by } \\
\text { age. In some cases, a discretionary card may be } \\
\text { granted if 'undue hardship' is found to exist. }\end{array}$ & $\begin{array}{l}\text { For persons aged under (over) 70, there is a } \\
\text { prescription charge of } € 1.50 \text { (€1) for each item, up } \\
\text { to a maximum of } € 15 \text { (€10) per month, for each } \\
\text { individual or family. }\end{array}$ \\
\hline DP & $\begin{array}{l}\text { Primarily aimed at those who do not have a } \\
\text { Medical Card or LTI book and, thus, those who } \\
\text { would have to pay the full cost of their } \\
\text { medication. }\end{array}$ & $\begin{array}{l}\text { No payments above } € 114 \text { (€124 before April 2019) } \\
\text { per month for each individual or family. }\end{array}$ \\
\hline $\begin{array}{l}\text { Those with any condition(s) covered in the LTI } \\
\text { book. }\end{array}$ & $\begin{array}{l}\text { None } \\
\text { Those requiring any medication covered by this } \\
\text { scheme (which had previously only been supplied } \\
\text { by hospitals). }\end{array}$ & $\begin{array}{l}\text { Subject to the relevant coverage under the other } \\
\text { schemes }\end{array}$ \\
\hline HT & &
\end{tabular}

A number of government-led initiatives are in place to ensure sustainability and cost-effectiveness under each of the four schemes. Under the Health (Pricing and Supply of Medical Goods) Act 2013, the Government introduced a system of generic substitution and reference pricing (Government of Ireland, 2013). This Act permits pharmacists to substitute prescription medicines provided they have been designated as safely interchangeable by the Health Products Regulatory Authority (HPRA). Reference pricing involves the setting of a common reimbursement price, or reference price, for a group of interchangeable medicines. This is the price that the HSE will pay to pharmacies for all medicines in the group, regardless of the price of the individual medicine.

In July 2016, the Irish Pharmaceutical Healthcare Association (IPHA) and the Government negotiated a new four-year Framework Agreement on the Supply of Medicines to the public health system. Under the agreement, the pricing of onpatent medicines in Ireland is annually set to an average of $14 \mathrm{EU}$ member states, while competitor products to off-patent medicines also experience significant price cuts upon market entry (Irish Pharmaceutical Healthcare Association, 2020b). ${ }^{34}$ While this agreement was due to expire in 2020 , it has been rolled over until July manufacturers, either due to patent protection or to no other identical product being available on the market. Offpatent propriety medicines are those which are no longer protected by patent, and generic versions of the proprietary medicines are available. Generic pharmaceuticals enter the market once patent protection on the proprietary medicine has expired (Connors, 2017b). 
2021 when it is expected to be replaced with a new supply agreement (Irish Pharmaceutical Healthcare Association, 2021)

As the HT scheme is dominated by on-patent drugs, it is difficult to implement costsaving measures such as generic substitution and reference pricing, and expenditure reductions achieved across other PCRS schemes have been masked in recent years by the large growth in expenditure on the HT scheme (Connors, 2017a). However, there have been some recent developments aimed at encouraging cost sustainability for high-tech medicines. Tumour necrosis factor (TNF) inhibitor medicines accounted for approximately $€ 220.9 \mathrm{~m}$ in 2016, representing the highest expenditure category in the HT scheme (Medicines Management Programme, 2018). In 2019, as part of the HSE's gain-share initiative, the Medicines Management Programme (MMP) identified best-value biological (BVB) medicines for TNF inhibitors and progressed implementation of the BVB initiative in 2020, which should lead to large savings (Medicines Management Programme, 2019).

\subsection{DATA AND METHODS}

\subsubsection{Data}

Activity and expenditure data for this analysis were provided by the PCRS for 2019. Activity data capture the total annual volume of prescription items recorded on each of the community schemes. Expenditure data capture the related total annual gross cost (i.e. ingredient cost, fees and mark-up, and VAT) of prescription items on each of these schemes. Activity and expenditure data are disaggregated by age group and sex for each scheme. Population projections by sex and SYOA for each year from 2019 to 2035 are generated through the ESRI demographic model.

\subsubsection{Methods}

\section{Activity rates}

Base-year activity rates for 2019 , for each scheme, are generated by dividing the volume of prescription items for each age and sex group by the population volume for each age and sex group. In this chapter we adjust activity rates through the projection horizon in two ways.

The first adjustment is to account for the impact of healthy ageing. Analysis conducted using Irish data by Moore et al. (2017) has shown that projecting pharmaceutical expenditure based on demographic change alone can lead to overestimation of future expenditures. Therefore, in this chapter, we account for the reduced role of ageing in driving pharmaceutical expenditures through modelling healthy ageing effects. Fundamentally, this involves shifting age- and sex-specific 
activity curves to the right in proportion to projected life-expectancy change. The strength of this shift is determined by the healthy ageing assumption under consideration. In this chapter we apply dynamic equilibrium and moderate healthy ageing effects.

For the GMS, DP, and LTI schemes, this is the only adjustment made to activity rate profiles through the projection horizon. We feel this is a reasonable approach based on historical trends in prescription items rates over recent years (see Appendix D). ${ }^{35}$ Under the HT scheme, however, the growth in the rate of prescription items has been consistently high year-on-year. Over the period 20102019, growth in prescription items averaged 7.5 per cent per year (see Appendix D). Underlying these trends, there has been a significant increase in both the number of items dispensed and number of claimants in receipt of drugs under this scheme in recent years (Health Service Executive, 2020a). This may be reflective of a continued expansion in the number of drugs and range of conditions treatable under this scheme as well as improved detection and treatment of disease (e.g. cancer) increasing the average length of time when individuals avail of treatments. ${ }^{36}$ Connors (2017a) also notes that, once a drug under this scheme is introduced, its annual budgetary impact grows considerably, driven by a volume effect as utilisation increases. Therefore, based on current trends, if we were to model HT scheme demand based purely on demographic effects, we would likely significantly underestimate projected expenditure. For this reason, we also adjust the HT scheme activity rate growth, informed by historical increases.

\section{Demand projections}

Annual demand for prescription pharmaceutical items is projected by multiplying annual age- and sex-specific activity rate profiles by annual age- and sex-specific projected population volumes.

\section{Unit costs}

For each scheme, age and sex-specific unit costs for prescription items are calculated by dividing age- and sex-specific gross cost on prescription items by the volume of age- and sex-specific prescription items. Gross cost in this context is inclusive of ingredient cost, fees and mark-up, and VAT.

In this analysis we assume that recent unit-cost growth trends provide a reasonable guide to the future. Specifically, across schemes we use the period

35 While the LTI scheme has recorded large increases in the rate of prescription items over the period, these increases have been concentrated in certain years (2014-2015) related to the movement of LTI eligible claimants away from the GMS scheme to the LTI scheme as a means of avoiding prescription charges (Wren et al., 2017). Since then, the rate of growth of LTI prescription items per 1,000 has been falling year-on-year (see Appendix B).

Personal communication with the Department of Health. 
2015-2019 as the basis for informing unit-cost growth. ${ }^{37}$ Over this period, there has been large variation in unit-cost growth across schemes. Particularly, the ability to realise savings in drug unit costs across schemes will be influenced by the mix of patent-expired and new patented medicines. The HT scheme has traditionally been dominated by on-patent drugs, making cost savings difficult. In contrast, the other community schemes, with a higher share of off-patent drugs, facilitate greater cost control through measures such as reference pricing and generic substitution (Medicines Management Programme, 2020). Unit costs under the HT scheme have grown by 3.8 per cent annually in average annual terms since 2015. In contrast, unit-cost growth in average annual terms has been static (DP, $0.3 \%$ p.a.) or declining (LTI $-0.2 \%$ p.a.; GMS, $-3.0 \%$ p.a.) across the other community schemes over the same period.

\section{Expenditure projection}

Base-year and projected age- and sex-specific expenditure volumes are generated by combining (for the relevant year) age- and sex-specific activity profiles with age and sex-specific unit-cost profiles. As in other chapters, we then decompose scheme-specific expenditure growth into its constituent drivers.

37 In the earlier half of the last decade, large reductions in the unit cost of drugs on the GMS, DP, LTI schemes were observed. Contributing to these large reductions were structural changes to the pharmaceutical market in terms of the introduction of internal reference pricing and greater generic substitution. At the same time reductions in pharmacy and wholesaler fees took place through various measures under the Financial Emergency Measures in the Public Interest (FEMPI) legislation. We exclude this period from informing our analysis under the assumption that unit-cost reductions of this magnitude are unlikely to represent a reasonable basis for projection over the coming years. 
TABLE 6.2 Community pharmaceuticals: data and methods

\begin{tabular}{|c|c|}
\hline Dataset name & Data \\
\hline PCRS prescription data & $\begin{array}{l}\text { Number of prescription items by scheme. } \\
\text { Gross cost (ingredient cost, fees and mark-up, VAT) of prescription items by scheme. } \\
\text { Data are disaggregated by age cohorts }(<5,5-11,12-15,16-24,25-34,35-44,45-54,55-64,65-69 \text {, } \\
70-74,75+) \text { and sex. }\end{array}$ \\
\hline Demographic data & $\begin{array}{l}\text { Projected population volumes for each year } 2019 \text { to } 2035 \text {. } \\
\text { Disaggregation by SYOA and sex. }\end{array}$ \\
\hline \multicolumn{2}{|l|}{ Methods } \\
\hline Activity & $\begin{array}{l}\text { For each scheme, base-year age- and sex- specific activity rates are calculated by dividing } \\
\text { number of prescription items by corresponding age- and sex-specific population volumes for } \\
2019 . \\
\text { Activity rates are adjusted through the projection horizon to account for healthy ageing effects. } \\
\text { For the HT scheme, we apply additional activity rate increases informed by historical trends. }\end{array}$ \\
\hline Cost & $\begin{array}{l}\text { For each scheme, base-year age- and sex- specific unit costs are generated by dividing gross } \\
\text { cost by corresponding activity. } \\
\text { Gross cost in this context is inclusive of ingredient cost, fees and mark-up, and VAT. } \\
\text { Projections of gross unit cost are informed by analysis of the historical annual average growth } \\
\text { rates of these costs. }\end{array}$ \\
\hline Expenditure & $\begin{array}{l}\text { Expenditure for a given scheme in a given year is calculated by multiplying age- and sex-specific } \\
\text { activity rates by their corresponding unit costs. }\end{array}$ \\
\hline
\end{tabular}

\section{Projection scenarios}

The projection scenarios used in this chapter are presented in Table 6.3. Under our central scenario, across all schemes, demand for prescription items evolves in line with our central population growth scenario, combined with dynamic equilibrium healthy ageing. For the HT scheme we additionally model an activity rate increase of 3.5 per cent annually (prior to the impact of healthy ageing adjustments). ${ }^{38}$ Gross unit costs for the HT scheme are assumed to evolve in line with historical average annual growth of 3.5 per cent (2015-2019). Gross unit cost for the other schemes is projected on a no-change basis and is reflective of the static average annual cost growth experienced in recent years under the DP and LTI schemes.

Under the low-pressure scenario, demand evolves in line with lower projected population growth and with dynamic equilibrium healthy ageing. Additionally, the HT scheme is subject to an activity rate increase of 2 per cent annually (prior to the impact of healthy ageing adjustments). Under the low-pressure scenario, gross unit costs for the HT scheme are projected to increase by 3 per cent annually; this reflects the central scenario assumption, minus half a percentage point per year. For the other community schemes, unit costs are projected to decline by 1.5 per cent annually to $2035 .{ }^{39}$

38 While larger per annum increases of 7.5 per cent have been observed since 2010 , we model more conservative, yet still substantial, annual average increases in the HT activity rate to 2035 across our scenarios. We believe that sustained annual average increases of 7.5 per annum over the medium term would be unrealistic.

39 Between 2015 and 2019, unit costs on the GMS scheme declined on average by 3.0 per cent per year. Between 2017 and 2019, the decline slowed (1.5\%). Consultation with the Department of Health indicated that the later observed decline would likely be a more accurate predictor of future trends. 
Under the high-pressure scenario, demand evolves in line with central population growth and moderate healthy ageing. Additionally, the HT scheme is subject to an activity rate increase of 5 per cent p.a. (prior to the impact of healthy ageing adjustments). Under this scenario, growth in unit cost for the HT scheme is projected to increase by 4 per cent p.a., which reflects historical average annual growth plus a half a percentage point per year. For the other community schemes, unit costs are projected to increase by 1.0 per cent annually to 2035. Expenditure projections are presented in both real and nominal terms between the years 2019 and 2035. Real projections hold costs constant at 2019 values, thus enabling analysis of projected volumes of care as if the cost of care had not changed. Nominal projections capture both demand and cost effects.

TABLE 6.3 Projection scenarios

\begin{tabular}{|c|c|c|c|c|}
\hline & Scheme & Low-pressure & Central & High-pressure \\
\hline \multicolumn{5}{|l|}{ Demand assumptions } \\
\hline $\begin{array}{l}\text { Population growth and } \\
\text { ageing }\end{array}$ & GMS, DP, LTI, HT & Low & Central & Central \\
\hline Healthy ageing & GMS, DP, LTI, HT & $\begin{array}{l}\text { Dynamic } \\
\text { Equilibrium }\end{array}$ & $\begin{array}{l}\text { Dynamic } \\
\text { Equilibrium }\end{array}$ & $\begin{array}{l}\text { Moderate } \\
\text { Healthy Ageing }\end{array}$ \\
\hline $\begin{array}{l}\text { Additional modelled } \\
\text { activity growth }\end{array}$ & HT & 2\% p.a. & 3.5\% p.a. & 5\% p.a. \\
\hline \multicolumn{5}{|l|}{ Cost assumptions } \\
\hline \multirow[t]{2}{*}{ Unit Cost } & GMS, DP, LTI & $-1.5 \%$ p.a. & No change & $1.0 \%$ p.a. \\
\hline & HT & 3.0 \% p.a. & 3.5\% p.a. & 4.0\% p.a. \\
\hline
\end{tabular}

\subsection{FINDINGS - BASELINE ANALYSIS}

Table 6.4 presents a breakdown of volumes of prescription items, gross expenditure and unit cost, by scheme, in 2019 . Overall, $78.1 \mathrm{~m}$ prescription items were dispensed under the four community schemes. This is slightly below the range of $79.4 \mathrm{~m}$ to $79.6 \mathrm{~m}$ items projected for 2019 based on 2014 items data in Wren et al. (2017). The GMS scheme was the largest in volume terms, accounting for $60.1 \mathrm{~m}$ items (76.9\% per cent of total prescription items). Across other schemes, 9.3m were dispensed under the LTI scheme (12.0\%), 7.8m under the DP scheme (10.0\%), and $0.9 \mathrm{~m}$ under the HT scheme (1.1\%).

Total expenditure across all schemes is estimated at $€ 2,264.6 \mathrm{~m}$ in 2019 . Overall, the GMS scheme accounted for the largest component (42.0\%) of this expenditure, at $€ 950.7 \mathrm{~m}$. This equates to an overall unit cost of $€ 15.83$ per GMS prescription item. The expensive nature of the HT scheme can be seen in that items prescribed under it accounted for only 1.1 per cent of overall items, but 39.5 per cent of overall expenditure $(€ 894.9 \mathrm{~m})$. This equates to an overall unit cost of $€ 1,025.41$ per HT scheme prescription item. Of remaining expenditure recorded, €258.7m related to the LTI scheme (11.4\%) and $€ 160.2 \mathrm{~m}$ to the DP scheme (7.1\%). The estimated unit cost per LTI scheme prescription item is $€ 27.68$ while the estimated unit cost per DP scheme prescription item is $€ 20.60$. 
TABLE 6.4 Breakdown of prescription items and gross expenditure by scheme, 2019

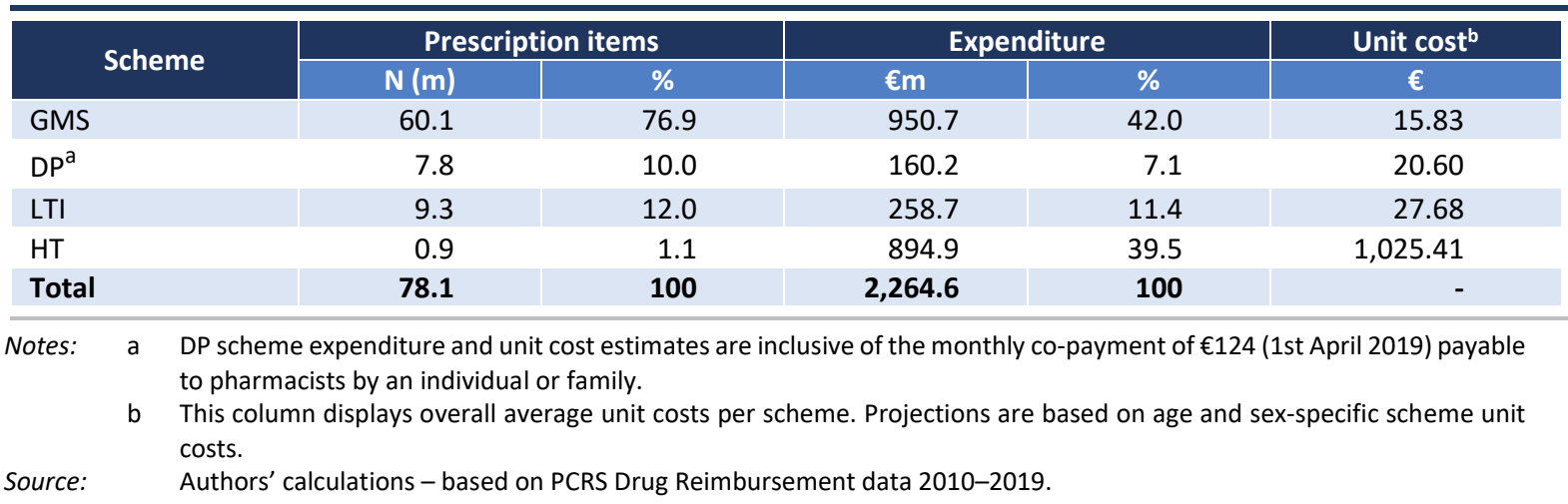

Figure 6.1 shows age- and sex-specific activity volumes and activity rates per 1,000 population by scheme in 2019.

GMS scheme: The number of prescription items increases across age groups for both males and females, albeit falling slightly for those aged between 65 and 69 . At age 75 and over, females recorded $13.7 \mathrm{~m}$ prescription items compared with $8.9 \mathrm{~m}$ for males. When adjusted for population, we observe that the GMS prescription items rate per 1,000 population increases rapidly with age. For both males $(69,957$ per 1,000 population) and females (83,086 per 1,000 population), prescription item rates peak at age 75 and older. While polypharmacy (multiple medication use by patients) can be expected to increase with age (Richardson et al., 2012), the lower GMS income eligibility thresholds for those aged 70 years and older may also be driving the shape of the GMS prescription item curve..$^{40}$

DP scheme: Similar to the GMS scheme, the number of prescription items increases broadly with age, although for both males and females there are noticeable peaks at age 55 to 64 and at age 75 and older. At age 75 and older, males and females both recorded $1.1 \mathrm{~m}$ prescription items in 2019. When adjusted for population, the DP prescription items rate increases with age, peaking at age 75 and over for both males ( 8,288 per 1,000 population) and females ( 6,550 per 1,000 population).

$L T I$ scheme: The volume of prescription items for males exceeds that of females across all age groups. The overall volumes of items peak at age 55-64 for males at $1.3 \mathrm{~m}$ items (although a second peak is also observable at 75 and over) and at age 75 and over for females at $1.2 \mathrm{~m}$ items. LTI prescription item rates rise with age, peaking at age 75 and over for both males and females. Similarly, across all age groups the male prescription item rate $(9,736$ per 1,000 population) exceeds the female prescription items rate $(5,041$ per 1,000 population), with noticeable divergence from age 35 onwards.

40 As eligibility effects, in addition to morbidity effects, drive the shape of the GMS age-related activity curve, it may not represent an ideal basis on which to model healthy ageing shifts applied in this analysis. 
HT scheme: For younger age groups (apart from those aged 5-11) and older groups (65+ years), the volume of prescription items recorded under this scheme is greater for males than females. Between ages 25 and 64, however, the volumes of items for females exceed those of males. The volume of items peaks for females at age $35-44$ (98,926 items) and for males at age 75 and older (84,749 items). Similar to the distribution of volumes, a peak in the prescription items rate is observable for females at age 35-44 but not for males. Overall, the prescription items rate peaks for females aged 70-74 (371 per 1,000 population) and for males aged 75 and over (666 per 1,000 population). 
FIGURE 6.1 Age- and sex-specific activity volumes and activity rates per 1,000 population by scheme, 2019
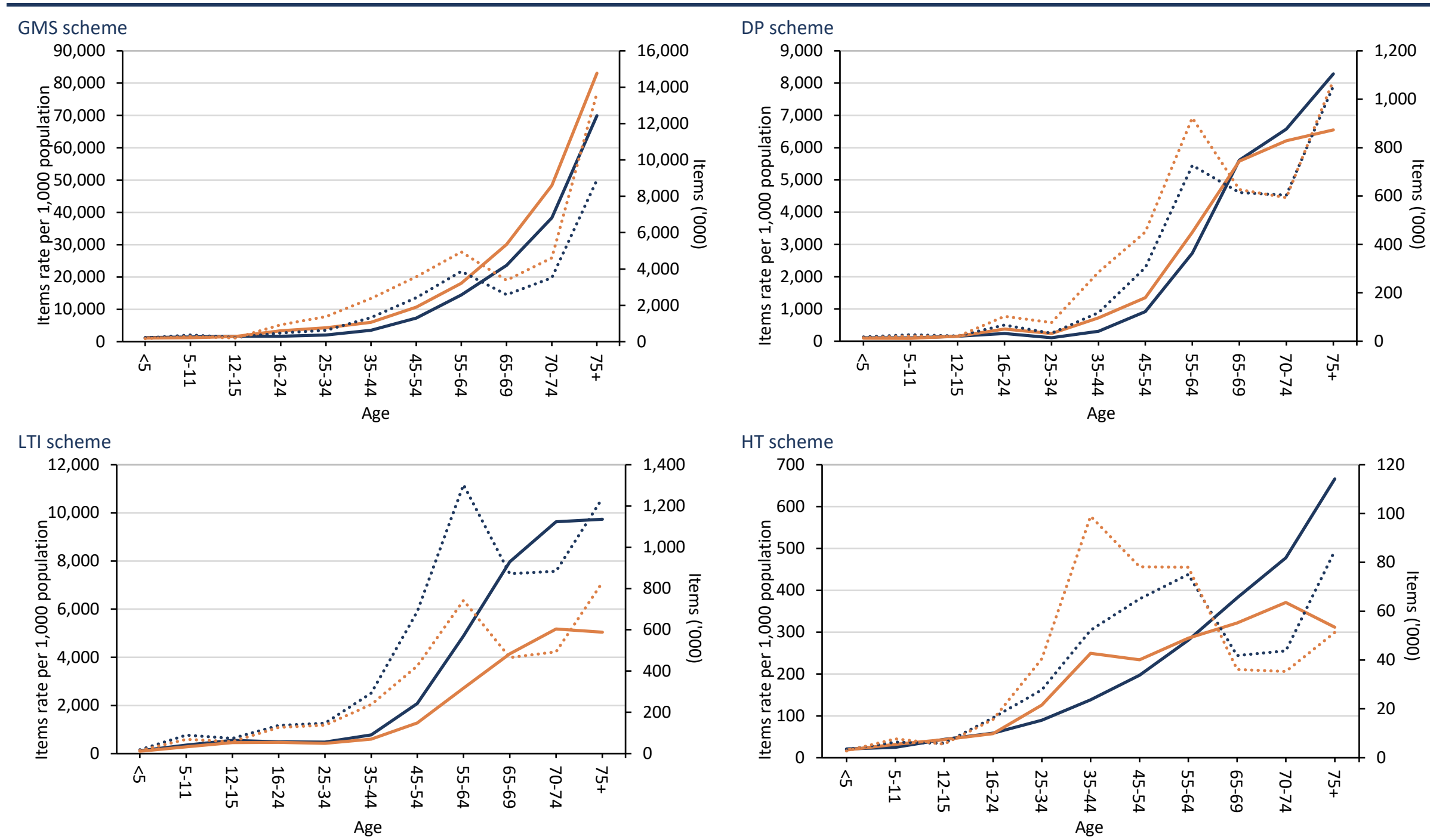

HT scheme

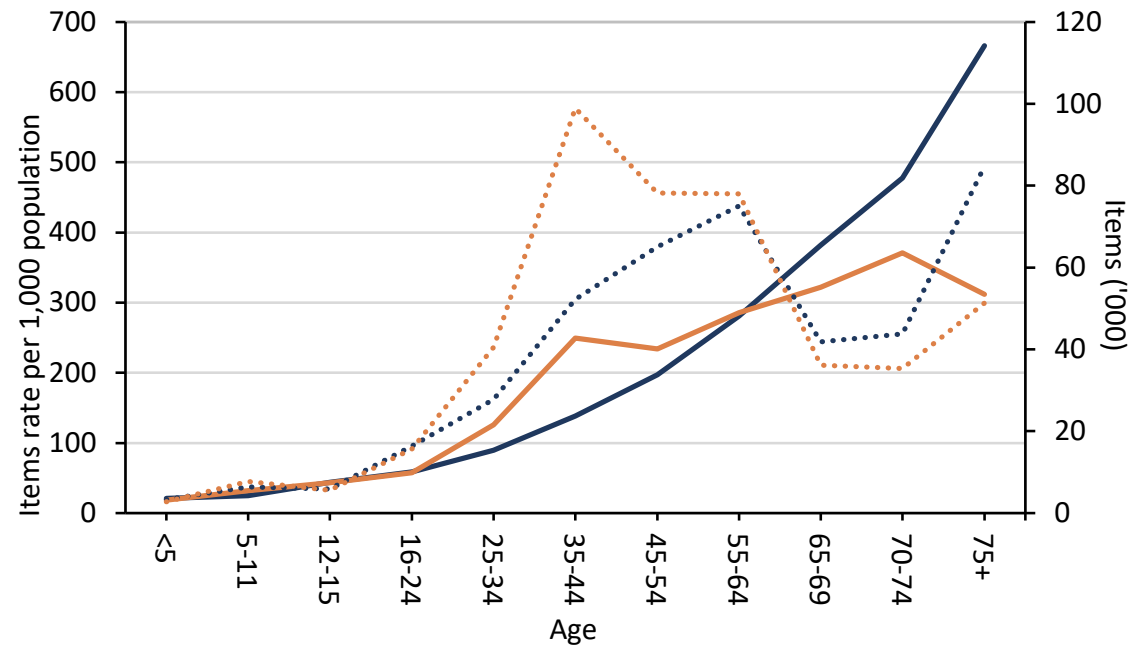

Male - Rate Female - Rate

Male - N

Female - N

Source: $\quad$ Authors' calculations - based on PCRS Drug Reimbursement data. 


\subsection{FINDINGS - EXPENDITURE PROJECTIONS}

Table 6.5 presents real and nominal projected expenditure growth across the four schemes from 2019 to 2035 based on our three projection scenarios. Between 2019 and 2035, across all schemes combined, we estimate projected annual average growth requirements of between 2.2. and 4 per cent in real terms and 3.1 and 6.9 per cent in nominal terms. For the GMS, DP and LTI schemes, projected real expenditure growth increases are higher than projected nominal growth expenditure increases. This is a result of negative unit-cost growth and zero-unitcost growth under the low-pressure and central scenarios when projecting nominal expenditure growth.

GMS scheme: In real terms, expenditure requirements are projected to increase by between 33.2 and 39.4 per cent under the GMS scheme between 2019 and 2035 . This equates to projected real expenditure requirements of between $€ 1,266.2 \mathrm{~m}$ and $€ 1,325.2 \mathrm{~m}$ in 2035 . In nominal terms, expenditure requirements are projected to increase by between 4.6 and 63.4 per cent. This equates to projected nominal expenditure requirements of between $€ 944.2$ and $€ 1,553.9 \mathrm{~m}$ in 2035. Projected average annual growth ranged between 1.8 and 2.1 per cent in real terms and 0.3 and 3.1 per cent in nominal terms over the projection period.

$D P$ scheme: In real terms, expenditure requirements are projected to increase by between 26.0 and 32.1 per cent under the DP scheme between 2019 and 2035. This equates to projected real expenditure requirements of between $€ 201.9 \mathrm{~m}$ and $€ 211.7 \mathrm{~m}$ in 2035 . In nominal terms, expenditure growth is projected to range between -1.0 and 54.9 per cent. This equates to projected nominal expenditure requirements of between $€ 158.6$ and $€ 248.2 \mathrm{~m}$ in 2035 . Projected average annual growth ranged between 1.5 and 1.8 per cent in real terms and -0.1 and 2.8 per cent in nominal terms over the projection period.

$L T I$ scheme: In real terms, expenditure requirements are projected to increase by between 16.6 and 22.3 per cent under the LTI scheme between 2019 and 2035. This equates to projected real expenditure requirements of between $€ 301.7 \mathrm{~m}$ and $€ 316.3 \mathrm{~m}$ in 2035 . In nominal terms, expenditure growth is projected to range between -8.4 and 43.4 per cent. This equates to projected nominal expenditure requirements of between $€ 236.9 \mathrm{~m}$ and $€ 370.9 \mathrm{~m}$ in 2035 . Projected average annual growth ranged between 1.0 and 1.3 per cent in real terms and -0.5 and 2.3 per cent in nominal terms over the projection period.

HT scheme: Reflecting strong modelled demand and unit-cost growth based on historical patterns, future expenditure requirements both in real and nominal terms are projected to be substantially higher under the $\mathrm{HT}$ scheme relative to the other community schemes. In real terms, expenditure requirements are projected to increase by between 60.3 and 164.5 per cent for the HT between 2019 and 2035 . 
This equates to projected real expenditure requirements of between $€ 1,434.2 \mathrm{~m}$ and $€ 2,367.1 \mathrm{~m}$ in 2035. In nominal terms, expenditure requirements are projected to increase by between 157.2 and 395.4 per cent. This equates to projected nominal expenditure requirements of between $€ 2,301.4 \mathrm{~m}$ and $€ 4,433.6 \mathrm{~m}$ in 2035 . Across all scenarios, in both real and nominal terms, these projections suggest that the HT scheme will overtake the GMS scheme as the largest of the community schemes in expenditure terms by 2035.

Projected average annual growth for the HT scheme ranged between 3.0 and 6.3 per cent in real terms and 6.1 and 10.5 per cent in nominal terms over the projection period. While these annual average increases far exceed those of the other community schemes, they remain conservative relative to an historical average annual growth rate in HT scheme expenditure of 11.4 per cent between 2010 and 2019. ${ }^{41}$

TABLE 6.5 Community pharmaceuticals - projected real and nominal expenditure growth by projection scenario and scheme, 2019-2035

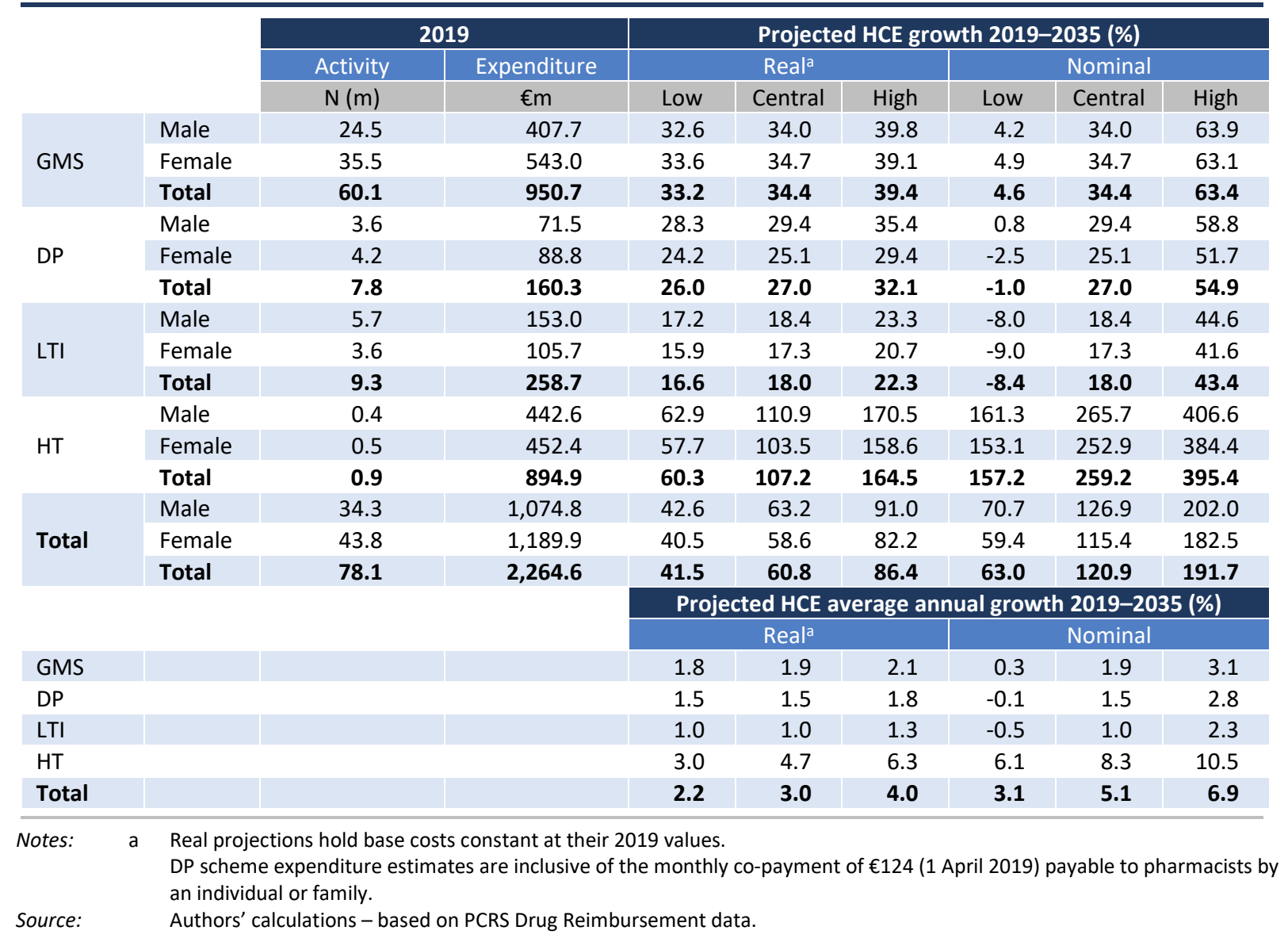

$41 \quad$ Average annual growth was 12.9 per cent between 2015 and 2019. 
Figure 6.2 takes a closer look at the relative contribution of demand and cost drivers, through decomposing nominal expenditure projections by scenario for community pharmaceutical expenditure. Here we consider one set of decompositions for the HT scheme, and one set for the other community schemes combined.

GMS, DP, LTI schemes (combined): Across all scenarios, demand for prescription items is projected to be the dominant driver of expenditure growth. Most notably under the central scenario, all projected expenditure growth is demand-based as we assume no growth in unit costs. Under this scenario, changes to the population age structure account for 68.9 per cent of projected expenditure growth, with the remaining relative to population growth. The impact of cost is observably different across scenarios. Under the low-pressure scenario, assumed per annum reductions in unit costs have a negative effect on expenditure requirements $(€ 380.2 \mathrm{~m})$. Under the high-pressure scenario, cost growth over the projection horizon accounts for 39.8 per cent of additional projected expenditure required by 2035 .

HT scheme: The large projected expenditure growth under the HT scheme is driven by both large demand and cost effects, reflecting previous experience (Connors, 2017a). Particularly, additional modelled demand, over and above the impact of pure population growth and ageing, is projected to be the biggest driver of expenditure across all scenarios. For instance, under the central scenario, this additional demand (reflecting uptake of new drugs) is projected to contribute $€ 1,392.8 \mathrm{~m}$ to projected expenditure in 2035 , accounting for 60.0 per cent of the total projected expenditure increase by 2035 . This additional demand accounts for 45.6 per cent of total projected expenditure increase under the low-pressure scenario, and 68.5 per cent of total projected expenditure increase under the highpressure scenario.

The projected growth in cost also contributes substantially to projected expenditure growth under the HT scheme. Under the central scenario, for example, the increasing unit cost of items is projected to contribute $€ 771 \mathrm{~m}$ to the total projected expenditure increase by 2035, accounting for 33.2 per cent of projected growth. Cost growth accounts for 44.5 per cent of projected growth under the low-pressure scenario, and 26.5 per cent of projected growth under the high-pressure scenario. 
FIGURE 6.2 Community pharmaceuticals - decomposition of projected nominal expenditure growth, 20192035, by projection scenario

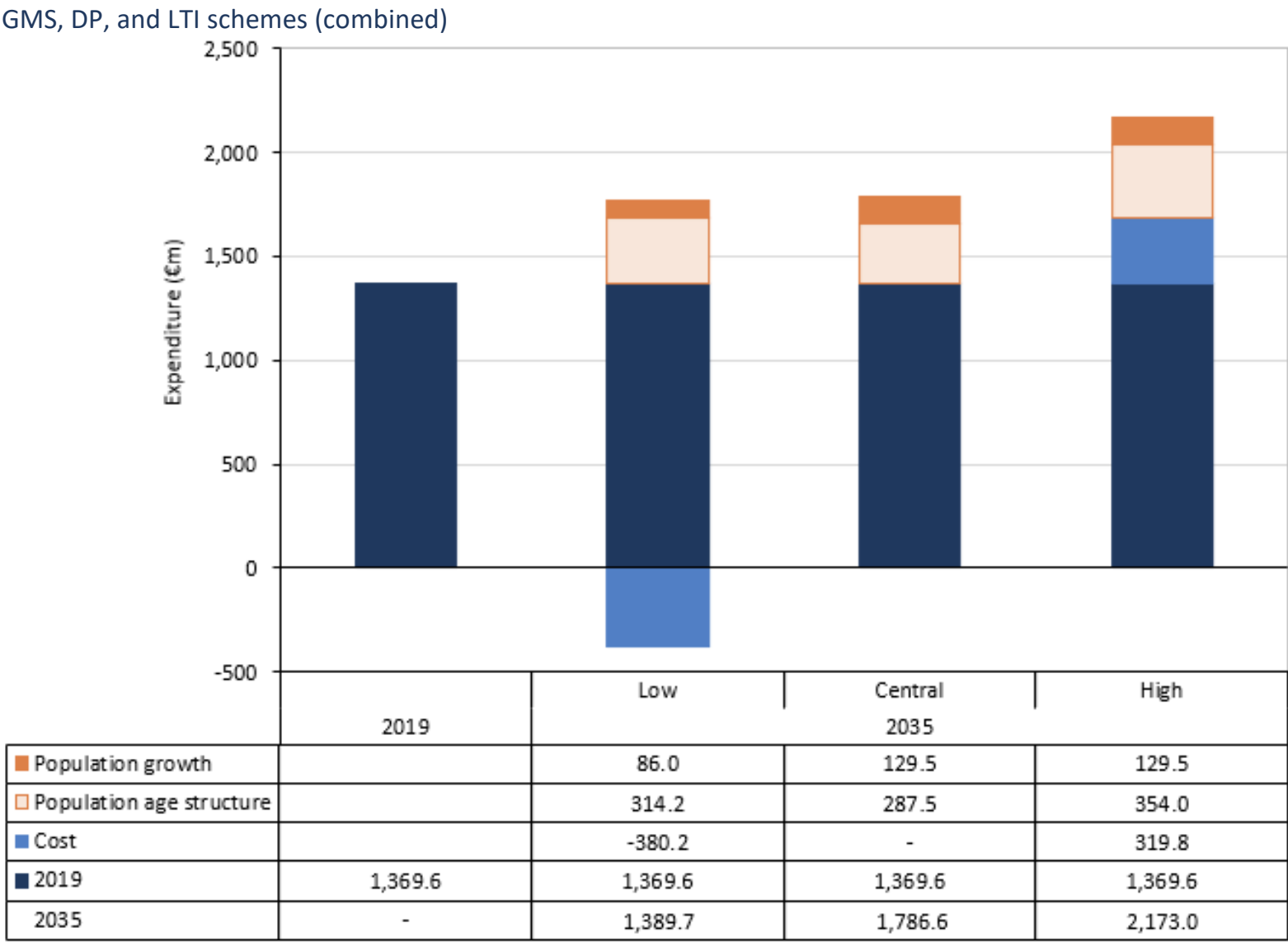

HT scheme

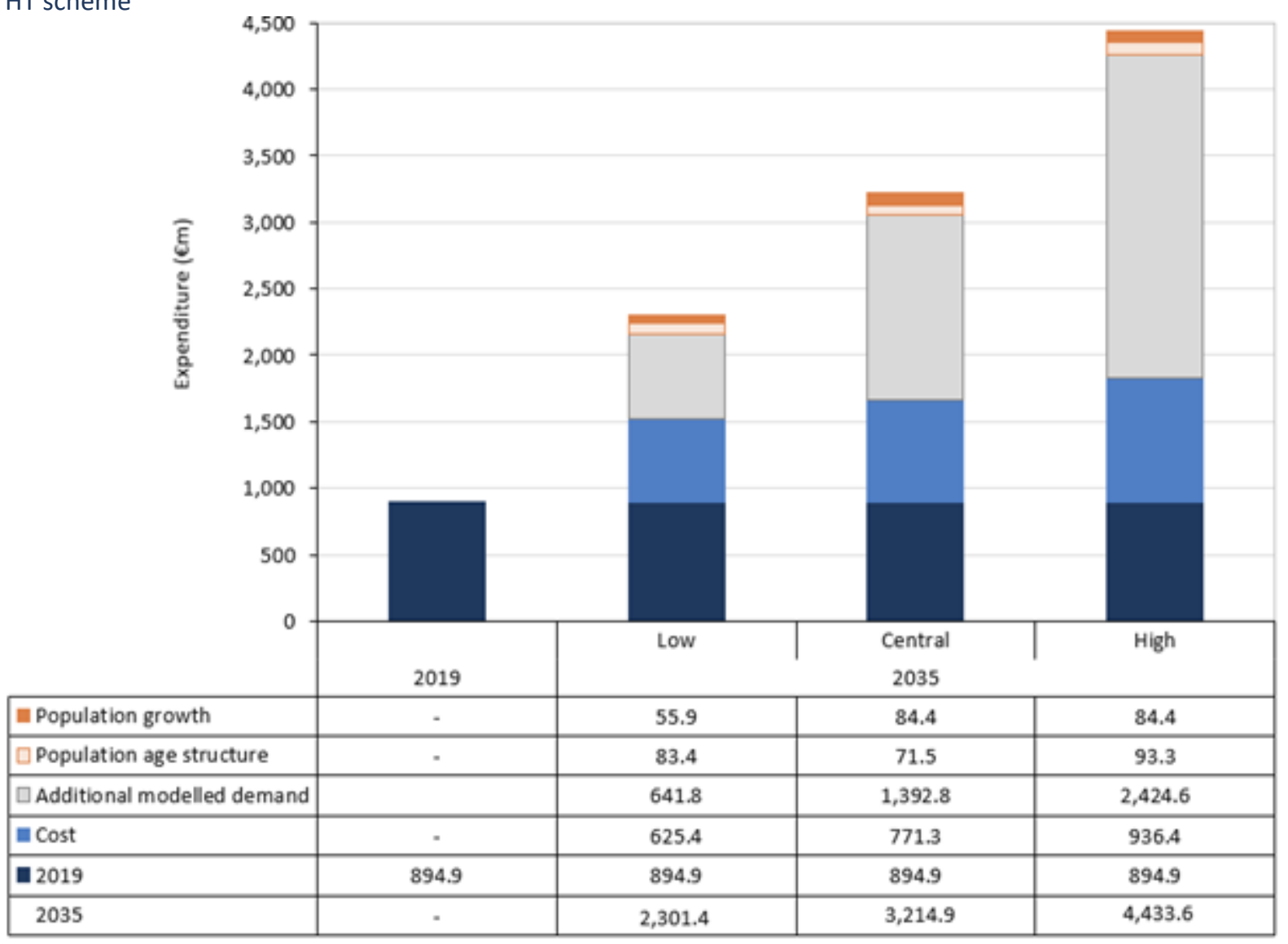

Source: Authors' calculations - based on PCRS Drug Reimbursement data. 
Figure 6.3 presents baseline expenditure by age and projected expenditure by age and projection scenario, in 2035. Here we consider one set of projections for the HT scheme, and one set for the other community schemes combined.

GMS, DP, LTI schemes (combined): Under the GMS, DP and LTI schemes (combined) growth in expenditure over the period 2019 to 2035 takes place predominantly at the older end of the age distribution, driven by population ageing. Notably, under the low-pressure scenario, the impact of modelled unit-cost reductions outweighs demographic effects for all age groups (resulting in reduced expenditures) apart from those aged 75 and over.

HT scheme: Under the HT scheme, two peaks in expenditure are observable, the first at age group 55-64 and the second at 75 and over, mirroring the underlying activity rate distribution. Relative to the other community schemes, there is a much larger increase in expenditure observable across all age groups under the HT scheme; this is predominantly a function of strong assumed growth in demand and cost. Relative to GMS, DP and LTI, there is also noticeably greater variation in projected expenditure by age group across the three scenarios, reflecting the greater sensitivity of HT scheme projections to assumptions in relation to projected demand and cost. 
FIGURE 6.3 Community pharmaceuticals - expenditure by age, projection scenario and scheme, 2019 and projected 2035 (nominal)

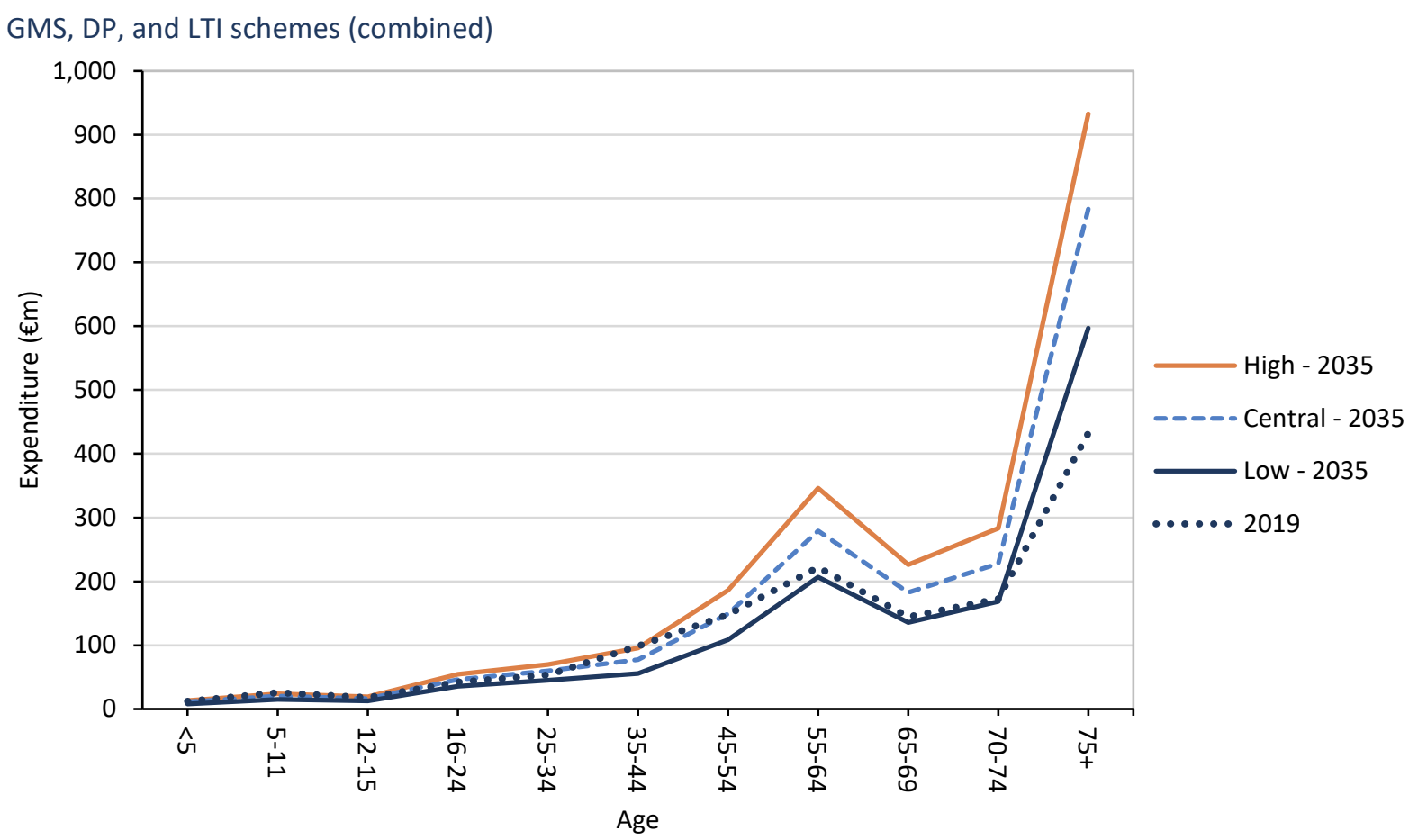

HT scheme

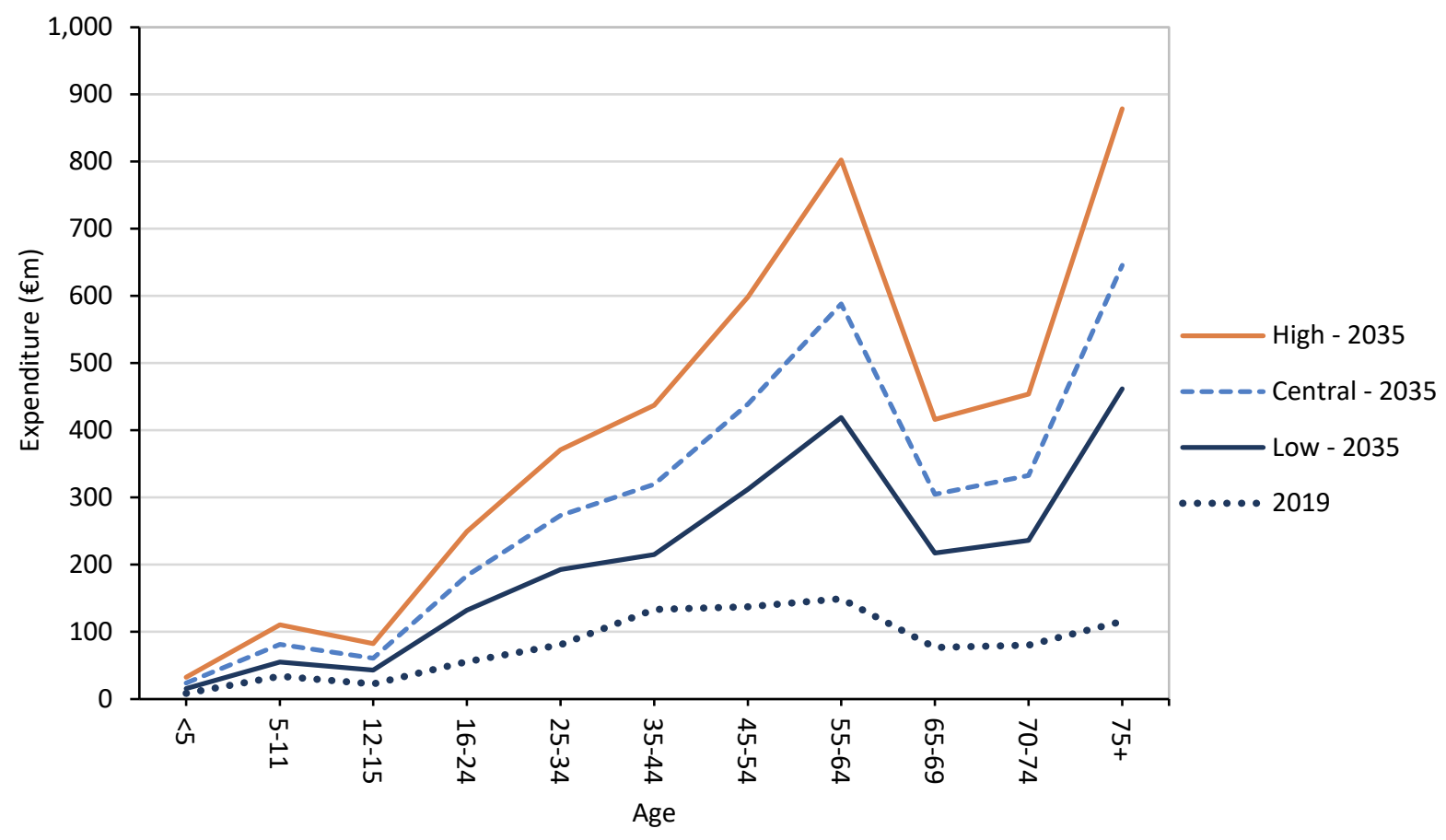




\subsection{SUMMARY}

The analysis presented in this chapter estimated expenditure for four community schemes to 2035 for three scenarios: low pressure, central and high pressure. Between 2019 and 2035, across all schemes combined, we estimate projected annual average growth requirements for community pharmaceuticals of between 2.2. and 4.0 per cent in real terms and 3.1 and 6.9 per cent in nominal terms. However, we project expenditure growth to vary at scheme level, most notably between the HT scheme and the other community schemes.

In recent years, unit costs per prescription item under the GMS, DP and LTI schemes have been static or declining, keeping projected expenditures below what they otherwise would have been. This is largely due to initiatives such as reference pricing and generic substitution, negotiated pricing agreements with industry, and the large share of off-patent drugs. Particularly in light of a soon-to-be-negotiated new supply agreement with industry, our projections assume these trends to continue into the future. The increased expenditure projected for these schemes is therefore largely demand-based, driven by the sensitivity of underlying agerelated activity profiles to projected population ageing, even after adjusting for Irish evidence in relation to healthy ageing. Wren et al. (2017) reported similar conclusions in relation to the impact of a changing population age structure on demand for community pharmaceuticals.

Expenditure under the HT scheme is projected to exceed that of the other community schemes for two main reasons. First, in recent years growth in demand for high-tech medicines far exceeded the impact of demographic change. As discussed in the chapter, this is likely linked to factors such as increases in the range of conditions treatable under the scheme and increased annual use of new drugs (once introduced), among other factors. Informed by these historical patterns, we therefore model additional demand growth for high-tech medicines (albeit somewhat conservatively relative to recent experience) as not to do so would likely significantly underestimate future demand. Secondly, this scheme is dominated by on-patent drugs which tend to be highly expensive and have resulted in large yearon-year growth in the unit cost of HT scheme prescription items. Our projections assume similar increases into the future. While the projected expenditure range under the HT scheme is quite large, qualitatively, this analysis clearly suggests that, based on underlying assumptions, expenditure on the HT scheme is likely to become unsustainable into the future. Policy focus should therefore be directed towards initiatives (such as implementing BVB medicines for off-patent drugs) aimed at reducing $\mathrm{HT}$ scheme expenditure pressures. In particular, as the pace of spending pressure on the HT scheme will predominantly be driven by on-patent medicines, a focus on reducing on-patent spend will be key. 
For the purpose and scope of this report, this analysis modelled no changes to eligibility or charges/co-payments. Any changes to these factors would likely alter the path of projected expenditure. The analysis was also undertaken at a broad scheme level over a medium-term horizon. However, similar to previous work undertaken in the UK (O'Neill et al., 2014), greater insights into short-term trends could be gained from in-depth analysis considering in detail factors such as the life cycle of new medicines, the stream of new medicines coming on board, and trends in patent expiration. 


\section{CHAPTER 7}

\section{Findings: Long-term residential care expenditures}

\subsection{INTRODUCTION}

This chapter presents findings for baseline public expenditure in 2019 and projected expenditure to 2035 for LTRC. The chapter details the LTRC sector in Ireland. The analysis encompasses residential care provided outside acute hospital settings (mainly nursing homes), which may be of varying duration. It includes care provided as part of the NHSS ('Fair Deal') as well as intermediate, transitional and short-stay care. The estimated unit cost for each scheme is based on the cost of a bed per week. The projections included in the chapter are based on scenarios with varying assumptions about pressures on home support services to 2035. These scenarios are intended to broadly reflect possible changes in the model of care and increases in demand for the NHSS.

\subsection{ROLE OF LONG-TERM RESIDENTIAL CARE IN HEALTH SYSTEMS}

LTRC is provided mainly to older people in need of care for impairments that require personal help and nursing care. LTRC therefore is residential care provided outside acute hospital settings. It may be of varying duration, and in particular it includes shorter stays for respite, rehabilitation, convalescence and palliative care - a broad categorisation applied by Wren et al. (2017) in analysis of LTRC demand in Ireland. ${ }^{42}$ While the majority of LTRC residents are aged 65 and older, younger people with needs for care can also receive care in LTRC settings and therefore are included in the analysis. All LTRC homes in Ireland are regulated by the Health Information and Quality Authority (HIQA). In 2020, HIQA had 576 registered facilities across the country (Frazer et al., 2021). The CSO has estimated that residential care accounted for $€ 3.97 \mathrm{bn}$ or 18 per cent of overall (public and private) non-capital healthcare expenditure in Ireland in 2018 (Central Statistics Office, 2020). This total encompasses care for older people and care for people with disabilities. This chapter does not analyse expenditure on residential care for people with disabilities. Utilisation of disability services has been examined in a previous report (Brick et al., 2020a) but, due to data challenges, projections for expenditure on these services have not been included in the development of the Hippocrates Model for this report.

LTRC institutions in Ireland are frequently defined by their form of ownership, with three broad categories: public (HSE-owned), voluntary, and private. In public long-

42 Long-stay beds include those for: extended/continuing care for people who had been assessed as needing long-term care; psychiatry of old age, for specialised psychiatric services; and 'young chronic sick' for young people with longlasting illness which is usually irreversible and may be progressive. Short or limited-stay beds include beds for rehabilitation or convalescence after an illness/injury; palliative care for patients at a time 'when the medical expectation is no longer cure'; and respite, for 'the planned admission of dependent persons for short periods of time in order to assist carers in their task of caring' (Wren et al., 2017). 
stay facilities, distinctions are made based on duration or nature of stay. As well as long-stay (over three months), a further category of beds is referred to as shortstay (Department of Health, 2015). Shorter stays may occur in both public and voluntary/public LTRC homes. Short-stay beds in public facilities may be attached to a community hospital or community nursing home or may be stand-alone units. Short-stay beds include respite, convalescent, rehabilitation, assessment and palliative-care beds (Department of Health, 2015).

From 2012, in response to pressures on acute hospitals and delayed LTRC funding, a further category of LTRC beds arose, described as transitional care beds. These beds are publicly funded in private LTRC homes and may be used for rehabilitation or assessment of LTRC need (Wren et al., 2017).

\subsubsection{Nursing Home Support Scheme}

The majority of LTRC beds are financed under the NHSS. The HSE administers the NHSS, but the contract is between the resident and the LTRC home. The price of a bed in a voluntary/private LTRC is negotiated on a home-by-home basis by the National Treatment Purchase Fund (NTPF). Under the NHSS, individuals contribute 80 per cent of their income and 7.5 per cent of the value of any assets towards the cost of care, and the State pays the balance. The first $€ 36,000$ of assets $(€ 72,000$ for a couple) is not counted in the financial assessment. Current funding through the NHSS does not recognise dependency levels, which have implications for care when, increasingly, residents are of higher dependency, especially those with significant disabilities under 65 years of age. Despite HIQA requiring LTRC homes to meet standards for the provision of care for residents living with dementia, the NHSS does not currently allocate additional funding for cognitive impairment, including dementia. A small number of LTRC residents continue to be funded through legacy schemes that existed prior to the introduction of the NHSS in 2009 (Wren et al., 2017).

\subsection{DATA AND METHODS}

\subsubsection{Data}

Resident, bed and expenditure data for this analysis for 2019 were provided by the HSE and through the 2019/2020 Private \& Voluntary Nursing Home Survey ${ }^{43}$ from $\mathrm{BDO}$ and Nursing Homes Ireland (NHI).

\section{Health Service Executive}

The number of residents funded via the NHSS and publicly financed long-stay residents under legacy schemes at end December 2019 was provided by Older

43 See full report and survey here: https://www.bdo.ie/getattachment/News/2021/Some-small,-rural-nursing-homesfacing-closure,-BD/NHI-Private-Voluntary-Nursing-Home-Survey-Results-2019-2020-v7.pdf.aspx?lang=en-GB 
People Operations in the HSE. Resident data were disaggregated by sex and SYOA. Expenditure data capture the average weekly cost of a bed provided via the NHSS and within the legacy schemes.

The number of publicly funded short-stay residents in HSE care homes in 2019 was also provided by the Older People Operations in the HSE. Resident data were disaggregated by sex and SYOA. Expenditure data capture the average weekly cost of providing care in a convalescent/respite care bed.

The number of people on the NHSS waiting list at end December 2019 was provided by Older People Operations in the HSE.

\section{Nursing Homes Ireland Survey}

The 2019/2020 Private \& Voluntary Nursing Home Survey from BDO and Nursing Homes Ireland (NHI) is used to estimate the number of residents in privately financed long-stay and short-stay beds and the number of publicly funded shortstay residents in voluntary/private nursing homes.

\subsubsection{Methods}

In this analysis, base-year activity rates and expenditures for 2019, for each scheme and bed category, are generated separately.

NHSS

Activity: Activity rates in 2019 are estimated by dividing the number of residents in NHSS-financed beds in each age and sex group by the population for each age and sex group.

Expenditure: The average cost of an NHSS-financed bed in both HSE and voluntary/private LTRC homes was provided by the HSE. The average cost of a bed funded via the NHSS in a public LTRC home in 2019 was $€ 1,615$ per week (Smith et al., 2021). The average cost negotiated by the NTPF for a bed financed via the NHSS in a voluntary or private LTRC home in 2019 was €992 per week. However, it is common for NHSS residents in voluntary/private LTRC homes to pay for additional personal and health services (e.g. physiotherapy). Following correspondence with the $\mathrm{NHI}$, we added a 5 per cent additional cost to cover these additional services. Using information on the percentage of NHSS-financed residents in public (23\%) and voluntary/private (77\%) LTRC homes, including costs paid by the State and residents, we estimate that the average cost of an NHSS bed in 2019 was $€ 1,039$ per week (€58,078 per annum). 
Following discussions with Older People Operations in the HSE, an 89:11 pay:nonpay ratio for the annual cost for residents financed via the NHSS and legacy in public LTRC homes was assumed for the analysis. Using information from the 2019/2020 NHI survey, a 60:40 pay:non-pay ratio was assumed for residents financed via the NHSS in voluntary/private LTRC homes. Using information on the percentage of NHSS-financed residents in public (23\%) and voluntary/private $(77 \%)$ homes, we estimate an average 66:33 pay:non-pay ratio in 2019 for NHSS-financed beds.

\section{Publicly financed legacy scheme}

Activity: Activity rates in 2019 are estimated by dividing the number of residents in publicly financed legacy scheme beds in each age and sex group by the population for each age and sex group.

Expenditure: The average cost of an NHSS-financed bed ( $€ 58,078$ per annum) and the pay:non-pay ratio estimated for the NHSS are assumed to be the same for residents in publicly financed legacy schemes. An average 66:33 pay:non-pay ratio in 2019 for these residents was assumed also.

\section{Privately financed long-stay and short-stay residents}

Activity: The 2019/2020 Private \& Voluntary Nursing Home Survey found that 16 per cent of the 26,211 beds in voluntary/private nursing homes were privately financed. These residents may include long-stay care financed through out-ofpocket payments, convalescent care reimbursed by insurance companies and respite care funded by some charities (Wren et al., 2017). These beds were a combination of privately financed long-stay and short-stay beds. ${ }^{44}$ Using the 91 per cent occupancy estimate from the survey, we estimate that there were 3,815 privately financed LTRC residents at the end of 2019. Following the assumptions from Wren et al. (2017), the age and sex distribution from the NHSS scheme is applied. We assume that all privately financed LTRC residents reside in voluntary/private LTRC homes.

Expenditure: There is no central database that captures the average cost of a privately financed LTRC bed. Following discussions with $\mathrm{NHI}$, we included the average cost negotiated by the NTPF for a bed funded via the NHSS in a voluntary or private LTRC home in 2019, with a 5 per cent addition for additional services, totalling $€ 50,341$ per annum. This equates to the assumed cost of an NHSS-funded resident in a voluntary/private LTRC home. Using pay:non-pay ratios outlined in the NHI survey, a 60:40 pay:non-pay ratio was assumed for these residents. 


\section{Publicly financed short-stay residents}

Activity: The HSE provided data on the number of publicly financed short-stay residents in HSE care homes. The 2019/2020 Private \& Voluntary Nursing Home Survey found that 84 per cent of occupied beds in voluntary/private LTRC homes were occupied by publicly financed long- and short-stay residents. In addition, the survey found that 13 per cent of all beds in voluntary/private LTRC homes were occupied by (public and private) short-stay residents. Assuming an 84:16 public:private financed resident ratio for short-stay beds and using the 91 per cent occupancy from the survey, this equates to 2,369 publicly financed short-stay residents in voluntary/private LTRC home, and 4,374 publicly financed short-stay residents across all LTRC homes. Following the assumptions in Wren et al. (2017), the age and sex distribution from the NHSS scheme is applied.

Expenditure: The 2019/2020 Private \& Voluntary Nursing Home Survey found that the average cost of a publicly financed convalescent bed in a voluntary/private nursing home in 2019 was $€ 54,500$ ( $€ 1,050$ weekly). No such figure was available for short-stay beds in public nursing homes. Using the percentage difference of beds financed through the NHSS scheme between public and voluntary/private nursing homes (62.8\%), an average cost of $€ 88,889(€ 1,709)$ was assumed for a publicly funded short-stay bed in a public care home. This provides an average cost of $€ 68,378$ per annum for publicly financed short-stay residents in 2019 . Using the pay:non-pay ratios outlined above, a 73:27 pay:non-pay ratio was estimated for these residents.

\section{Expenditure projections}

Base-year and projected age- and sex-specific expenditure volumes are generated by combining age- and sex-specific utilisation profiles with unit-cost profiles. As for other services included in this report, the expenditure projections are decomposed into their constituent drivers.

\section{Projection scenarios}

The projection scenarios used in this chapter are presented in Table 7.1. Under the central scenario, demand for LTRC evolves in line with the central population growth scenario, combined with compression of morbidity. No unmet demand or substitution effects were included in the central scenario.

Under the low-pressure scenario, demand for LTRC evolves in line with the low population growth scenario, combined with compression of morbidity. The lowpressure scenario also includes an assumption that some activity is substituted from LTRC to home support. Previous research has found that 8 per cent of home support recipients enter LTRC in a 12-month period (Aspell et al., 2019). Following 
the approach of Walsh and Lyons (2021), in the low-pressure scenario we assume that this rate is halved to 4 per cent per annum following the introduction of the statutory home support scheme. This substitution is included fully from 2023, the year in which the statutory home support scheme is assumed to be fully operational. The assumed reduction in LTRC residents between 2019 and 2023, in favour of home support, may also help capture much of the reduction in LTRC numbers that has occurred in 2020 and 2021 as a consequence of the Covid-19 pandemic.

Under the high-pressure scenario, demand for LTRC evolves in line with the central population growth scenario combined with dynamic equilibrium. The highpressure scenario assumes that, despite the introduction of the statutory home support scheme, rates of substitution to home support are low, and/or reductions in use of long-stay beds are met with proportionate increases in use of short-stay beds. We use the high-pressure scenario to reflect some key sources of uncertainty. As the statutory home support scheme has not yet been established, the extent to which the scheme will reduce use of residential care cannot yet be quantified. The high-pressure scenario also assumes that unmet demand, based on numbers waiting for the NHSS, will be addressed.

Across all scenarios, pay and non-pay costs are assumed to increase at the same rates. Under the central scenario, pay and non-pay components are projected to increase by $2.5 \%$ per annum; under the low-pressure scenario, by $2.2 \%$ per annum, and under the high-pressure scenario, by $3.5 \%$ per annum.

TABLE 7.1 Projection scenario assumptions

\begin{tabular}{|c|c|c|c|}
\hline & Low pressure & Central & High pressure \\
\hline \multicolumn{4}{|l|}{ Demand assumptions } \\
\hline $\begin{array}{l}\text { Population growth and } \\
\text { ageing }\end{array}$ & Low & Central & Central \\
\hline Healthy ageing & Compression of Morbidity & Compression of Morbidity & Dynamic Equilibrium \\
\hline Unmet demand & No & No & Yes \\
\hline $\begin{array}{l}\text { Substitution to home } \\
\text { support }\end{array}$ & Yes & No & No \\
\hline \multicolumn{4}{|l|}{ Cost assumptions } \\
\hline Pay & $\begin{array}{c}\text { COSMO Downside - } \\
\text { projected government- } \\
\text { sector wage growth }(2.2 \% \\
\text { p.a.) }\end{array}$ & $\begin{array}{l}\text { COSMO Upside - } \\
\text { projected government-sector } \\
\text { wage growth ( } 2.5 \% \text { p.a.) }\end{array}$ & $\begin{array}{c}\text { COSMO Upside - } \\
\text { projected government-sector } \\
\text { wage growth }+1 \text { pct point p.a. } \\
(3.5 \% \text { p.a. })\end{array}$ \\
\hline Non-pay & $2.2 \%$ per annum & $2.5 \%$ per annum & $3.5 \%$ per annum \\
\hline
\end{tabular}




\subsection{FINDINGS - BASELINE ANALYSIS}

Table 7.2 provides details on LTRC residents and unit costs across categories of beds (short-stay vs. long-stay) and funding. In 2019, there were an estimated 31,966 LTRC residents in Ireland. This compares to 30,856 residents in 2015, estimated by Wren et al. (2017), and is at the upper end of the range of the number of residents projected in 2019 in the previous analysis. ${ }^{45}$ Residents funded as part of the NHSS represent 73 per cent of all LTRC residents. An estimated 12 per cent of LTRC residents funded their care privately. In 2019, we estimate that almost $€ 2 \mathrm{bn}$ was spent on LTRC in Ireland. Across all bed and financing categorisations, the average cost of an LTRC bed was €61,209 per annum (€1,177 weekly).

The cost of residents funded through the NHSS in 2019 was $€ 1,422.2 \mathrm{~m}$. The State contributed $€ 994.1 \mathrm{~m}$ to the NHSS, corresponding to approximately 69.9 per cent of the cost of the scheme. Short-stay beds were, on average, estimated to cost $€ 68,378$ per annum. This higher cost reflects the fact that many short-stay beds provide convalescent, rehabilitation and transitional care and thus require more healthcare resources than an average long-stay bed.

At the end of 2019, there were 569 people on the waiting list for the NHSS but not already in a long-stay bed. Expenditure to meet this demand is included in our highpressure scenario.

TABLE 7.2 Long-term residential residents and unit costs by category of bed and financing, 2019

\begin{tabular}{|c|c|c|c|c|c|}
\hline \multirow[t]{2}{*}{ Category } & Residents & $\begin{array}{l}\text { Residents } \\
\text { aged } 65+\end{array}$ & $\begin{array}{l}\text { Unit } \\
\text { cost }\end{array}$ & Pay:non-pay & Expenditure \\
\hline & $\mathrm{N}$ & $\mathrm{N}$ & $€$ & Ratio & $€ \mathrm{~m}$ \\
\hline NHSS long-stay residents & 23,307 & 22,033 & 61,021 & $67: 33$ & $1,422.2$ \\
\hline $\begin{array}{l}\text { Publicly financed long-stay } \\
\text { residents under legacy schemes }\end{array}$ & 470 & 418 & 61,021 & $67: 33$ & 28.7 \\
\hline $\begin{array}{l}\text { Privately financed long and short- } \\
\text { stay residents }\end{array}$ & 3,815 & 3,632 & 54,163 & $60: 40$ & 206.6 \\
\hline $\begin{array}{l}\text { Publicly financed short-stay } \\
\text { residents }\end{array}$ & 4,374 & 4,134 & 68,378 & $73: 27$ & 299.1 \\
\hline Total & 31,966 & $30,217^{a}$ & 61,209 & $67: 33$ & $1,956.6$ \\
\hline \multicolumn{6}{|l|}{ Unmet demand } \\
\hline NHSS Waiting List & 569 & & - & - & - \\
\hline
\end{tabular}

Figures 7.1 shows the age- and sex-specific total expenditure and expenditure per capita on LTRC in 2019. As expected, there is a clear age effect, with LTRC expenditure much higher at older ages. In accordance with Wren et al. (2017),

45 Wren et al. (2017, Appendix Table 7.5) projected that LTRC residents in 2019 would be in a range of between 30,000 and 32,000 . 
different expenditure patterns are seen for males and females, driven by varying utilisation rates. At younger ages, per capita and total expenditure patterns are similar for males and females. However, from age 75 a clear divergence develops, with LTRC expenditures much higher for females compared to males. These contrasting utilisation patterns in per capita expenditure, as discussed in Wren et al. (2017), are likely due to differing life expectancies for men and women causing differing care patterns. Since women on average live longer, they are more likely to be available to care for their partners in older age, so that men are more likely to remain in the community, with admission to hospital for care close to death. In contrast, women are more likely to outlive their partners and live alone in older ages, a risk factor for admission to LTRC, with end-of-life care occurring in LTRC.

FIGURE 7.1 Long-term residential care - age- and sex-specific expenditure and expenditure per capita, 2019

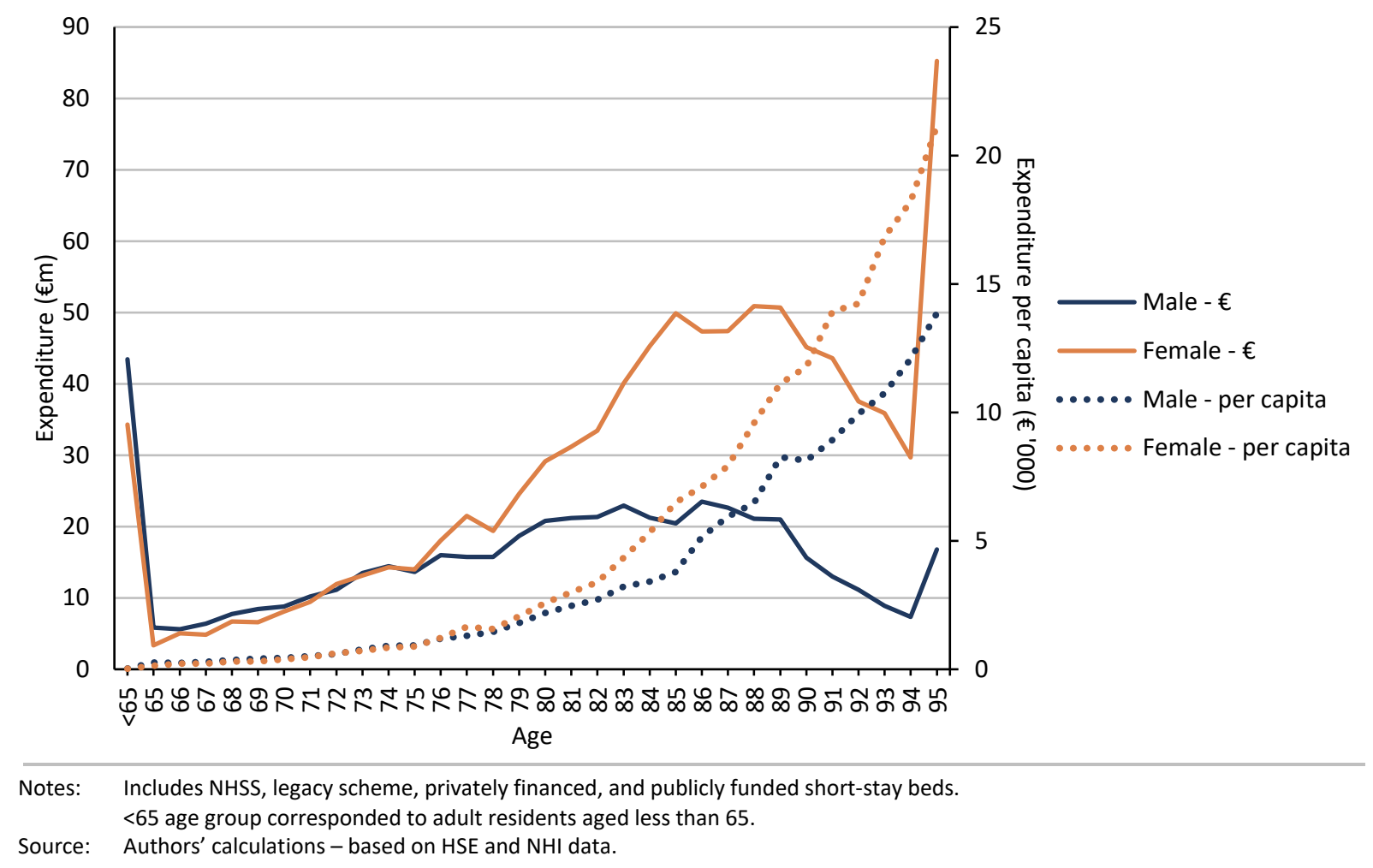

\subsection{FINDINGS - EXPENDITURE PROJECTIONS}

Table 7.2 presents the projected increase in LTRC expenditure between 2019 and 2035 in real and nominal terms for the low-pressure, central and high-pressure scenarios.

Between 2019 and 2035, real expenditure requirements are projected to grow by between 37.8 and 66.9 per cent in LTRC. In 2035, expenditure required in real terms on LTRC is projected to be between $€ 2,696.5 \mathrm{~m}$ and $€ 3,264.9 \mathrm{~m}$. This represents an average annual increase of between 2.0 and 3.3 per cent. The rates of increase are projected to be slightly higher for males than females. This reflects 
an assumed convergence in life expectancy between the sexes over time (i.e. the demographic projection estimate that male life expectancy will improve at a quicker rate in the medium term).

Nominal projected expenditure growth is affected by assumptions on the evolution of both demand and cost drivers. Nominal expenditure on LTRC is projected to grow by between 95.2 and 189.3 per cent between 2019 and 2035. In 2035, expenditure required in nominal terms on LTRC is projected to be between $€ 3,819.7 \mathrm{~m}$ and $€ 5,664.3 \mathrm{~m}$. This represents an average annual increase of between 4.3 and 6.9 per cent.

TABLE 7.3 Long-term residential care - projected real and nominal expenditure growth by projection scenario, 2019-2035

\begin{tabular}{|c|c|c|c|c|c|c|c|c|c|}
\hline & & \multicolumn{2}{|c|}{2019} & \multicolumn{6}{|c|}{ Projected HCE growth (\%) 2019-2035 } \\
\hline & & \multirow{2}{*}{$\begin{array}{c}\text { Residents } \\
\text { N }\end{array}$} & \multirow{2}{*}{$\begin{array}{c}\text { Expenditure } \\
€ \mathrm{~m}\end{array}$} & \multicolumn{3}{|c|}{ Real $^{\mathrm{a}}$} & \multicolumn{3}{|c|}{ Nominal } \\
\hline & & & & Low & Central & High & Low & Central & High \\
\hline \multirow{6}{*}{ LTRC (all) } & Male & 11,369 & 695.9 & 42.8 & 56.7 & 74.9 & 102.2 & 132.6 & 203.4 \\
\hline & Female & 20,597 & $1,260.7$ & 35.1 & 48.1 & 62.4 & 91.3 & 119.9 & 181.6 \\
\hline & Total & 31,966 & $1,956.6$ & 37.8 & 51.2 & 66.9 & 95.2 & 124.4 & 189.3 \\
\hline & & & & \multicolumn{6}{|c|}{ Projected average HCE annual growth (\%) 2019-2035 } \\
\hline & & & & \multicolumn{3}{|c|}{ Real $^{\mathrm{a}}$} & \multicolumn{3}{|c|}{ Nominal } \\
\hline & & & & Low & Central & High & Low & Central & High \\
\hline \multirow{3}{*}{ LTRC (all) } & Male & & & 2.3 & 2.8 & 3.6 & 4.5 & 5.4 & 7.2 \\
\hline & Female & & & 1.9 & 2.5 & 3.1 & 4.1 & 5.0 & 6.7 \\
\hline & Total & & & 2.0 & 2.6 & 3.3 & 4.3 & 5.2 & 6.9 \\
\hline
\end{tabular}

Figure 7.2 takes a closer look at the relative contributions of demand and cost drivers in each scenario by showing the contribution made by each cost driver to projected nominal expenditures. Under all scenarios, changes in pay and non-payrelated costs are the greatest driver of projected LTRC expenditure growth. Across all scenarios, increases in costs contribute between 58.9 per cent and 65.8 per cent to projected expenditure growth. Compared to the case in other chapters, population ageing contributes a relatively large percentage of projected expenditure growth: between 28.5 per cent (high-pressure) and 46.1 per cent (lowpressure) across scenarios.

The projected impact on LTRC expenditures of incorporating substitution and meeting unmet demand is relatively modest. In the low-pressure scenario, substituting home support for LTRC reduces projected LTRC expenditure in 2035 by $€ 346.8 \mathrm{~m}$ (i.e. LTRC expenditure growth would be 15.7 per cent higher in the absence of this substitution). Accounting for unmet demand increases projected LTRC expenditure in 2035 by $€ 114.1 \mathrm{~m}$ in 2035 (i.e. LTRC expenditure growth would be 3 per cent higher if NHSS waiting lists were cleared). 
FIGURE 7.2 Long-term residential care - decomposition of projected nominal expenditure growth, 2019-2035, by projection scenario

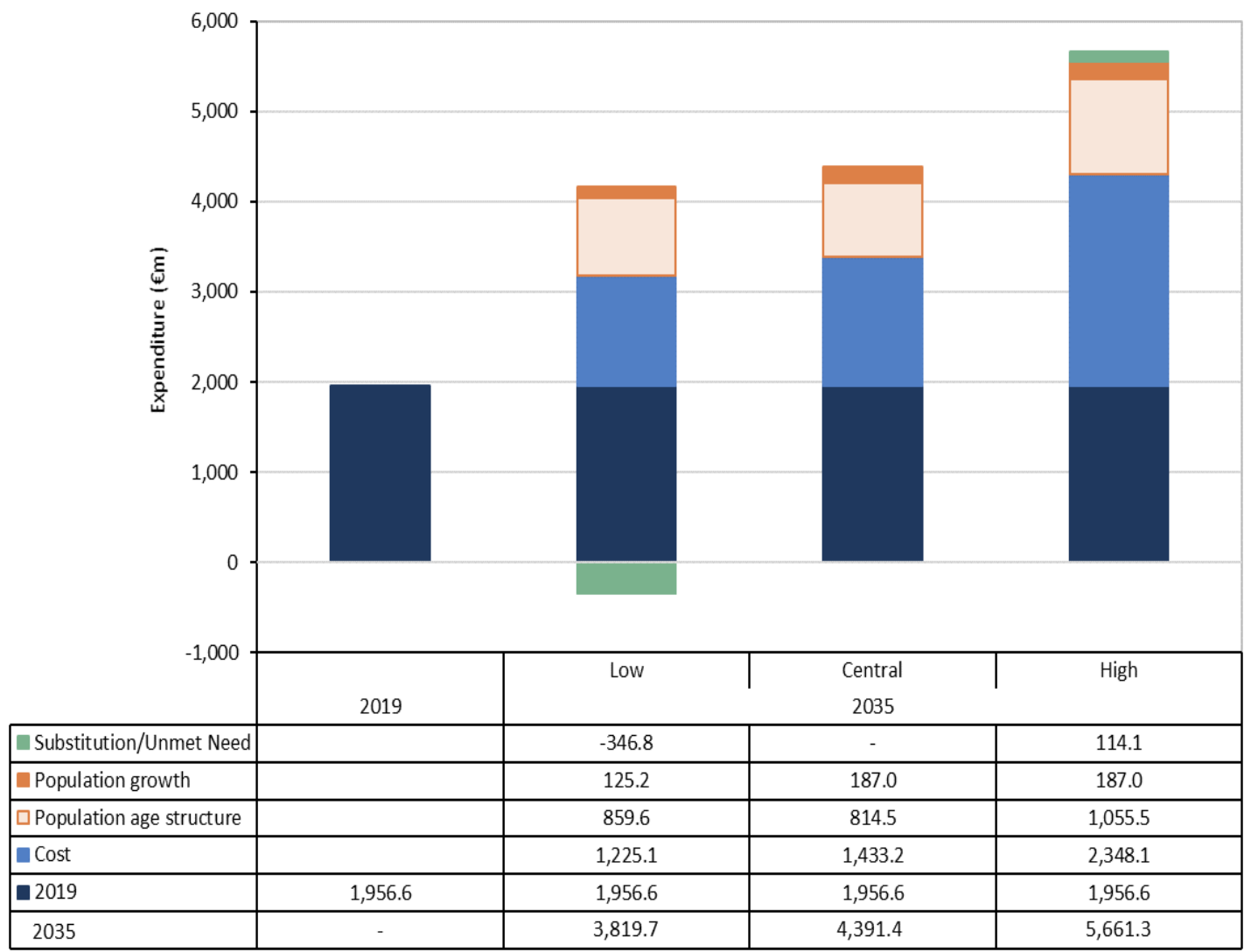

Source: HSE Social Care Division, Nursing Homes Ireland Survey. Authors' calculations.

Figure 7.3 presents baseline expenditure by age and projected expenditure by age and projection scenario in 2035. Growth in expenditure over the period 2019 to 2035 takes place predominantly at the older end of the age distribution, driven by population ageing. 
FIGURE 7.3 Long-term residential care - expenditure by age and projection scenario, 2019 and projected 2035 (nominal)

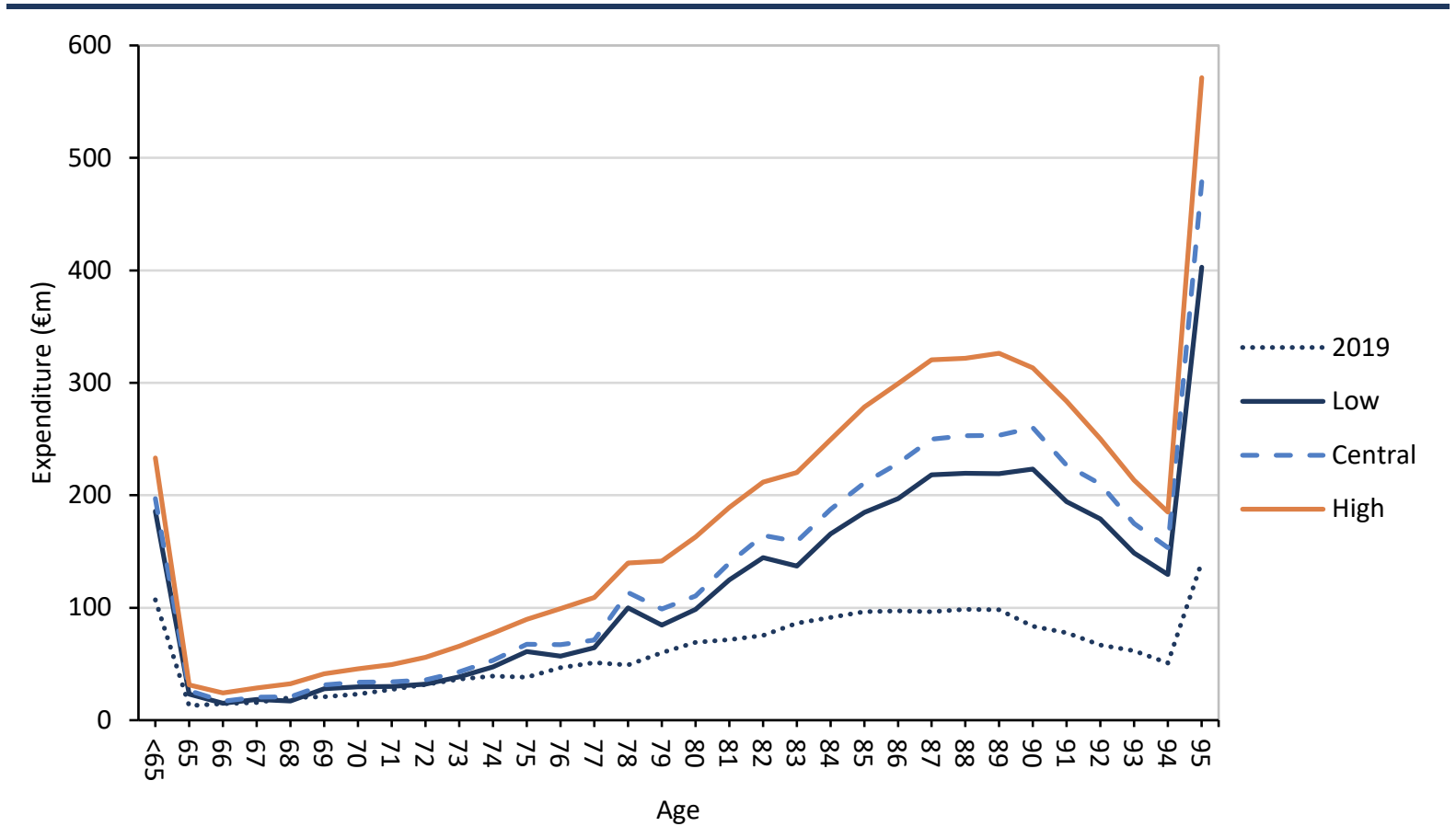

Source: Authors' calculations - based on HSE and NHI data.

\subsection{SUMMARY}

The analysis presented in this chapter estimated expenditure for long-stay and short-stay residential care, both publicly financed and privately financed, to 2035 for three scenarios - low-pressure, central and high-pressure. Increases in expenditure between 2019 and 2035 are projected at between 37.8 and 66.9 per cent in real terms and 95.2 and 189.3 per cent in nominal terms. Estimated as average annual increases, this equates to between 2.0 and 3.3 per cent in real terms and 4.3 and 6.9 per cent in nominal terms per annum.

One important system change examined in this report is the planned establishment of a statutory home support scheme. Under the assumption that the scheme will be fully operational in 2023, and following substitution assumptions made in previous analysis (Walsh and Lyons, 2021), we examined the impact of halving the number of people leaving home support (from $8 \%$ to $4 \%$ ) to enter LTRC. This substitution analysis was incorporated in the low-pressure scenario. We estimate that this substitution can reduce the growth in LTRC costs by over 15 percentage points (€346.8m) by 2035 .

Using information on the bed category and funding source, we can estimate the percentages of LTRC that are funded by the State and privately funded. In 2019, the HSE stated that it provided $€ 994.1 \mathrm{~m}$ for NHSS, or 69.9 per cent of the $€ 1,422.2 \mathrm{~m}$ total estimated in this report. In addition, we estimated that the State funded $€ 299.1 \mathrm{~m}$ on short-stay beds across public and voluntary/private nursing 
homes, and $€ 28.7 \mathrm{~m}$ on legacy schemes. Using these numbers, we estimate that $€ 1,321.9 \mathrm{~m}$ (67.6\%) of the $€ 1,956.6 \mathrm{~m}$ LTRC budget in 2019 was funded by the State. This means that personal contributions of NHSS residents and privately purchased LTRC represent 22.4 per cent (€634.7m) of LTRC expenditure in 2019.

It needs to be emphasised that the expenditure projections in this report are based on a pre-Covid-19 year, 2019, and therefore, in the short term, the rate of increase may be lower than over the longer time horizon. For example, while 23,307 residents were financed through NHSS at the end of 2019, this number was 21,710 at the end of March 2021. The lower number reflects lower use of the NHSS scheme during the Covid-19 pandemic and also the relatively high fatality rate among LTRC residents during the pandemic. The HPSC estimates that between 22 November 2020 and 20 March 2021 (encompassing the third wave), there were 929 Covid-19 deaths in nursing homes and community hospital/long-stay units. ${ }^{46}$ We did not have the requisite data in 2021 to explicitly model projections from that year. However, our low-pressure scenario, where approximately 2,200 LTRC residents are substituted towards home support by 2023, should capture some of the reduction in use of LTRC as a consequence of Covid-19 in the short term. We also assume that, in the absence of a large increase in home support and other community care services, the growth in LTRC residents will revert to the pre-Covid19 period in the medium term.

A number of data limitations reduced the scope of this research. While we have information on the age and sex profile of NHSS residents and legacy scheme residents, less information is available on privately financed and short-stay residents. Therefore, age and sex profiles from the NHSS were used for these other services. Similarly, we did not have expenditure data for some bed categories, such as publicly financed short-stay beds in public care homes. We therefore inferred costs from other bed categories (i.e. NHSS) or from costs of similar beds in voluntary/private nursing homes. 


\section{CHAPTER 8}

\section{Findings: Home support expenditures}

\subsection{INTRODUCTION}

This chapter presents findings for baseline public expenditure in 2019 and projected expenditure to 2035 for public and privately financed home support (home care) services for older people (aged 65+). The chapter first outlines the arrangements for provision of home support in Ireland and discusses the implementation of a statutory home support scheme in 2022 and its continued implementation in 2023. Estimates are presented for the hourly cost of both publicly funded ('public') and privately purchased ('private') home support. The projection scenarios incorporate assumptions that place varying pressures on home support services to 2035 that are reflective of model of care changes and demand increases likely to be observed following the introduction of a statutory home support scheme.

\subsection{ROLE OF HOME SUPPORT IN HEALTH SYSTEMS}

In this chapter 'home support' or 'home care' refer to health, personal and domestic care services provided to people in their own homes (Murphy et al., 2015). The services provided can involve healthcare (e.g. administration of medicine), but in general home support enables people to live their lives in the comfort of their own homes (i.e. social care). Home support can be provided by both unpaid carers such as spouses, children and neighbours, or by paid 'formal' professional carers. The home support structure in Ireland is heavily dependent on families providing most of the personal and domestic care. The approach taken in Ireland differs from other northern European countries where formal home support plays a more central role; Ireland's system resembles a family-based structure similar to that of Italy, Spain and Greece (Ilinca et al., 2015; Hanly and Sheerin, 2017). The heavy reliance placed on family carers as well as variation in the provision of home support services by the State have resulted in a recommendation in the Sláintecare report to establish a statutory scheme for home support.

In the current model of care for home support, individuals access home support funded by the HSE ('public) or purchase private support (which may supplement public home support) from for-profit agencies ('private'). Among the older population in receipt of home support, approximately 25 per cent of home support is privately purchased, and 75 per cent is provided within the public home support scheme (Walsh and Lyons, 2021). In the HSE-funded scheme, provision of care is outsourced in many cases to carers from voluntary (Section 39) organisations and carers from for-profit agencies. In recent years, there has been a substantial 
increase in the role played by for-profit agencies in Ireland (Mercille and O'Neill, 2020). Walsh and Lyons (2021) estimate that, across public and private home support, HSE carers provide 33.4 per cent of home support hours, voluntary organisations 8.4 per cent, and for-profit agencies 58.2 per cent.

The Sláintecare proposals and the Covid-19 Nursing Homes Expert Panel (Frazer et al., 2021) have emphasised the need to place home support on a statutory footing, just as was previously done for nursing home care through the NHSS. Accordingly, a new statutory scheme for the financing and regulation of home-support services is currently under development. In our analysis, we examine the potential expenditure implications of such a scheme.

\subsection{DATA AND METHODS}

A number of sources were used to estimate baseline home support activity and expenditure. Key data were provided by the HSE Social Care Division and Home and Community Care Ireland ( $\mathrm{HCCl}$ ), and some parameters were estimated using individual-level survey data from TILDA. Smith et al. (2021) also provided information on pay and non-pay for publicly funded home carers.

\section{Health Service Executive}

Data on the number of people in receipt of HSE-funded home support, hours provided and the level of associated expenditure in 2019 were provided by the HSE Social Care Division. Recipient data was not disaggregated by sex or age. Expenditure data is based on the average cost of a public home support hour in 2019.

The number of people for home support at end December 2019 was provided by HSE Social Care Division. Information (number of recipients and hours) on intensive Home Care Packages (iHCPs) and those on the public home support waiting list was also obtained from this source.

\section{Home and Community Care Ireland}

The $\mathrm{HCCl}$ is the representative membership organisation for companies that provide home support in Ireland. For the purpose of informing this analysis, the $\mathrm{HCCl}$ surveyed its home-care organisation members on activity and revenue from privately purchased clients in 2019. Members provided information to the $\mathrm{HCCl}$ on the total number of privately purchasing clients seen, total number of hours provided to private clients, total revenue from private clients, and average pay for a healthcare assistant. Overall, 60 per cent of members, representing 90 per of turnover, responded to the survey. These data were used to estimate the average 
number of home support hours provided to privately purchasing recipients and the average cost of an hour of privately purchased home support.

\section{The Irish Longitudinal Study on Ageing}

Data from TILDA waves 2-4 (collected in 2012-2016) were used to examine who receives public and private home support and how the quantity of care received varies with recipients' age and sex profiles. In the TILDA self-completion questionnaire, the following questions are used to create an indicator variable denoting receipt of home support. For public home support, respondents were asked:

'In the last 12 months, did you receive any of the following State services?'

- Home help (a person employed by State to help you with household chores such as cleaning and cooking)

- Personal care attendant (a person employed by the State to assist [you/him/her] with bathing, showering, bodily care etc.)

- Home Care Package.

Information on average hours for public home support recipients was also taken from the TILDA survey.

For private home support, respondents were asked:

'In the last 12 months, did you pay any individual or private company to provide home help or personal care?'

\subsubsection{Methods}

The methods used in this analysis extend those used in Walsh and Lyons (2021). A more detailed discussion of methods can be found in this previous report (Chapter 4).

\section{Public home support}

Activity (Hours): The distribution of activity by age and sex from TILDA was used to disaggregate HSE data on total number of public home support recipients and hours and iHCP recipients and hours. A similar approach was used for numbers for public home support waiting lists.

TILDA data were also used to estimate baseline average home support hours used by those reporting a difficulty with an Activity of Daily Living (d-ADL) or not. In our 
central and high-pressure scenarios, in line with Walsh and Lyons (2021) and the HSE 2020/21 Winter Plan, 20 per cent and 10 per cent additional hours were apportioned to recipients with and without a d-ADL, respectively.

Expenditure: The average cost of a public home support hour provided by the HSE was assumed to be applicable to all public home support and to iHCP recipient hours. The HSE estimates that 57 per cent of public home support hours are provided by non-HSE carers, and 43 per cent by HSE carers. While the cost of a public home support hour takes this split into account, in order to estimate pay and non-pay costs different ratios were adopted according to whether the hours were provided by HSE or non-HSE carers. The pay:non-pay ratio for HSE-provided hours was estimating using the pay:non-pay breakdown for Healthcare Support Assistants (formally home helps) estimated in Smith et al. (2021). The pay:non-pay ratio for non-HSE-provided hours was estimating using the pay:non-pay breakdown estimated in the $\mathrm{HCCl}$ survey of its members. An average pay:non-pay ratio for a public home support was estimated using an assumed 43:57 HSE:nonHSE carer provision split.

\section{Private home support}

Activity (Hours): TILDA data were used to estimate the number of privately purchased home support recipients by sex and age. The average number of hours that the $\mathrm{HCCl}$ survey indicated was provided to those with privately purchased home support was assumed to apply to all private home support recipients. The group indicated by TILDA data to be in receipt of both public and private home support were assumed to receive the average hours from the $\mathrm{HCCl}$ survey in addition to their public home support hours.

Expenditure: The average cost of a privately purchased home support hour was estimated in the $\mathrm{HCCl}$ survey of its members by dividing the total number of hours provided by total revenue. The pay:non-pay ratio was estimating using the pay:non-pay breakdown estimated in the $\mathrm{HCCl}$ survey.

\section{Expenditure projections}

Base-year and projected age and sex-specific expenditure volumes were generated by combining age- and sex-specific utilisation profiles with unit-cost profiles. As for other services included in this report, the expenditure projections are decomposed into their constituent drivers. 


\section{Projection scenarios}

The projection scenarios used in this chapter are presented in Table 8.1. Under the low-pressure scenario, demand for home support evolves in line with the low population growth scenario, combined with compression of morbidity. The lowpressure scenario assumes no increases in home support due to substitution from other services and no additional hours per recipient. This scenario broadly reflects continuance of the service arrangements in the 2019 base year and does not include any of the likely effects of introducing a statutory home support scheme.

Under the central scenario, demand for home support evolves in line with the central population growth scenario, combined with compression of morbidity. The central scenario also includes adjustments to reflect changes to home support provision that occurred following the HSE 2020/21 Winter Plan and some likely effects of the establishment of a statutory home support scheme. In this scenario, unmet demand is assumed to be met through increased service provision following a brief transition period. Those on waiting lists are assumed to receive support based on the average utilisation currently provided to recipients with the same age and sex profiles. Waiting lists are assumed to be fully cleared from 2023. This scenario also assumes that some services are substituted from LTRC to home support. Previous research has found that 8 per cent of home support recipients enter LTRC in a 12-month period (Aspell et al., 2019). Following the approach of Walsh and Lyons (2021), we assume that this rate is halved to 4 per cent per annum following the introduction of a statutory home support scheme. These individuals are assumed to receive 52 home support hours weekly, the average number of (public and private) weekly home support hours used by iHCP recipients (Walsh and Lyons, 2021). The age and sex profile of NHSS residents (see Chapter 7) is applied to those substituting into home support. This substitution is also included fully from $2023 .{ }^{47}$

Under the high-pressure scenario, demand for home support is assumed to evolve in line with the central population growth scenario, combined with dynamic equilibrium. The scenario also assumes that, as a result of the establishment of a statutory home support scheme, realised demand would increase due to additional demand being expressed by those living with a d-ADL in the community who are not in receipt of home support under the status quo scheme. Using information from TILDA, the rate of home support demand among those with a d$A D L$ is assumed to increase by 50 per cent. ${ }^{48}$ Many of these recipients may also be in receipt of unpaid care. Therefore, this may be interpreted as allowing for some

$47 \quad$ This scenario is the antithesis to the low-pressure LTRC scenario in Chapter 7.

48 For example, if 10 per cent of TILDA respondents with a d-ADL report being in receipt of home support, we assume that this increases to 15 per cent under the high-pressure scenario. As discussed in Walsh and Lyons (2021), this may represent an underestimate of actual demand that occurs from those in the community once a statutory scheme is established as it does not take into account potential increases in demand from those with no d-ADL. 
substitution of paid professional care for unpaid care (at least partially) in the context where home support is placed on a statutory footing. This substitution is included fully from 2023. Once more, these new recipients are assumed to have the same age and sex distribution as our baseline home support population and are apportioned the average number of hours provided to d-ADL recipients in the central scenario.

Across all scenarios, pay and non-pay costs are assumed to increase at the same rates in line with other services examined in this report. Under the central scenario, pay and non-pay components are projected to increase by $2.5 \%$ per annum; under the low-pressure scenario, by $2.2 \%$ per annum, and under the high-pressure scenario by $3.5 \%$ per annum.

TABLE 8.1 Projection scenario assumptions

\begin{tabular}{|c|c|c|c|}
\hline & Low pressure & Central & High pressure \\
\hline \multicolumn{4}{|l|}{ Demand assumptions } \\
\hline $\begin{array}{l}\text { Population growth and } \\
\text { ageing }\end{array}$ & Low & Central & Central \\
\hline Healthy ageing & Compression of Morbidity & Compression of Morbidity & Dynamic Equilibrium \\
\hline Unmet demand & No & Yes & Yes \\
\hline Substitution from LTRCa & No & Yes & Yes \\
\hline $\begin{array}{l}\text { Substitution from } \\
\text { unpaid home support }\end{array}$ & No & No & Yes \\
\hline \multicolumn{4}{|l|}{ Cost assumptions } \\
\hline Pay & $\begin{array}{c}\text { COSMO Downside - } \\
\text { projected government- } \\
\text { sector wage growth }(2.2 \% \\
\text { p.a.) }\end{array}$ & $\begin{array}{c}\text { COSMO Upside - } \\
\text { projected government-sector } \\
\text { wage growth ( } 2.5 \% \text { p.a. })\end{array}$ & $\begin{array}{c}\text { COSMO Upside - } \\
\text { projected government-sector } \\
\text { wage growth }+1 \text { pct point p.a. } \\
(3.5 \% \text { p.a. })\end{array}$ \\
\hline Non-pay & $2.2 \%$ per annum & $2.5 \%$ per annum & $3.5 \%$ per annum \\
\hline $\begin{array}{l}\text { a Following Aspe } \\
\text { LTRC in a given } \\
\text { b This assumes t }\end{array}$ & $\begin{array}{l}\text { al. (2019) and Walsh and Lyons } \\
\text { ar reduces from } 8 \text { per cent to } 4 \\
\text { those with a d-ADL in the comr }\end{array}$ & $\begin{array}{l}\text { 21), we assume that the percentag } \\
\text { cent once the statutory home sup } \\
\text { ity are in receipt of unpaid home }\end{array}$ & $\begin{array}{l}\text { of home supports recipients entering } \\
\text { ort scheme is established. } \\
\text { oport. }\end{array}$ \\
\hline
\end{tabular}

\subsection{FINDINGS - BASELINE ANALYSIS}

Table 8.2 provides details on baseline numbers of home support recipients, hours, unit costs and expenditures for publicly and privately financed home support. Overall, in 2019 , there were over 64,000 home support recipients, with $24.5 \mathrm{~m}$ hours provided to these recipients. Over 24 per cent of home support hours were estimated to be privately purchased. The total expenditure on home support in 2019 was $€ 615.8 \mathrm{~m}$, with $€ 455.9 \mathrm{~m}$ (74\% of total home support expenditure) funded by the State.

At the end of 2019, there were 5,436 people on waiting lists for receipt of any home support. A further 2,473 current recipients were waiting for additional support hours at the end of 2019. In the central and high-pressure scenarios, we assume that this unmet demand is addressed by providing extra services and that the number of hours provided to current recipients would increase. Using information 
from Aspell et al. (2019), halving the percentage leaving home support to enter LTRC from 8 per cent to 4 per cent would increase the number of home support recipients by 2,147 in the base year. Finally, assuming an increase in demand from people with $\mathrm{d}$-ADLs in the community by 50 per cent implies provision of service to 11,590 additional home support recipients in the base year. We include these additional recipients fully from 2023 in our high-pressure scenario.

TABLE 8.2 Home support use and unit costs by category of bed and funding, 2019: aged 65+

\begin{tabular}{|c|c|c|c|c|c|}
\hline \multirow{2}{*}{ Category } & Recipients & Hours & Unit cost & Pay:non-pay & Expenditure \\
\hline & $\mathrm{N}$ & $\mathrm{N}$ (million) & $€$ & Ratio & $€ m$ \\
\hline Public home support & 53,417 & 18.200 & 24.67 & $66: 34$ & 447.0 \\
\hline Intensive home care package & 235 & 0.360 & 24.67 & $66: 34$ & 8.9 \\
\hline Private home support & $10,615^{a}$ & 5.969 & 26.66 & 49:51 & 159.9 \\
\hline Total & 64,267 & 24.529 & 25.15 & $62: 38$ & 615.8 \\
\hline Home support waiting list & 5,436 & - & - & - & - \\
\hline $\begin{array}{lll}\text { Jotes: } & \text { a } & \text { Some private home } \\
\text { ource: } & & \text { Authors' calculation }\end{array}$ & $\mathrm{SE}$ and $\mathrm{HC}$ & public hom & & & \\
\hline
\end{tabular}

Figure 8.1 shows the age- and sex-specific expenditure on home support in 2019. As expected, there is a pronounced age profile, with much higher home support expenditure among those at older ages. Similar to LTRC, but not as stark, there are differing levels of expenditure for males and females. Females have higher expenditure on home support overall. At younger ages, patterns of expenditure per capita are similar for males and females. However, from age 80, a clear divergence develops, with higher home support expenditures for females compared to males. These contrasting utilisation patterns in per capita expenditure are likely due to higher life expectancy among females, with more older men than women being cared for by their spouse. 
FIGURE 8.1 Home support - age- and sex-specific expenditure and expenditure per capita, 2019: aged 65+

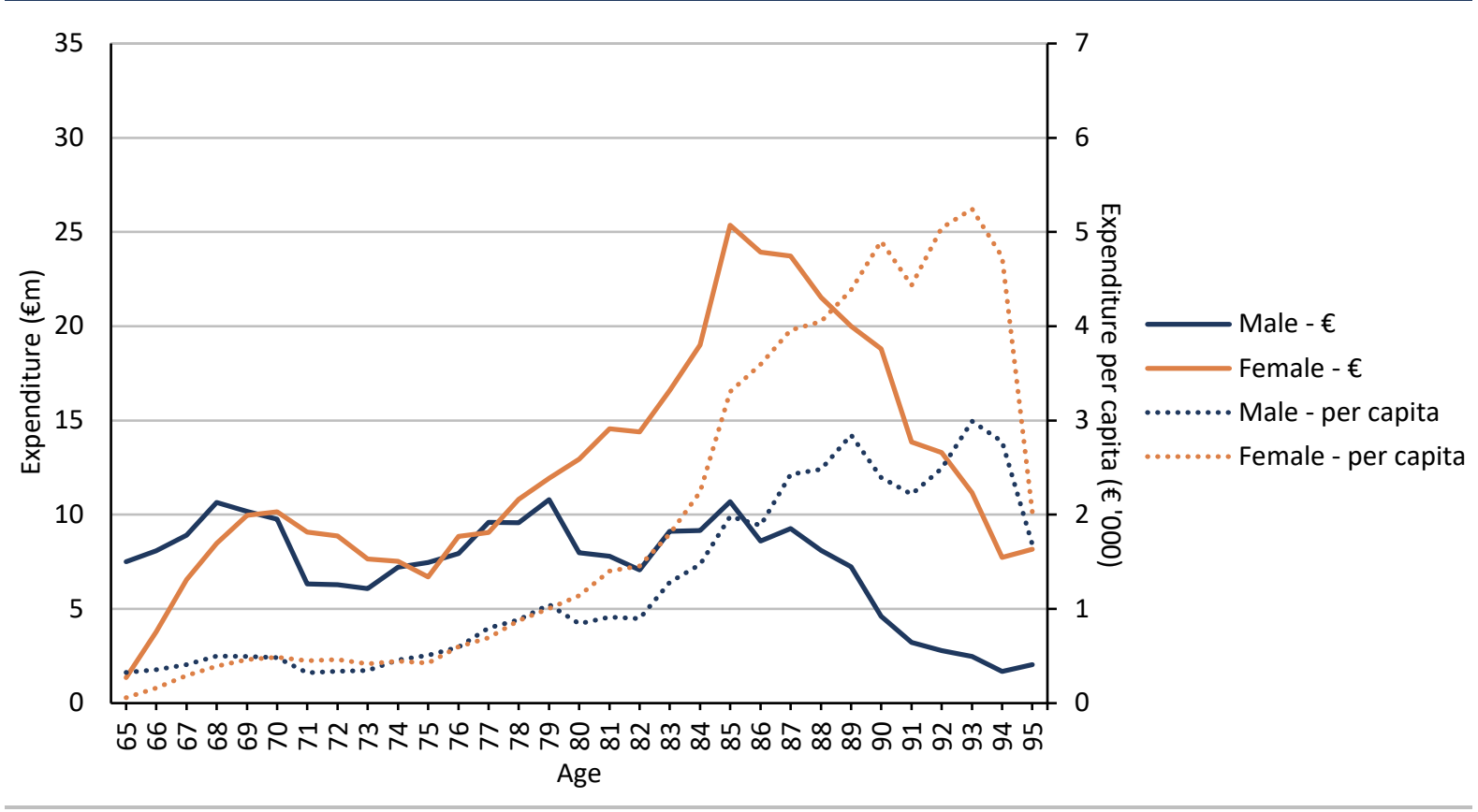

Notes: Includes public home support, iHCPs and private home support.

Source: Authors' calculations - based on HSE and HCCl data.

\subsection{FINDINGS - EXPENDITURE PROJECTIONS}

Table 8.3 presents the projected increase in home support expenditure between 2019 and 2035 in real and nominal terms for the low-pressure, central and highpressure scenarios.

Between 2019 and 2035, real home support expenditure requirements are projected to grow by between 40 and 179.8 per cent. In 2035, additional expenditure required in real terms on home support is projected to be between $€ 863.6 \mathrm{~m}$ and $€ 1,726.6 \mathrm{~m}$. This represents an average annual increase of between 2.1 and 6.6 per cent from 2019. The rates of increase are projected to be similar for males and females.

Projected nominal expenditure growth is affected by assumed changes in both demand and cost drivers. Nominal expenditure on home support is projected to grow by between 97.3 and 382.8 per cent between 2019 and 2035. In 2035, expenditure required in nominal terms on home support is projected to be between $€ 1,217.2 \mathrm{~m}$ and $€ 2,978.8 \mathrm{~m}$. This represents an average annual increase of between 4.4 and 10.4 per cent. The higher expenditure figure for home support in 2035 reflects a scenario in which a new statutory home support scheme reduces the use of LTRC and increases the number of people with a d-ADL (and implicitly reduces the burden on unpaid carers) receiving home support. 
TABLE 8.3 Home support - projected real and nominal expenditure growth by projection scenario, 2019-2035: aged $65+$

\begin{tabular}{|c|c|c|c|c|c|c|c|c|c|}
\hline & & \multicolumn{2}{|c|}{2019} & \multicolumn{6}{|c|}{ Projected HCE growth (\%) 2019-2035 } \\
\hline & & \multirow{2}{*}{$\begin{array}{c}\text { Hours } \\
\mathrm{N} \text { (million) }\end{array}$} & \multirow{2}{*}{$\begin{array}{c}\text { Expenditure } \\
€ m\end{array}$} & \multicolumn{3}{|c|}{ Reala } & \multicolumn{3}{|c|}{ Nominal } \\
\hline & & & & Low & Central & High & Low & Central & High \\
\hline \multirow{6}{*}{$\begin{array}{l}\text { Home } \\
\text { Support } \\
\text { (all) }\end{array}$} & Male & 9.1 & 228.3 & 40.2 & 113.3 & 198.6 & 98.7 & 216.8 & 418.0 \\
\hline & Female & 15.4 & 387.5 & 39.8 & 112.7 & 168.7 & 97.0 & 214.2 & 363.5 \\
\hline & Total & 24.5 & 615.8 & 40.0 & 113.0 & 179.8 & 97.3 & 214.6 & 382.8 \\
\hline & & & & \multicolumn{6}{|c|}{ Projected average HCE annual growth (\%) 2019-2035 } \\
\hline & & & & \multicolumn{3}{|c|}{ Real $^{\mathrm{a}}$} & \multicolumn{3}{|c|}{ Nominal } \\
\hline & & & & Low & Central & High & Low & Central & High \\
\hline \multirow{3}{*}{$\begin{array}{l}\text { Home } \\
\text { Support } \\
\text { (all) }\end{array}$} & Male & & & 2.1 & 4.8 & 7.1 & 4.4 & 7.5 & 10.8 \\
\hline & Female & & & 2.1 & 4.8 & 6.4 & 4.4 & 7.5 & 10.1 \\
\hline & Total & & & 2.1 & 4.8 & 6.6 & 4.4 & 7.5 & 10.4 \\
\hline lotes: & $\begin{array}{l}\text { Includes } \\
\text { Real pro }\end{array}$ & $\begin{array}{l}\text { lic home sup } \\
\text { ions hold bas }\end{array}$ & $\begin{array}{l}\mathrm{rt} \text {, iHCPs and } \mathrm{p} \\
\text { osts constant a }\end{array}$ & e hom & $\begin{array}{l}\text { port. } \\
\text { les. }\end{array}$ & & & & \\
\hline
\end{tabular}

Figure 8.2 takes a closer look at the relative contribution of demand and cost drivers by decomposing nominal expenditure projections for each scenario. Under all scenarios, changes in pay and non-pay-related costs are the most important driver of projected growth in home support expenditure. Across all scenarios, increases in costs contribute between 47.7 per cent and 59.3 per cent of projected expenditure growth. However, substitution and unmet demand are also important drivers of expenditure growth in the central and high-pressure scenarios. This reflects assumptions about the effects of introducing a statutory home support scheme. Depending on the realised demand for the scheme, the substitution/unmet demand driver equates to an additional $€ 450.7 \mathrm{~m}$ in the central scenario and $€ 778.8 \mathrm{~m}$ in the high-pressure scenario. 
FIGURE 8.2 Home support - decomposition of projected nominal expenditure growth, 2019-2035, by projection scenario: aged 65+

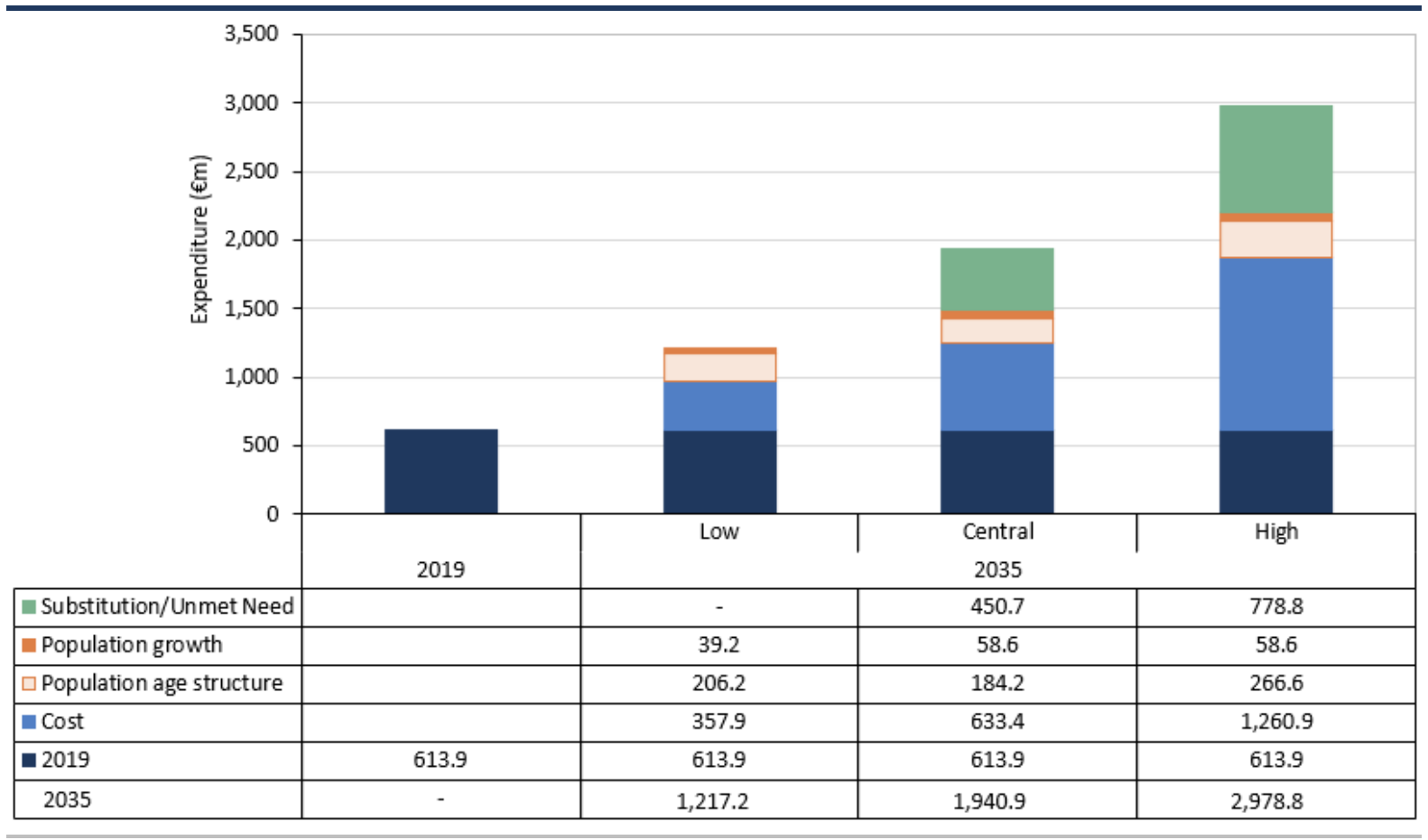

Notes: Includes public home support, iHCPs and private home support.

Source: Authors' calculations - based on HSE and HCCl data.

Figure 8.3 illustrates baseline and projected expenditures by age in 2035. Growth in expenditure over the period 2019 to 2035 is likely to take place predominantly at the older end of the age distribution, driven by population ageing. There are very large differences in expenditure across the scenarios. Some of this difference is due to the high-pressure scenario assuming a more pessimistic healthy ageing affect than the central and low-pressure scenarios. However, as shown in Figure 8.3, much of the difference is a result of the assumption that many people will substitute formal home support for unpaid care once a statutory scheme is introduced. 
FIGURE 8.3 Home support - expenditure by age and projection scenario, 2019 and projected 2035 (nominal): aged $65+$

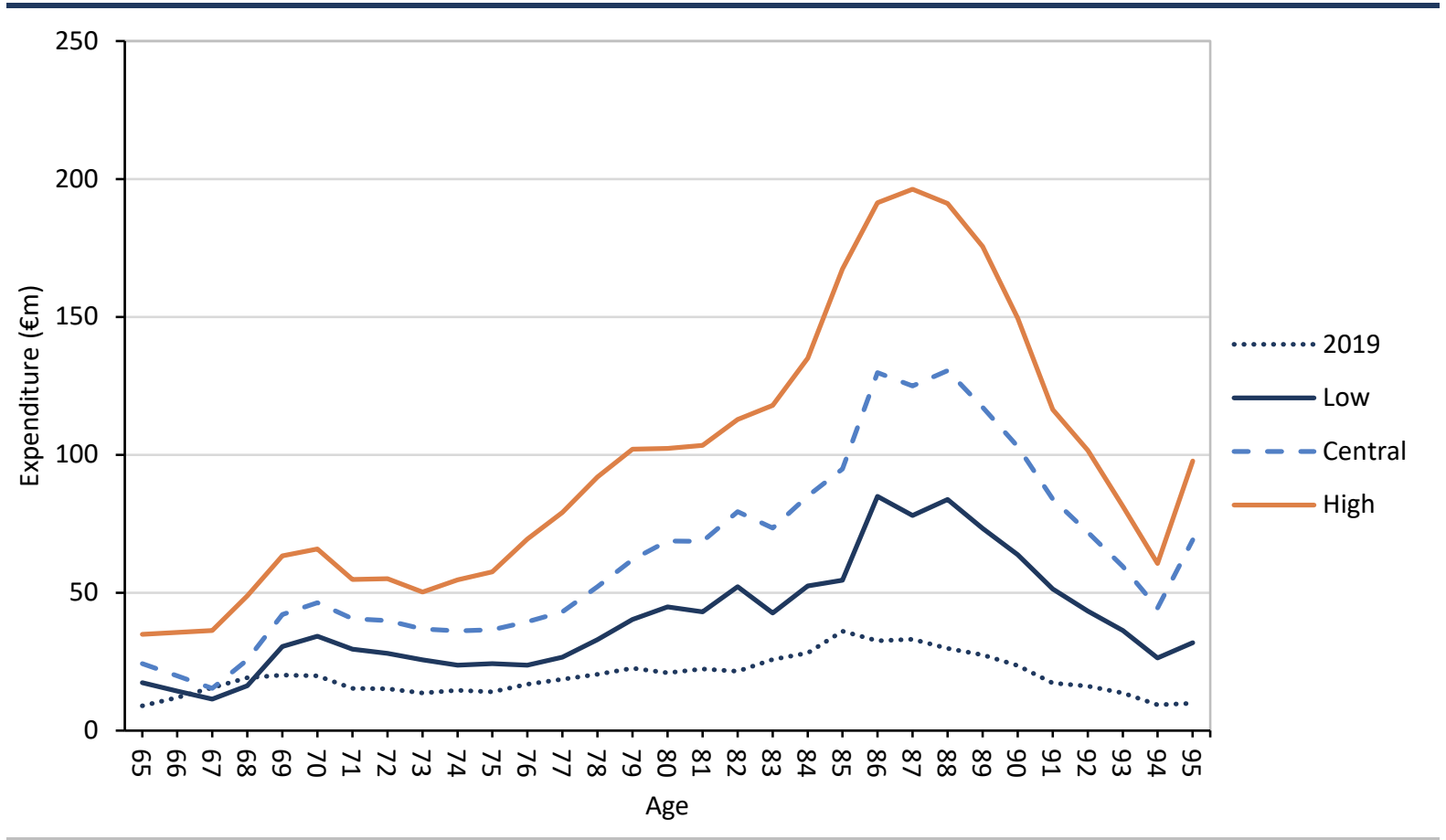

Notes: Includes public home support, iHCPs and private home support.

Source: Authors' calculations - based on HSE and HCCl data.

\subsection{SUMMARY}

This chapter presented projections of expenditure for publicly funded and privately purchased home support to $\mathbf{2 0 3 5}$ for three scenarios: low-pressure, central and high-pressure. Increases in expenditure between 2019 and 2035 are projected at between 40 per cent and 179.8 per cent in real terms and 97.3 per cent and 383.8 per cent in nominal terms. Converted to average annual increases, this equates to between 2.1 per cent and 6.6 per cent in real terms and 4.4 per cent and 10.4 per cent in nominal terms per annum.

The projected percentage increases in home support expenditure are the largest across all services examined in this report. One reason for this is that home support is used predominantly by older people (the median age of home support recipient in 2019 was 83 years), so population ageing has a disproportionate effect on these services. However, the main reason for relatively high projected increases in home support expenditures are that we explore the possibility that significant increases in demand might arise when a statutory home support scheme is established. The scenarios for possible increases in demand match those outlined in Walsh and Lyons (2021). People substituting to home support services from LTRC and from unpaid home support are assumed to be the main drivers of increases in demand from a new statutory home support scheme. The increase in demand from such substitution is projected to add between $€ 450.7 \mathrm{~m}$ and $€ 778.8 \mathrm{~m}$ to home support expenditure in 2035. 
Under the assumption that a statutory home support scheme will be fully operational in 2023, and following substitution assumptions made in previous analysis (Walsh and Lyons, 2021), we examined the impact of halving the number of people leaving home support to enter LTRC. This substitution analysis was incorporated in the LTRC low-pressure scenario. We estimate that this substitution can reduce the growth in LTRC costs by over 15 percentage points ( $€ 346.8 \mathrm{~m}$ ) by 2035. Further analysis will be required to estimate a more accurate substitution effect between LTRC and home support, and to what extent some LTRC residents will substitute away from long-stay towards short-stay care in addition to home support.

Similarly to when discussing LTRC, it needs to be emphasised that the expenditure projections in this report are based on a pre-Covid-19 year, 2019. However, in our scenarios we have incorporated some aspects of the increases in home support supply and expenditure from the State due to the pandemic. For example, the HSE 2020/21 Winter Plan increased the supply of home support by up to 20 per cent in 2021. We have incorporated this increase in our central scenario. The Winter Plan also included increased reablement provisions to help reduce the number of people requiring LTRC. Here too we captured this effect in our assumptions about substitution from LTRC.

A number of data limitations reduced the scope of this research. The HSE administrative data do not split home support or iHCP recipients by age and sex. To work around this data gap, TILDA data were used to impose demographic profiles in line with Wren et al. (2017) and Walsh and Lyons (2021). However, as a robustness check, we compared the age and sex profiles from TILDA with information from a small number of LHOs and Aspell et al. (2019). A similar profile was found across all three sources. Similarly, no age or sex breakdown is available for privately purchased home support, with TILDA once more used in lieu of this information. The introduction of the interRAl single assessment tool for assessing home support and LTRC need will allow for greater understanding of home support recipients and their needs in the future, and it should allow more accurate substitution estimates to be calculated. 


\section{CHAPTER 9}

\section{Summary and Discussion}

\subsection{INTRODUCTION}

This report builds on previous applications of the Hippocrates Model (Wren et al., 2017; Keegan et al., 2018; Keegan et al., 2020) to provide baseline estimates of expenditure for primary, community and long-term care in Ireland in 2019 and to project expenditures for these services to 2035. The analysis encompasses expenditure projections for most of the publicly funded primary, community and long-term care services in Ireland. The services examined account for a substantial amount of care in Ireland (Wren et al., 2017), involve a sizeable proportion of the frontline health and social care workforce (Smith et al., 2019), and a high proportion of the total health and social care budget (Wren and Fitzpatrick, 2020).

The base year for analysis in this report is 2019. Some effects of the Covid-19 pandemic of 2020 and 2021 are taken into account when preparing our projection scenarios. For instance, demographic and macroeconomic projections were updated and revised in light of the ongoing impact of Covid-19. However, the broad development of demographic and non-demographic drivers of health and social care demand and expenditure in this report closely resemble those incorporated in Keegan et al. (2020).

Early evidence has shown that the pandemic reduced demand for some services (Brick et al., 2020c) and changed the mode for receiving care for others (i.e. telemedicine became more important within general practice) (Homeniuk and Collins, 2021). Many healthcare staff were redeployed to other roles, for example to Covid-19 testing and contact tracing, further reducing the availability of some services. In addition, the Covid-19 pandemic led to an acceleration of the redirection of resources from acute hospital and residential care settings towards delivery in the community and in people's homes. This is most clearly seen in the HSE's 2020/21 Winter Plan and the planned establishment of the statutory home support scheme. In this report, to account for changes to models of care in longterm care that were initiated or affected by the Covid-19 pandemic, additional modelling scenarios were incorporated. These examine the expenditure implications of the proposed statutory home support scheme on demand for and expenditure on home support and LTRC.

To allow for the uncertainty that surrounds likely trends in the drivers of health and social care demand and expenditure, a range of expenditure projection scenarios were developed in this report. For each service examined, three alternative expenditure projection scenarios were included: low-pressure, central 
and high-pressure. The assumptions underpinning each scenario were servicespecific. Where feasible, the scenarios varied assumptions related to population growth and ageing, healthy ageing, unmet demand, cost drivers and changes to models of care. However, it is important to reiterate that findings from this report are expenditure projections, not forecasts. In the short term, uncertainty surrounding Covid-19 and other unanticipated shocks may affect demand and expenditure from year to year. In addition, spending decisions, budgetary constraints and changes in government policy surrounding models of care will affect the trajectory of health and social care expenditures. However, informed by the anticipated evolution of key drivers of expenditures, this approach to modelling healthcare expenditures is considered to provide a reasonably reliable guide to the medium-term future (Charlesworth and Johnson, 2018).

\subsection{SUMMARY AND DISCUSSION OF FINDINGS ON BASELINE AND PROJECTED ACUTE EXPENDITURE BY SERVICE}

\subsubsection{Baseline expenditure, 2019}

Table 9.1 summarises the report's findings for baseline and projected expenditure for each health and social care service examined in Chapters 4 to 8. Table 9.2 summarises nominal and real average annual expenditure growth rates for services examined in this report. Where appropriate, separate estimates are provided for publicly and privately financed services. The baseline expenditure findings are the most comprehensive developed to date for primary, community and long-term care services in Ireland. For example, this is the first time that overall, and age- and sex-specific, expenditures on long-term care (LTRC and home support) have been estimated for Ireland. The long-term care demand and expenditure profiles developed have in turn formed the foundation for a recent Department of Health submission, for the first time, of Irish age-cost profiles to the European Commission to inform their Ageing Reports. Below we discuss the main findings on baseline expenditure.

General practice: In 2019, we estimate general practice expenditure was $€ 1,009.6 \mathrm{~m}$. Expenditure on Medical Card and GPVC holders accounted for $€ 556.3 \mathrm{~m}$. The majority of general practice expenditure, €875.5m (87\%), was spent on care delivered by a GP. Ancillary expenditure contributed an additional $€ 32.4 \mathrm{~m}$.

Public health nursing and primary care community therapy services: In 2019, we estimate that expenditure on PHN was $€ 269 \mathrm{~m}$. Estimated expenditure on community-based occupational therapy, physiotherapy, and speech and language therapy provided through HSE Primary Care services was $€ 51 \mathrm{~m}, € 54 \mathrm{~m}$ and $€ 50 \mathrm{~m}$ respectively. 
Community pharmaceuticals: In 2019, we estimate expenditure on all publicly funded community pharmaceutical items to be $€ 2,265 \mathrm{~m}$. Items dispensed to individuals on the GMS scheme accounted for $€ 951 \mathrm{~m}$ (42\% of total expenditure), with items dispensed to individuals via the HT scheme accounting for $€ 850 \mathrm{~m}$ (39.5\% of total expenditure). The average cost per HT scheme prescription item was $€ 1,025$.

Long-term residential care: In 2019, we estimate expenditure on LTRC to be $€ 1,957 \mathrm{~m}$, across almost 32,000 residents. We estimate that 4.3 per cent of all individuals aged 65 years and older in 2019 were in LTRC. The NHSS accounted for the largest category of LTRC expenditure, at $€ 1,422 \mathrm{~m}$. Overall, across the NHSS and publicly financed short-stay beds, the State contributed $€ 1,322 \mathrm{~m}(68 \%)$ of total LTRC expenditure.

Home support: In 2019, we estimate expenditure on home support to be $€ 616 \mathrm{~m}$, across over 64,000 recipients. We estimate that over 9 per cent of all individuals aged 65 years and older in 2019 were home support recipients. The State contributed $€ 456 \mathrm{~m}$ (74\%) of total home support expenditure.

\subsubsection{Projected expenditure, 2019-2035}

Expenditure is projected to increase across almost all health and social care services shown in Table 9.1 and Table 9.2. ${ }^{49}$ Overall, the size of projected increases estimated is large, yet the increases differ substantially across the services examined. Projected increases in the cost of care delivery, specifically related to pay, are estimated to be the main driver of health and social care expenditure for most of the services examined. However, for long-term care, increases in the older population and the introduction of a statutory home support scheme are found to be key drivers of projected long-term care expenditure growth. The largest increases in real expenditures (which removes the effects of cost increases) are observed for community pharmaceuticals (HT scheme), LTRC and home support.

General practice: Between 2019 and 2035, real expenditure (including ancillary expenditure) is projected to increase by between 14 and 18 per cent for general practice. This equates to a 0.8 to 1.1 per cent average annual increase in expenditure. This implies projected real 2035 expenditure requirements of $€ 1,174 \mathrm{~m}$ to $€ 1,214 \mathrm{~m}$. Given the high utilisation rates of general practice services across all age-groups (not just the older age groups), general practice expenditure growth is less affected than other services by population ageing. Consequently,

49 However, some projected expenditure reductions were reported for community-based speech and language therapy and some community pharmaceutical schemes. 
general practice expenditure is projected to grow by less than many other services examined in this report, and less than most acute services in Keegan et al. (2020).

In nominal terms, changes to pay and non-pay-related costs are the main drivers of general practice expenditure growth. Decomposition analysis shows in the central scenario that, between 2019 and 2035, increases in pay contribute 52 per cent to projected expenditure growth, and increases in non-pay contribute 26 per cent expenditure growth. Population growth and ageing contribute only a small percentage of the projected expenditure increases.

Public health nursing and primary care community therapy services: Between 2019 and 2035, real expenditure is projected to increase by between 42 and 47 per cent for PHN, 38 and 42 per cent for occupational therapy, and 27 and 30 per cent for physiotherapy. Due in particular to the concentration of current service provision in the youngest age cohorts, a decrease of between 4.5 and 10.3 per cent for speech and language therapy is estimated. Estimated annually, this equates to a 0.7 and 0.3 per cent average annual decrease in expenditure for speech and language therapy and an increase of between 1.5 and 2.4 per cent for the other services considered. This implies projected real 2035 expenditure requirements of $€ 383 \mathrm{~m}$ to $€ 396 \mathrm{~m}$ for PHN, €72m to $€ 74 \mathrm{~m}$ for occupational therapy, $€ 68 \mathrm{~m}$ to $€ 70 \mathrm{~m}$ for physiotherapy, and $€ 45 \mathrm{~m}$ to $€ 48 \mathrm{~m}$ for speech and language therapy.

In nominal terms, changes to pay-related costs and the population age structure are the main drivers of expenditure growth for these services. For example, decomposition analysis for PHN shows in the central scenario that, between 2019 and 2035, increases in pay contribute approximately half of the projected expenditure growth, and changes to the population age structure contribute 33 per cent expenditure growth.

Due to substantive data limitations for these services, we were unable to incorporate assumptions on healthy ageing, waiting-list management, or models of care change. This, in addition to the inability to generate comprehensive baseline utilisation profiles, overall may lead to an underestimate of future expenditure requirements for these services.

Community pharmaceuticals: Between 2019 and 2035, real expenditure is projected to increase by between 42 and 86 per cent for community pharmaceuticals. Estimated annually, this equates to a 2.2 to 4.0 per cent average annual increase in expenditure. This implies projected real 2035 expenditure requirements of $€ 3,204 \mathrm{~m}$ to $€ 4,220 \mathrm{~m}$. 
The overall projected increases in community pharmaceutical expenditure are largely due to increases projected under the HT scheme. This reflects an assumed continuation of historical growth in use of high-tech medicines that far exceeds the impact of demographic change. The HT scheme is also dominated by on-patent drugs which tend to be highly expensive and have resulted in large year-on-year growth in the unit cost of HT prescription items. In contrast, unit costs per prescription item under the GMS, DP and LTI schemes have been static or declining in recent years due to initiatives such as reference pricing and generic substitution, negotiated pricing agreements with industry, and the large share of off-patent drugs.

In nominal terms, the projected growth in cost contributes substantially to projected expenditure growth for HT drugs, more so than for other schemes. For example, cost growth accounts for 27 per cent (high-pressure) to 45 per cent (lowpressure) of projected expenditure growth across scenarios. However, decomposition analysis shows that additional modelled demand is projected to be the dominant driver of expenditure growth for HT drugs. Under the high-pressure scenario for example, additional modelled demand is projected to account for 60 per cent of projected expenditure growth by 2035. Changes to the population age structure is the largest driver of expenditure growth for the GMS, DP and LTI schemes.

Long-term residential care: Between 2019 and 2035, real expenditure is projected to increase by between 38 and 66 per cent for LTRC. This equates to a 2.0 to 3.3 per cent average annual increase in expenditure. This implies projected real 2035 expenditure requirements of $€ 2,696 \mathrm{~m}$ to $€ 3,326 \mathrm{~m}$. The projected growth in LTRC expenditure is slightly higher for males than females due to relatively better life expectancy improvements projected for males. These expenditure increases are inclusive of relatively optimistic healthy ageing assumptions.

Cost growth is the main driver of LTRC expenditure growth, accounting for 59 to 66 per cent of expenditure growth between 2019 and 2035. Across scenarios, the increasing cost of delivering a LTRC bed is projected to contribute between 59 and 66 per cent to the total projected expenditure increase by 2035 . That cost increases contribute up to two-thirds of projected expenditure increases may be surprising given that LTRC services are used mainly by the older population, which is expected to grow substantially in the coming years. However, this increase in the older population will also be a key contributor to expenditure growth. Decomposition analysis shows that the population age structure contributes between 29 and 46 per cent to LTRC expenditure growth by 2035. 
In this analysis, we modelled the potential impact of introducing a statutory home support scheme that substitutes home support for LTRC based on assumptions made in a previous analysis (Walsh and Lyons, 2021). The impact of our substitution is relatively small. We estimate that LTRC expenditure growth would be 16 per cent higher in the absence of this home support substitution. Accounting for unmet demand increases, projected LTRC expenditure in 2035 would be 3 per cent higher were NHSS waiting lists eradicated.

Home support: Between 2019 and 2035, real expenditure is projected to increase by between 40 and 180 per cent for home support. This equates to a 2.1 to 6.6 per cent average annual increase in expenditure. This implies projected real 2035 expenditure requirements of $€ 1,217 \mathrm{~m}$ to $€ 2,979 \mathrm{~m}$. The projected growth in home support expenditure is similar for males and females. These expenditure increases are inclusive of relatively optimistic healthy ageing assumptions. The higher expenditure figure of almost $€ 3 \mathrm{bn}$ for home support in 2035 follows the assumed introduction of a statutory home support scheme that reduces the use of LTRC and increases the number of people with a d-ADL receiving home support. However, this estimated expenditure figure may be reduced slightly if co-payments were to be introduced as part of the financing model for the statutory scheme and demand were to be dampened as a consequence. Research at the ESRI is currently examining the impact of co-payments and eligibility on the potential cost of a statutory home support scheme.

In nominal terms, the projected growth in cost contributes substantially to projected expenditure growth on home support. Cost growth is the main driver of home support expenditure growth, accounting for 48 to 59 per cent of expenditure growth between 2019 and 2035. Similar to LTRC, that cost increases contribute up to two-thirds of projected expenditure increases may be surprising due to home support services being used mainly by the older population, which is expected to grow substantially in the coming years. However, this increase in the older population will also be a key contributor to expenditure growth. Decomposition analysis shows that the population age structure contributes up to 34 per to home support expenditure growth by 2035 . 
TABLE 9.1 Projected real and nominal expenditure growth - 2019 baseline and 2035 low- and high-pressure projections by service

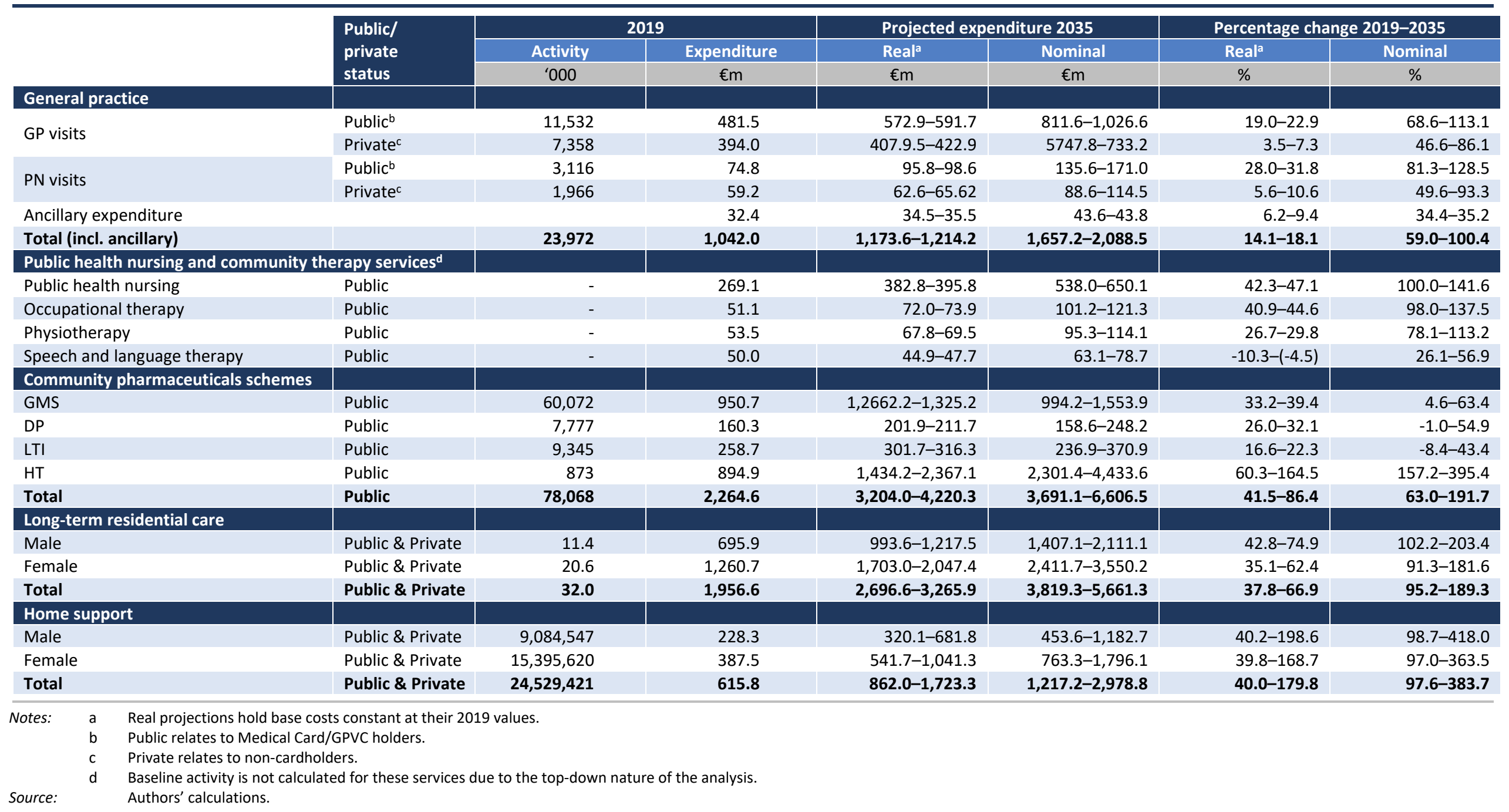




\begin{tabular}{|c|c|c|}
\hline & \multicolumn{2}{|c|}{ Projected average annual expenditure growth 2019-2035 (\%) } \\
\hline & Reala & Nominal \\
\hline & $\%$ & $\%$ \\
\hline General practice & $0.8-1.1$ & $2.9-4.5$ \\
\hline Public health nursing & $2.2-2.4$ & $4.4-5.7$ \\
\hline Occupational therapy & $2.2-2.3$ & $4.4-5.6$ \\
\hline Physiotherapy & $1.5-1.6$ & $3.7-4.8$ \\
\hline Speech and language therapy & $-0.7--0.3$ & $1.5-2.9$ \\
\hline Community pharmaceuticals & $2.2-4.0$ & $3.1-6.9$ \\
\hline Long-term residential care & $2.0-3.3$ & $4.3-6.9$ \\
\hline Home support & $2.1-6.6$ & $4.4-10.4$ \\
\hline $\begin{array}{lll}\text { Notes: } & & \text { Low-high-pressure sc } \\
& \text { a } & \text { Real projections hold } \\
\text { Source: } & & \text { Authors' calculations }\end{array}$ & eir 2019 values. & \\
\hline
\end{tabular}

\section{$9.3 \quad$ SENSITIVITY ANALYSIS}

Table 9.3 presents the projected expenditure in 2035 arising from assuming our central projection scenario for each service, and examines the percentage change in expenditure if key (common) assumptions are altered independently of other assumptions.

This sensitivity analysis shows that sensitivity to population growth assumptions is greatest in general practice, PHN and community-based therapy services, where care is delivered more uniformly across the age distribution. Applying alternative low or high population growth assumptions to these services affects projected expenditure to a greater extent than services where care delivery is more concentrated at older ages (e.g. long-term residential care or home support services). These differential effects arise due to the differences in population projections, in particular future migration, which mostly affect numbers in the younger and middle age cohorts (see Keegan et al. (2020)).

However, the sensitivity analysis also demonstrates that services for which expenditures are more concentrated in older ages (e.g. long-term residential care or home support services) are more sensitive to healthy ageing effects. For example, compared to the central projection scenario for these services (applying the most optimistic compression of morbidity healthy ageing assumption), assuming no healthy ageing effects would increase projected expenditure in 2035 by 24.4 per cent and 18.9 per cent for LTRC and home support, respectively. Due to data constraints, no healthy ageing assumptions were applied to PHN and community-based therapy services.

Table 9.3 also shows that projected expenditures are sensitive to alternative assumptions in relation to trends in cost of care delivery. This is particularly true of the high-pressure scenario cost assumption, which assumes an additional one 
percentage point increase in cost growth per annum relative to the central scenario's Cosmo Upside cost assumption. Under the high-pressure scenario cost assumption, projected expenditure in 2035 is 13.2 per cent, as well as 16.8 per cent higher across all services where pay is modelled (i.e. unit-cost growth for pharmaceuticals dispensed in the community is subject to alternative growth assumptions). 
TABLE 9.3 Sensitivity analysis - effect on projected expenditure for main services of varying common key assumptions

\begin{tabular}{|c|c|c|c|c|c|c|c|c|c|c|c|c|c|}
\hline & & \multicolumn{2}{|c|}{ General practice $^{a}$} & \multicolumn{4}{|c|}{$\begin{array}{l}\text { Public health nursing and } \\
\text { community-based therapy services }{ }^{b, c}\end{array}$} & \multicolumn{4}{|c|}{ Community pharmaceuticals } & \multirow{2}{*}{$\begin{array}{c}\begin{array}{c}\text { Long-term } \\
\text { residential care }\end{array} \\
\text { Total }\end{array}$} & \multirow{2}{*}{$\begin{array}{c}\text { Home support } \\
\text { Total }\end{array}$} \\
\hline & & GP & PN & PHN & OT & PHY & SLT & GMS & DP & LTI & HT & & \\
\hline \multicolumn{2}{|c|}{$\begin{array}{l}\text { Projected } 2035 \text { expenditures based } \\
\text { on central scenario ( } € \text { millions) }\end{array}$} & 1,495 & 240 & 574 & 107 & 101 & 69 & 1,278 & 204 & 305 & 3,215 & 4,391 & 1,941 \\
\hline \multicolumn{2}{|c|}{ Assumption } & \multicolumn{12}{|c|}{ Percentage effect on 2035 expenditure of changing one assumption (\%) } \\
\hline \multirow{2}{*}{ Population } & Low & -2.6 & -1.9 & -3.3 & -2.6 & -2.4 & -6.0 & -0.9 & -0.8 & -1.1 & -1.7 & -0.6 & -0.6 \\
\hline & High & 6.3 & 4.4 & 6.3 & 4.9 & 5.1 & 15.3 & 2.2 & 2.2 & 3.3 & 4.2 & 1.2 & 1.2 \\
\hline \multirow{4}{*}{$\begin{array}{l}\text { Healthy } \\
\text { ageing }\end{array}$} & None & 0.7 & 2.1 & - & - & - & - & 7.4 & 8.0 & 7.3 & 2.3 & 24.4 & 18.9 \\
\hline & MHA & - & - & - & - & - & - & 3.7 & 4.0 & 3.7 & 1.2 & 16.3 & 12.6 \\
\hline & $\mathrm{DE}$ & -0.7 & -2.1 & - & - & - & - & - & - & - & - & 8.1 & 6.3 \\
\hline & $\mathrm{CM}$ & -1.5 & -4.1 & - & - & - & - & -3.7 & -4.0 & -3.7 & -1.2 & - & - \\
\hline \multirow{2}{*}{ Pay } & $\begin{array}{l}\text { COSMO Downside } \\
\text { (2.2\% p.a.) }\end{array}$ & -4.6 & -4.6 & -3.6 & -3.6 & -3.6 & -3.6 & - & - & - & - & -4.6 & -4.6 \\
\hline & $\begin{array}{l}\text { COMSO Upside }+1 \text { pct } \\
\text { point p.a. ( } 3.5 \% \text { p.a.) }\end{array}$ & 16.8 & 16.8 & 13.2 & 13.2 & 13.2 & 13.2 & - & - & - & - & 16.8 & 16.8 \\
\hline
\end{tabular}

Notes: a GP practice expenditure excludes ancillary expenditure.

b Provided through HSE Primary Care services.

c As data limitations necessitated the adoption of an alternative methodology to project expenditure for these services (see Chapter 5), sensitivity estimates are not directly comparable with other community

Source: $\quad$ Authors' calculations. services presented in this table. 


\section{$9.4 \quad$ LIMITATIONS}

The scope of the analysis in this report has been hampered by the poor data infrastructure on primary, community and long-term care in Ireland. While the HIPE dataset provides detailed information on public acute hospital utilisation, there is no equivalent dataset for non-acute services. Consequently, it was necessary to identify and apply for access to a large number of both administrative and survey datasets to undertake the analysis. In some instances, no data were available (or available to the research team) that could meaningfully be used to identify utilisation and unit costs for particular services. The lack of data available on services such as community-based specialist mental health services and community-based specialist disability services also meant we could not examine these services in this report.

Due to the poor activity data captured in administrative datasets for PHN and community therapy services, a different methodological approach had to be adopted for projections of these services. A potential advantage of administrative datasets is that they capture comprehensive information such as the totality of activity and caseload for a particular publicly funded service. However, it was not possible to estimate a meaningful activity metric for PHN or community therapy services to which a unit cost could be applied. Limitations exist for all services examined. No central registry on general practice use exists, while much of the data on long-term care is collected at an aggregated level. Due to some of these limitations, and variations in underlying levels of age aggregation of expenditure profiles, care should be taken when comparing expenditure projections across services, and with acute public hospital expenditure projections in Keegan et al. (2020).

The failure to integrate an IHI and EHR also makes it almost impossible to follow individuals through time and across health and social care services. For example, for many services the same individual receiving care at different points in time will be captured as different episodes. The ability to follow patients across services and through time is not a necessary requirement for the type of component-based projection modelling undertaken in this report. However, this inability to track people across services and through time curtails the ability to understand their overall use of services or to get a picture of the complexity of the patients being treated. Consequently, there is little understanding of how service utilisation is linked to resource use or expenditure on healthcare. Where possible, we supplemented our analysis using survey data. Survey data often have the advantage of collecting information on the demographic profiles of service recipients. 
We included privately financed activity and expenditure for general practice, LTRC and home support. However, a lack of data prevented examination of privately financed/provided therapy and pharmaceutical activity and expenditure. Due to the large role played by private purchasers and private providers of health and social care in Ireland, a lack of knowledge of this care inhibits a true reflection of health and social care expenditure currently. It also makes projections of expenditure for the future difficult and hinders the ability to plan for public healthcare and social care requirements within a universal system where there is potentially a greater provision of publicly financed services.

In the medium term, the development of a modern health information system based on the $\mathrm{IHI}$ that covers both public and private health and social care should be a clear goal for policymakers in Ireland. Some of the benefits of such a system have been outlined recently (Walsh et al., 2021). In the short term, development of a minimum dataset for publicly funded community-based therapy services that captures information on activity, caseload and patient demographics should be a priority for policymakers. This system must be designed to cater for the requirements of both local and national-level service planners. It should allow for accurate day-to-day patient management but should also be able to facilitate detailed future demand projections and workforce planning. In addition, due to the large role played by private providers (e.g. GPs), development of an infrastructure and datasets that capture privately provided activity should also be prioritised.

\subsection{POLICY IMPLICATIONS}

This report provides a number of important analyses and findings on utilisation and costs of primary, community and long-term care hereto unavailable in the Irish context.

The findings highlight that expenditure on most primary care, community care and long-term care services examined are projected to grow substantially by 2035 . The projected growth is particularly evident in community pharmaceuticals and longterm care. The findings also provide an evidence base for planning for workforce and capacity, and for the implementation of some Sláintecare proposals such as the establishment of a new statutory home support scheme. Below we briefly outline some of the potential implications of the findings in relation to the specific services included in this report.

Primary care and community care: Despite primary and community care being at the centre of health and social care in Ireland, the smallest projected increases in expenditure are seen for general practice, PHN and community therapy services. 
This is because these services are less affected by population ageing than other services such as long-term care.

The report findings on primary and community care services are important in the context of Sláintecare. A key component of Sláintecare is the substitution of care, where appropriate, out of hospitals and residential care settings into the community and people's homes. Considerable debate has also occurred about the expansion of free primary and community care to the full population. While this would require large increases in workforce, the expenditure projections may not be insurmountable. Previous research quantifying the potential costs of a universal entitlement to free GP care, a proposal of Sláintecare, would result in an additional cost of approximately $€ 500 \mathrm{~m}$ to the Exchequer (Connolly et al., 2018). In the context of some of the expenditure increases projected in this analysis and by Keegan et al. (2020), if reductions in other services are realised by increased general practice care this additional expenditure is not insurmountable. Previous research has shown that many GPs in Ireland already have a heavy workload (Crosbie et al., 2020), so there is unlikely to be a lot of spare capacity in the existing workforce. Consequently, optimising processes for training, recruitment and retention of GPs is likely to be increasingly important in future. The feasibility of approaches such as enabling ancillary professions to provide assistance with a wider range of activities and innovation in the use of technology could also be explored as ways to help augment the future supply of services.

Some changes towards increasing expenditure on community therapy services have already occurred. As part of Sláintecare's plan to reorientate acute care to community-based settings, a total of $€ 186 \mathrm{~m}$ between 2020 and 2021 was designated to enhance community services (Government of Ireland, 2021). This includes the expansion of the Community Health Networks, Community Intervention Teams and integrated care teams. Moreover, these measures will see over 3,000 staff recruited, with a particular focus on nursing and community therapists such as physiotherapists, occupational therapists and speech and language therapists (Government of Ireland, 2021).

Community pharmaceuticals: In recent years, the unit costs per item prescribed under the GMS, DP and LTI schemes have been static or declining. Assuming similar trends over the medium term, the projected increases in expenditure for these schemes are relatively modest, driven primarily by population growth and ageing. However, based on recent patterns in utilisation and cost growth, large increases in HT scheme expenditure are projected over this period of analysis. Should these patterns continue over the medium term, there is a risk that expenditure on the HT scheme may become unsustainable. There is therefore an urgent need to identify and implement measures aimed at reducing HT scheme expenditure 
pressures. For instance, a recent initiative (discussed in Chapter 6) focusing on BVB medicines is one example of a potential expenditure saving measure.

Long-term care: Some of the largest projected expenditure increases in this report are seen in long-term care - LTRC and home support. This may not be surprising as these services are mainly concentrated in the older population and are therefore most affected by population ageing. However, we estimate that cost growth is the main driver of projected LTRC expenditure growth. The additional modelled demand from the establishment of a statutory home support scheme is the main driver of home support expenditure increases.

Using information from Walsh and Lyons (2021), analysis of long-term care examined the potential implications of substitution effects between LTRC and home support. We estimate that substituting home support for LTRC reduces projected LTRC expenditure in 2035 by $€ 346.8 \mathrm{~m}$. While not provided in the results, we estimate a similar increase in costs is projected for home support under this scenario. The cost of providing similar care to an individual through an intensive home support package, can be as expensive as an LTRC bed. Future research could examine substitution between LTRC and home support in greater detail. It will also better partition demand and expenditure on long-stay and short-stay beds separately. It is clear from the results that the establishment of a statutory home support scheme that has the workforce resources to meet increased demand will greatly increase expenditure on long-term care.

\subsection{CONCLUSIONS AND REFLECTIONS}

The main finding of this report is that, due to a combination of a growing and ageing population, increasing costs of care delivery and potential policy reforms, expenditure on primary, community and long-term care will be required to increase significantly by 2035 .

Changes in the cost of delivering care are a key driver of expenditure growth. Delivery of healthcare is labour-intensive, and, in line with findings by Keegan et al. (2020), an important driver of projected expenditure increase will be the expected cost of care, particularly the pay-related cost. These findings also reflect analysis by Wren and Fitzpatrick (2020) which shows that Ireland's apparent high healthcare expenditure in an international context is likely more related to the high price of healthcare delivery in Ireland rather than the volume of care delivered. Healthcare salaries in Ireland, which are the largest component of the cost of healthcare delivery (and as we show are the biggest drivers of expenditure growth), need to be adjusted to reflect broader wage developments in Ireland's high-wage, high-cost economy. However, we also show that the additional 
demand, as a consequence of, for example, increases in the number of high-tech medicines and the establishment of statutory schemes, are also key drivers of projected expenditure.

Identifying approaches to address the projected increases in the unit cost of care delivery should be an important consideration for policymakers. They should consider, for example, how workforce planning, including appropriate skill-mix, and targeted investment in information and communication technologies may be important in this regard. While it may be possible in some instances to substitute to less costly care (e.g. increasing the use of PNs in place of GPs for some general practice care), there are few examples in the literature that have identified substantial cost-saving substitution measures. While we show that substituting some people out of LTRC into home support will reduce LTRC expenditure, this does not appear to reduce overall expenditure. Similarly, while greater use of less labour-intensive models of healthcare delivery such as telemedicine may reduce costs, evidence remains sparse in this area.

For home support and pharmaceuticals dispensed under the HT scheme, additional modelled demand is the largest driver of expenditure increases. The establishment of a statutory home support scheme is projected to substantially increase demand for home support. However, such a scheme, if adequately planned and resourced, may allow for lower use of acute hospital care (Walsh et al., 2019b), residential care and unpaid care. The increased additional demand for the HT scheme is largely due to additional modelled demand of expensive on-patent drugs. To put this growth into context, the $€ 4,433.6 \mathrm{~m}$ nominal projected expenditure on drugs provided via the HT scheme by 2035 would be 2.3 times the total projected expenditure on general practice under the high-pressure scenario $(€ 1,960.0 \mathrm{~m})$. There is a risk that HT scheme expenditure may become unsustainable into the future; a policy focus needs to be placed on measures that address these expenditure pressures.

When considering the sustainability of future health and social care expenditure, it is important to view these additional requirements in the context of growing national income which will contribute to the tax base necessary to finance future care needs. Notably prior to Covid-19, the Irish economy, whether measured on a GDP or GNI* basis, had grown at a greater rate than overall current healthcare expenditure increases as recorded under the SHA (Central Statistics Office, 2020a). 


\subsection{FUTURE RESEARCH}

Analysis in this report, and on acute public hospital expenditure projections in Keegan et al. (2020), highlights the need to plan for increases in health and social care demand and expenditure. The ESRI plans to continue to develop research to provide policymakers with the evidence to make informed choices on health and social care planning. Some areas of research are discussed below.

Meeting rising demand for non-acute care will require a corresponding supply of skilled labour. Appropriate processes for workforce training, recruitment and retention will need to be in place to help meet these needs. We have not projected workforce requirements related to projected demand increases in this report, but another strand of research is underway at the ESRI, in collaboration with the HSE and the Department of Health to examine this. This strand of research will also allow for the Hippocrates Model to be developed at a regional level, further expanding the potential of the model.

In addition to regional workforce planning, the development of an equitable and efficient resource allocation model in Ireland is required. In order to plan for a growing and diverse population, where care is provided to those who need it most, a resource allocation model is required. There is considerable scope for the ESRI to undertake research to inform this model.

Future analysis will also focus on examining other important health and social care services. Currently, analysis is being undertaken projecting private hospital expenditure in Ireland. Further examining other privately provided and financed care such as community-based private therapy services will provide a holistic analysis of community care in Ireland. Dental and optical services, specialist mental health services and specialist disability services are extremely important parts of the health and social care system. We plan to continue our work (Brick et al., 2020b; a; Henry et al., 2020) on these services in future developments of the model.

Future research can also be used to examine the potential impact of introducing proposed Sláintecare reforms, specifically regarding changing models of care of specific patient groups. In this and previous research, we have modelled the potential demand and expenditure implications of a new statutory home support scheme for older people. A similar approach could be taken to explore other proposals such as the integrated models of chronic disease prevention and management. 
Finally, Covid-19 has had a substantial impact on the Irish healthcare system. The implications of the pandemic are likely to be far-reaching. The flexibility of Hippocrates, and its integration with other ESRI demographic and macroeconomic models, allowed us to adjust projections in this report to account for some of the potential impacts of Covid-19 on projected medium-term expenditure. However, there is further scope to model issues arising out of the pandemic such as the medium- to longer-term impact on health and social care demand and expenditure of 'long-Covid'. 


\section{REFERENCES}

Aspell, N., M. O'Sullivan, E. O'Shea, K. Irving, C. Duffy, R. Gorman and A. Warters (2019). "Predicting admission to long-term care and mortality among community-based, dependent older people in Ireland." International Journal of Geriatric Psychiatry 34(7): 999-1007. https://doi.org/10.1002/gps.5101.

Association of Occupational Therapists of Ireland (2017). What is Occupational Therapy? Retrieved 15/02, 2019, https://www.aoti.ie/what-is-ot.

Baltagi, B. and F. Moscone (2010). "Health care expenditure and income in the OECD reconsidered; Evidence from panel data." Econ Model 27(4): 804-811. https://doi.org/10.1016/j.econmod.2009.12.001.

Baltagi, B.H., R. Lagravinese, F. Moscone and E. Tosetti (2017). "Health Care Expenditure and Income: A Global Perspective." Health Econ 26(7): 863-874. https://doi.org/10.1002/hec.3424.

Banks, J., M. Farr, C. Salisbury, E. Bernard, K. Northstone, H. Edwards and J. Horwood (2018). "Use of an electronic consultation system in primary care: a qualitative interview study." Br J Gen Pract 68(666): e1-e8. 10.3399/bjgp17X693509.

Batura, N., A.M. Pulkki-Brännström, P. Agrawal, A. Bagra, H. Haghparast-Bidgoli, F. Bozzani, T. Colbourn, G. Greco, T. Hossain, R. Sinha, et al. (2014). "Collecting and analysing cost data for complex public health trials: reflections on practice." Glob Health Action 7: 23257. 10.3402/gha.v7.23257.

Beecham, J. (1995). Collecting and estimating costs. In: M. R. J. Knapp (ed.) The Economic Evaluation of Mental Health Care. Arena, Aldershot: Personal Social Services Research Unit, University of Kent.

Bergin, A., N. Conroy, A. Garcia Rodriguez, D. Holland, N. Mclnerney, E. Morgenroth and D. Smith (2017). COSMO: A new COre Structural MOdel for Ireland. Economic and Social Research Institute, Dublin.

Bergin, A., A. Garcia Rodriguez, N. Mc Inerney and E. Morgenroth (2016). Baseline: Methodology, Assumptions and Projections. Ireland's Economic Outlook. Dublin: Economic and Social Research Institute.

Blanco-Moreno, A., R.M. Urbanos-Garrido and I.J. Thuissard-Vasallo (2013). "Public healthcare expenditure in Spain: measuring the impact of driving factors." Health Policy 111(1): 34-42. https://doi.org/10.1016/j.healthpol.2013.03.012.

Brick, A. and S. Connolly (2021). "Waiting Times for Publicly Funded Hospital Treatment: How does Ireland Measure Up?" Economic and Social Review 52(1): 41-52.

Brick, A. and C. Keegan (2020a). Utilisation of Public Acute Hospital Services in Ireland Baseline Analysis for the Hippocrates Model. Survey and Statistical Report Series Number 100. Economic and Social Research Institute Dublin. https://doi.org/10.26504/sustat100.

Brick, A. and C. Keegan (2020b). Paying more to wait less: Estimating the cost of reducing Ireland's public hospital waiting lists. Working Paper Series Number 688. Economic and Social Research Institute, Dublin, https://www.esri.ie/system/files/publications/WP688_0.pdf.

Brick, A., C. Keegan and M.A. Wren (2020a). Utilisation of Specialist Disability Services in Ireland - Baseline Analysis for the Hippocrates Model. Survey and Statistical Report Series Number 89. Economic and Social Research Institute Dublin. https://doi.org/10.26504/sustat89.

Brick, A., C. Keegan and M.A. Wren (2020b). Utilisation of Specialist Mental Health Services in Ireland - Baseline Analysis for the Hippocrates Model. Survey and Statistical Report Series Number 90. Economic and Social Research Institute Dublin. https://doi.org/10.26504/sustat90.

Brick, A., B. Walsh, C. Keegan and S. Lyons (2020c). COVID-19 and emergency department attendances in Irish public hospitals. QEC Special Article. ESRI, Dublin. https://doi.org/10.26504/qec2020may_SA_lyons. 
Car, J. and A. Sheikh (2003). "Telephone consultations." BMJ 326(7396): 966-969. 10.1136/bmj.326.7396.966.

Carter, M., E. Fletcher, A. Sansom, F.C. Warren and J.L. Campbell (2018). "Feasibility, acceptability and effectiveness of an online alternative to face-to-face consultation in general practice: a mixed-methods study of webGP in six Devon practices." BMJ Open 8(2): e018688. 10.1136/bmjopen-2017-018688.

Central Statistics Office (2020a). Ireland's System of Health Accounts, Annual Results 2018. Central Statistics Office, Dublin.

Central Statistics Office (2020b). System of Health Accounts. Retrieved 3 October, 2020, https://www.cso.ie/en/statistics/governmentaccounts/systemofhealthaccounts/.

Charlesworth, A., M. Anderson, C. Donaldson, P. Johnson, M. Knapp, A. McGuire, M. McKee, E. Mossialos, P. Smith, A. Street, et al. (2021). "What is the right level of spending needed for health and care in the UK?" The Lancet 397(10288): 2012-2022. https://doi.org/10.1016/S0140-6736(21)00230-0.

Charlesworth, A. and P. Johnson, Eds. (2018). Securing the future: funding health and social care to the 2030s. London, England, The Institute for Fiscal Studies.

Citizens Information (2015). Community care services. Retrieved 26/09/2019, 2019, https://www.citizensinformation.ie/en/health/health_services/care_in_your_communit y/community_care_services.html.

Citizens Information (2020). Prescription charges for medical card holders. Retrieved 20 May, 2021, https://www.citizensinformation.ie/en/health/drugs_and_medicines/prescription_char ges_for_medical_card_holders.html.

Collins, C. and R. Homeniuk (2021). "How many general practice consultations occur in Ireland annually? Cross-sectional data from a survey of general practices." BMC Family Practice 22(1): 40. 10.1186/s12875-021-01377-0.

Collins, C. and M. O'Riordan (2015). "The future of Irish general practice: ICGP member survey 2015."

Collins, D. (2019). Social Impact Assessment Series Nursing Home Support Scheme (NHSS). IGEES, https://igees.gov.ie/wp-content/uploads/2019/10/Nursing-Home-SupportScheme-NHSS.pdf.

Connolly, S., A. Nolan, B. Walsh and M. Wren (2018). "Universal GP Care in Ireland: Potential Cost Implications." Econ Soc Rev 49(1): 93-91.99, https://www.esr.ie/article/view/871.

Connolly, S. and R. Whyte (2019). "Uptake of cancer screening services among middle and older ages in Ireland: the role of healthcare eligibility." Public Health 173: 42-47. https://doi.org/10.1016/j.puhe.2019.05.025.

Connolly, S. and M.-A. Wren (2019). "Universal Health Care in Ireland-What Are the Prospects for Reform?" Health Systems \& Reform 5(2): 94-99. https://doi.org/10.1080/23288604.2018.1551700.

Connolly, S., M.-A. Wren and C. Keegan (2021). "Universal primary care in Ireland: Cost and capacity implications."

Connors, J. (2017a). Budget 2018: Primary Care Reimbursement Service Trend Analysis. Department of Public Expenditure and Reform, Dublin, https://igees.gov.ie/wpcontent/uploads/2018/04/8.Primary-Care-Reimbursement-Service-\%E2\%80\%93-TrendAnalysis.pdf.

Connors, J. (2017b). Spending Review 2017: Future Sustainability of Pharmaceutical Expenditure. Department of Public Expenditure and Reform.

Constenla, D., A. Sinha, J.E. Valencia, E. Gomez, F. De La Hoz, M.T. Valenzuela and C.A. De Quadros (2009). "Identifying unit costs for use in regional economic evaluation: An illustrative analysis of childhood pneumococcal conjugate vaccine in Latin America and the Caribbean." Revista Panamericana de Salud Publica/Pan American Journal of Public Health 26(5): 458-468. 
Crosbie, B., M.E. O'Callaghan, S. O'Flanagan, D. Brennan, G. Keane and W. Behan (2020). "A real-time measurement of general practice workload in the Republic of Ireland: a prospective study." Br J Gen Pract 70(696): e489-e496. 10.3399/bjgp20X710429.

Curtis, L. and A. Burns (2019). Unit Costs of Health \& Social Care 2019. Personal Social Services Research Unit, University of Kent, Canterbury. https://doi.org/10.22024/UniKent/01.02.79286.

de la Maisonneuve, C. and J. Martins Oliveira (2015). The future of health and long-term care spending. OECD Journal: Economic Studies. OECD. https://dx.doi.org/10.1787/eco_studies-2014-5jz0v44s66nw.

Department of Health (2015). Review of the Nursing Homes Support Scheme, A Fair Deal. Department of Health, http://health.gov.ie/blog/publications/review-of-the-nursinghomes-support-scheme-a-fair-deal/.

Department of Health (2019a). Sláintecare Action Plan 2019. Department of Health, Dublin. https://assets.gov.ie/9379/05384619bb2240c18c294b60578117e1.pdf.

Department of Health (2019b). Health in Ireland: Key Trends 2019. Department of Health, Dublin.

Department of Health and Children (2001). Primary care: A new direction. The Stationery Office, Dublin, Ireland.

Department of Health, Health Service Executive, and Irish Medical Organisation (2019c). Terms of Agreement between the Department of Health, the HSE and the IMO regarding GP Contractual Reform and Service Development. Health Service Executive, https://www.hse.ie/eng/about/who/gmscontracts/2019agreement/.

Drummond, M., M. Sculpher, K. Claxton, G. Stoddart and G. Torrance (2015). Methods for the Economic Evaluation of Health Care Programmes. Oxford, United Kingdom, Oxford University Press.

Edbrooke, D.L. and C.L. Hibbert (1999). "Cost determinants and economic assessment in the critical care setting." Current Opinion in Critical Care 5(4): 316.

Eighan, J., B. Walsh, S. Smith, M.A. Wren, S. Barron and E. Morgenroth (2019). "A profile of physiotherapy supply in Ireland." Ir J Med Sci 188(1): 19-27. 10.1007/s11845-018-18061.

European Commission (2011). The 2012 Ageing Report: Underlying Assumptions and Projection Methodologies. European Commission, Brussels.

European Commission (2014). The 2015 Ageing Report: Underlying Assumptions and Projection Methodologies. European Commission, Brussels. https://doi.org/10.2765/76255.

European Commission (2015). The 2015 Ageing Report: Economic and budgetary projections for the 28 EU Member States (2013-2060). European Commission, Brussels. https://doi.org/10.2765/877631.

European Commission (2017). The 2018 Ageing Report: Underlying Assumptions and Projection Methodologies. European Commission, Brussels https://doi.org/10.2765/286359.

European Commission (2018). The 2018 Ageing Report: Economic and Budgetary Projections for the 28 EU Member States (2016-2070). The European Commission, Brussels. https://doi.org/10.2765/615631

Findlay, R. (2017). "The cost of restoring 18 week waits." Health Services Journal. https://blog.gooroo.co.uk/2017/11/the-cost-of-restoring-18-week-waits/.

Frazer, K., L. Mitchell, D. Stokes, E. Crowley and C. Kelleher (2021). COVID-19 Nursing Homes Expert Panel Examination of Measures to 2021: Report to the Minister for Health. Department of Health, Dublin.

French, H. and R. Galvin (2017). "Musculoskeletal services in primary care in the Republic of Ireland: an insight into the perspective of physiotherapists." Physiotherapy 103(2): 214221.

Fries, J.F. (1980). "Aging, natural death, and the compression of morbidity." N Eng/ J Med 303(3): 130-135. https://doi.org/10.1056/NEJM198007173030304. 
Government of Ireland (2013). Health (Pricing and Supply of Medical Goods) Act 2013 (No. 14 of 2013). Dublin, Stationery Office.

Government of Ireland (2020). Expenditure Report 2021 Part II - Expenditure Allocations 2021. Government of Ireland, Dublin. http://budget.gov.ie/Budgets/2021/Documents/Budget/Part\%20II\%20\%20Expenditure\%20Allocations\%202021.pdf.

Government of Ireland (2021). Sláintecare Implementation Strategy and Action Plan 20212023, Dublin, Ireland. https://www.gov.ie/ga/foilsiuchan/6996b-slaintecareimplementation-strategy-and-action-plan-2021-2023/.

Gruenberg, E.M. (1977). "The failures of success." Milbank Memorial Fund Q Health Society 55. https://doi.org/10.2307/3349592.

Hanly, P. and C. Sheerin (2017). "Valuing Informal Care in Ireland: Beyond the Traditional Production Boundary." Econ Soc Rev 48(3, Autumn): 28, https://www.esr.ie/article/view/773.

Hartwig, J. (2008). "What drives health care expenditure? Baumol's model of 'unbalanced growth' revisited." J Health Econ 27(3): 603-623. https://doi.org/10.1016/j.jhealeco.2007.05.006.

Health Insurance Authority (2020). Annual Report and Accounts 2019. Health Insurance Authority, Dublin, https://www.hia.ie/sites/default/files/81105\%20HIA\%20Annual\%20Report\%202019\%20 FULL\%20WEB.pdf.

Health Service Executive (2020a). Primary Care Reimbursement Service: Statistical Analysis of Claims and Payments 2019. Health Service Executive, Dublin.

Health Service Executive (2020b). Winter Planning within the COVID-19 Pandemic. Health Service Executive, Dublin, https://www.hse.ie/eng/services/publications/winterplanning-within-the-covid19-pandemic-october-2020-april-2021.pdf.

Health Service Executive (2021a). Long-Term IIIness Scheme. Retrieved 18/05, 2021, https://www2.hse.ie/services/long-term-illness-scheme/long-term-illness.html.

Health Service Executive (2021b). Speech and Language Therapy Department. Retrieved 13/05, 2021, https://www.hse.ie/eng/services/list/3/acutehospitals/hospitals/waterford/speech-andlanguage-therapy-department-.html.

Health Service Executive (2021c). Public health nurses and community registered general nurses (ONMSD). Retrieved 14/05, 2021, https://healthservice.hse.ie/aboutus/onmsd/onmsd/specific-programmes/phn-community-registered-generalnurses.html.

Health Service Executive (2021d). Occupational Therapy Services. Retrieved 13/05, 2021, https://www.hse.ie/eng/services/list/1/lho/northdublin/therapy/occupational-therapyservices---lho---north-dublin.html.

Health Service Executive (2021e). National Service Plan 2021. HSE, https://www.hse.ie/eng/services/publications/serviceplans/national-service-plan2021.pdf.

Hendriks, M.E., P. Kundu, A.C. Boers, O.A. Bolarinwa, M.J. Te Pas, T.M. Akande, K. Agbede, G.B. Gomez, W.K. Redekop, C. Schultsz, et al. (2014). "Step-by-step guideline for diseasespecific costing studies in low- and middle-income countries: a mixed methodology." Glob Health Action 7: 23573. 10.3402/gha.v7.23573.

Henry, E., A. Brick and C. Keegan (2020). Utilisation of Dental and Optical Services in Ireland - Baseline Analysis for the Hippocrates Model. Survey and Statistical Report Series Number 99. Economic and Social Research Institute Dublin. https://doi.org/10.26504/sustat99.

Homeniuk, R. and C. Collins (2021). "How COVID-19 has affected general practice consultations and income: general practitioner cross-sectional population survey evidence from Ireland." BMJ Open 11(e044685). doi:10.1136/bmjopen-2020-044685. 
Houses of the Oireachtas Committee on the Future of Healthcare (2017). Sláintecare Report. Houses of the Oireachtas, Dublin.

http://www.oireachtas.ie/parliament/media/committees/futureofhealthcare/Oireachta s-Committee-on-the-Future-of-Healthcare-Slaintecare-Report-300517.pdf.

HSE Health Protection Surveillance Centre (2020). Annual Epidemiological Report - DTaPIPV \& MMR vaccine uptake in Junior Infants \& children aged 4-5 years, in Ireland 2017/2018, https://www.hpsc.ie/a-

z/vaccinepreventable/vaccination/immunisationuptakestatistics/immunisation...pdf.

HSE Health Protection Surveillance Centre (2021). HPV/Tdap/MenC/MenACWY uptake statistics, https://www.hpsc.ie/a-

z/vaccinepreventable/vaccination/immunisationuptakestatistics/hpvtdapmencmenacwy uptakestatistics/...xlsx.

Ilinca, S., K. Leichsenring and R. Rodrigues (2015). From care in homes to care at home: European experiences with (de)institutionalisation in long-term care. E. C. f. S. W. P. a. Research, Vienna, https://www.euro.centre.org/downloads/detail/1540.

Ipsos MRBI (2018). Healthy Ireland, Technical report 2018. Department of Health, D. o. Health, Dublin, Ireland.

Irish Association of Speech and Language Therapists (2017). What is a Speech and Language Therapist? Retrieved 14/04, 2021, https://www.iaslt.ie/about/about_whatwedo.php.

Irish Fiscal Advisory Council (2018). Stand-Still Scenario for Government Spending in the Medium Term, 2019-2023. Irish Fiscal Advisory Council, Dublin.

Irish Pharmaceutical Healthcare Association (2020a). Prices of Medicines. Retrieved 27/04, 2021, https://www.ipha.ie/About-the-Industry/Price-of-Medicines/.

Irish Pharmaceutical Healthcare Association (2020b). Framework Agreement on the Supply of Medicines to the Health Services 2016-2020. Retrieved 27/04, 2021, https://www.ipha.ie/about-us/our-role/agreement-on-the-supply-of-medicines/.

Irish Pharmaceutical Healthcare Association (2021). €30m released for 'backlogged' medicines at same time as industry agrees new Agreement extension. Retrieved 20th April, 2021, https://www.ipha.ie/e30m-released-for-backlogged-medicines-at-sametime-as-industry-agrees-new-agreement-extension/.

Irish Practice Nurses Association (2014). General Information Leaftlet, I. P. N. Association, https://irishpracticenurses.ie/about-us/.

Irish Society of Chartered Physiotherapists (2017). What is physiotherapy? Retrieved 14/05, 2021, https://www.iscp.ie/why-choose-chartered/what-is-physiotherapy.

Johnston, B.M., S. Burke, S. Barry, C. Normand, M. Ní Fhallúin and S. Thomas (2019). "Private health expenditure in Ireland: Assessing the affordability of private financing of health care." Health Policy 123(10): 963-969.

https://doi.org/10.1016/j.healthpol.2019.08.002.

Keane, C., M. Regan and B. Walsh (2021). "Failure to Take-Up Public Healthcare Entitlements: Evidence from the Medical Card System in Ireland." Social Science and Medicine Forthcoming.

Keegan, C. (2020). "The introduction of lifetime community rating in the Irish private health insurance market: Effects on coverage and plan choice." Soc Sci Med 255: 113006. 10.1016/j.socscimed.2020.113006.

Keegan, C., A. Brick, A. Bergin, M.-A. Wren, E. Henry and R. Whyte (2020). Projections of expenditure for public hospitals in Ireland, 2018-2035, based on the Hippocrates model. ESRI Research Series Report 117. ESRI, Dublin. https://doi.org/10.26504/rs117.

Keegan, C., A. Brick, B. Walsh, A. Bergin, J. Eighan and M. Wren (2018). "How many beds? Capacity implications of hospital care demand projections in the Irish hospital system, 2015-2030." The International Journal of Health Planning and Management 34(1). https://doi.org/10.1002/hpm.2673.

Laudicella, M., P. Di Donni, K. Rose Olsen and D. Gyrd-Hansen (2020). "Age, morbidity, or something else? A residual approach using microdata to measure the impact of technological progress on health care expenditure." DaCHE discussion papers 2020:4. 
Long, S.K., J. King and T.A. Coughlin (2005). "The implications of unmet need for future health care use: findings for a sample of disabled Medicaid beneficiaries in New York." Inquiry 42(4): 413-420. https://doi.org/10.5034/inquiryjrnl_42.4.413.

Ma, Y. and A. Nolan (2016). "Public Healthcare Entitlements and Healthcare Utilisation among the Older Population in Ireland." Health Econ. https://doi.org/10.1002/hec.3429.

Manton, K.G. (1982). "Changing concepts of morbidity and mortality in the elderly population." Milbank Mem Fund Q Health Soc 60(2): 183-244, https://www.ncbi.nlm.nih.gov/pubmed/6919770.

Marino, A., D. Morgan, L. Lorenzoni and C. James (2017). Future trends in health care expenditure: A modelling framework for cross-country forecasts. OECD Publishing, Paris. https://doi.org/10.1787/5667f23d-en.

Martın, J.J., M. Puerto Lopez del Amo Gonzalez and M. Dolores Cano Garcıa (2011). "Review of the literature on the determinants of healthcare expenditure." Applied Economics 43: 19-46. https://doi.org/10.1080/00036841003689754.

Mayer, S., C. Fischer, I. Zechmeister-Koss, H. Ostermann and J. Simon (2020). "Are Unit Costs the Same? A Case Study Comparing Different Valuation Methods for Unit Cost Calculation of General Practitioner Consultations." Value Health 23(9): 1142-1148. https://doi.org/10.1016/j.jval.2020.06.001.

McDonald, A., K. Frazer, C. Duignan, M. Healy, A. Irving, P. Marteinsson, B. Molloy and E. McNicholas (2015). "Validating the 'Intervention Wheel' in the context of Irish public health nursing." British Journal of Community Nursing 20(3): 140-146, http://www.ncbi.nlm.nih.gov/pubmed/25754782.

McKinstry, B., J. Walker, C. Campbell, D. Heaney and S. Wyke (2002). "Telephone consultations to manage requests for same-day appointments: a randomised controlled trial in two practices." Br J Gen Pract 52(477): 306-310, https://www.ncbi.nlm.nih.gov/pubmed/11942448.

Medicines Management Programme (2018). MMP roadmap for the prescribing of bestvalue biological (BVB) medicines in the Irish healthcare setting. Health Service Executive, Dublin, Ireland.

Medicines Management Programme (2019). Best-Value Biological Medicines: Tumour Necrosis Factor- $\alpha$ Inhibitors on the High Tech Drug Scheme. HSE, https://www.hse.ie/eng/about/who/cspd/ncps/medicines-management/best-valuemedicines/best-value-biologicalmedicines/mmp\%20report\%20bvb\%20medicines\%20tnf\%20alpha\%20inhibitors\%20may \%202019.pdf.

Medicines Management Programme (2020). Statin monotherapy for the treatment of hypercholesterolemia and prevention of cardiovascular events in adults. HSE, https://www.hse.ie/eng/about/who/cspd/ncps/medicines-management/latestupdates/statin-preferred-drug-report-july-2020.pdf.

Mercille, J. and N. O'Neill (2020). "The growth of private home care providers in Europe: The case of Ireland." Social Policy \& Administration n/a(n/a). 10.1111/spol.12646.

Mogyorosy, Z. and P. Smith (2005). The main methodogical issues in costing health care services: A literature review, The University of York, Centre for Health Economics. Research Paper 7.

Moore, P.V., K. Bennett and C. Normand (2017). "Counting the time lived, the time left or illness? Age, proximity to death, morbidity and prescribing expenditures." Soc Sci Med 184: 1-14. https://doi.org/10.1016/j.socscimed.2017.04.038.

Murphy, C.M., B.J. Whelan and C. Normand (2015). "Formal home-care utilisation by older adults in Ireland: evidence from the Irish Longitudinal Study on Ageing (TILDA)." Health Soc Care Community 23(4): 408-418. https://doi.org/10.1111/hsc.12157.

Newbould, J., G. Abel, S. Ball, J. Corbett, M. Elliott, J. Exley, A. Martin, C. Saunders, E. Wilson, E. Winpenny, et al. (2017). "Evaluation of telephone first approach to demand management in English general practice: observational study." BMJ 358: j4197. 10.1136/bmj.j4197. 
Newhouse, J.P. (1992). "Medical care costs: how much welfare loss?" J Econ Perspect 6(3): 3-21. https://doi.org/10.1257/jep.6.3.3.

Nolan, A. (2007). The financing and delivery of GP services in Ireland. In: B. Nolan (ed.) The provision and use of health services, health inequalities and health and social gain. Dublin, Ireland: Economic and Social Research Institute.

Nolan, A. and R. Layte (2017). "The impact of transitions in insurance coverage on GP visiting among children in Ireland." Soc Sci Med 180: 94-100. https://doi.org/10.10.1016/j.socscimed.2017.03.026.

O'Neill, P., J. Mestre-Ferrandiz, R. Puig-Peiro and J. Sussex (2014). Projecting Expenditure on Medicines in the NHS: Second Edition. Office of Health Economics. Research Paper $14 / 01$.

O'Callaghan, M.E., L. Zgaga, D. O'Ciardha and T. O'Dowd (2018). "Free Children's Visits and General Practice Attendance." The Annals of Family Medicine 16(3): 246-249. 10.1370/afm.2229.

OECD, Eurostat and WHO (2017). A system of health accounts 2011: revised edition. OECD Publishing, Paris.

Olsson, T.M. (2011). "Comparing top-down and bottom-up costing approaches for economic evaluation within social welfare." Eur J Health Econ 12(5): 445-453. 10.1007/s10198-010-0257-z.

Oostenbrink, J.B., M.A. Koopmanschap and F.F. Rutten (2002). "Standardisation of costs: the Dutch Manual for Costing in economic evaluations." Pharmacoeconomics 20(7): 443454. https://doi.org/10.2165/00019053-200220070-00002.

Parliamentary Budget Office (2020). Drivers of Government Spending on Health: Effect of National Income, Dublin: Houses of the Oireachtas, https://data.oireachtas.ie/ie/oireachtas/parliamentaryBudgetOffice/2020/2020-0508_drivers-of-government-spending-on-health-effect-of-national-income_en.pdf.

Raftery, J. (2000). "Costing in economic evaluation." BMJ 320(7249): 1597. https://doi.org/10.1136/bmj.320.7249.1597.

Richardson, K., P. Moore, J. Peklar, Rose Galvin, K. Bennett and R.A. Kenny (2012). Polypharmacy in adults over 50 in Ireland: Opportunities for cost saving and improved healthcare. The Irish Longitudinal Study on Ageing, Dublin.

Ronksley, P.E., C. Sanmartin, H. Quan, P. Ravani, M. Tonelli, B. Manns and B.R. Hemmelgarn (2013). "Association between perceived unmet health care needs and risk of adverse health outcomes among patients with chronic medical conditions." Open Med 7(1): e2130, https://www.ncbi.nlm.nih.gov/pubmed/23687534.

Smith, S., S. Barron, M.-A. Wren, B. Walsh, E. Morgenroth, J. Eighan and S. Lyons (2019). Geographic Profile of Healthcare Needs and Non-Acute Healthcare Supply in Ireland. ESRI Research Series No. 90, https://www.esri.ie/publications/geographic-profile-ofhealthcare-needs-and-non-acute-healthcare-supply-in-ireland.

Smith, S. and S. Connolly (2020). "Re-thinking unmet need for health care: introducing a dynamic perspective." Health Econ Policy Law 15(4): 440-457. 10.1017/S1744133119000161.

Smith, S., J. Jiang, C. Normand and C. O'Neill (2021). "Unit costs for non-acute care in Ireland 2016-2019 [version 1; peer review: awaiting peer review]." HRB Open Research 4(39). https://doi.org/10.12688/hrbopenres.13256.1.

Teljeur, C., E. Tyrrell, A. Kelly, T. O'Dowd and S. Thomas (2014). "Getting a handle on the general practice workforce in Ireland." Ir J Med Sci 183(2): 207-213. https://doi.org/10.1007/s11845-013-0991-1.

Thomas, S., B. Johnston, S. Barry, R. Siersbaek and S. Burke (2021). "Slaintecare implementation status in 2020: Limited progress with entitlement expansion." Health Policy 125(3): 277-283. 10.1016/j.healthpol.2021.01.009.

Turner, B. (2018). "Putting Ireland's health spending into perspective." Lancet 391(10123): 833-834. https://doi.org/10.1016/s0140-6736(18)30461-6. 
Vargas Bustamante, A. and S. V Shimoga (2018). "Comparing the Income Elasticity of Health Spending in Middle-Income and High-Income Countries: The Role of Financial Protection." International journal of health policy and management 7(3): 255-263. 10.15171/ijhpm.2017.83.

Walsh, B., C. Keegan, A. Brick and S. Lyons (2020). How is Ireland's healthcare system coping with coronavirus? Retrieved 22 October, 2020, https://www.coronavirusandtheeconomy.com/question/how-irelands-healthcaresystem-coping-coronavirus.

Walsh, B. and S. Lyons (2021). "Demand for the Statutory Home Support Scheme." ESRI Research Series Report Number 122. doi.org/10.26504/rs122.

Walsh, B., G. Mohan and C. Mac Domhnaill (2021). Developments in Healthcare Information Systems in Ireland and Internationally. Survey and Statistical Report Series Number 105. Economic and Social Research Institute, Dublin. doi.org/10.26504/sustat105.

Walsh, B., A. Nolan, A. Brick and C. Keegan (2019a). "Did the expansion of free GP care impact demand for Emergency Department attendances? A difference-in-differences analysis." Soc Sci Med 222: 101-111. https://doi.org/10.1016/j.socscimed.2018.12.029.

Walsh, B., M. Silles and C. O'Neill (2012). "The role of private medical insurance in socioeconomic inequalities in cancer screening uptake in ireland." Health Econ 21(10): 12501256. https://doi.org/10.1002/hec.1784.

Walsh, B., M.-A. Wren, S. Smith, S. Lyons, J. Eighan and E. Morgenroth (2019b). An Analysis of the Effects on Irish Hospital Care of the Supply of Care Inside and Outside the Hospital. ESRI Research Series No. 91.

Waters, H.R. and P. Hussey (2004). "Pricing health services for purchasers--a review of methods and experiences." Health Policy 70(2): 175-184. 10.1016/j.healthpol.2004.04.012.

Whyte, R., C. Keegan, A. Brick and M.-A. Wren (2018). Review of the Irish and international literature on health and social care unit cost methodology. Working Paper Series Number 602. Economic and Social Research Institute, https://www.esri.ie/system/files/media/file-uploads/2018-11/WP602.pdf.

Whyte, R., M.-A. Wren, C. Keegan and A. Brick (2020). An analysis of trends in Irish public healthcare expenditure and staffing. Working Paper Series Number 660. Economic and Social Research Institute, Dublin, https://www.esri.ie/system/files/publications/WP660_2.pdf.

Wren, M.-A. and A. Fitzpatrick (2020). How does Irish healthcare expenditure compare internationally? Economic and Social Research Institute, Dublin. Research Series Number 114.

Wren, M.A., C. Keegan, B. Walsh, A. Bergin, J. Eighan, A. Brick, S. Connolly, D. Watson and J. Banks (2017). Projections of Demand for Healthcare in Ireland, 2015-2030. First Report from the Hippocrates Model. ESRI Research Series No. 67. Economic and Social Research Institute Dublin.

Xu, K., P. Saksena and A. Holly (2011). The determinants of health expenditure. A countrylevel panel data analysis. Working Paper. World Health Organisation, https://www.who.int/health_financing/documents/report_en_11_deter-he.pdf?ua=1. 


\section{APPENDIX A}

\section{Local Health Offices and Community Health Organisations}

TABLE A.1 Local Health Offices in each Community Health Organisation

\begin{tabular}{l|l}
\hline $\begin{array}{l}\text { Community Health } \\
\text { Organisation }\end{array}$ & Local Health Offices \\
\hline CHO 1 & Donegal, Sligo/Leitrim/West Cavan, Cavan/Monaghan \\
\hline CHO 2 & Galway, Roscommon, Mayo \\
\hline CHO 3 & Clare, Limerick, North Tipperary/East Limerick \\
\hline CHO 4 & Kerry, North Cork, North Lee, South Lee, West Cork \\
\hline CHO 5 & South Tipperary, Carlow/Kilkenny, Waterford, Wexford \\
CHO 6 & Wicklow, Dun Laoghaire, Dublin South East \\
\hline CHO 7 & Kildare/West Wicklow, Dublin West, Dublin South City, Dublin South West \\
\hline CHO 8 & Laois/Offaly, Longford/Westmeath, Louth, Meath \\
\hline CHO 9 & Dublin North, Dublin North Central, Dublin North West \\
\hline
\end{tabular}




\section{APPENDIX B}

\section{Medical Card and Private Health Insurance coverage}

FIGURE B.1 Medical Card and Private Health Insurance coverage in Ireland by age: aged 18+

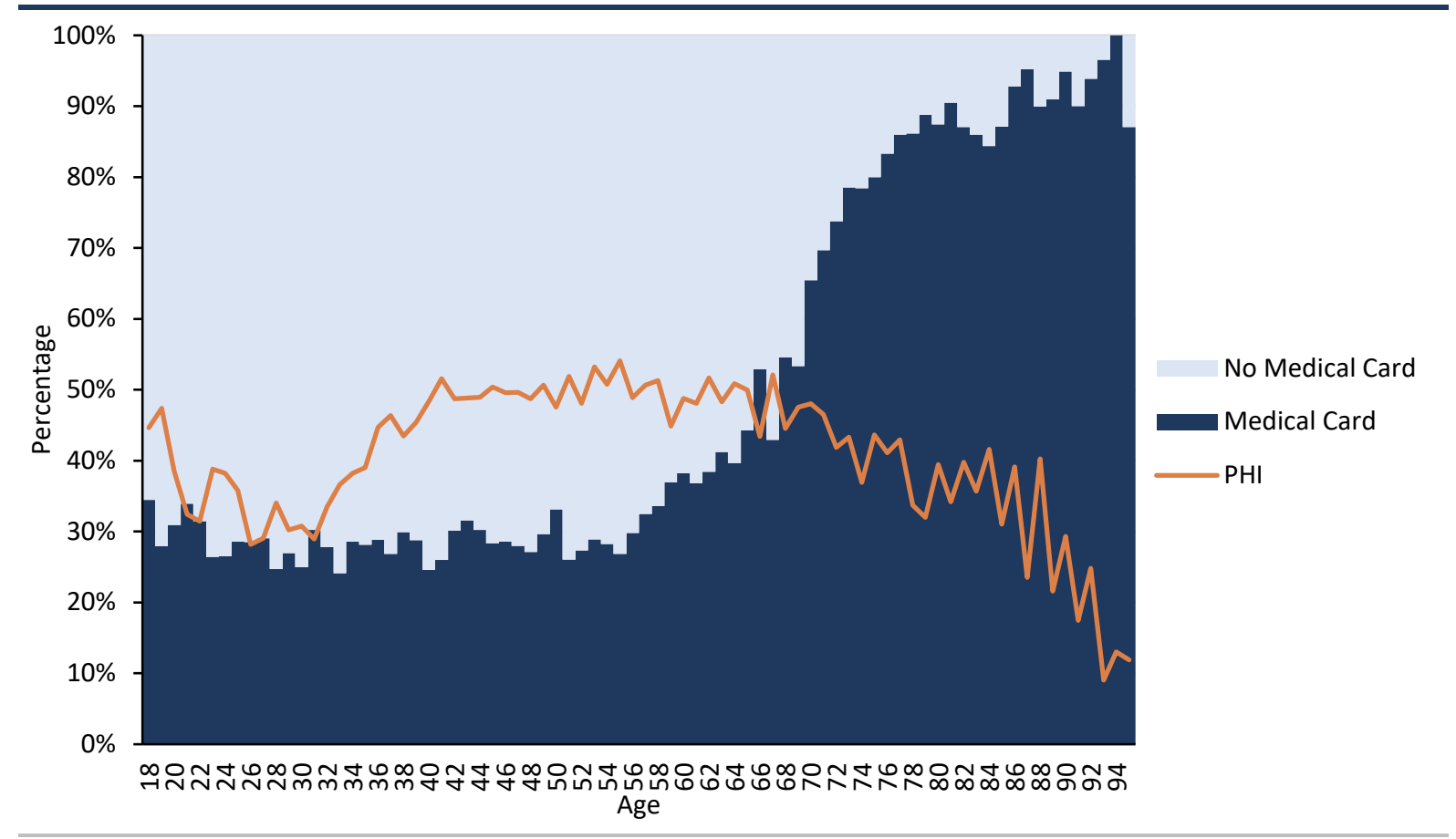

Notes: No Medical Card now includes those with a GPVC.

Source: Healthy Ireland Survey waves 3-4. 


\section{APPENDIX C}

\section{Waiting-list management: Community therapy services}

Waiting lists are an issue across most services in the Irish public healthcare system. While there has been research on waiting lists for public acute hospital care (Brick and Keegan, 2020b; Brick and Connolly, 2021), less analysis of community therapy waiting lists has been undertaken. In this analysis we employ a methodology originally developed in the UK (Findlay, 2017) which was refined and employed previously for public acute hospital waiting lists (Brick and Keegan, 2020b; Keegan et al., 2020). ${ }^{50}$

For this analysis, for each of the HSE Primary Care community therapy services under consideration from 2017 to 2020, the HSE BIU provided monthly waiting list data on:

- $\quad$ the number of referrals accepted;

- the number of clients on the waiting list for more than $12 / 16^{51}$ weeks; and

- the total number of clients on the waiting list.

Following Brick and Keegan (2020b), we estimate the additional activity required to clear the backlog within five years, assuming that the backlog pressure will ease at the end of 2021, ${ }^{52}$ and we take the maximum of our backlog calculations. We also calculate, based on trends in the total waiting-list size and trends in referrals accepted, the number of additional appointments required to maintain waiting times at 12/16 weeks during the backlog clearance and thereafter.

The metrics differ across services. For example, for speech and language therapy several waiting lists are in operation: the number waiting for initial assessment, initial treatment, and further treatment. For consistency in the analysis, we focus on lists for initial/first-time assessment across services. It is important to note that the figures presented here are based on observed or reported waiting lists. It may be the case that long waiting times or lack of service in a particular area may act as a deterrent to referral. Therefore, these figures may underestimate the level of additional service required.

50 This method is described in detail in Brick and Keegan (2020b).

51 The waiting times for occupational therapy and physiotherapy refer to 12 weeks and those for speech and language therapy to 16 weeks.

52 We acknowledge that at the time of writing there is uncertainty around the true impact of Covid-19 on waiting lists in the community. 
Unfortunately, the lack of detailed complexity-adjusted activity data for non-acute services means this cannot be included in the projection scenarios, so it is not possible to estimate the impact this additional activity requirement would have on future expenditure.

Figure C.1 shows that, in December 2020, 38,000 clients were awaiting a first-time assessment with an occupational therapist, 48,000 clients were awaiting physiotherapy assessment and 23,000 were awaiting a first-time assessment with a speech and language therapist. The numbers on the waiting lists and the proportion waiting more than $12 / 16$ weeks had been increasing over time. This has been further exacerbated by Covid-19, particularly in mid-2020.53 In addition, while the numbers on the waiting lists have been increasing over time, the number of referrals accepted appears, except for the early months of the pandemic (March to June 2020), relatively predictable, with some seasonal variation for all services.

53 For the acute system, the Sláintecare report proposed a target waiting time of 10 weeks for OPD appointments and 12 weeks for admitted treatment. As there do not appear to be recommended targets for community therapy services waiting times, we use the HSE key performance metric of patients seen within 12 weeks as our target (Health Service Executive, 2021e). 
FIGURE C.1 Community therapy services: waiting lists 2017-2020

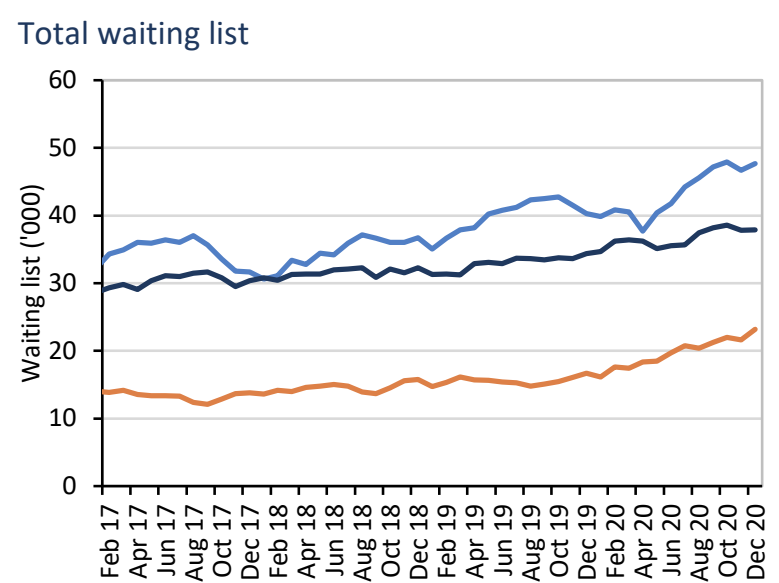

Referrals accepted

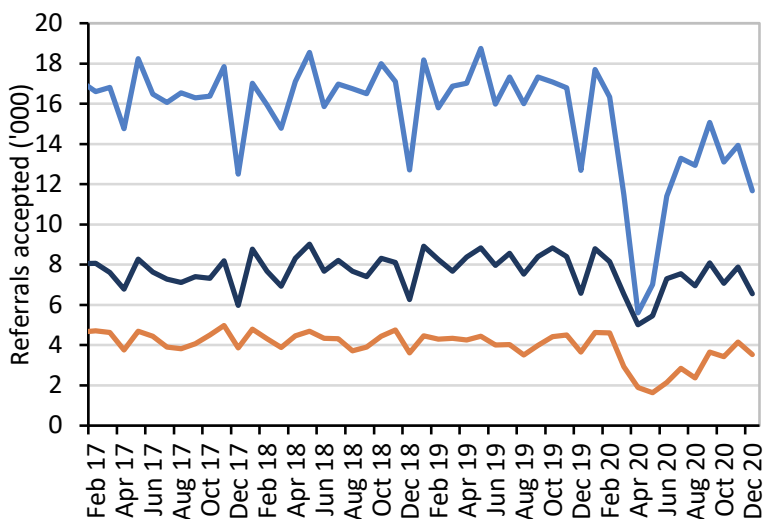

Proportion waiting more than $12 / 16$ weeks $^{\mathrm{a}}$

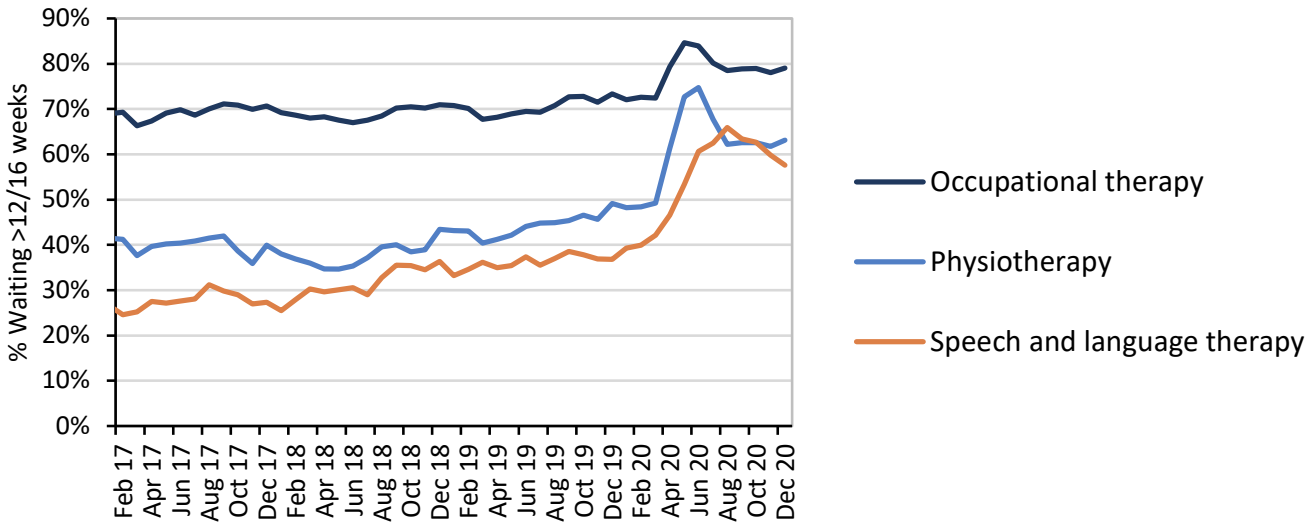

Notes: 12 weeks for occupational therapy and physiotherapy and 16 weeks for speech and language therapy.

Source: $\quad$ Authors' calculations - based on HSE BIU data.

Occupational therapy: To clear the backlog of cases, which we estimate will be approximately 33,000 clients by the end of 2021 , an additional 6,500 new clients would need to be seen annually over the next five years. We estimate that, to stop waiting lists from growing due to demand pressures, an additional 200 new clients would have to be seen in 2022, adjusting with population in subsequent years. Consequently, we estimate that in 2022 an additional 560 new clients would need to be seen per month to address the estimated waiting-list and demand pressure growth. To put this in context, in 2019 an average of 7,800 new clients were seen for a first-time assessment each month, implying an additional 7.2 per cent are required.

Physiotherapy: To clear the backlog of cases, which we estimate will be approximately 37,000 new clients by the end of 2021, an additional 7,400 new clients would need to be seen annually over the next five years. We estimate that, to stop waiting lists from growing due to demand pressures, an additional 3,500 new clients would have to be seen in 2022, adjusting with population in subsequent years. Consequently, we estimate that in 2022 an additional 910 new clients would need to be seen per month to address the estimated waiting-list and demand pressure growth. To put this in context, in 2019 an average of 13,400 new 
clients were seen for a first-time assessment each month, implying an additional 6.8 per cent are required.

Speech and language therapy: To clear the backlog of cases, which we estimate will be approximately 16,250 new clients by the end of 2021, an additional 3,250 new clients would need to be seen annually over the next five years. We estimate that, to stop waiting lists from growing due to demand pressures, an additional 1,900 new clients would have to be seen in 2022, adjusting with population in subsequent years. Consequently, we estimate that in 2022 an additional 430 new clients would need to be seen per month to address the estimated waiting-list and demand pressure growth. To put this in context, in 2019 an average of 3,200 new clients were seen for a first-time assessment each month, implying an additional 13.4 per cent are required. Given the current concentration of service provision in the youngest age groups, should the model of care remain the same, it is likely that demand will fall due to the projected decrease in population in these age groups. 


\section{APPENDIX D}

\section{Community pharmaceuticals}

TABLE D.1 Trends in items rate (per 1,000 population), gross drug unit costs, and expenditure, by scheme, 2010-2019

\begin{tabular}{|c|c|c|c|c|c|c|c|c|}
\hline & \multicolumn{8}{|c|}{ Items per 1,000 population } \\
\hline & \multicolumn{2}{|c|}{ GMS } & \multicolumn{2}{|c|}{ DP } & \multicolumn{2}{|c|}{ LTI } & \multicolumn{2}{|c|}{ HT } \\
\hline & $\mathrm{N}$ & $\%$ change & $\mathrm{N}$ & $\%$ change & $\mathrm{N}$ & $\%$ change & $\mathrm{N}$ & $\%$ change \\
\hline 2010 & $11,796.4$ & & $2,382.0$ & & 576.8 & & 92.8 & \\
\hline 2011 & $12,582.4$ & 6.7 & $2,176.0$ & -8.6 & 576.9 & 0.0 & 105.5 & 13.7 \\
\hline 2012 & $13,382.9$ & 6.4 & $2,002.9$ & -8.0 & 616.8 & 6.9 & 111.5 & 5.7 \\
\hline 2013 & $13,361.9$ & -0.2 & $1,631.5$ & -18.5 & 638.8 & 3.6 & 118.0 & 5.9 \\
\hline 2014 & $12,685.9$ & -5.1 & $1,485.3$ & -9.0 & 984.0 & 54.1 & 122.9 & 4.1 \\
\hline 2015 & $12,291.2$ & -3.1 & $1,507.1$ & 1.5 & $1,408.5$ & 43.1 & 132.3 & 7.6 \\
\hline 2016 & $12,310.4$ & 0.2 & $1,501.2$ & -0.4 & $1,568.5$ & 11.4 & 141.4 & 6.9 \\
\hline 2017 & $12,186.6$ & -1.0 & $1,474.4$ & -1.8 & $1,703.2$ & 8.6 & 153.7 & 8.7 \\
\hline 2018 & $12,140.1$ & -0.4 & $1,553.9$ & 5.4 & $1,808.4$ & 6.2 & 166.1 & 8.1 \\
\hline 2019 & $12,168.7$ & 0.2 & $1,575.4$ & 1.4 & $1,893.0$ & 4.7 & 176.8 & 6.5 \\
\hline Avg. p.a. 2015-2019 & \multicolumn{2}{|c|}{-0.2} & \multicolumn{2}{|c|}{1.1} & \multicolumn{2}{|c|}{7.7} & \multicolumn{2}{|c|}{7.5} \\
\hline \multirow[t]{4}{*}{ Avg. p.a. 2010-2019 } & \multicolumn{2}{|c|}{0.3} & \multicolumn{2}{|c|}{-4.5} & \multicolumn{2}{|c|}{14.1} & \multicolumn{2}{|c|}{7.4} \\
\hline & \multicolumn{8}{|c|}{ Unit cost } \\
\hline & \multicolumn{2}{|c|}{ GMS } & \multicolumn{2}{|c|}{$\mathrm{DP}$} & \multicolumn{2}{|c|}{ LTI } & \multicolumn{2}{|c|}{ HT } \\
\hline & $€$ & $\%$ change & $€$ & $\%$ change & $€$ & $\%$ change & $€$ & $\%$ change \\
\hline 2010 & 22.2 & & 30.0 & & 44.0 & & 799.2 & \\
\hline 2011 & 20.4 & -8.1 & 27.4 & -8.9 & 40.6 & -7.8 & 722.3 & -9.6 \\
\hline 2012 & 20.4 & -0.1 & 27.1 & -0.9 & 39.2 & -3.4 & 754.0 & 4.4 \\
\hline 2013 & 19.3 & -5.5 & 24.6 & -9.1 & 34.9 & -11.1 & 807.8 & 7.1 \\
\hline 2014 & 18.5 & -4.3 & 22.2 & -10.1 & 29.5 & -15.4 & 851.9 & 5.5 \\
\hline 2015 & 17.9 & -3.4 & 20.4 & -8.0 & 27.9 & -5.3 & 884.4 & 3.8 \\
\hline 2016 & 17.3 & -3.2 & 21.2 & 4.1 & 27.2 & -2.5 & 909.2 & 2.8 \\
\hline 2017 & 16.5 & -4.4 & 20.7 & -2.5 & 26.6 & -2.2 & 931.1 & 2.4 \\
\hline 2018 & 16.0 & -3.2 & 20.4 & -1.3 & 27.1 & 1.7 & $1,001.9$ & 7.6 \\
\hline 2019 & 15.8 & -1.1 & 20.6 & 0.9 & 27.7 & 2.2 & $1,025.4$ & 2.3 \\
\hline Avg. p.a. 2015-2019 & \multicolumn{2}{|c|}{-3.0} & \multicolumn{2}{|c|}{0.3} & & & & .8 \\
\hline \multirow[t]{4}{*}{ Avg. p.a. 2010-2019 } & & & & & & .0 & & .8 \\
\hline & & & & Expenc & ure & & & \\
\hline & & & & & & II & & HT \\
\hline & $€ \mathrm{~m}$ & $\%$ change & $€ \mathrm{~m}$ & $\%$ change & $€ \mathrm{~m}$ & $\%$ change & $€ \mathrm{~m}$ & $\%$ change \\
\hline 2010 & $1,195.2$ & & 325.9 & & 115.7 & & 337.8 & \\
\hline 2011 & $1,180.3$ & -1.2 & 273.2 & -16.2 & 107.5 & -7.1 & 349.6 & 3.5 \\
\hline 2012 & $1,263.3$ & 7.0 & 250.8 & -8.2 & 111.8 & 4.0 & 388.2 & 11.0 \\
\hline 2013 & $1,198.5$ & -5.1 & 186.7 & -25.5 & 103.4 & -7.5 & 442.8 & 14.1 \\
\hline 2014 & $1,096.7$ & -8.5 & 153.9 & -17.6 & 135.7 & 31.2 & 489.8 & 10.6 \\
\hline 2015 & $1,033.9$ & -5.7 & 144.7 & -6.0 & 185.3 & 36.6 & 551.1 & 12.5 \\
\hline 2016 & $1,013.1$ & -2.0 & 151.7 & 4.8 & 203.2 & 9.7 & 612.2 & 11.1 \\
\hline 2017 & 967.7 & -4.5 & 146.6 & -3.4 & 217.8 & 7.2 & 687.3 & 12.3 \\
\hline 2018 & 946.7 & -2.2 & 154.7 & 5.5 & 238.7 & 9.6 & 811.2 & 18.0 \\
\hline 2019 & 950.7 & 0.4 & 160.2 & 3.6 & 258.7 & 8.4 & 894.9 & 10.3 \\
\hline Avg. p.a. 2015-2019 & & & & & & & & 2.9 \\
\hline Avg. p.a. 2010-2019 & & & & & & & & 1.4 \\
\hline
\end{tabular}

Notes: DP expenditure, and unit cost estimates, are inclusive of the monthly co-payment of €124 (1 April 2019) payable to pharmacists by an individual or family.

Source: PCRS Drug Reimbursement Data 2010-2019; ESRI Population Data 2010-2019. 
Whitaker Square,

Sir John Rogerson's Quay, Dublin 2

Telephone +35318632000

Email admin@esri.ie

Web www.esri.ie

Twitter @ESRIDublin 